UNIVERSIDAD AUTÓNOMA METROPOLITANA

Unidad Iztapalapa

División de Ciencias Biológicas y de la Salud

\title{
ESTUDIO FISIOLÓGICO DE LA NITRIFICACIÓN EN PRESENCIA DE 2-CLOROFENOL UTILIZANDO UN CONSORCIO NITRIFICANTE
}

\section{TES IS}

QUE PARA OBTENER EL GRADO DE DOCTOR EN BIOTECNOLOGÍA

PRESENTA

JESÚS EMMANUEL PÉREZ ALFARO

DIRECTORA DE TESIS:

DRA. FLOR DE MARÍA CUERVO LÓPEZ

MÉXICO, D.F. $\quad$ ABRIL 2015 
Esta tesis se llevó a cabo en el Laboratorio de Fisiología Microbiana W-004 del Departamento de Biotecnología de la Universidad Autónoma Metropolitana unidad Iztapalapa, gracias al apoyo otorgado por el Consejo Nacional de Ciencia y Tecnología con los proyectos CB-2011-01-165174 CONACyT.

El Doctorado en Biotecnología de la Universidad Autónoma Metropolitana está incluido en el Programa Nacional de Posgrados de Calidad (PNPC) del Consejo Nacional de Ciencia y Tecnología con la referencia 001466. 
El H. Jurado designado por la División de Ciencias Biológicas y de la Salud de la Universidad Autónoma Metropolitana unidad Iztapalapa aprobó la tesis

\title{
ESTUDIO FISIOLÓGICO DE LA NITRIFICACIÓN EN PRESENCIA DE 2-CLOROFENOL UTILIZANDO UN CONSORCIO NITRIFICANTE
}

\author{
Que presentó \\ M. en B. Jesús Emmanuel Pérez Alfaro
}

\begin{abstract}
Comité tutorial
Dra. Flor de María Cuervo López

Directora, Universidad Autónoma Metropolitana-Iztapalapa

Dra. Anne-Claire Texier

Asesora, Universidad Autónoma Metropolitana-Iztapalapa

Dr. Germán Buitrón Méndez

Asesor, Universidad Nacional Autónoma de México-Juriquilla
\end{abstract}

H. Jurado

Presidente: Dr. Germán Buitrón Méndez

Secretario: Dr. Pablo G. Damián Matzumura

Vocal: Dr. Sergio Martínez Hernández

Vocal: Dra. Anne-Claire Texier 
A mi esposa Isabel gracias por todo el apoyo, paciencia y amor que me has dado.

A mi hija Sofía por darme el mayor grado que se puede tener en la vida.

A mis padres y mis hermanos por todos los buenos momentos y su cariño. 


\section{AGRADECIMIENTOS}

Agradezco la dirección de la Dra. Flor de María Cuervo López durante la escritura de esta tesis, así como su apoyo durante mis estudios de posgrado. Gracias por su profesionalismo, dedicación, consejos y el tiempo invertido en este trabajo.

A la Dra. Anne-Claire Texier y al Dr. Germán Buitrón Méndez por su colaboración en este trabajo y en todos los proyectos que realicé durante mi estancia en el laboratorio de Fisiología Microbiana. Gracias por sus sugerencias, disposición y críticas constructivas.

Al jurado que revisó este trabajo por sus comentarios y sugerencias.

A todos los compañeros y amigos del laboratorio de Fisiología Microbiana, Gehovana, Dennys y Ricardo, gracias por su ayuda y los buenos consejos. A todos con quienes he convivido a lo largo de tantos años en este laboratorio Felipe, Emir, Diego, Karina, Citlali, Vicente, Arturo, Edna, Sergio, Miguel, Toño gracias por su amistad, el buen ambiente de trabajo y hacerme sentir como en casa cuando laborábamos juntos en el laboratorio.

A los compañeros y amigos del edificio $\mathrm{W}$ y del Posgrado en Biotecnología gracias Zayzi, Omar, César, Carlos por su amistad y compañerismo. 


\section{Contenido}

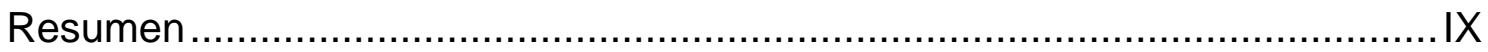

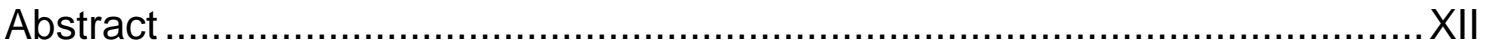

1.0 Panorama actual del AGUA y su disponibilidad ..................................... 1

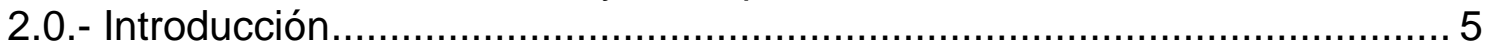

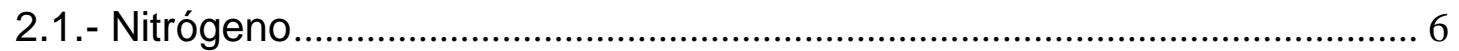

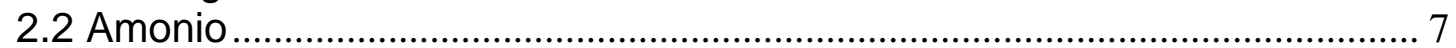

2.3.- Métodos de eliminación de amonio en aguas residuales ........................... 8

2.3.1.- Métodos Fisicoquímicos ........................................................................ 8

2.4.- Métodos Biológicos ...................................................................................... 8

2.4.1. - Sistema de alta remoción de amonio a través de nitrito en un solo reactor (Single reactor system for High Ammonia Removal Over Nitrite SHARON) ......................................................................................... 8

2.4.2.- Oxidación anaerobia de amonio (Anaerobic ammonium oxidation ANAMMOX) ...................................................................................... 9

2.4.3.- Remoción completamente autotrófica de nitrógeno a través de nitrito (Completely Autotrophic Nitrogen removal Over Nitrite CANON) ....... 9

2.4.4.-Desnitrificación ..................................................................................... 10

2.4.6. - Lote enriquecido por bioaumentación (Bioaugmentation Batch Enhanced BABE) …………………………………………………...... 10

2.4.7. - Nitrificación de bajo costo (Inexpensive Nitrification INTRI)........... 10

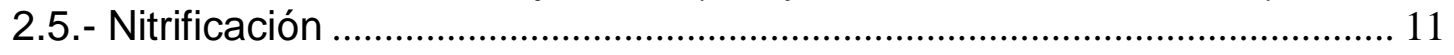

2.5.1.- Microbiología de la nitrificación ........................................................... 11

2.5.2.- Bioquímica y fisiología de la nitrificación .............................................. 12

2.5.3.- Transporte de amonio y nitrito a través de la membrana .................. 16

2.5.4.- Factores que afectan la nitrificación................................................... 20

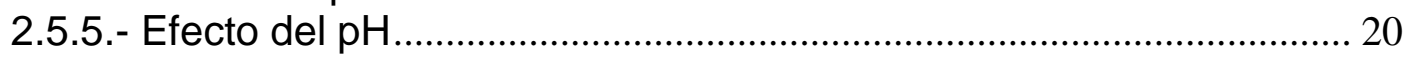

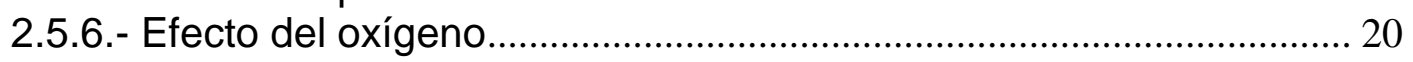

2.5.7.- Efecto de la materia orgánica en la nitrificación................................... 21

2.5.8.- Efecto de la materia orgánica sobre la membrana celular ................ 22

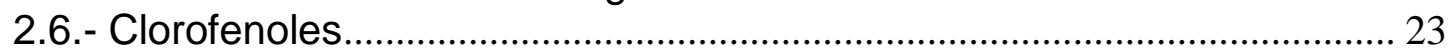

2.6.1.- Degradación de compuestos aromáticos en condiciones aerobias 24

2.6.2.- Degradación de clorofenoles en condiciones aerobias....................... 26

2.7.- 2-Clorofenol (o-Clorofenol, 2-cloro-1-hidroxibenceno) …………............... 28

2.7.1.- Efecto del 2-CP sobre la nitrificación ................................................. 30

2.7.2.- Degradación de 2-clorofenol bajo condiciones nitrificantes .............. 31

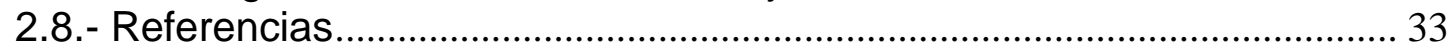

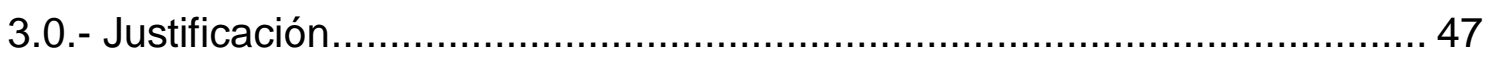

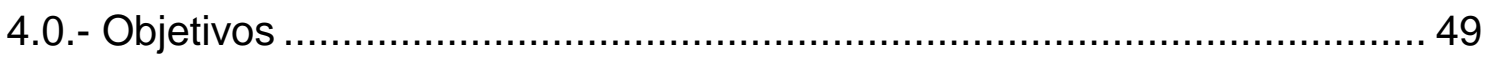

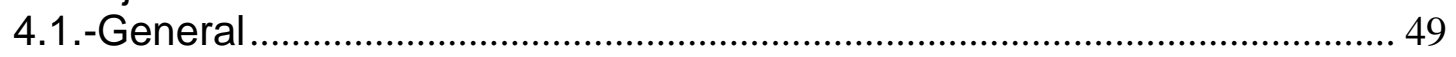

4.2.-Particulares ............................................................................................ 49

5.0.- Materiales y métodos .................................................................... 51

5.1.- Consorcio nitrificante en cultivo continúo en el reactor de tanque agitado

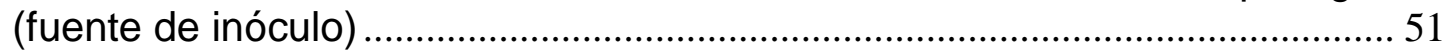

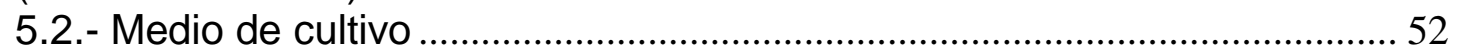

5.3.- Cultivos nitrificantes control o de referencia en lote ................................ 52

5.4.- Ensayos abióticos de adsorción pérdida por volatilización y oxidación

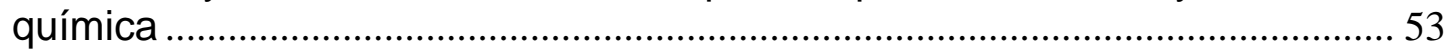

5.5.- Cultivos nitrificantes en presencia de 2-CP.............................................. 54

5.6.- Ensayos de recuperación de la actividad amonio y nitrito oxidante........54 
5.7.- Ensayos de inhibición de la amonio y nitrito oxidación ............................... 54

5.8.- Efecto del 2-CP en el transporte de amonio y nitrito ................................ 55

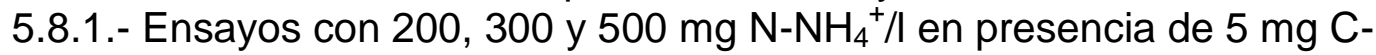

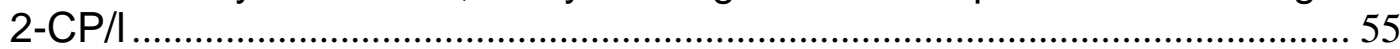

5.8.2.- Ensayos con extractos libres de células............................................. 55

5.8.3.- Obtención de extractos libres de células ............................................... 55

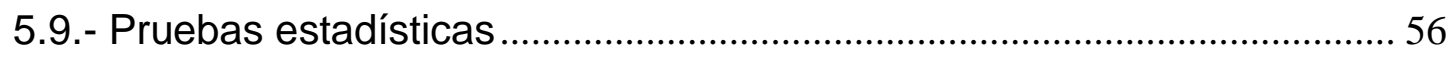

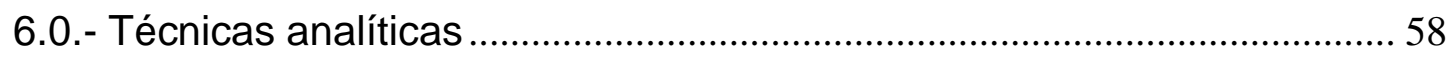

6.1.- Cuantificación de amonio ..................................................................... 58

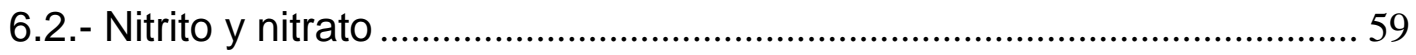

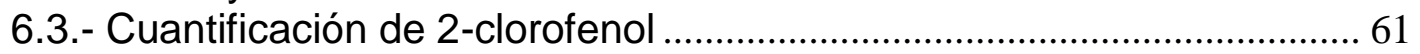

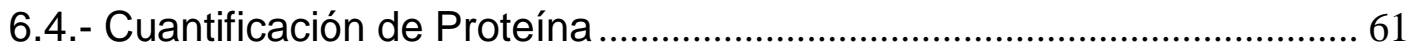

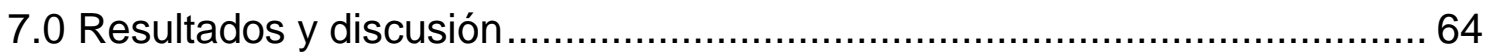

7.1.-Evaluación cinética y fisiológica de los procesos amonio y nitrito oxidantes en presencia de 2-clorofenol..................................................... 64

7.2.- Mejora de la actividad nitrificante en un consorcio microbiano expuesto a 2-clorofenol y diferentes concentraciones de amonio: Ensayos con células completas y extractos libres de células. ................................................. 76 7.3.- Aumento en la velocidad de consumo de 2-clorofenol en un consorcio nitrificante: participación de la amonio monooxigenasa.............................. 95

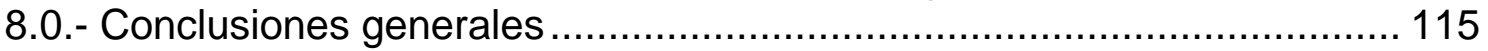

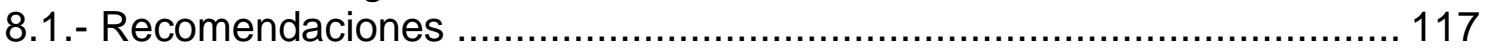

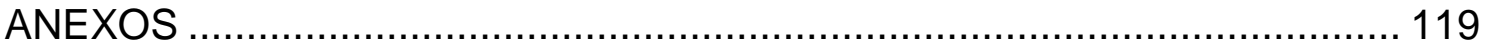




\section{Introducción}

Figura 1. Esquema del ciclo del nitrógeno.

Figura 2. Etapas de reacción para la completa oxidación de amonio hasta nitrato

Figura 3. Esquema de la amonio oxidación.............................. 9

Figura 4. Esquema de la nitrito oxidación................................. 11

Figura 5. Rutas de degradación aeróbica para diferentes compuestos aromáticos............................................................. 20

Figura 6.- Ruta de oxidación para el 2-CP y sus isómeros.............. 22

\section{Materiales y métodos}

Figura 1. Configuración del reactor de tanque agitado para el consorcio nitrificante......................................................

Figura 2. Ejemplo de curva estándar de $\mathrm{N}$-amonio utilizando un electrodo de ion selectivo.

Figura 3. Ejemplo de curva estándar de nitrito por HPLC.

Figura 4. Ejemplo de curva estándar de nitrato por HPLC.............. 54

Figura 5. Ejemplo de curva estándar de 2-clorofenol por HPLC.

Figura 6. Ejemplo de curva estándar de proteína por el método de Lowry

\section{Artículo 1}

Figura 1. Perfil de nitrito oxidación a) consumo de nitrito en presencia de 2.5, 5, $10 \mathrm{mg} \mathrm{C-2-CP/l} \mathrm{y} \mathrm{b)} \mathrm{producción} \mathrm{de} \mathrm{nitrato} \mathrm{en} \mathrm{presencia} \mathrm{de}$ 2.5, 5 y $10 \mathrm{mg} \mathrm{C}-2-\mathrm{CP} / \mathrm{l}$

Figura 2. Ensayos de recuperación de la amonio y nitrito oxidación...... Figura 3. Perfil de consumo de 2.5, 5.0, y $10.0 \mathrm{mg} \mathrm{2-CP-C/l} \mathrm{bajo}$ condiciones nitrificantes

\section{Artículo 2}

Figura 1. Consumo de $100 \mathrm{mg} \mathrm{N}-\mathrm{NH}_{4}^{+} / \mathrm{l}$ sin 2-CP y de $100 \mathrm{mg} \mathrm{N}$ $\mathrm{NH}_{4}{ }^{+} / \mathrm{l}, 200 \mathrm{mg} \mathrm{N}-\mathrm{NH}_{4}{ }^{+} / /, 300 \mathrm{mg} \mathrm{N}-\mathrm{NH}_{4}{ }^{+} / /$y $500 \mathrm{mg} \mathrm{N}-\mathrm{NH}_{4}{ }^{+} / /$en presencia de $5 \mathrm{mg} \mathrm{C}-2-\mathrm{CP} / \mathrm{l}$.

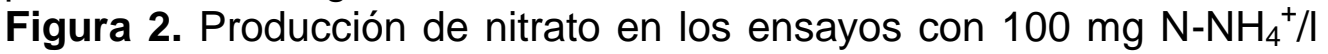

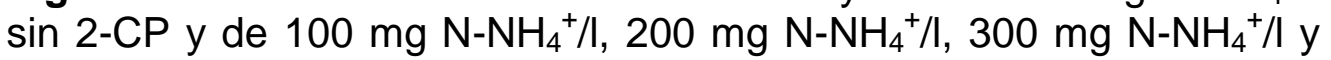
$500 \mathrm{mg} \mathrm{N}-\mathrm{NH}_{4}{ }^{+} / \mathrm{l}$ en presencia de $5 \mathrm{mg} \mathrm{C}-2-\mathrm{CP} / \mathrm{l}$....

Figura 3. Perfiles obtenidos con los ensayos utilizando extractos libres de células $\mathrm{N}-\mathrm{NH}_{4}{ }^{+}, \mathrm{N}-\mathrm{NO}_{2}{ }^{-}, \mathrm{N}-\mathrm{NO}_{3}{ }^{-}$ 
Figura 4. Perfiles de $\mathrm{N}-\mathrm{NH}_{4}{ }^{+}, \mathrm{N}-\mathrm{NO}_{2}{ }^{-}, \mathrm{N}-\mathrm{NO}_{3}{ }^{-}$obtenidos con los ensayos utilizando células completas y con extractos libres de células.

\section{Artículo 3}

Figura 1.- Perfil de incremento de consumo de 2-clorofenol en presencia y ausencia de inhibidores específicos de la amonio y nitrito oxidación.

Figura 2.- Perfil de incremento de consumo de $5 \mathrm{mg} \mathrm{C-2-CP/l} \mathrm{en}$ presencia de altas concentraciones de amonio bajo condiciones nitrificantes. 


\section{Introducción}

Tabla 1. Clasificación de la EPA de los compuestos fenólicos por su toxicidad

Tabla 2. Algunos trabajos que se han llevado a cabo en condiciones aerobias para la eliminación de clorofenoles............................. 22

Tabla 3. Propiedades fisicoquímicas del 2-clorofenol................... 24

\section{Materiales y métodos}

Tabla 1. Composición del medio de cultivo para el reactor de tanque agitado

Tabla 2. Composición del medio de cultivo utilizado en el cultivo en lote.

Tabla 3. Variables de respuesta utilizadas para la evaluación de los procesos de amonio y nitrito oxidación así como para el consumo de 2-CP

Tabla 4. Técnicas analíticas empleadas en la etapa experimental

Artículo 1

Tabla 1. Variables de respuesta para evaluar el proceso respiratorio nitrificante

Tabla 2. Eficiencias de consumo de nitrógeno, rendimiento de producción de nitrito y nitrato y velocidades específicas de consumo y producción del consorcio nitrificante en presencia y ausencia de 2CP.....

\section{Artículo 2}

Tabla 1. Variables de respuesta para el consumo de amonio en presencia y ausencia de $5 \mathrm{mg} \mathrm{C}-2 \mathrm{CP} / \mathrm{l}$

Tabla 2. Variables de respuesta para la producción de nitrato con $100,200,300$ y $500 \mathrm{mg} \mathrm{N}^{-N_{4}}{ }_{4}^{+} / /$en presencia y ausencia de $5 \mathrm{mg} \mathrm{C}$ $2-\mathrm{CP} / \mathrm{l}$

Tabla 3. Variables de respuestas calculadas para los ensayos con los extractos libres de células en presencia y ausencia de 2-CP

\section{Artículo 3}

Tabla 1.- Variables de respuestas en los ensayos con inhibidores específicos

Tabla 2.- Variables de respuesta obtenidas en los ensayos con diferentes concentraciones de $\mathrm{N}-\mathrm{NH}_{4}{ }^{+} / \mathrm{l}$ 


\section{Abreviaturas utilizadas en el texto}

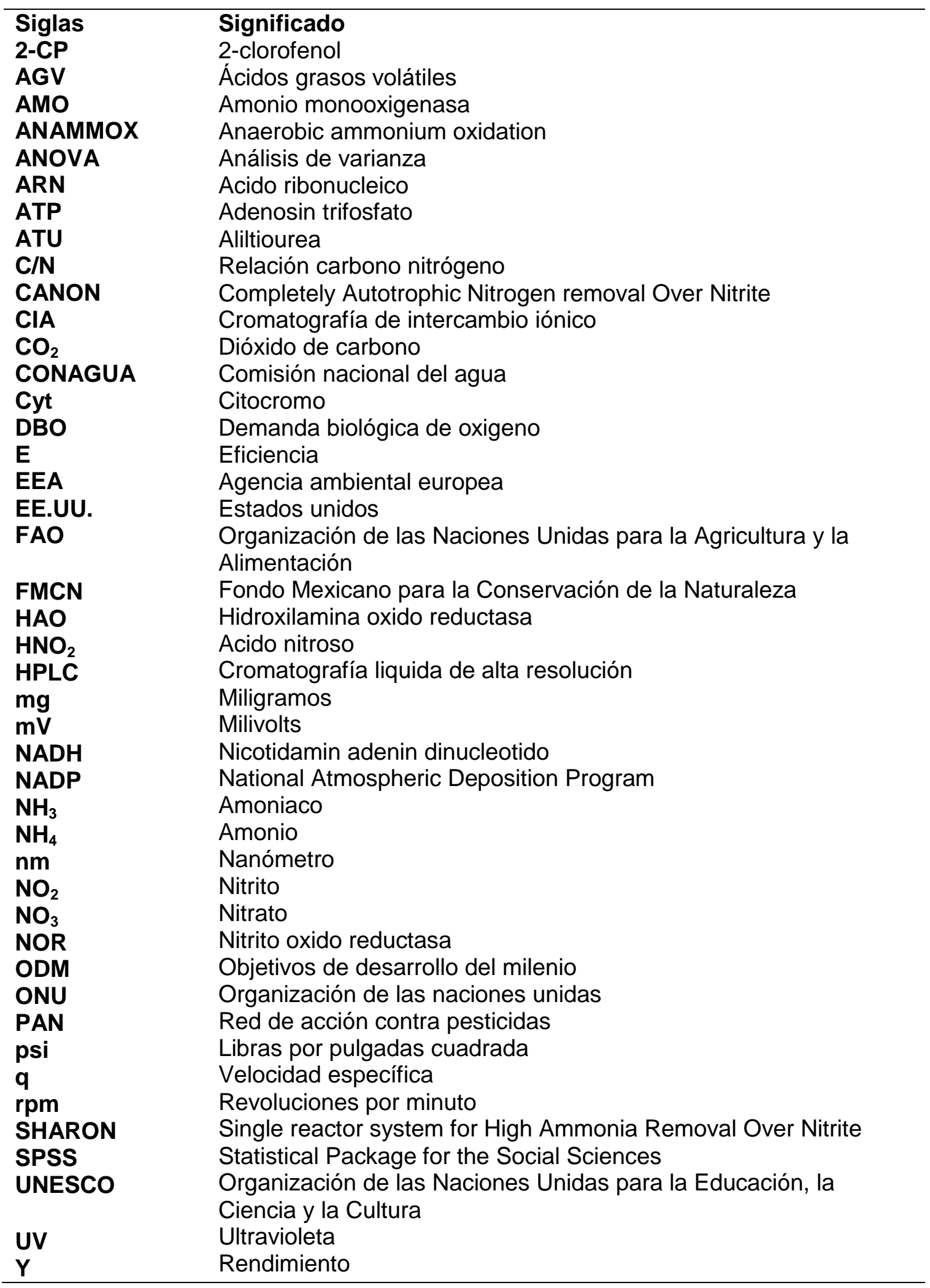




\section{Resumen}

En esta tesis se estudió el efecto del 2-clorofenol (2-CP) sobre los procesos de amonio y nitrito oxidación así como el consumo de 2-CP por un consorcio nitrificante, utilizando variables de respuesta como la eficiencia de consumo, el rendimiento de producción y las velocidades específicas de los procesos. Para tal propósito este documento se divide en tres etapas principales. En la primera se llevaron a cabo diferentes ensayos en cultivos en lote diseñados para evaluar la actividad de amonio y nitrito oxidación de manera independiente usando amonio o nitrito como fuente de nitrógeno y energía, respectivamente. Posteriormente se evaluó el efecto de diferentes concentraciones de 2-CP (2.5, 5 y $10 \mathrm{mg} \mathrm{C-2-CP/l)} \mathrm{sobre} \mathrm{estas} \mathrm{rutas} \mathrm{oxidativas} \mathrm{y} \mathrm{la} \mathrm{capacidad} \mathrm{del} \mathrm{consorcio}$ nitrificante para recuperar la actividad amonio y nitrito oxidante tras el contacto con el 2-CP. La segunda etapa de este estudió se enfocó en evaluar el posible efecto de $5 \mathrm{mg}$ de $\mathrm{C}-2-\mathrm{CP} / \mathrm{l}$ en el transporte de amonio hacia dentro de la célula. Se realizaron experimentos en lote donde la concentración de nitrógeno de amonio $\left(\mathrm{N}^{-} \mathrm{NH}_{4}{ }^{+}\right)$se incrementó de 100 a 200, 300 y $500 \mathrm{mg} / \mathrm{l}$. Con el objetivo de generar mayor información que permitiera determinar si el efecto de 2-CP es a nivel enzimático o de transporte de sustratos, se realizaron ensayos con extractos libres de células. Dichos extractos se obtuvieron a partir del consorcio nitrificante mediante una técnica diseñada en el laboratorio, los extractos conservaron cerca del $80 \%$ de la actividad amonio y nitrito oxidante original (en comparación con las células completas) por un periodo de 24 horas. Por último, se evaluó la participación de las enzimas amonio monooxigenasa (AMO) y nitrito oxidoreductasa (NOR) en el consumo de 2-CP. Para lo cual se utilizaron inhibidores específicos de la AMO y NOR (aliltiourea y clorato de sodio respectivamente). Se evaluó además el efecto de la concentración de amonio en el consumo de 2-CP.

En la primera etapa se observó en presencia de 2-CP que la amonio oxidación puede ser inhibida totalmente con una concentración de $2.5 \mathrm{mg} \mathrm{C-2-CP/l.} \mathrm{Por}$ su parte, la nitrito oxidación se inhibió a partir de una concentración de10 mg C2-CP/l, se observó que las velocidades de consumo de nitrito y producción de nitrato disminuyeron más del 50\%. Cuando se incubó con 2-CP durante 40 días, se observó que ambas rutas oxidantes pueden restablecerse, pero solo Jesús Emmanuel Pérez Alfaro | 
de manera parcial. Para ello se requiere de una fase de retardo que puede ser de hasta 120 horas para la amonio oxidación y de cerca de 50 horas para la nitrito oxidación. Es importante mencionar que el consorcio microbiano presentó la capacidad de consumir el 2-CP independientemente de su concentración inicial, con la previa necesidad de fases de retardo, cuya duración pudiera ser dependiente de la concentración de 2-CP.

Los ensayos de la segunda etapa mostraron que con 200 y hasta $500 \mathrm{mg} \mathrm{N}$ $\mathrm{NH}_{4}{ }^{+} /$l, y luego de 48 horas de cultivo, el consorcio microbiano conservó la capacidad de consumir amonio y de oxidarlo a nitrito y nitrato aún en presencia de $5 \mathrm{mg} \mathrm{C}-2-\mathrm{CP} / \mathrm{l}$. Sin embargo también se observó que las velocidades específicas de consumo de amonio y producción de nitrito y nitrato disminuyeron más del $70 \%$ en promedio, lo que podría indicar un daño causado por el 2-CP a nivel de la membrana celular, ya que al parecer el 2-CP altera o detiene el transporte de amonio. En los resultados obtenidos con los ensayos con extracto libres de células a diferencia de los ensayos con las células

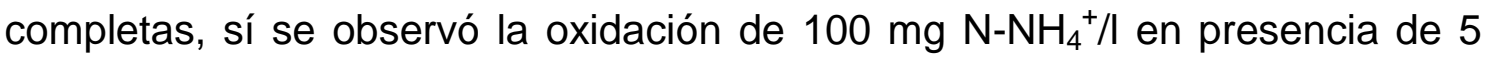
mg C-2-CP/l de manera inmediata pero también se observó que la velocidad específica de los procesos amonio oxidante y nitrito oxidante puede disminuir hasta 40 y $38 \%$ respectivamente en presencia de 2-CP. Por lo anterior puede decirse que el 2-CP podría afectar el proceso amonio oxidante a nivel membrana y a nivel enzimático.

Además de los resultados ya descritos, se observó que el consorcio nitrificante tuvo la capacidad de consumir 2-CP en todos los casos y con todas las concentraciones evaluadas, requiriendo de fases de retardo de 12, 15 o hasta 30 días, por lo cual se evaluó la participación de la AMO y NOR en el consumo de 2-CP. En los ensayos con inhibidores específicos de la AMO (aliltiourea) y NOR (clorato de sodio), se observó que la velocidad específica de consumo de 2-CP en ausencia de inhibidores o en presencia de clorato de sodio, no presentó diferencia estadísticamente significativa, es decir la NOR no tiene participación en el consumo de 2-CP. Mientras que al inhibirse la AMO en presencia de aliltiourea, la velocidad específica de consumo de 2-CP disminuyó cerca del $50 \%$, con lo cual se pudo concluir que la $A M O$ podría tener participación importante en la oxidación de 2-CP. También se observó que la 
concentración de amonio puede estimular el consumo de 2-CP, ya que al aumentar la concentración de amonio a $500 \mathrm{mg} \mathrm{N}^{-\mathrm{NH}_{4}}{ }^{+} / \mathrm{l}$, el consumo de 2-CP cambió drásticamente, pues de requerirse fases de retardo de 12 a 30 días para el consumo total de $5 \mathrm{mg} \mathrm{C}-2-\mathrm{CP} / \mathrm{l}$, con $500 \mathrm{mg} \mathrm{N}^{-\mathrm{NH}_{4}}{ }^{+} / \mathrm{l}$ la fase de retardo no fue requerida y el consumo de más del $80 \%$ del 2-CP se realizó en un tiempo de 48 horas. Estos resultados pueden contribuir en el entendimiento de los factores que pueden dificultar el tratamiento de aguas residuales con altas concentraciones de amonio y que contengan compuestos semejantes al 2-CP. 


\section{Abstract}

The effect of 2-chlorophenol on the ammonium and nitrite oxidation and 2chlorophenol (2-CP) oxidation processes by a nitrifying consortium were studied, using consumption efficiency, production yield and specific consumption and production rates as response variables. For this purpose this thesis was divided into three main stages. In the first, batch culture assays were carried out to study the ammonium and nitrite oxidation processes independently, using ammonium or nitrite as nitrogen and energy source. Then the effect of different concentrations of 2-CP $(2.5,5$ and $10 \mathrm{mg} \mathrm{2-CP-C/l)}$ on these oxidative pathways was evaluated. Furthermore the ability of nitrifying consortium to recover ammonium and nitrite oxidizing activity after contact with the 2-CP was studied. The second stage of this study was focused on evaluating the potential impact of $5 \mathrm{mg}$ of $2-\mathrm{CP}-\mathrm{C} / \mathrm{l}$ on ammonium transport. Batch experiments were performed. The concentration of ammonium nitrogen $\left(\mathrm{NH}_{4}{ }^{+}-\mathrm{N}\right)$ was increased to 200,300 and $500 \mathrm{mg} / \mathrm{l}$. In order to generate more information to establish the level where 2-CP could cause damage, assays with cell free extracts were performed. The cell free extracts generated retained up to $80 \%$ of the original ammonium and nitrite oxidation activity (compared to whole cells) for a period of 24 hours. Finally, the participation of ammonium monooxygenase $(\mathrm{AMO})$ and nitrite oxidoreductase (NOR) enzymes during 2-CP consumption was evaluated. Specific inhibitors of AMO and NOR (allyltiourea and sodium chlorate, respectively) were used. Furthermore the effect of ammonium concentration in 2-CP consumption was evaluated.

The experimental conditions for conducting ammonium and nitrite oxidation were established in the first stage. It was observed that ammonium oxidation can be inhibited by $100 \%$ at $2.5 \mathrm{mg} 2-\mathrm{CP}-\mathrm{C} / \mathrm{l}$ since no nitrifying activity was observed throughout the culture time of 40 days. It was concluded that 2-CP affected ammonium oxidation at physiological and kinetic level. A negative effect of $10 \mathrm{mg} \mathrm{2-CP-C/l}$ was observed in the kinetics of nitrite oxidation, as nitrite consumption and nitrate production rates decreased more than $50 \%$. After contact with 2-CP for 40 days, it was observed that both oxidizing pathways can be partially restored as lag phases up to $120 \mathrm{~h}$ for ammonium and about $50 \mathrm{~h}$ for nitrite oxidation were required. In all cases the microbial 
consortium was able to consume 2-CP regardless its initial concentration. Nevertheless, different lag phases were needed apparently depending on the concentration of $2-\mathrm{CP}$.

Assays in the second stage, showed that even in the presence of $5 \mathrm{mg} 2-\mathrm{CP}-\mathrm{C} / \mathrm{l}$ the increment in ammonium concentration of 100 to 200,300 and $500 \mathrm{mg} \mathrm{NH}_{4}{ }^{+}-$ $\mathrm{N} / \mathrm{l}$ resulted in the microbial consortium ability to consume ammonium and oxidized it to nitrite and nitrate within $48 \mathrm{~h}$ of culture. Nevertheless, consumption and production rates of ammonium, nitrite and nitrate decreased more than $70 \%$. Thus apparently $2-\mathrm{CP}$ has an effect on the cell membrane that alters or stops the ammonium transport. The results obtained in assays with free cell extract showed that in contrast to assays with whole cells, the oxidation of 100 $\mathrm{mg} \mathrm{NH}_{4}{ }^{+}-\mathrm{N} / \mathrm{I}$ was possible and immediately in presence of $5 \mathrm{mg} 2-\mathrm{CP}-\mathrm{C} / \mathrm{l}$. However, specific rates of ammonium consumption and nitrate production decreased to 40 and $38 \%$ respectively in the presence of $2-\mathrm{CP}$. Therefore it could be concluded that 2-CP may affects ammonium oxidizing process at membrane and enzyme level.

In addition to the results described above, it always was observed that the nitrifying consortium was able to consume the different 2-CP concentrations requiring lag phases of 12,15 or $30 \mathrm{~d}$. Therefore in a third stage the participation of $\mathrm{AMO}$ and NOR in consumption of 2-CP was evaluated. In assays with specific inhibitors of $\mathrm{AMO}$ and NOR it was observed that the specific consumption rate of 2-CP in absence of inhibitors or in the presence of sodium chlorate did not show statistical difference. Therefore, NOR has no participation in 2-CP consumption. Contrary, the specific consumption rate of 2CP decreased about $50 \%$ when the AMO was inhibited in the presence of allyltiourea, suggesting that the AMO may have an important role in the 2-CP consumption. Finally the ammonium concentration may lead a positive effect on 2-CP consumption, since increasing the ammonium concentration to $500 \mathrm{mg}$ $\mathrm{NH}_{4}{ }^{+}-\mathrm{N} / \mathrm{l}$ resulted in $5 \mathrm{mg} 2-\mathrm{CP}-\mathrm{C} / \mathrm{l}$ consumption close to $80 \%$ within $48 \mathrm{~h}$ without lag phase. These results can aid in improving the treatment of wastewater with high concentrations of ammonia and containing compounds similar to $2-\mathrm{CP}$. 


\subsection{Panorama actual del AGUA y su disponibilidad}

Con sus diversas y abundantes formas de vida, que incluyen a más de 6000 millones de seres humanos, nuestro planeta se enfrenta en este comienzo del siglo veintiuno con una grave crisis del agua. Todas las señales parecen indicar que la crisis está empeorando y que continuará haciéndolo, a no ser que se emprenda una acción correctiva. Su efecto es más evidente sobre la vida cotidiana de las poblaciones pobres (UNESCO-WWAP, 2003).

La disponibilidad anual promedio de agua en el mundo es de aproximadamente 1386 millones de $\mathrm{km}^{3}$, de los cuales el $97.5 \%$ es agua salada y sólo el $2.5 \%$, es decir, 35 millones de $\mathrm{km}^{3}$, es agua dulce. De esta cantidad casi el $70 \%$ no está disponible para consumo humano debido a que se encuentra en forma de glaciares, nieve o hielo (CONAGUA 2011).

Del agua que técnicamente está disponible para consumo humano, sólo una pequeña porción se encuentra en lagos, ríos, humedad del suelo y depósitos subterráneos relativamente poco profundos, cuya renovación es producto de la infiltración. Pero muchos de ellos se encuentran lejos de las zonas pobladas, lo cual dificulta o encarece su utilización efectiva.

En el 2000, la Organización de las Naciones Unidas (ONU), estableció los Objetivos de Desarrollo del Milenio (ODM), con el fin de reducir la pobreza extrema para el año 2015. En el objetivo número siete, "Garantizar la sostenibilidad del medio ambiente", se encuentra la meta 7.C, relacionada al agua potable y su saneamiento, que establece reducir a la mitad, la proporción de personas $\sin$ acceso sostenible a fuentes de abastecimiento de agua potable $y$ a servicios de saneamiento, entre el año de referencia 1990 y el 2015.

La meta 7.C de los ODM debe contemplarse bajo dos ópticas. La primera es la íntima relación que existe entre la salud y el agua, por lo cual la ampliación en la cobertura del servicio de agua potable y saneamiento contribuiría a reducir la mortalidad por estos padecimientos. La segunda, en general, es el efecto que tendría el cambio climático sobre el recurso hídrico y en particular, sobre la disponibilidad del agua y su calidad.

Sin embargo, la utilización de agua, conlleva a su contaminación. En el siglo $\mathrm{XX}$, mientras la población mundial se triplicó, las extracciones de agua se 
sextuplicaron. Esta situación aumenta el grado de presión sobre los recursos hídricos a nivel mundial. México se ubica en el octavo lugar de los países con mayor extracción de agua (CONAGUA 2004).

Por otra parte, la industria es uno de los principales motores de crecimiento y desarrollo económico y también uno de los principales consumidores de agua. Entre los mayores consumidores industriales de agua se encuentran las plantas petroleras, las industrias metalúrgicas, papelera, maderas, procesamiento de alimentos y la industria manufacturera (CONAGUA 2004). En general los principales contaminantes que se generan son: materia orgánica, nutrientes (nitrógeno y fósforo) y microorganismos (coliformes totales y coliformes fecales), pero hay otros, como los metales y los derivados de hidrocarburos. El volumen de agua usada en la industria es de $6 \mathrm{~km}^{3} / a n ̃ o$, del cual se descargan cerca de $5.36 \mathrm{~km}^{3} /$ año como aguas residuales, es decir, más de 6 millones de toneladas al año de carga orgánica expresada como demanda bioquímica de oxígeno (DBO), de las cuales, sólo el 15\% son tratadas (CONAGUA 2004).

Es entonces urgente proporcionar los medios y aplicar las metodologías necesarias que permitan continuar y optimizar el abastecimiento y tratamiento de aguas a nivel mundial y por supuesto en nuestro país. Así, la mejora de los procesos biológicos, el mejor entendimiento de los mecanismos que estos involucran y los efectos que los compuestos contaminantes causan sobre los microorganismos utilizados en dichos procesos biológicos, puede contribuir a la mejora de la calidad del tratamiento de las aguas residuales y por lo tanto, a la recirculación y aprovechamiento de éstas en las diferentes actividades que se realizan, tanto en las industrias como en la vida cotidiana.

El propósito de esta tesis fue generar información desde el punto de vista fisiológico y cinético que permita entender de qué manera pueden afectar los compuestos aromáticos recalcitrantes como el 2-CP al proceso de la nitrificación. Dicha información puede ser aprovechada para evitar o disminuir los posibles contratiempos que se presentan durante el tratamiento de efluentes que contengan compuestos semejantes, como podría ser el caso de los generados en la industria papelera y agrícola. Para lo cual esta tesis fue dividida en las siguientes secciones: 
Introducción: Se incluye una revisión bibliográfica detallada del proceso nitrificante y del efecto de compuestos aromáticos como el 2-CP sobre la nitrificación

Materiales y métodos: Donde se describen los métodos y técnicas empleados para la evaluación del proceso nitrificante.

Resultados: Esta sección está divida en tres partes que corresponden a un artículo ya publicado en una revista indexada y dos manuscritos en preparación para su publicación, en los cuales se analizan, el comportamiento fisiológico del lodo nitrificante en presencia de 2-CP y los perfiles cinéticos obtenidos en los diferentes ensayos.

Conclusiones y recomendaciones: En esta sección se puntualizan las conclusiones a las que se llegó y se hacen algunas recomendaciones para profundizar en los resultados obtenidos en este trabajo. Así como sugerencias de cómo aplicar los datos generados en el tratamiento de aguas residuales. 


\section{Introducción}




\section{0.- Introducción}

Cuando un producto de desecho se incorpora al agua, el líquido resultante recibe el nombre de agua residual. Este tipo de aguas tienen un origen doméstico, industrial, subterráneo y meteorológico, y se denominan respectivamente, domésticas, industriales, de infiltración y pluviales. Las aguas residuales domésticas son resultado de las actividades cotidianas de las personas. La composición y cantidad de los desechos encontrados en estas aguas están relacionadas con los hábitos de vida (Fondo Mexicano para la Conservación de la Naturaleza FMCN 2006). Un área metropolitana estándar vierte un volumen de aguas residuales de entre 60 y $80 \%$ de sus requerimientos diarios totales (FMCN 2006). En las aguas industriales, la cantidad y naturaleza de los contaminantes es muy variada, dependiendo del tipo de industria, de la gestión del consumo de agua y del grado de tratamiento que reciben antes de su descarga. Una acerera, por ejemplo, puede descargar entre 5700 y 151 mil litros por tonelada de acero fabricado la cual debe ser tratada para poder ser reutilizada.

El tratamiento de aguas residuales es un conjunto de distintos procesos relacionados con la extracción y control sanitario de los productos de desecho arrastrados por el agua y procedentes de viviendas e industrias. Consiste en varias etapas: tratamiento preliminar, primario, secundario $y$ terciario (Romero Rojas y col., 1994).

El tratamiento secundario es un punto crítico del proceso. Está basado en los procesos biológicos de descomposición de la materia orgánica e inorgánica disuelta en el agua residual, que los microorganismos realizan naturalmente. Sin embargo, debido a que los compuestos disueltos en estas aguas residuales pueden causar efectos adversos sobre los microorganismos, pueden presentarse algunas dificultades en esta etapa. El nitrógeno en sus diferentes formas (amonio, nitrito, nitrato, urea, etc.,) puede llegar a afectar dicha etapa. 


\section{1.- Nitrógeno}

El nitrógeno molecular $\left(\mathrm{N}_{2}\right)$ es un gas incoloro e inodoro que constituye el $78 \%$ de nuestra atmósfera. Sobre cada metro cuadrado de la superficie terrestre se encuentran 8 toneladas de nitrógeno. El $\mathrm{N}_{2}$ es estable y para convertirlo a otros compuestos químicos se requiere una cantidad considerable de energía. Un relámpago contiene energía suficiente para lograrlo, haciendo que el $\mathrm{N}_{2}$ y el $\mathrm{O}_{2}$ que se encuentran en el aire formen óxidos de nitrógeno. La energía fotosintética de las plantas y la energía química de los microorganismos del suelo también pueden convertir el nitrógeno molecular en otras formas químicas. Todos estos procesos naturales ocurren en nuestro medio ambiente y corresponden al ciclo del nitrógeno (Figura 1), (National Atmospheric Deposition Program, NADP 2000).

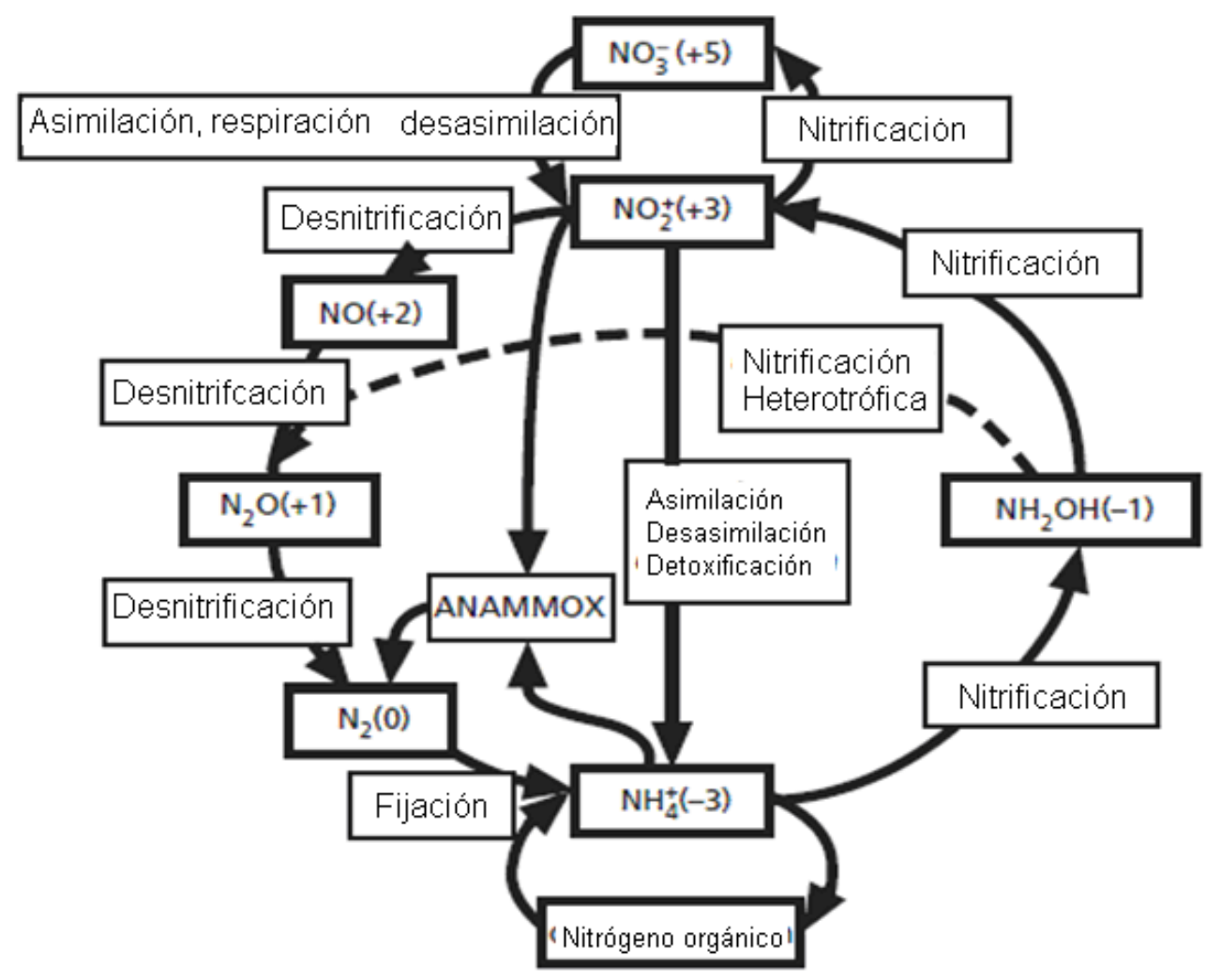

Figura 1. Esquema del ciclo del nitrógeno.

El ciclo del nitrógeno involucra principalmente cuatro procesos: fijación, mineralización, nitrificación y desnitrificación. La fijación biológica del $\mathrm{N}_{2}$ es una etapa importante del ciclo del nitrógeno y generalmente, es un proceso anaerobio. La nitrificación, o formación de nitrato a partir de amonio, es un 
proceso catalizado secuencialmente por dos grupos de bacterias aerobias: un grupo que oxida el amonio a nitrito, y un segundo grupo que oxida el nitrito a nitrato. El tercer proceso de importancia del ciclo del nitrógeno es la desnitrificación, que permite la reducción del nitrato a $N_{2}$ (producto final del ciclo) por medio de bacterias facultativas.

\subsection{Amonio}

Los compuestos nitrogenados pueden estar presentes en el agua en diferentes estados de oxidación: nitrógeno orgánico (-3 a -1), nitrógeno amoniacal (amoniaco) (-3), nitrito (+3) y nitrato (+5) (Jiménez 2005). Las formas iónicas de nitrógeno inorgánico más comunes en los ecosistemas acuáticos son el amonio $\left(\mathrm{NH}_{4}{ }^{+}\right)$, el nitrito $\left(\mathrm{NO}_{2}{ }^{-}\right)$y el nitrato $\left(\mathrm{NO}_{3}{ }^{-}\right)$. Su presencia es consecuencia de la deposición atmosférica, la escorrentía superficial y subterránea, la disolución de depósitos geológicos ricos en nitrógeno, la descomposición biológica de la materia orgánica, y la fijación de nitrógeno por ciertos procariontes. Sin embargo, las actividades humanas son fuentes muy variadas de contaminación y han alterado de manera significativa el ciclo global del nitrógeno (y de otros elementos químicos), aumentando su disponibilidad en muchas regiones del planeta (Camargo y Alonso 2007).

El amonio es un contaminante que, además de ser un producto natural, es también un producto industrial clave, que puede producirse por desaminación de compuestos orgánicos o por hidrólisis de urea. Concentraciones elevadas de $\mathrm{NH}_{4}{ }^{+}$junto con el fósforo, pueden promover el desarrollo, mantenimiento y proliferación de los productores primarios (fitoplancton, algas bentónicas, macrófitos), contribuyendo al muy extendido fenómeno de la eutrofización de los ecosistemas acuáticos (Wetzel, 2001; Anderson y col., 2002; Smith, 2003; Agencia ambiental europea (EEA), 2005; Jiménez 2005). Esta proliferación, y su posterior muerte y descomposición, suelen conducir a una marcada disminución de la concentración de oxígeno disuelto y causar la muerte masiva de peces (y de otros animales), por hipoxia o anoxia (Camargo y Alonso 2007). En su forma no ionizada $\left(\mathrm{NH}_{3}\right)$ se considera muy tóxico para la mayoría de los animales, pues la membrana celular es muy permeable a este compuesto (Dejours y col., 1989). Por tanto para atacar los problemas ocasionados por la 
excesiva presencia de este tipo de compuestos se han ideado diferentes métodos para procurar su eliminación.

\section{3.- Métodos de eliminación de amonio en aguas residuales}

\subsection{1.- Métodos Fisicoquímicos}

El nitrógeno amoniacal puede eliminarse por diferentes procesos, entre los que destacan el intercambio iónico y la desorción. El proceso de intercambio iónico conlleva a la necesidad de establecer las condiciones de operación más adecuadas $(\mathrm{pH}$, tipo de resina, tiempo de contacto, etc.) para la remoción del contaminante clave. La literatura reporta varios trabajos realizados para establecer la influencia del pH sobre la eficiencia del proceso de intercambio iónico (Vaca-Mier y col., 2000). El principal inconveniente de este método consiste en la saturación del intercambiador, que obliga a regenerarlo periódicamente, además de los costos de la mayoría de las resinas comerciales (Silva 2011).

La desorción de nitrógeno (stripping), es uno de los métodos más usados para la remoción de amonio. Consiste en transferir el amonio de la fase líquida a la sólida por medio de aire, para después ser absorbido en un medio con ácido sulfúrico. Para esto se requiere ajustar el $\mathrm{pH}$ a valores superiores a 11 y se pueden alcanzar eficiencias de eliminación de hasta un 95\% (Kurniawan y col., 2006).La desventaja de este proceso es el elevado costo de la aireación y que el amoniaco sólo se separa del efluente, pero no se le transforma a un compuesto de menor impacto.

\section{4.- Métodos Biológicos}

\subsection{1. - Sistema de alta remoción de amonio a través de nitrito en un solo reactor (Single reactor system for High Ammonia Removal Over Nitrite SHARON)}

Es un proceso biológico que se basa en una nitrificación parcial, donde mediante el control de la temperatura, $\mathrm{pH}$ y tiempo de residencia hidráulico $(\mathrm{TRH})$, se obtiene una acumulación de nitrito (Hellinga y col., 1998), para su posterior acoplamiento con una desnitrificación vía nitrito (Khin y Annachhatre, 2004). La nitrificación parcial seguida de la desnitrificación, ha sido adoptada 
como una opción real para la eliminación de nitrógeno debido al ahorro de hasta un $25 \%$ en la energía y un $40 \%$ en la adición de carbono orgánico en comparación con el tratamiento convencional nitrificación-desnitrificación (Paredes y col., 2007). Este proceso parece ser adecuado para el tratamiento de aguas residuales con alta concentración de amonio, no obstante, el control de las variables del sistema puede ser complejo en operaciones a gran escala (Khin y Annachhatre, 2004).

\subsection{2.- Oxidación anaerobia de amonio (Anaerobic ammonium oxidation ANAMMOX)}

En la oxidación anaerobia de amonio (ANAMMOX), el amonio es utilizado como donador de electrones y se oxida a nitrógeno molecular, mientras que el nitrito es el aceptor final de electrones y el dióxido de carbono es la principal fuente de carbono para el crecimiento de las bacterias (Kartal y col., 2011). Las bacterias que llevan a cabo el proceso de anammox fueron identificadas por primera vez en un sistema de tratamiento de agua residual por Mulder y colaboradores en 1995 y en 2002 en ambientes naturales por Thamdrup y Dalsgaard (Wenk y col., 2013). Todas las bacterias pertenecen al orden Planctomycetales, y han sido clasificadas en cinco géneros de Candidatus. Algunas de ellas han sido tentativamente llamadas Candidatus brocadia, Candidatus kuenenia, Candidatus scalindua, Candidatus anammoxoglobus, y Candidatus jettenia (Van Niftrik y Jetten 2012).

\subsection{3.- Remoción completamente autotrófica de nitrógeno a través de nitrito (Completely Autotrophic Nitrogen removal Over Nitrite CANON)} Este proceso involucra la combinación de la nitrificación parcial y anammox en un solo reactor aireado (Third y col., 2002). Implica la cooperación de dos grupos de bacterias que llevan a cabo dos reacciones secuenciales, donde el amonio es parcialmente oxidado a nitrito por las bacterias amonio oxidantes, lo cual consume oxígeno y crea las condiciones anóxicas para que posteriormente, este nitrito junto con el amonio restante, sea convertido a nitrógeno molecular por las bacterias anammox (Schmidt y col., 2003). Este proceso se ha probado varias veces a escala laboratorio y se ha observado que requiere de cargas volumétricas más bajas que el anammox y que además es necesario un control minucioso para prevenir la acumulación de nitrito por exceso de oxígeno (Schmidt y col., 2003). 


\subsection{4.-Desnitrificación}

Mediante la desnitrificación, es posible producir nitrógeno molecular a partir de la reducción de nitrito o nitrato y oxidar materia orgánica de tipo fenólica hasta $\mathrm{CO}_{2}$ (Hernández 2005; Hernández y col., 2008). La desnitrificación es un proceso anóxico donde el nitrato es reducido a nitrógeno molecular por una sucesión de reacciones catalizadas por enzimas específicas (Martínez, 2007). La desnitrificación puede ser organotrófica o litotrófica, dependiendo de su fuente de energía. Este proceso, acoplado a la nitrificación, es hasta el momento, el sistema que ofrece las mayores ventajas de tipo operacional y de manejo, pues involucra costos bajos y muestra una gran estabilidad, así como altas eficiencias de remoción (Lin y col., 2009).

\subsection{6. -Lote enriquecido por bioaumentación (Bioaugmentation Batch Enhanced BABE)}

En este proceso la nitrificación y la desnitrificación se llevan a cabo en un solo reactor, donde se combinan lodos que han estado en contacto con altas concentraciones de amonio con lodos sedimentados del reactor de lote secuenciado, en este caso los lodos con previo contacto sirven para bioaumentar el lodo sedimentado. El utilizar reactores de lotes secuenciados permite tiempos de residencia largos en los cuales pueden crecer tanto bacterias nitrificantes como desnitrificantes. La operación en lotes secuenciados consta de 5 etapas: 1) llenado, 2) mezclado y aireación, 3) mezclado, 4) sedimentado y 5) decantado (Stowa 2006). Los primeros dos pasos se realizan en condiciones aerobias. El tercero involucra una fase sin aireación para alcanzar condiciones anóxicas, las cuales son propicias para que se realice la desnitrificación posteriormente se realizan los pasos 4 y 5 (EPA 2008).

\subsection{7. - Nitrificación de bajo costo (Inexpensive Nitrification INTRI)}

En general el proceso consiste en agregar constantemente microorganismos nitrificantes suplementarios a los lodos activados para reponer los nitrificantes que se pierden en el lavado del mismo. Estos nitrificantes suplementarios se cultivan en un pequeño tanque de aireación que se alimenta con amonio.

En este proceso se optimiza el mezclado y la transferencia de masa, permitiendo realizar la nitrificación con tiempos de retención celular menores a 
los comunes y a bajas temperaturas, se requiere de tanques de aireación más pequeños y básicamente fue desarrollado para proveer una alternativa más barata para plantas ubicadas en climas fríos, que generalmente requieren de ser aireadas con oxígeno puro o con flujos de aire muy altos (EPA 2007).

\section{5.- Nitrificación}

La nitrificación se define como un proceso respiratorio aerobio litoautotrófico, donde se lleva a cabo la oxidación del amonio hasta nitrato vía nitrito, mediante dos grupos de bacterias quimiolitoautótrofas, las amonio oxidantes y nitrito oxidantes, ambas pertenecientes a la familia Nitrobacteraceae (Prosser, 1989). La nitrificación se realiza en dos etapas sucesivas. En una primera etapa de la ruta metabólica, por acción de las bacterias amonio oxidantes, el amonio se oxida a nitrito. En la segunda etapa, las bacterias nitrito oxidantes, oxidan el nitrito a nitrato.

En la naturaleza, la nitrificación forma parte del ciclo del nitrógeno (Figura 1), a fin de mantener una eficiente recirculación del nitrógeno, pero debido a la enorme generación de amonio por el hombre, la velocidad de recirculación de este elemento puede verse disminuida y causar grandes problemas ambientales.

\subsection{1.- Microbiología de la nitrificación}

Las bacterias nitrificantes se pueden dividir en dos grupos. En el primero encontramos a las bacterias amonio oxidantes, que incluyen a los géneros Nitrosococcus, Nitrosospira, Nitrosovibrio, Nitrosomonas y Nitrosolobus (Bock y col., 1991). Estos géneros están ampliamente distribuidos en la naturaleza, ya que se han localizado en ríos, suelos y mares. El más estudiado es Nitrosomonas, y se describen como bacterias gram negativas con diversas morfologías (cocos, bacilos y espirales), que pueden desarrollarse preferentemente en un intervalo de temperatura que va desde 25 hasta $30{ }^{\circ} \mathrm{C}$, en valores de $\mathrm{pH}$ entre 7.5 y 8.0 y que pueden tolerar concentraciones de amonio que van desde 36 hasta 900 mg/l (Bock y col., 1991).

En cuanto a las bacterias que participan en la segunda etapa, las nitrito oxidantes, se han identificado géneros tales como: Nitrococcus, Nitrobacter, 
Nitrospira, Nitrospina, de los cuales Nitrobacter es el más estudiado (Prosser y col., 1989). También son gram-negativas y con morfologías de cocos y bacilos. En general son microorganismos mesófilos y su mejor actividad se registra a valores de $\mathrm{pH}$ neutro a alcalino. Estos géneros se han aislado principalmente en ambientes marinos y en el caso de Nitrobacter, se ha aislado de rocas, suelos y ríos (Bock y col., 1991).

\subsection{2.- Bioquímica y fisiología de la nitrificación}

Hasta el momento no se ha identificado una bacteria capaz de oxidar completamente el amonio hasta nitrato y se ha observado que la nitrificación puede dividirse en tres pasos (Figura 2), en los cuales intervienen los diferentes géneros bacterianos amonio o nitrito oxidantes antes mencionados.

1) $\mathrm{NH}_{4}^{+}+2 \mathrm{H}^{+}+1.5 \mathrm{O}_{2}+2 \mathrm{e}^{-} \longrightarrow \mathrm{NH}_{2} \mathrm{OH}+\mathrm{H}_{2} \mathrm{O}+2 \mathrm{H}^{+}$

2) $\mathrm{NH}_{2} \mathrm{OH}+\mathrm{H}_{2} \mathrm{O}+2 \mathrm{H}^{+} \longrightarrow \mathrm{NO}_{2}^{-}+6 \mathrm{H}^{+}+4 \mathrm{e}^{-} \quad \Delta \quad \Delta \mathrm{G}^{\prime}=-240 \mathrm{~kJ}$

3) $\mathrm{NO}_{2}{ }^{-}+1 / 2 \mathrm{O}_{2} \longrightarrow \mathrm{NO}_{3}{ }^{-} \longrightarrow \Delta \mathrm{G}^{\circ}=-74 \mathrm{~kJ}$

Figura 2. Etapas de reacción para la completa oxidación de amonio hasta nitrato.

En la primera etapa (Figura 2), se da la conversión de $\mathrm{NH}_{4}{ }^{+}$a hidroxilamina $\left(\mathrm{NH}_{2} \mathrm{OH}\right)$ por la enzima amonio monooxigenasa (AMO) (Castingnetti y Hollocher, 1985). Esta reacción requiere de oxígeno molecular $\left(\mathrm{O}_{2}\right)$ y parece ser que la enzima está asociada a las proteínas de la membrana, aunque esto último no ha sido totalmente demostrado, ya que la enzima pierde parte de su actividad al ser aislada (Bedard y Knowles 1989). Se ha visto que la AMO está constituida por tres polipéptidos que fueron clasificados como AmoA, AmoB y AmoC, los cuales fueron identificados por medios bioquímicos y genéticos (Arp y Stien, 2003). Se cree que el polipéptido AmoA contiene el sitio catalítico para la oxidación del $\mathrm{NH}_{4}{ }^{+}$. Se sabe que los genes que codifican los polipéptidos $A$ y $B$ son $a m o A$ y $a m o B$. En cuanto a AmoC, la evidencia de su existencia es indirecta, ya que los genes que codifican a las tres subunidades son co- 
transcritos en un solo ARNm (Arp y col., 2002). Sin embargo se sugiere que codifica los péptidos chaperones que ayudan a los péptidos A y B a anclarse a la membrana citoplásmica (Klotz y col., 1997). Se ha sugerido que el cobre es el cofactor de esta enzima basándose principalmente en la evidencia de que al poner extractos libres de células en presencia de cobre y en condiciones nitrificantes, la AMO se reactiva (Arp y col.,2002). Se ha reportado que esta enzima, además de oxidar al amonio, es capaz de oxidar compuestos orgánicos de bajo peso molecular como el propano, benceno, ciclohexano y fenol, entre otros (Hynes y Knowles 1978).

La segunda etapa (Figura 3), la oxidación de la hidroxilamina a nitrito, se lleva a cabo por la actividad de la enzima hidroxilamina óxido-reductasa (HAO), que se ha estudiado principalmente en el género Nitrosomonas. Esta enzima es una proteína con grupos hemo (Andsersson y col., 1984) y está localizada en el espacio periplásmico (Hooper y Dispirito 1985). Cataliza la deshidrogenación de la hidroxilamina formando ácido nítrico $\left(\mathrm{HNO}_{3}\right)$, el cual, de manera espontánea, da lugar a la formación transitoria de óxido nitroso $\left(\mathrm{N}_{2} \mathrm{O}\right)$ y en menor proporción a óxido nítrico (NO) (Blackmer y col., 1980). La oxidación de la hidroxilamina es el paso donde las bacterias amonio oxidantes obtienen su energía (ATP). En total se obtienen 4 electrones en la oxidación del amonio a nitrito, en donde 2 de ellos son utilizados en la formación de la hidroxilamina, siendo por lo tanto sólo 2 los electrones que generan energía.

La HAO es un complejo enzimático con un peso aproximado de 180315190315 y consiste de un $\alpha$-oligòmero estrechamente relacionado con tres grupos hemo, incluyendo siete tipos de hemo-c un hemo P-460 (Igarashi y col., 1997; Bergmann y Hooper, 1994b). 


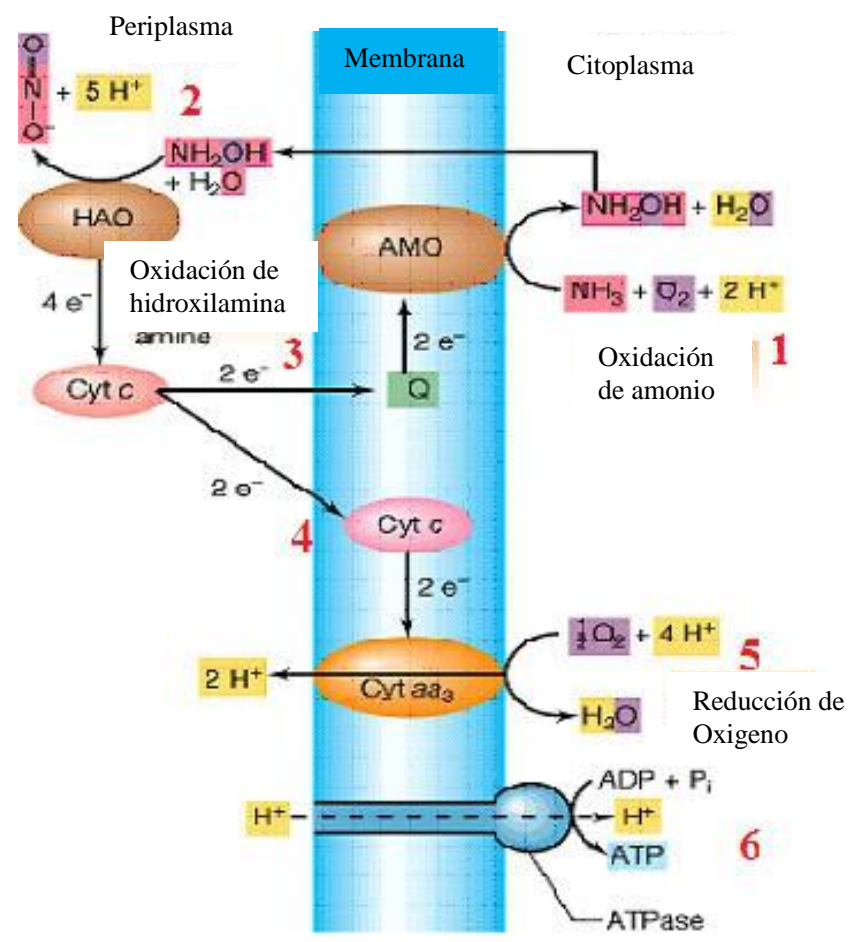

Figura 3. Esquema de la amonio oxidación (Madigan y col., (2003).Los números en rojo indican la secuencia de la ruta amonio oxidante.

El cambio de energía libre $\left(\Delta \mathrm{G}^{\circ}\right)$ para la reacción global de oxidación de $\mathrm{NH}_{4}{ }^{+}$ a $\mathrm{NO}_{2}{ }^{-}$es de $-240 \mathrm{~kJ} /$ reacción (Madigan y col., 2003). Dado el valor bajo de $\Delta \mathrm{G}^{\mathrm{o}}$ ' se puede pronosticar que el crecimiento de las bacterias amonio oxidantes será también muy bajo y estará limitado por la disponibilidad energética (Gómez y col., 1995).

La última etapa, la oxidación de nitrito a nitrato, se lleva a cabo por un complejo enzimático formado por la nitrito óxido reductasa (NOR), el citocromo $\mathrm{C}$, una ubiquinona y una deshidrogenasa dependiente de $\mathrm{NADH}+\mathrm{H}^{+}$. Además se requiere de media molécula de oxígeno $\left(1 / 2 \mathrm{O}_{2}\right)$. Este complejo es inducible y se conoce como nitrito óxido reductasa (Stouthamer, 1976). La nitrito oxidación es un proceso reversible, ya que la NOR puede catalizar la oxidación de nitrito a nitrato y en condiciones anaerobias, la reducción de nitrato a nitrito (Bock y Wagner 2006). Esta característica permite a los microorganismos nitrito oxidantes sobrevivir en ambientes anóxicos (Bock y Wagner 2006).

La nitrito óxido reductasa que cataliza la oxidación del nitrito está compuesta por dos sub-unidades de aproximadamente 115 y $65 \mathrm{kD}$, asociadas a la 
membrana citoplasmática (Meincke y col., 1992; Bock y Wagner 2006). La enzima contiene en $\mathrm{ng} / \mathrm{mg}$ de proteína: 0.70 de molibdeno, 23.0 de hierro, 1.76 de zinc y 0.89 de cobre. El molibdeno es esencial para la nitrito oxidación (Ingledew y Halliug 1976; Kruger y col., 1987; Meincke y col., 1992). De acuerdo con los análisis realizados a la NOR por Ingledew y Halliug (1976) y Meincke y col., (1992), se ha encontrado molibdeno en forma de molibdoproteinas en la membrana de Nitrobacter winogradsky y Nitrobacter hamburgensis.

Como resultado de la oxidación de nitrito a nitrato, dos electrones son liberados para la generación de energía y son transferidos a los citocromos a y $c$ y posteriormente a la citocromo oxidasa del tipo aa3 (Figura 4).

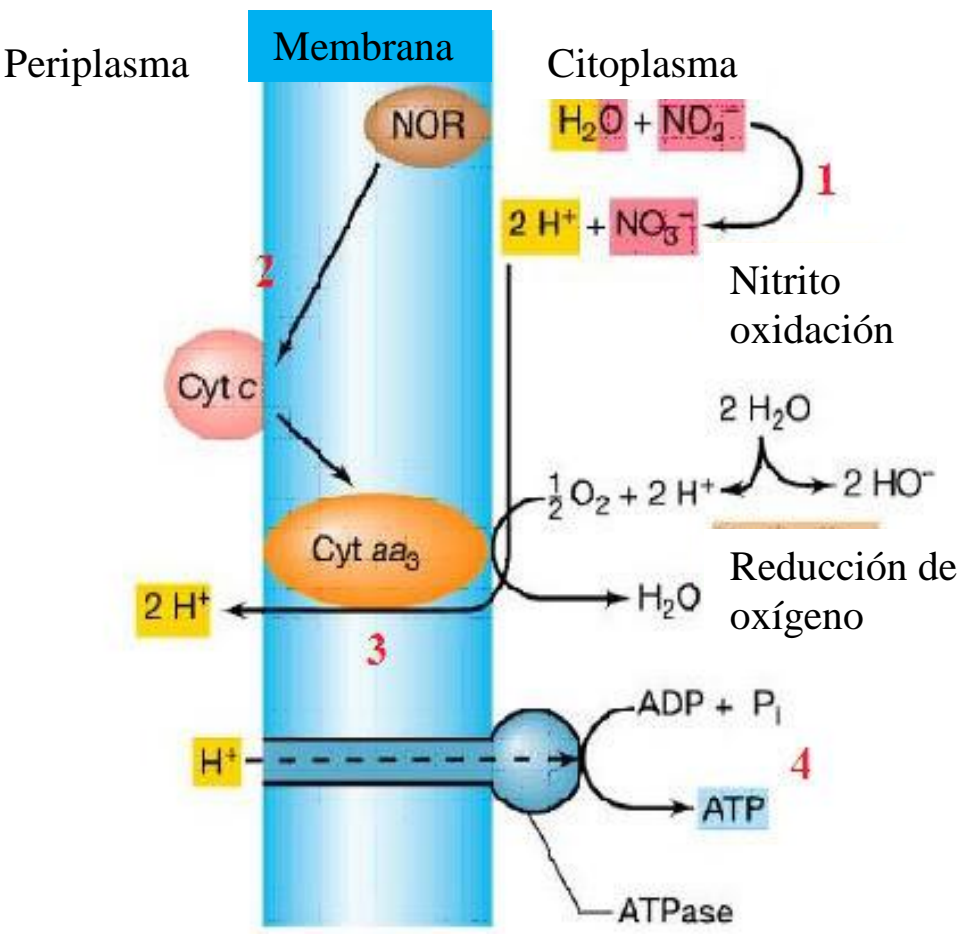

Figura 4. Esquema de la nitrito oxidación tomado de Madigan y col., (2003). Los números en rojo indican la secuencia de la ruta nitrito oxidante.

La enzima citocromo $c$ oxidasa del tipo aa3, ha sido purificada a partir de algunas especies de Nitrobacter y su función fue determinada como una oxidasa terminal (Sewell y col., 1972, Yamanaka y col., 1981). Estos electrones entran a una cadena respiratoria aún no del todo clara (Bock y Wagner, 2006). Respecto a la producción de ATP que conlleva el flujo de electrones, parece que las teorías no están todavía unificadas. Cobley (1976) señaló que la 
producción de ATP está relacionada con la liberación de protones dentro del citoplasma, mientras que Wetzstein y Ferguson (1985) detectaron una expulsión de protones dentro del periplasma acoplada con la oxidación de nitrito. Desde el punto de vista energético, se ha visto que el par $\mathrm{NO}_{2}{ }^{-} / \mathrm{NO}_{3}{ }^{-}$ formado por la nitrito óxido-reductasa genera un potencial de $\mathrm{E}_{0}=+430 \mathrm{mV}$, el cual se emplea en la fosforilación oxidativa y para la reducción de NAD. EI cambio de energía libre calculado para esta reacción es de $\Delta G^{\circ}$ de -74 kJ/reacción (Madigan y col., 2003) que resulta menor en comparación con la amonio oxidación, es de esperarse entonces que en esta etapa final de la nitrificación, el crecimiento bacteriano sea aún más bajo.

\subsection{3.- Transporte de amonio y nitrito a través de la membrana}

La nitrificación es un proceso biológico muy importante usado en el tratamiento de aguas residuales. Pero antes de que inicie la nitrificación, el ingreso de amonio y nitrito a la célula es una etapa crucial para que este proceso oxidativo ocurra. En este punto, la membrana celular es de vital importancia ya que ésta es el soporte de muchas estructuras; como los canales iónicos, las proteínas transportadoras, las bombas iónicas, las proteínas de reconocimiento, las proteínas que sirven de soporte a elementos del citoesqueleto, entre otros (Liu, 1990). Estas estructuras son las encargadas de realizar un gran número de actividades, como el transporte de sustratos, por lo cual, es importante considerar que este transporte puede ser afectado por la presencia de los compuestos orgánicos que podrían estar contenidos en los influentes que serán tratados por nitrificación.

De manera general, se puede hablar del transporte activo y pasivo o facilitado, este último está mediado por canales iónicos y permeasas.

El transporte activo es un mecanismo celular por medio del cual algunas moléculas atraviesan la membrana plasmática contra un gradiente de concentración, es decir, desde una zona de baja concentración a otra de alta concentración con el consecuente gasto de energía. Los ejemplos típicos son la bomba de sodio-potasio, la bomba de calcio o simplemente el transporte de 
glucosa. Para desplazar estas sustancias contra corriente es necesario el aporte de energía procedente del ATP. Las proteínas involucradas en el transporte activo poseen actividad ATPasa, que significa que pueden escindir el ATP (Adenosin Tri Fosfato) para formar ADP (dos Fosfatos) o AMP (un Fosfato) con liberación de energía de los enlaces fosfato de alta energía Mathews (2003).

El transporte pasivo o facilitado involucra la presencia de canales iónicos y permeasas Los canales iónicos están formados por proteínas que recorren todo el espesor de la membrana plasmática. Este poro permite, de manera selectiva, el pasaje de iones a través de la membrana. La importancia de estos canales aumenta debido a la capacidad de regulación en los procesos de apertura y cierre de los mismos, existiendo canales que permanecen siempre abiertos, mientras que otros se abren y cierran dependiendo de señales químicas, mecánicas, o eléctricas (http://www.korion.com.ar/archivos/ membranacelular.pdf). Las proteínas denominadas permeasas o carriers. Son, al igual que los canales iónicos, sumamente específicas. La molécula transportada debe de unirse a un sitio específico de la permeasa, lo que provoca un cambio conformacional en la misma que facilita el pasaje del soluto de un lado al otro de la membrana sin generar gasto energético alguno Mathews (2003).

Se ha propuesto que el mecanismo de transporte de amonio es de tipo facilitado, ya que puede llevarse a cabo por medio de permeasas (Hakette y col 1970; Robert y col., 1978). Y también se plantea que puede darse por canales iónicos (Khademi y col., 2004). La acuaporina 8 (AQP8) participa en el transporte de amoniaco en levaduras, pero se ha visto también que al acidificarse el medio puede transportar amonio (Jahn y col., 2004).

Kadhemi y col. (2004), proponen que los canales iónicos para el transporte de amonio en $E$. coli constan de dos paredes hidrofóbicas, de aproximadamente 1.35 angstroms que puede transportar $\mathrm{NH}_{3} \circ \mathrm{NH}_{4}{ }^{+}$dependiendo del $\mathrm{pH}$ del medio. Sin embargo, no está del todo establecido si se lleva a cabo alguna reacción química del amonio con los constituyentes del canal, si se trata de un 
tipo de canal iónico que se mantiene abierto todo el tiempo o si su apertura está en función de la concentración de amonio.

Hakette y col 1970; Robert y col., 1978 reportaron que las permeasas transportadoras de amonio están relacionadas estructuralmente con las proteínas de transporte de membrana denominadas proteínas Amt, metilamonio/permeasas del tipo RhAG, RhBG y RhCG a su vez relacionadas estructuralmente con el factor Rh en los mamíferos. El RhAG, RhBG y rhCG son proteínas constituyentes de una familia de transportadores de soluto formada por 42 tipos de transportadores estructuralmente relacionadas.

La estructura tridimensional de la proteína de transporte de amonio AmtB de Escherichia coli se determinó por cristalografía de rayos $\mathrm{x}$. La estructura tiene un canal de amonio hidrófobo. Se encontró que esta proteína transportadora es similar a la RhCG encontrada en humanos. La estructura encontrada en $E$. coli, muestra un trímero de 11 subunidades, cada una compuesta por $\alpha$-hélices transmembranales. Cada monómero contiene un canal de conducción de amonio y además tienen una región $\mathrm{N}$-terminal que actúa como una secuencia señal para la recepción del sustrato (Destch y Stulk 2003).

Se ha observado que el gen AmtB se expresa sólo en los niveles de nitrógeno limitantes. Se co-expresada con el gen GlnK que codifica una proteína PII. Esta proteína es también trimérica y permanece en el citoplasma. Cuando los niveles de nitrógeno son altos la permeasa puede desactivarse para evitar que niveles excesivos de amonio entren en la célula. Esta desactivación se consigue por de-uridilación de la proteína GlnK que luego se une a la parte de la proteína AmtB que esta en el citoplasma (Destch y Stulk 2003).

En condiciones aerobias en E. coli se ha observado que el transporte de nitrito se puede llevar a cabo por difusión facilitada por medio de proteínas NirC (Peckman y col. 1990).Estas proteínas de transporte están estructuralmente relacionadas con la familia de proteínas transportadoras FNT (formate nitrite transporters) encontradas en diversos procariotas. Estas proteínas transportan compuestos estructuralmente relacionados con el formiato y el nitrito Suppmann y Sawers 1994; Clegg y col. 2002). La función de los 
transportadores NirC es semejante a la de las permeasas y se ha propuesto que están formandas por seis dominios $\alpha$-hélice implicados en el transporte de nitrito (Moir y Wood 2001).

En condiciones desnitrificantes algunos autores contemplan que proteínas del tipo NarK están involucradas, ya que se han identificado este tipo de proteínas en bacterias como E.coli, y se ha observado que el consumo de nitrito en los proteoliposomas de esta bacteria aumenta con la presencia de proteínas tipo Nark (Moir y Wood 2001). Sin embargo, hay algunos autores que refieren que es posible que se tengan algunos otros mecanismos por los cuales el nitrito puede ingresar a la célula, puesto que en experimentos donde los genes que codifican para las proteínas Nark producen una proteína dañada, se sigue observando consumo de nitrito (Moir y Wood 2001).

Se ha observado que las diferentes proteínas transportadoras de amonio y nitrito tienen características y comportamientos semejantes a las enzimas, ya que cuentan con un sitio activo, tiene gran especificidad por su correspondiente sustrato, se saturan al alcanzar la máxima velocidad de transporte. y pueden ser afectadas por diferentes factores como: cambios en el pH, la concentración de amonio o nitrito, la temperatura y posiblemente por la presencia de compuestos orgánicos (Denis y col., 1990; Destch y Stulk 2003; Khademi y col., 2004 ). Sin embargo aunque se han alcanzado grandes avances y reportado evidencia a nivel genético, sobre regulación y síntesis de los posibles transportadores de amonio y nitrito, aun hay mucho que aportar sobre el mecanismo de transporte de estos. Básicamente puede decirse que el tipo de transporte depende de la concentración y del tipo de microorganismos. Por lo que no se pude generalizar que bajo ciertas condiciones o utilizando ciertos microorganismos, se puede predecir el tipo de transporte que puede darse. En el caso específico de las bacterias nitrificantes, este campo podría considerarse inexplorado, ya que la información prácticamente es inexistente, pues básicamente se asume que el transporte en estos microorganismos puede ser semejante al encontrado en otros microorganismos con características fenotípicas semejantes (gram negativos). 


\subsection{4.- Factores que afectan la nitrificación}

Como cualquier proceso biológico, la nitrificación está condicionada al ambiente que la rodea. Por ejemplo, se sabe, que la eficiencia de la transformación de amonio a nitrato puede estar determinada por la concentración de oxígeno, $\mathrm{pH}$, temperatura y también por la presencia del mismo sustrato (amonio) o de materia orgánica (Hynes y Knowles 1982). Si la nitrificación se ve afectada por cualquiera de estos factores, se puede dar lugar a la acumulación de nitrito, óxido nitroso o ácido nítrico, compuestos que resultan tóxicos (Lema y col., 1996) y pueden afectar el proceso nitrificante.

\subsection{5.- Efecto del pH}

Watson (1974), reporta que el intervalo óptimo de $\mathrm{pH}$ para el crecimiento de los organismos amonio oxidantes es de 5.8-8.5 y para las bacterias nitrito oxidantes de 6.5-8.5. Se tiene evidencia que por debajo de dichos valores la velocidad específica de crecimiento de las nitrito oxidantes disminuye abruptamente (Keen y Prosser 1987) y que a valores de $\mathrm{pH}$ menores que 5 la nitrificación se detiene por completo (Prosser, 1989). En parte esto es debido a que el $\mathrm{pH}$ influye en la disponibilidad del sustrato, ya que se ha observado que el sustrato para las amonio oxidantes puede ser el amoniaco (Watson y col., 1981), por lo que la disminución del pH provocará que la especie predominante sea el amonio. Asimismo, se ha visto que la disminución de la actividad nitrificante a pH menores que 5 también se atribuye a la acumulación de ácido nitroso $\left(\mathrm{HNO}_{2}\right)$, el cual inhibe la oxidación del amonio. Aunque también se dice que la reducción en el valor del pH afecta la actividad enzimática (Anthonisen y col., 1976).

\subsection{6.- Efecto del oxígeno}

La nitrificación es un proceso que requiere de oxígeno molecular para la oxidación del amonio y para la respiración tanto de las bacterias amonio como de las nitrito oxidantes (Prosser, 1989), aunque existen reportes donde se sugiere que por la baja disponibilidad de oxígeno, la nitrito oxidación puede verse más afectada que la amonio oxidación (Gunderson 1966). En este sentido, autores como Helder y Vries (1983) reportan que la amonio oxidación se ve inhibida a concentraciones cercanas a $30 \mu \mathrm{mol} / \mathrm{l}$ mientras que la nitrito oxidación a $125 \mu \mathrm{mol} / \mathrm{l}$. 


\subsection{7.- Efecto de la materia orgánica en la nitrificación}

Se tiene conocimiento que tanto en cultivos axénicos como en lodos nitrificantes, la nitrificación es un proceso sensible a la presencia de materia orgánica, pero con diferente magnitud en función del tipo y de la concentración del compuesto orgánico, así como del tipo de cultivo (Gómez y col., 2002; Zepeda y col., 2006; Pérez y col., 2008). Acerca del efecto de la materia orgánica en nitrificación, existen varias propuestas, por ejemplo, se dice que la presencia de materia orgánica favorece el crecimiento de organismos heterotróficos sobre los microorganismos nitrificantes (Michael y col., 1985; Daigger y col., 1985). Así pues, la presencia de la materia orgánica podría ocasionar la disminución en la eficiencia nitrificante al desviar el proceso respiratorio a uno asimilativo. También se propone un efecto directo sobre las enzimas nitrificantes. Al respecto, Eilersen y col. (1994); Takai y col. (1997) y Gómez y col. (2000), observaron en cultivos en lote, que al adicionar diferentes ácidos grasos volátiles (AGVs) y en diferentes concentraciones, se acumula nitrito y se disminuye la velocidad nitrificante, a lo cual los autores sugieren un efecto inhibitorio sobre las enzimas nitrificantes, aunque no dejan claro sobre cuál enzima puede darse dicha inhibición. Por otra parte, Keener y Arp. (1994), realizaron ensayos con Nitrosomonas europaea en los cuales observaron que si la concentración de materia orgánica se aumentaba, se veía afectada la oxidación de amonio. Los autores proponen una competencia entre el amonio y la materia orgánica por el sitio activo de la enzima encargada de la oxidación del amonio (inhibición competitiva), o bien, que la materia orgánica se une al sitio activo de la enzima cambiando su configuración espacial y alterando su capacidad oxidativa.

En el caso de la materia orgánica del tipo aromática, Zepeda y col. (2003), evaluaron en un consorcio nitrificante, el efecto de diferentes concentraciones de benceno sobre la nitrificación, encontrando que con una concentración de $10 \mathrm{mg} \mathrm{C}$-benceno/l, el rendimiento de producción de nitrato disminuye en 53\% y las velocidades específicas de consumo de amonio y producción de nitrato caen hasta un 82 y $74 \%$ respectivamente. Texier y col. (2002) evaluaron el efecto del $p$-cresol en el proceso nitrificante, encontrando que con $17 \mathrm{mg} / \mathrm{l}$ disminuye la formación de nitrato en un $70 \%$ mientras que con $10 \mathrm{mg} / \mathrm{l}$, no se observa una disminución considerable. Reportan también una recuperación de 
la actividad nitrificante del $44 \%$ después de 315 horas de cultivo y del contacto previo con p-cresol. Silva y col., (2009) al adicionar $25 \mathrm{mg} / \mathrm{l}$ de $p$-cresol observan una disminución en la velocidad específica de consumo de amonio de $83 \%$, mientras que para la de producción de nitrato, calculan una disminución de $60 \%$.

En general, el efecto que la materia orgánica tiene sobre el proceso nitrificante es asociado con la inhibición de las enzimas que intervienen en éste, pues comúnmente se reporta la disminución de las velocidades específicas de consumo de amonio y producción de nitrato, es decir un efecto en la cinética del metabolismo. Sin embargo, no está del todo establecido si el daño que se reporta es exclusivamente a nivel enzimático o si la materia orgánica puede tener algún efecto a nivel genético o en la membrana de los microorganismos. Por otro lado, aunque el efecto de la materia orgánica sobre los microorganismos puede ser muy severo a nivel cinético, en muchos casos se ha visto que estos pueden recuperar su capacidad nitrificante después de unas horas de cultivo, pero no queda claro si esta recuperación está relacionada con la desinhibición de las enzimas de la nitrificación o a la síntesis de nuevas enzimas, o si esto depende del tipo de compuesto orgánico al que han sido expuestas, por lo que este campo ofrece una posibilidad bastante amplia para su investigación.

\subsection{8.- Efecto de la materia orgánica sobre la membrana celular}

Además de que la materia orgánica puede afectar cinéticamente el proceso nitrificante, es posible que haya un efecto adicional de ésta sobre la membrana de los microorganismos. Asimismo, hay que considerar que el efecto de la materia orgánica puede estar en función de varios factores, como su concentración, liposolubilidad y/o estructura molecular del compuesto.

Desde 1921, Jentsch reporta que los hidrocarburos cíclicos detienen el crecimiento de bacterias y hongos. Baier y col. (1937) reportan que los hidrocarburos volátiles como el benceno y xilenos resultan más tóxicos que los alcanos de mayor peso molecular. Otros como los terpenos, en específico el $\alpha$ y $\beta$-pineno, se ha reportado destruyen la integridad celular e inhiben la actividad respiratoria de la mitocondria en la levadura Saccharomyces cerevisiae (Andrews y col., 1980). 
En lo referente a los compuestos aromáticos como el tolueno, se reporta que en E. coli, este puede incrementar la permeabilidad de la membrana citoplasmática y también alterar la concentración de iones de magnesio presentes en la membrana (Smet y col., 1978). Por su parte, Sikkema y col. (1992), reportan que la tetralina puede causar daño a la membrana celular al incrementar el flujo de protones a través de ésta, disipando su fuerza protón motriz.

Existe poca información para el caso específico del efecto del 2-clorofenol. La Pesticide Action Network (PAN) lo reporta como un compuesto de toxicidad moderada a alta con una dosis letal 50 ( $\left.\mathrm{DL}_{50}\right)$ para Photobactereum phosphoreum de $27 \mathrm{mg} / \mathrm{l}$. Sin embargo, no se sabe si el efecto sobre los microorganismos es debido al rompimiento de la membrana, ya sea total 0 parcial, o si se trata de un efecto a otro nivel, por lo que el entendimiento de la interactividad de la materia orgánica, en este caso el 2-clorofenol, con la barrera celular, debe ser analizado de manera más profunda.

\section{6.- Clorofenoles}

Dentro de la gran variedad de residuos peligrosos generados en la actualidad, los compuestos organoclorados poseen especial relevancia. Las corrientes acuosas que contienen este tipo de contaminantes deben recibir un tratamiento o estabilización que los transforme de residuos peligrosos altamente tóxicos para el ser humano y el medio ambiente a residuos inocuos (del Real Olvera y col., 2008).

El origen de estas corrientes contaminantes puede ser de los efluentes residuales de algunas industrias que los vierten sin tratamiento previo o bien tratarse de aguas residuales contaminadas por infiltración de plaguicidas $u$ otros compuestos organoclorados a través del suelo (del Real Olvera y col., 2008). La mayoría de los compuestos organoclorados son muy estables y difícilmente biodegradables, permaneciendo en el ambiente durante cientos de años, de ahí su denominación como compuestos orgánicos persistentes (COP). Además, estos químicos son también liposolubles, lo que significa que tienen tendencia de concentrarse en los tejidos adiposos de los seres vivos a lo largo de su vida (del Real Olvera y col,. .2008). 
La mayor parte de los compuestos organoclorados son cancerígenos y causan efectos negativos sobre el sistema inmunológico, reproductivo y nervioso, entre otras afecciones (Lomnicki y col., 2003). Se ha detectado la presencia de compuestos organoclorados en numerosas corrientes industriales, tales como los residuos de la fabricación de monómeros o de plaguicidas, en los procesos de desengrasado de metales, procesado de maderas e industria petrolera (López y col., 1999). Un tipo de industria especialmente contaminante de estos compuestos es la industria papelera, puesto que el uso de compuestos de cloro para el blanqueo de la pulpa celulósica y el papel, da lugar a la formación de compuestos organoclorados con elevada toxicidad. Entre los compuestos organoclorados vertidos por este tipo de industrias destacan los clorofenoles, las resinas ácidas cloradas y los hidrocarburos clorados (Ali y Sreekrishman, 2001).

De acuerdo con una lista publicada por la Agency for toxic substances and disease registry $(A T S D R)$ en el 2005 , en la Tabla 1 se puede observar el posicionamiento de los distintos clorofenoles entre ellos el 2-clorofenol (2-CP) dentro de las 275 sustancias más peligrosas en lo que se refiere a su toxicidad.

Tabla 1 Clasificación de la ATSDR de los compuestos fenólicos por su toxicidad en el 2005.

\begin{tabular}{cc}
\hline Lugar en la lista & Nombre del compuesto \\
\hline \hline 45 & Pentaclorofenol \\
86 & $2,4,6$-triclorofenol \\
173 & Tetraclorofenol \\
183 & Fenol \\
212 & 2,4-diclorofenol \\
248 & 2-clorofenol \\
\hline
\end{tabular}

Debido a su toxicidad, es común encontrar reportes donde se menciona que estos compuestos pueden alterar diferentes procesos biológicos, provocando incluso su inhibición. Sin embargo, existen también diversos reportes que indican que bajo condiciones aerobias y anaerobias, estos pueden ser eliminados oxidándolos o reduciéndolos según sea el caso.

\subsection{1.- Degradación de compuestos aromáticos en condiciones aerobias}

Dada la estabilidad de los compuestos aromáticos, su metabolismo supone un reto importante para los microorganismos. Para esto, los microorganismos han 
desarrollado soluciones que implican una gran variedad de "rutas periféricas" encargadas de oxidar los diversos sustratos aromáticos a un número limitado de intermediarios centrales, los cuales posteriormente, perderán su carácter aromático y se transformarán en compuestos del metabolismo primario de la célula a través de las denominadas "rutas centrales" (Heider y Fuchs, 1997; Heider y col., 1998; Harwood y col., 1999; Pieper y col., 2004). A esta estrategia de canalizar un gran número de rutas periféricas distintas hacia unas pocas rutas centrales se le ha denominado "embudo catabólico" (Harayama y Timmis, 1989).

El catabolismo de los compuestos aromáticos implica dos procesos secuenciales: 1) modificación de la densidad electrónica del anillo aromático, y 2) ruptura del anillo. Estos procesos suponen la aplicación de reacciones de oxidación o reducción dependiendo de si el metabolismo se lleva a cabo en condiciones aerobias o anaerobias, respectivamente (Heider y Fuchs, 1997; Díaz, 2004).

La estrategia clásica de mineralización aerobia del anillo aromático, se fundamenta en la desestabilización del mismo mediante rutas periféricas que implican la incorporación de grupos hidroxilo. Con esta adición de grupos hidroxilo, la estructura electrónica del anillo aromático se ve acrecentada, debido al aumento de electrones en el anillo y es más susceptible a la acción de las oxigenasas, que catalizan su conversión a un compuesto alifático, el cual será oxidado progresivamente hasta obtener intermediarios del ciclo de Krebs. Esta incorporación de grupos hidroxilo en el anillo bencénico lo realizan las oxigenasas, monooxigenasas y/o dioxigenasas, según incorporen uno o dos grupos hidroxilo (Gibson y Parales, 2000), generándose así derivados aromáticos mono-, di-, o tri-hidroxilados (catecol, protocatecuato, homoprotocatecuato, gentisato, homogentisato, etc.) (Figura 5). Las enzimas de las "rutas periféricas" son más o menos específicas de sus sustratos y generalmente se inducen por estos (Heider y Fuchs, 1997).

Una característica frecuente es que un mismo compuesto aromático puede degradarse a través de distintas rutas catabólicas como ocurre, por ejemplo, con el tolueno. 


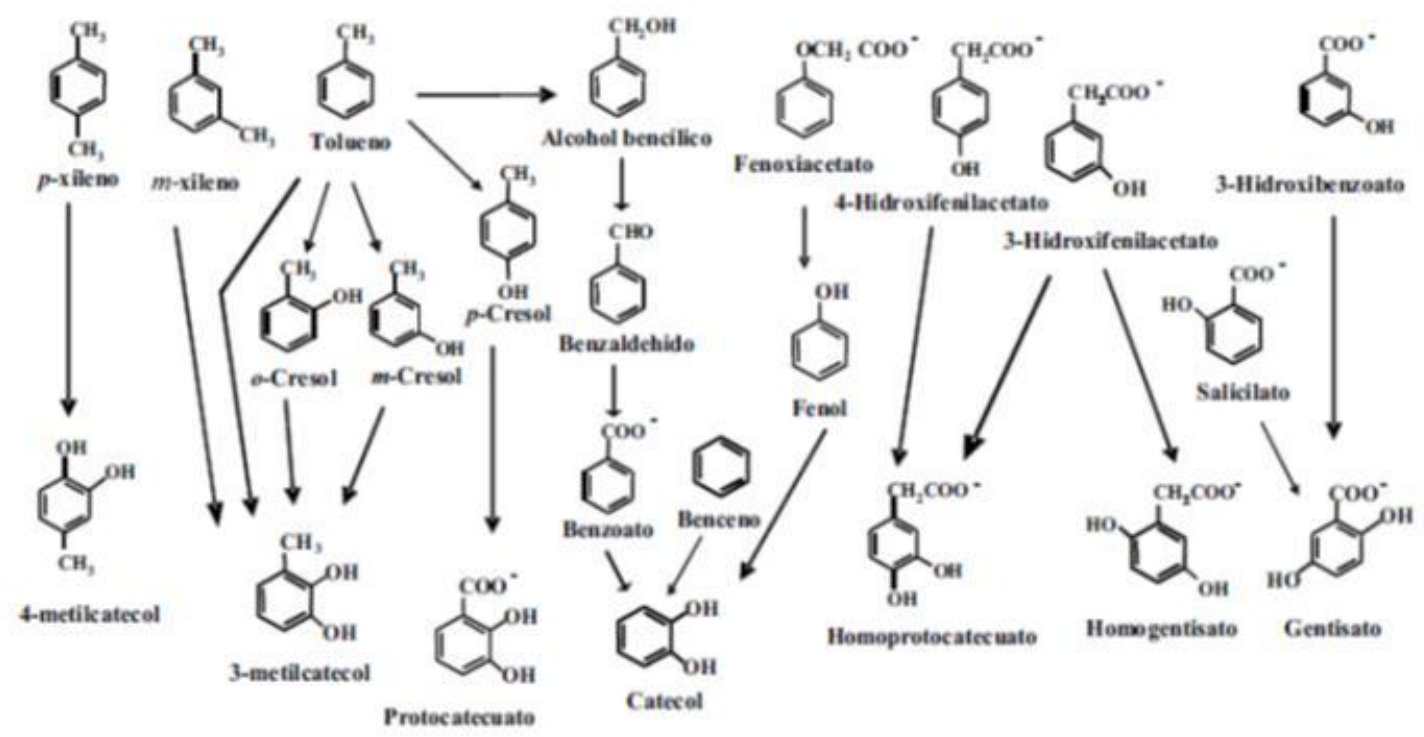

Figura 5. Rutas de degradación aeróbica para diferentes compuestos Aromáticos.

\subsection{2.- Degradación de clorofenoles en condiciones aerobias}

Los trabajos de eliminación de clorofenoles por vía biológica se han llevado a cabo principalmente con bacterias heterótrofas en procesos aerobios (Basu y Oleszkiewicz 1995; Fava y col., 1995; Buitrón y col., 2003) y anaerobios (Bae y col., 2002; Beristain-Montiel 2010; 2012). Incluso combinando ambos sistemas (Macarie y col., 1995). Bajo condiciones aerobias, se han sugerido las rutas de oxidación del 2-clorofenol y sus isómeros (Farell y Brid 1990).

En la literatura (Buitrón y col., 1998; Schmidt y col., 1999; Jechorek y col., 2003) se indica que la degradación biológica de los clorofenoles tanto arerobia como anaerobia requiere de tiempos de residencia mayores que en un proceso químico, aunque se debe considerar que el proceso biológico precisa de condiciones menos drásticas de operación que en proceso químico. Por ejemplo, se han considerado tiempos de 32 días para una eliminación prácticamente total de pentaclorofenol (PCP) mediante un tratamiento biológico aerobio por un cultivo axénico (Schmidt y col., 1999).

Como una alternativa a la elección de cultivos puros se han utilizado cultivos mixtos (consorcios) aclimatados a diferentes clorofenoles como el 4 y el 2,4clorofenol entre otros (Young y col., 2002; Jechorek y col., 2003; Kargi y Eker, 2004). Así se han degradado clorobenceno (Jechorek y col., 2003), 1,2- 
dicloroetileno y 1,1- dicloroetano (Young y col., 2002) y 2,4-diclorofenol (Kargi y Eker, 2005). Aunque en algunos casos, el tiempo de aclimatación es prolongado.

Liu y Parcepavicius (1990) proponen que el 2-CP es uno de los clorofenoles más persistentes en condiciones aerobias, sin embargo debe aclararse que pueden ser muchos los factores que pueden afectar la degradabilidad de los clorofenoles, como el tipo de reactor o el tipo de inóculo utilizado, por ejemplo. Estos autores encontraron que la biodegradabilidad de algunos de estos compuestos fenólicos presenta el siguiente orden:

- Fenol > 2,4-diclorofenol > 4-clorofenol > 2,4,6-triclorofenol> pentaclorofenol> 2-clorofenol.

Otros trabajos en los cuales se ha evaluado el consumo o eliminación de 4clorofenol, 2-clorofenol, 2,4-diclorofenol, 2,4,6-triclorofenol y pentaclorofenol en condiciones aerobias (no nitrificantes) se muestran en la tabla 2.

Tabla 2.- Algunos trabajos que se han llevado a cabo en condiciones aerobias para la eliminación de clorofenoles.

\begin{tabular}{|c|c|c|c|c|c|c|c|}
\hline Referencia & Compuesto & Condiciones & Reactor & Ec. & $\boldsymbol{Y}$ & $q$ & SSV \\
\hline Basu y & 2-CP (30 mg/l) & aerobias & SBR & 99 & - & - & 2.0 \\
\hline $\begin{array}{l}\text { Oleszkiewicz } \\
\text { (1995) }\end{array}$ & $2-\mathrm{CP}(140 \mathrm{mg} / \mathrm{l})$ & aerobias & Matraces EM & 90 & - & - & - \\
\hline \multicolumn{8}{|l|}{$\begin{array}{l}\text { Fava y } \\
\text { col.,(1995) }\end{array}$} \\
\hline $\begin{array}{l}\text { Farebagoli y col., } \\
\text { (2008) }\end{array}$ & 2-CР (40mg/l & aerobias & SBR & 50 & & & 2.0 \\
\hline $\begin{array}{l}\text { Moreno y col., } \\
\text { (2003) }\end{array}$ & $\begin{array}{l}4-C P \\
350-7000 \mathrm{mg} / /\end{array}$ & aerobias & SBR & 99 & - & - & 2.0 \\
\hline $\begin{array}{l}\text { Moreno y col., } \\
(2004)\end{array}$ & $\begin{array}{l}4-C P 50,100 \\
\text { y200mg }\end{array}$ & aerobias & $\begin{array}{l}\text { SBR } \\
\text { Ayuno }\end{array}$ & 99 & * & $\begin{array}{l}28 \\
55 \\
41\end{array}$ & 2.5 \\
\hline $\begin{array}{l}\text { Macarie y col., } \\
\text { (1995) }\end{array}$ & $\begin{array}{l}\text { Pentaclorofenol } \\
150 \mathrm{mg} / \mathrm{l}\end{array}$ & $\begin{array}{l}\text { aerobio } \\
\text { anaerobio }\end{array}$ & $\begin{array}{l}\text { Híbrido de flujo } \\
\text { asendente }\end{array}$ & 95 & * & - & 26.7 \\
\hline $\begin{array}{l}\text { Quan y col., } \\
\text { (2003) }\end{array}$ & 2,4-DCP & aerobias & $\begin{array}{l}\text { SBR } \\
\text { inmovilizado }\end{array}$ & 90 & - & $\begin{array}{l}35 \\
48 \\
58\end{array}$ & 2.8 \\
\hline
\end{tabular}

Ec) eficiencia de consumo (\%), Y) rendimiento, q) velocidad específica de consumo ( $\mathrm{mg} \mathrm{CP} / \mathrm{mg}$ SSV*h), SSV) sólidos suspendidos volátiles, ( $\left.{ }^{*}\right)$ reportan intermediarios.

Como puede verse, en la mayoría de los trabajos se reportan eficiencias de consumo entre el 50 y 99\%, independientemente del grado de cloración que tenga el anillo aromático, sin embargo en pocos trabajos son mencionados los rendimientos y las velocidades específicas de consumo y producción. 
Farell y Quilty (1990) proponen bajo condiciones aerobias, una posible ruta de oxidación del 2-CP y sus isómeros, el 3 y 4-clorofenol (Figura 6). Para los 2 primeros se observó la formación de catecoles, en específico el 3-clorocatecol, el cual posteriormente mediante una oxigenasa, forma el ácido 5-cloroformil-2hidroxi-penta-2,4-dienoico. Este compuesto ha sido determinado como suicida, ya que inactiva a la enzima, resultando por tanto en la acumulación del 3clorocatecol. Considerando que la nitrificación es un proceso aerobio, cabe la posibilidad que también se presente esta ruta metabólica y se formen compuestos suicidas, que podrían complicar aún más el que la nitrificación se lleve a cabo exitosamente. Sin embargo, no existen reportes al respecto. Por el contrario, para el caso del 4-CP, los autores proponen su completa oxidación, debido a que por la acción de dioxigenasas, una vez roto el anillo bencénico, es posible su posterior incorporación al ciclo de los ácidos tricarboxílicos.

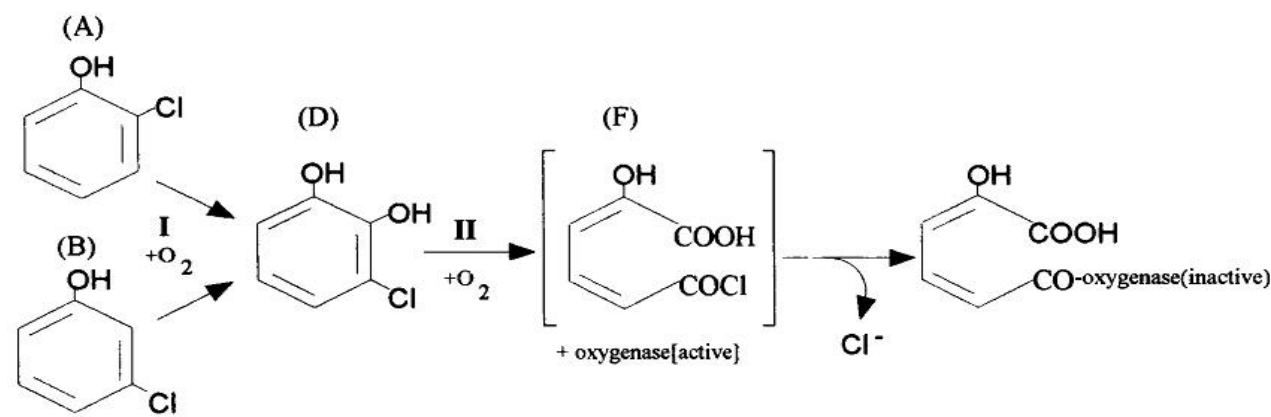

(C)<smiles>Cc1cc(O)cc(Cl)c1</smiles><smiles>O=C(C=C(Cl)c1ccccc1Cl)OC(=O)C(=O)O</smiles>

Figura 6.- Ruta de oxidación para el 2-CP y sus isómeros, propuesta por Farell y Quilty (1990).

\section{7.- 2-Clorofenol (o-Clorofenol, 2-cloro-1-hidroxibenceno)}

El 2-clorofenol (2-CP) es un derivado clorado del fenol utilizado principalmente en la preparación de herbicidas como el ácido 2,4-diclorofenoxiacético. El 2clorofenol es un líquido que va de incoloro a ámbar con un olor desagradable. Se utiliza para fabricar tinturas y otras substancias químicas así como desinfectante, bactericida y germicida. El 2-clorofenol está en la Lista de Substancias Peligrosas porque ha sido citado por el DOT (Departamento de 
Transporte, de la agencia federal que regula el transporte de substancias químicas), NTP (Programa Nacional de Toxicología que examina los productos químicos y revisa las evidencias de cáncer), el HHAG (Grupo de Evaluación de la Salud Humana de la agencia federal EPA), el NFPA (Asociación Nacional para la Protección contra los Incendios, que clasifica las substancias de acuerdo al riesgo de explosión o de incendio) y la EPA (Agencia de Protección al Medio Ambiente, agencia federal responsable de regular peligros ambientales). Se ha reportado que el 2-CP puede descomponerse al calentarlo intensamente produciendo humos tóxicos y corrosivos de cloro y ácido clorhídrico. Este compuesto puede absorberse por inhalación o ingestión. Respirar el 2-clorofenol puede irritar la nariz, la garganta y los pulmones causando tos, respiración con silbido y/o falta de aire. Una exposición más alta puede causar dolores de cabeza, mareos, fatiga, agitación, debilidad muscular, temblores, ataques, coma y hasta la muerte. Es posible que el 2-clorofenol cause daño al hígado y los riñones.

Las principales características fisicoquímicas del 2-clorofenol se muestran en la tabla 3.

Tabla3.- Propiedades fisicoquímicas del 2-clorofenol.

\begin{tabular}{lc}
\hline Propiedad & Valor \\
\hline Punto de ebullición: & $175^{\circ} \mathrm{C}$ \\
Punto de fusión: & $9.0^{\circ} \mathrm{C}$ \\
Densidad relativa $($ agua $=1):$ & 1.26 \\
Solubilidad en agua: & Moderada $\left(2.85 \mathrm{~g} / 100 \mathrm{ml} \mathrm{a} 20^{\circ} \mathrm{C}\right)$ \\
Presión de vapor, Pa a $20^{\circ} \mathrm{C}:$ & 230 \\
Densidad relativa de vapor (aire = 1): & 4.4 \\
Densidad relativa de la mezcla & 1.08 \\
vapor/aire a $20^{\circ} \mathrm{C}($ aire = 1$): \quad 64^{\circ} \mathrm{C}$ \\
Punto de inflamación: & \\
Coeficiente de reparto octanol/agua & 2.15 \\
como log Pow: & \\
\hline
\end{tabular}

El 2-CP, se encuentra en suelos y acuíferos debido a su uso como parte estructural de pesticidas y preservantes en la industria de la madera. Aunque actualmente su uso para este fin está prohibido en casi todo el mundo, en muchos países madereros, los problemas de contaminación por clorofenoles persisten debido a su elevada vida media en el ambiente (Gallego y col., 1998). 
En la industria papelera, la generación de 2-clorofenol también puede ocurrir durante el pulpaje (Kraft) y el proceso de blanqueo, que es donde se genera la mayor cantidad de compuestos que han sido descritos en la literatura como bio-acumulables, tóxicos y con alto potencial carcinogénico (Solomon 1996). Sus características recalcitrantes son resultado de la unión cloro carbono que es muy difícil de romper, además de la estabilidad conferida por el anillo aromático (Farell y Quilty 2002). Por sus diferentes características físicoquímicas y sobre todo por su frecuente presencia en diferentes ecosistemas, el 2-CP es un compuesto modelo perfecto para generar información que permita un mejor entendimiento de los efectos en los microorganismos presentes en los tratamientos biológicos de aguas residuales, en específico, en la nitrificación.

\subsection{1.- Efecto del 2-CP sobre la nitrificación}

Existen estudios escasos sobre el efecto del 2-CP en la nitrificación. Por ejemplo, Satoh y col. (2005), refieren que el consumo de amonio es inhibido al 100\% cuando existe una concentración de 10 mg/l. Martínez-Hernández y col. (2011), reportan la disminución de la eficiencia de consumo de amonio en $90 \%$ y de la velocidad específica de consumo de amonio en un $95 \%$ en presencia de $5 \mathrm{mg} / \mathrm{l}$ de C-2-CP. Sin embargo, bajo estas condiciones el rendimiento de producción de nitrato no se vio afectado significativamente $\left(\mathrm{Y}_{\mathrm{NO} 3}=1\right)$, ya que aunque la eficiencia de consumo disminuyó drásticamente, el consorcio nitrificante mantuvo la capacidad de oxidar el amonio hasta nitrato. Los autores reportan además una disminución de más del $80 \%$ en la velocidad específica de producción de nitrato, lo cual podría ser debido a la baja en la velocidad de consumo de amonio. Bajo condiciones semejantes a las referidas por MartínezHernández y col. (2011), Pérez-Alfaro (2010), evaluaron el proceso nitrificante en presencia de diferentes concentraciones de C-2-CP $(2.5,5$ y 10 mg C-2$\mathrm{CP} / \mathrm{l})$, observando que incluso en presencia de $2.5 \mathrm{mgC}-2-\mathrm{CP} / \mathrm{l}$, la actividad nitrificante se vio totalmente inhibida, pues aun después de 80 días de cultivo, no se observa consumo de $\mathrm{N}-\mathrm{NH}_{4}{ }^{+}$. Estos resultados muestran, que el proceso de nitrificación puede verse comprometido cuando un efluente contenga compuestos aromáticos como el 2-CP. 
Después de realizar la revisión bibliográfica sobre el efecto del 2-CP sobre la nitrificación debe resaltarse que hasta el momento solo se ha estudiado el efecto del 2-CP sobre el proceso nitrificante de manera general, es decir no se ha evaluado el efecto de este compuesto sobre cada ruta oxidativa de la nitrificación, lo cual es importante y resultaría interesante evaluar, pues aunque ambos grupos de bacterias nitrificantes tienen características semejantes la reacción o el efecto que se observe sobre cada proceso por el contacto con el 2-CP puede ser distinto o en diferente nivel o magnitud.

\subsection{2.- Degradación de 2-clorofenol bajo condiciones nitrificantes}

Se ha observado que bajo condiciones nitrificantes, al utilizar consorcios microbianos (Texier y col., 2002; Amor y col., 2005) o bien cultivos axénicos (Keener y Arp, 1994), es posible oxidar materia orgánica como etanol, acetato y compuestos aromáticos como el benceno (Zepeda y col., 2003), p-xileno, estireno (Keener y Arp. 1994), tolueno, m-xileno (Zepeda y col., 2006, 2007), fenol (Pérez, 2007; Pérez y col., 2008) y p-cresol (Texier y Gomez. 2002, 2007; Silva, 2007; Silva y col., 2009). En el caso de los cultivos axénicos, se cree que la enzima amonio monooxigenasa tiene relación con la oxidación de este tipo de sustratos (Keener y Arp 1994). En cuanto a los consorcios microbianos, no está claramente definido el papel de las bacterias nitrificantes, pues en este caso, los organismos heterótrofos también podrían ser los responsables de la oxidación de la materia orgánica.

En lo referente al caso exclusivo del 2-CP, hasta el momento son pocos los reportes en la literatura sobre el proceso respiratorio nitrificante en presencia de este compuesto. Por ejemplo Inui y col. (2002), encuentran que en un sistema de tratamiento de aguas municipales en presencia de $0.9 \mathrm{mg} / \mathrm{l}$ de 2 clorofenol y al utilizar un cultivo de Nitrosomonas como biosensores para la presencia de clorofenoles y metales pesados, la actividad nitrificante disminuye un 10\%. Sin embargo, no hacen mención de si el 2-CP sufrió algún cambio, como oxidación, rompimiento del anillo, por ejemplo. Martínez-Hernández y col. (2011), reportan el consumo total de $5 \mathrm{mg}$ de C-2-CP/l con una velocidad específica de consumo de $0.001 \pm 0.0001 \mathrm{mg}$ de C-2-CP/mg proteína $\mathrm{h}$ bajo condiciones nitrificantes. 
Hasta el momento, la información generada no permite establecer con claridad cómo se afecta la nitrificación en general y en sus dos etapas en particular, y si es posible recuperar la actividad nitrificante tras el contacto con este compuesto. En caso de que se utilicen consorcios microbianos, qué microorganismos son los encargados de consumir este compuesto, y si las enzimas de los microorganismos nitrificantes tienen participación en el consumo de este compuesto. Generar conocimiento sobre lo anterior es importante, porque esta información nos permitiría poder contrarrestar de mejor manera las posibles dificultades que pudieran presentarse al tratar efluentes que contengan compuestos aromáticos clorados. 


\section{8.- Referencias}

1. Agency for toxic substances and disease registry (ATSDR) (2005). www.atsdr.cdc.gov/cercla/05list.html

2. Ali M., Sreekrishman, T. R. (2001). Aquatic toxicity from pulp and paper mill effluents: A review. Adv. Env. Res. 5(1):175-196.

3. Amor L., Eiroa M., Kennes C., Veiga M.C. (2005). Phenol biodegradation and its effect on the nitrification process. Wat. Res. 39, 2915-2920.

4. Anderson, D.M., Glibert, P.M. y Burkholder, J.M. (2002). Harmful algal blooms and eutrophication: nutrient sources, composition, and consequences. Estuaries 25: 704-726.

5. Andersson K. K., Kent T, A., Lipscom, J. D., Hooper, A. B. and Muck E. (1984). J. Biol. Chem.259, 6833-6840.

6. Andrews R. E., Parks L. W., y Spence K. D. (1980). Some effects of Douglas fir terpenes on certain microorganisms. Appl. Environ. Microbiol. 40:301-304.

7. Anthonisen A.C., Loehr R.C., Prakasom T.B.S. and Srinath E.G. (1976). Inhibition of nitrification by ammonia and nitrous acid. Journal of Water Pollution Control Federation. 48(5), 835-851.

8. Arp D. and Stein L.Y. (2003). Metabolism of inorganic N compounds by Ammonia-Oxidizing bacteria. Critical Reviews in Biochemistry and Molecular Biology. 38, 471-495.

9. Arp D., Sayavedra-Soto L. A. and Hommes N.G. (2002). Molecular biology and biochemistry of ammonia oxidation by Nitrosomonas europaea. Arch. Microbiol.178, 250-258.

10.Bae H.S., Yamagishi, T., Suwa Y., (2002). Evidence for degradation of 2chlorophenol by enrichment cultures under denitrifying conditions. Microbiology. 148, 221-227.

11.Baier, C. R. 1937. Bakteriologische Erdo"Istudien. Kiel. Meeresforsch. 2:149-156.

12. Basu S. K. and Oleszkiewicz J. A. (1995). Factors affecting aerobic biodegradation of 2-chlorophenol in sequencing batch reactors. Environmental Technology. 16, 1135-43. 
13. Bedard C. and Knowles R. (1989). Physiology, biochemistry, and specific inhibitors of $\mathrm{CH}_{4}, \mathrm{NH}_{4}{ }^{+}$and $\mathrm{CO}$ oxidation by methanotrphs and nitrifiers. Microbiol Rev. 53, 68-84.

14. Bergmann, D. J., Arciero, D. M. y Hooper, A. B. (1994). Organization of the hao gene cluster of Nitrosomonas europaea: genes for two tetraheme $C$ cytochromes. J Bacteriol .176, 3148-3153.

15. Beristain-Montiel L, Gomez-Hernández J, Monroy-Hermosillo O, CuervoLópez F. and Ramirez-Vives F. (2010) Methanization and mineralization of 2-chlorophenol by anaerobic digestion. Water Science and Technology. 62.8: 1791-1798

16.Beristain-Montiel L, Gomez-Hernández J, Monroy-Hermosillo O, CuervoLópez F. y Ramirez-Vives F. (2012) Biodegradation of 2-Chlorophenol (2CP) in an anaerobic sequencing batch reactor (ASBR). Water Science and Technol. 65(10):1721-1728

17. Blackmer A.M., Bremer J.M. and Schmidt E.L. (1980) Production of nitrous oxide by ammonia-oxidizing chemoautotrophic microorganisms in soil. Appl. Environ. Microbiol 40, 1060-1066.

18. Bock E. y Wagner M. (2006) Oxidation of Inorganic Nitrogen Compounds as an Energy Source. Prokaryotes. 2:457-495 DOI: 10.1007/0-387-30742-7_16 capitulo 1.16

19. Bock E., Koops, H.P., Harms H. y Ahlers B. (1991) The bichemistry of nitrifying microorganism, in variations in Autotrophic life, Bock $E$ (Ed) (academic Press London). 171-200.

20.Buitrón G., González A., López-Martín (1998). Biodegradation of phenolic compounds by an acclimated activated sludge and isolated bacteria. Water Science and Technology. 37, 371-378.

21.Buitrón G., Schoeb M.-E and Moreno J. (2003). Automated Sequencing batch bioreactor under extrem peaks of 4-chlorophenol. Water Science and Technology 47 (10), 175-181.

22. Camargo J.A., Alonso A. (2007). Contaminación por nitrógeno inorgánico en los ecosistemas acuáticos: problemas medio ambientales, criterios de calidad del agua, e implicaciones del cambio climático. Ecosistemas 16 (2): 98-110. 
23. Castingnetti D. and Hollocher, T.C. (1985). Heterotrophic nitrification among denitrifiers. Curr Microbiol 6, 229-231.

24. Cobley, J. B. (1976a). Energy-conserving reactions in phosphorylating electron-transport particles from Nitrobacter winogradskyi. Activation of nitrite oxidation by the electrical component of the proton motive force. Biochem. J. 156:481-491.

25. Cobley, J. B. (1976b). Reduction of cytochromes by nitrite in electrontransport particles from Nitrobacter winogradskyi. Biochem. J. 156:493-498.

26. Comisión nacional del Agua CONAGUA (2011). Agenda del Agua 2030 | Las iniciativas y acciones de la Agenda del Agua 2030. SEMARNAT.www.conagua.com.mx.

27. Comisión Nacional del Agua CONAGUA (2004). Instrumentos de gestión del agua. Estadísticas del agua en México. 201.116.60.96:8080/wb/ceeaa/estadisticas_del_agua_historico

28.Daigger G.T., Robbins, M.H. and Marshall, B.R. (1985) The desing of selector to control low F/M filamentous bulking. J. Pollut. Control fed. 57, $220-226$

29.Dejour, P., Armand, J. and Beekenkamph, H., 1989. La toxicit6 de l'ammoniac est fonction du $\mathrm{pH}$ de l'eau, Etude chez la salamandre Pleurodeles walti. C. R. Acad. Sci., Paris, serie III, 308: 55-60.

30. Del Real-Olvera J, Cortés-García R, Bravo-Garzón R,Viveros-Ferrando L. (2008).Tratamiento de aguas residuales contaminadas con 2-clorofenol mediante oxidación catalítica por vía húmeda. Tecnol. Ciencia Ed. (IMIQ) 23(2): pp 62-68.

31.Denis K. S., Dias F. M. and Rowe J. J. (1990) Oxygen regulation of nitrate transport by diversion of electron flow in Escherichia coli. J. Biol. Chem. 265: 18095-18097.

32. Detsch C. y Stulke J. (2003) Ammonium utilization in Bacillus subtilis: transport and regulatory functions of $\mathrm{NrgA}$ and NrgB Microbiology. 149, 3289-3297.

33. Díaz, E. (2004). Bacterial degradation of aromatic pollutants: a paradigm of metabolic versatility. Int. Microbiol. 7:173-180.

34. Eilersen A., Henze M. and Kloft I. (1994) Effect of volatile fatty acids and trimetilamine on nitrification in actived sludge. Wat. Sci. Tech. 24, 21-28. 
35.Environmental Protection Agency (EPA). (2006). National recommended water quality criteria. US Environmental Protection Agency, Washington, DC.

36. Environmental Protection Agency (EPA). (2008) Wastewater Technology Fact Sheet Side Stream Nutrient Removal. EPA -832-F-07-017.

37. Environmental Protection Agency EPA. (2007) Wastewater Technology Fact Sheet Side Stream Nutrient Removal. EPA 832-F-04-017 office of water.

38. European environmental agency (EEA). (2005). Source apportionment of nitrogen and phosphorus inputs into the aquatic environment. Copenhagen 2005. pp 3- 48.

39. Farrel A. y B. Quilty, (2002). The enhancement of 2-chlorophenol degradation by a mixed microbial community when augmented with Pseudomonas putidaCP1. Water Res. 36 pp. 2443-2450.

40. Farrell and Quilty (1990).Degradation of mono-chlorophenols by a mixed microbial community via meta- cleavage pathway Biodegradation 10, 353362.

41.Fava, F., Armenante, P.M., Kafkewitz, D., 1995. Aerobic degradation and dechlorination of 2-chlorophenol, 3-chlorophenol and 4-chlorophenol by a Pseudomonas pickettii strain. Lett. Appl. Microbiol. 21(5):307-12.

42. Field J. A y Sierra-Alvarez R. (2008): Microbial degradation of chlorinated phenols. Rev. Environ. Sci. Biotechnol., 7:211-241.

43. Fondo Mexicano para la Conservación de la Naturaleza (FMCN) (2006).El agua en México, lo que todas y todos debemos saber. www.agua.org.mx

44.Gallego A., Molina Tirado L.B., Fortunato M.S., Bevilacqua S., Camardella H., Kabbas S., Cenzano M.L., Gómez C.E., D’Aquino M., Korol S. Higa L.E. (1998). Biodegradación de 2-clorofenol en reactores aeróbicos empleando microorganismos autóctonos. Asociación Peruana de Ingeniería Sanitaria y Ambiental; AIDIS. Gestión ambiental en el siglo XXI. Lima, APIS. pp.1-8.

45. Gibson, D. T., y R. E. Parales. 2000. Aromatic hydrocarbon dioxygenases in environmental biotechnology. Curr. Opin. Biotechnol. 11:236-243.

46. Gómez J., Lema J.M. y Méndez J.R. (1995). La nitrificación biológica con cultivos axénicos o lodos activados. CIENCIA 46, 507-523.

47. Gómez J., Mendez J.R. and Lema J.M. (2000). Kinetic study of addition of volatile organic compounds to a nitrifying sludge. Appl. Biochem. Biotechnol. 88, 1-12. 
48. Gunderson K. (1966). The growth and respiration on Nitrocystis oceunus at different partial pressure of oxygen. Journal of General Microbiology. 42, 387-395.

49.Hackette, S.L., Skye, G.E., Burton, C. and Segel, I.H. (1970). Characterization of an ammonium transport system in filamentous fungi with methylammonium-14C as the substrate. J. Biol. Chem. 245, 4241-4250.

50. Harayama, S., y K. N. Timmis. (1989). Catabolism of aromatic hydrocarbons by Pseudomonas. In Genetics of bacterial diversity. Hopwood, A. and Chater, K.F. (eds). London: Academic Press.

51. Harayama, S., y M. Rekik. (1989). Bacterial aromatic ring-cleavage enzymes areclassified into two different gene families. J. Biol. Chem. 264:1532815333.

52. Harwood, C. S., y R. E. Parales. (1996). The $\beta$-ketoadipate pathway and the biology of self-identity. Annu. Rev. Microbiol. 50:553-590.

53. Heider, J., M. Boll, K. Breese, S. Breinig, C. Ebenau-Jehle, U. Feil, N. Gad'on, D. Laempe, B. Leuthner, M. E.-S. Mohamed, S. Schneider, G. Burchhardt, y G.Fuchs. (1998). Differential induction of enzymes involved in anaerobic metabolism of aromatic compounds in the denitrifying bacterium Thauera aromatica. Arch. Microbiol. 170:120-131.

54. Heider, J., y G. Fuchs. 1997. Anaerobic metabolism of aromatic compounds. Eur. J. Biochem. 243:577-596.

55. Helder W. and Vries R. T. P. (1983). Estuarine nitrite maxima and nitrifying bacteria Netherlans Journal of sea research. 17, 1-18.

56. Hellinga C., Schellen A.A.J.C., Mulder J.M. y van Loodsdrecht M.C.M. (1998). The SHARON process: an innovative method for nitrogen removal from ammonium-rich wastewaters. Water Science and Technology. 37(9), 135-142.

57. Hernández L. (2005). Estudio del proceso respiratorio y estructura de un lodo desnitrificante en presencia de acetato y tolueno en un SBR. Tesis de maestría UAM-Iztapalapa.

58. Hernández L., Buitrón G., Gómez J. and Cuervo-López F.M. (2008). Denitrification of toluene and sludge settleability. Proceedings of 4th IWA Specialized Conference on Sequencing Batch Reactor Technology SBR. S. Michele a Ripa, Rome, Italy.69-72. 
59. Hintze, J., NCSS and PASS (2001) Number Cruncher Statistical Systems. Kaysville. www.ncss.com.

60. Hooper A.B. y Dispirito A.A. (1985). In bacteria which grow on simple reductants, generation of a proton gradient involves extracytoplasmic oxidation of substrate. Microbiological reviews. 49(2), 140-157.

61. Hynes R.K. and Knowles R. (1982). Effect of acetylene on autotrophic and heterotrophic nitrification. Canadian Journal of Microbiology. 28(3), 334-340.

62. Hynes, R.K., and Knowles, R. (1978). Inhibition by ecetylene of ammonia oxidation in Nitrosomonas europae. FEMS Microbiol Lett. 4. 319-321.

63. Igarashi, N., Moriyama, H., Fujiwara, T., Fukumori, Y. \& Tanaka, N. (1997). The $2 \pm 8 \mathrm{~A} /$ structure of hydroxylamine oxidoreductase from a nitrifying chemoautotrophic bacterium, Nitrosomonas europaea. Nat Struct Biol 4, 276-284.

64. Ingledew, W. J., y P. J. Halling. (1976). Paramagnetic centers of the nitrite oxidizing bacterium Nitrobacter. FEBS Lett. 67:90-93.

65. Inui T., Tanaka Y., Okayasu Y. and Tanaka H. (2002). Application of toxicity monitor using nitrifying bacteria biosensor to sewerage systems. Water Science and technology.45, 271-278.

66. Jahn, T. P., Moller, A. L. B., Zeuthen, T., Holm, L. M., Klaerke, D. A.,Mohsin, B., Kuhlbrandt, W., and Schjoerring, J. K. (2004) FEBS Lett. 574,31-36.

67. Jain A., Gupta V., Jain S., Suhas R. (2004). Removal of chlorophenols using industrial wastes. Environ. Sci. Technol. 38(1):1195 1200.

68. Jechorek M., Wendlandt K. D., Beck M. (2003). Cometabolic degradation of chlorinated aromatic compounds. Journal of Biotechnology. 102, 93-98.

69. Jiménez B. (2005). Treatment technology and standards for agricultural wastewater reuse: a case study in Mexico. Irr. Drainage. 54, S23-S33.

70.Kargi F., Eker S. (2005). Removal of 2,4-dichlorophenol and toxicity from synthetic wastewater in a rotating perforated tube biofilm reactor. Process Biochemistry.40, 2105-2111.

71. Kartal, B. (2011). Molecular mechanism of anaerobic ammonium oxidation. Nature 479: 127-130, doi:10.1038/nature10453. 
72. Keen G.A., and Prosser J. I. (1987). Steady state and transient growth of autotrophic nitrifying bacteria. Archives of microbiology 147, 73-79.

73.Keener, W.K. and Arp, D. J, (1994) Transformations of aromatics compounds by Nitrosomonas europaea Appl. Microbiol 60, 1914-1920.

74. Khademi S., O'Connell J III., Remis J., Robles-Colmenares Y., Miercke L J. W., Stroud, Robert M. (2004). Mechanism of Ammonia Transport by Amt/MEP/Rh: Structure of AmtB at 1.35 A. Science. 305, 1587-1594.

75.Khin T. y Annachhatre A.P. (2004). Novel microbial nitrogen removal processes. Biotechnology Advances. 22, 519-532.

76. Klecka, G.M., Gibson, D.T., (1981). Inhibition of catechol 23 di oxygenase from Pseudomonas putida by 3.

77.Klecka, G.M., Maier, W.J., (1985). Kinetics of microbial growth on pentachlorophenol. Appl. Environ. Microbiol.

78. Klotz M.G., Alzerreca J. y Norton J.M. (1997). A gene encoding a membrane protein exists upstream of the $a m o A / a m o B$ genes in ammonia oxidizing bacteria: a third member of the amo operon?. FEMS Microbiol. Lett. 150: 65-73.

79. Klotz M.G., yNorton J.M., (1995). Sequence of an ammonia monooxygenase subunit A-encoding gene from Nitrosospira sp.NpAV. Gene 163:159-160.

80.Krüger B., Meyer O., Nagel M., Andreesen J. R., Meincke M., Bock E., Blümle S., y Zumft. W. G. (1987). Evidence for the presence of bactopterin in the eubacterial molybdoenzymes nicotinic acid dehydrogenase, nitrite oxidoreductase, and respiratory nitrate reductase. FEMS Microbiol. Lett. 48:225-227.

81. Kurniawan T. A., Wai-hung Lo, Chan G.Y.S. (2006). Physico-chemical treatments for removal of recalcitrant contaminants from landfill leachate Journal of Hazardous Materials B129 80-100

82. Lema J.M., Méndez J.R., y Gómez J. (1996). La nitrificación biológica con cultivo axénico o lodos activados. CIENCIA 46, 507-523.

83. Lin Y.M., Tay J-H., Liu Y. y Hung Y-T. (2009). Biological nitrification and denitrification processes. En: Biological treatment processes, volumen 8. Editorial: Humana Press. pp 539-580. 
84. Liu D. and Pacepavicius G. (1990). A systematic study of the aerobic and anaerobic biodegradation of 18 chlorophenols and 3 cresols. Toxicity Assessment: An Intel. J., 5, 367-387.

85. Liu D. y Pacepavicius G. (1990). A systematic study of the aerobic and anaerobic biodegradation of 18 chlorophenols and 3 cresols. Toxicity Assessment: An Intel. J., 5, 367-387.

86. Lomnicki S., Lichtenberger J., Xu Z., Waters M., Kosman J., Amiridis M. D. (2003). Catalytic oxidation of 2,4,6 trichlorophenol over vanadia/ titaniabased catalysts. Appl. Catal. B: Environ. 46(2):105-119.

87. López R. A., Núñez O., Morales F., Calderón C., Liewald W. (1999). Aplicación de sistemas oxidantes avanzados en el tratamiento de aguas residuales de la industria petrolera (Sistema Fenton). Act. Cient. Venez. 50(1):75-80.

88. Macarie H. and Guiot (1995). Pentachlorophenol degradation by a simultaneous aerobic/anaerobic process: a new technology for waste water treatment. Fronteras en biotecnología y bioingeniería Ed. Galindo. 317-322.

89. Madigan M., Martinko J. and Parker J. (2003). Brock Microbiología de los Microorganismos. 10ma edición. Editorial Pearson Prentice Hall. Madrid. 359-360.

90. Martínez S. (2007). Análisis ecofisiológico de la desnitrificación en presencia de acetato y tolueno. Tesis Doctoral. . Laboratorio de Fisiología Microbiana, CBS Departamento de Biotecnología, Universidad Autónoma MetropolitanaIztapalapa, México.

91. Martínez-Hernández S, Texier AC, Cuervo-López F.M. and Gómez J. (2011). 2-Chlorophenol consumption and its effect on the nitrifying sludge. J. Hazard. Mater. 185: 1592-1595.

92. Mathews, C. K.; Van Holde, K.E et Ahern, K.G (2003). Bioquímica (3 edición). ISBN 84-7892-053-2.

93. Meincke M., Bock E., Kastrau D., y Kroneck P. M. H. (1992). Nitrite oxidoreductase from Nitrobacter hamburgensis: Redox centers and their catalytic role. Arch. Microbiol. 158:127-131. 
94. Michael G.R., Shimitzu G.P. and Jenkins, D. (1985). The growth physiology of the filamentous organism type $021 \mathrm{~N}$ and its significance activated sludge bulking. J. Water Pollut. Control Fed. 57, 1152-1162.

95. Moir J. W. B. y Wood N. J. (2001) .Nitrate and nitrite transport in bacteria CMLS, Cell. Mol. Life Sci. 58 215-224.

96. National Atmospheric Deposition Program (NADP) (2000). El nitrógeno en la Iluvia nacional. http://nadp.sws.uiuc.edu. Illinois State Water Survey.

97.Paredes D., Kuschk P., Mbwette T.S.A., Stange F., Müller R.A. y Kösser H. (2007). New aspects of microbial nitrogen transformations in the context of wastewaters treatment: A review. Engineering in Life Sciences. 7(1), 13-25.

98. Peakman T., Crouzet J., Mayaux J., Busby S., Mohan S., Harborne N. et al. (1990) Nucleotide sequence, organisation and structural analysis of the products of genes in the nirBcysG region of the Escherichia coli chromosome. Eur. J. Biochem. 191: 315-323.

99.Pérez A. (2007). Evaluación del efecto del fenol en la nitrificación y sedimentabilidad de un lodo utilizando un reactor de lote secuenciado (SBR). Tesis de especialidad. Universidad Autónoma Metropolitana Iztapalapa.

100. Pérez J.E., Martínez F. and Cuervo-López F.M. (2008). Nitrification and phenol elimination: respiratory process and sludge settleability. Proceedings of 4th IWA Specialized Conference on Sequencing Batch Reactor Technology SBR. S. Michele a Ripa, Rome, Italy. 127-130.

101. Pérez-Alfaro J. E. Buitrón G. Gomez J. Texier A.-C. Cuervo-López F. M. (2013). Kinetic and Physiological Evaluation of Ammonium and Nitrite Oxidation Processes in Presence of 2-Chlorophenol. Appl. Biochem. Biotechnol. 169(3). pp. 990-1000.

102. Pieper, D. H., V. A. Martins dos Santos, y P. N. Golyshin. (2004). Genomic andmechanistic insights into the biodegradation of organic pollutants. Curr. Opin. Biotechnol. 15:215-224.

103. Prosser J.I. (1989). Autotrophic nitrification in bacteria. Adv. Microb. Physiol. 30, 125-181.

104. Romero Rojas J A. (1994). Lagunas de estabilización de aguas residuales. Editorial Escuela Colombiana de Ingeniería. 
105. Satoh H., Sasaki, Y., Nakamura Y., Okabe S., Suzuki T. (2005). Use of microelectrodes to investigate the effects of 2-chlorophenol on microbial activities in biofilms. Wiley Interscience. 91, 133-137.

106. Schmidt I., Sliekers O., Schmid M., Bock E., Fuerst J., Kuenen J.G., Jetten M. and Strous M. (2003). New concepts of microbial treatment processes for the nitrogen removal in wastewater. FEMS Microbiology Reviews. 27, 481-492.

107. Schmidt I., Sliekers O., Schmid M., Bock E., Fuerst J., Kuenen J.G., Jetten M.S.M y Strous M. (2003). New concepts of microbial treatment processes for the nitrogen removal in wastewater. FEMS Microbiology Reviews. 27 481-492.

108. Schmidt L. M., Delfino J. J., Preston J. F., Laurent G. (1999) Biodegradation of low aqueous concentration pentachlorophenol (PCP) contaminated groundwater. Chemosphere 38 (12) 2897-2912.

109. Sewell D. L., Aleem M. I. H., y Wilson D. F. (1972). The oxidationreduction potentials and rates of oxidation of the cytochromes of Nitrobacter agilis. Arch. Biochem. Biophys. 153:312-319.

110. Sikkema J., Poolman B., Konings W.N. y de Bont J.A.M. (1992). Effects of the membrane actions of tetralin on the functional and structural properties of artificial and bacterial membranes. J. Bacteriol. 174, 29862992.

111. Silva C. D., Gómez J., Houbron E., Cuervo-López F.M. and Texier A.-C. (2009). p-Cresol biotransformation by a nitrifying consortium. Chemosphere $75,1387-1391$.

112. Silva C.D., Cuervo-López F.M., Gómez J. y Texier A-C. (2011). Nitrite effect on ammonium and nitrite oxidizing processes in a nitrifying sludge. World Journal of Microbiology and Biotechnology. 27, 1241-1245. DOI 10.1007/s11274-010-0573-6.

113. Silva L. (2007) Estudio fisiológico de la nitrificación en presencia de pcresol. Tesis de maestría realizada en la Universidad Autónoma Metropolitana- Iztapalapa.

114. Smet M.-J., Kingma J., y Witholt B. (1978). The effect of toluene on the structure and permeability of the outer and cytoplasmic membranes of Escherichia coli. Biochim. Biophys. Acta. 506:64-80. 
115. Smith, V.H. (2003). Eutrophication of freshwater and coastal marine ecosystems: a global problem. Environ. Sci. Pollut. R. 10: 126-139.

116. Solomon K. R. (1996). Chloride in bleching of pulp and paper. Pure and Appl. Chem. 68(9). 1721-1730.

117. Stouthamer A.H. (1976). Biochemistry and genetics of nitrate reductase in bacteria. Adv. Microbiol Physiol 14, 315-375.

118. Stouthamer A.H. (1976). Biochemistry and genetics of nitrate reductase in bacteria. Adv. Microbiol Physiol 14, 315-375.

119. Stowa (Dutch Foundation for Applied Wate Research). (2006). SHASHARON/ANAMOX Process Sheet http://www.stowaselectedtechnologie/Sheets/index.html

120. Takai T., Hirata A., Yamauchi K. and Inamori Y. (1997). Effects of temperature and volatile fatty acids on nitrification-denitrification activity in small- scale anaerobic - aerobic recirculation biofilm process. Water Sci.and technology. 35, 101-108

121. Texier A-C. and Gomez J. (2002). Tolerance of nitrifying sludge to $p$ cresol. Biotecnol. Lett. 24, 321-324.

122. Texier A.-C. y Gómez J. (2004). Settleability and kinetics of a nitrifying sludge in a sequencing batch reactor. Canadian Journal of.Microbiology. 50, 943-949.

123. Texier A.-C. y Gómez J. (2007). Simultaneous nitrification and p-cresol oxidation in a nitrifying sequencing batch reactor. WaterResearch. 41, 315322.

124. Third K.A., Slicker A.O., Kuenne J.G., y Jetten M.S.M. (2002). The CANON system under ammonium limitation:interaction and competition between three groups of bacteria. Sys. Appl. Microbiol. 24, 588-596.

125. UNESCO-WWAP Water for People, Water for Life Executive Summary of the UNO World Water Development Report First published by the United Nations Educational, Scientific and Cultural Organization (UNESCO), Paris, France. Pp. 1-36.

126. Vaca, Mier M., López, Callejas, R., UER, R., Jiménez, Cisneros B., Álvarez, P. J. J. (2000).Heavy metal removal with mexican clinoptilolite: Multi component ionic exchange. Water Research. 35(2), 373-378. 
127. Vaca, Mier M., López, Callejas, R., UER, R., Jiménez, Cisneros B., Álvarez, P. J. J. (2000).Heavy metal removal with mexican clinoptilolite: Multi-component ionic exchange. Water Research. 35(2), 373-378.

128. Van Niftrik L., and Jetten M. S. M. (2012). Anaerobic ammonium oxidizing bacteria: Unique microorganisms with exceptional properties. Microbiol. Mol. Biol. Rev. 76: 585-596,

129. Watson S. W. (1974). In Bergeys manual of determinative bacteriology (R.E. Buchanan and N.E. Gibbson Eds). Williams and Wilkins Baltimore. $8^{\text {th }}$ ed. $450-456$.

130. Watson S. W., Bock E., Harms H., Koops H.-P., y Hooper, A. B. (1989). Nitrifying bacteria. In J. T.Stanley, M. P. Bryant, N. Pfennig, and J. G. Holt (Eds.), Bergey`s manual of systematic bacteriology, Vol. 3 (pp.1808-1834). Baltimore MD: Williams and Wilkins Co.

131. Watson S. W., Book E., Harms H., Koops H. P. and Hooper A. B. (1989) Family Nitrobacteraceae. In Bergey's Manual of Systematic Bacteriology (Edited by Staley J. T., Bryant M. P., Pfennig N. and Holt J. G.), pp. 18081834. Williams \& Wilkins, Baltimore.

132. Wenk C. B., Blees J., Zopfi J., Veronesi M., Bourbonnais A., Schubert C. J., Niemann H., y Lehmann Moritz F. (2013) Anaerobic ammonium oxidation (anammox) bacteria and sulfide-dependent denitrifiers coexist in the water column of a meromictic south-alpine lak. Limnol. Oceanogr., 58(1), pp. 1-12.

133. Wetzel, R.G. 2001. Limnology, 3rd edition. Academic Press, New York.

134. Wetzstein, H. G., y R. J. Ferguson. (1985). Respirationdependent proton translocation and the mechanism of proton motive force generation in Nitrobacter winogradskyi. FEMS Microbiol. Lett. 30:87-92.

135. Yamanaka T., Kamita Y., y Fukumori Y. (1981). Molecular and enzymatic properties of "cytochrome aa3 type" terminal oxidase derived from Nitrobacter agilis. J. Biochem. 89:265-273.

136. Young K., Daniel J., and Lewis S. (2002). Kinetic and inhibition studies for the aerobic cometabolism of 1,1,1-trichloroethane, 1,1-dichloroethylene and 1,1-dichloroethane by a butane-grown mixed culture. Biotechnology and Bioengineering. 80,498-508. 
137. Zepeda A., Texier A-C. and Gomez J. (2003). Benzene transformation in nitrifying batch culture. Biotecnol. Prog. 19, 789-793.

138. Zepeda A., Texier A-C. and Gomez J. (2007). Batch nitrifying cultures in presence of mixtures of benzene, toluene, and m-xylene. Environ. Technol. $28,355-360$.

139. Zepeda A., Texier A-C., Razo-Flores E. and Gomez J. (2006). Kinetic and metabolic study of benzene, toluene and $m$-xylene in nitrifying batch cultures. Wat. Res. 40, 1643-1649.

140. Zwietering M. H. Jongenburger I., Rombouts F. M., and Van 't riet. K. (1990). Modeling of the Bacterial Growth Curve. Applied and Environmental Microbiology, 56 (6) pp. 1875-1881. 


\section{Justificación}




\section{0.- Justificación}

Se ha reportado que compuestos como el 2-clorofenol pueden inhibir la nitrificación sin embargo los datos obtenidos aún son escasos, por lo que es necesario generar más que información, tanto cinética como fisiológica, que permita determinar en presencia de 2-CP:

- Como es el desempeño del proceso amonio y nitrito oxidante.

- Si el efecto de este compuesto está relacionado con una inhibición de la actividad enzimática de ambas rutas oxidantes.

- Si hay un efecto en el transporte de sustratos

Estos datos permitirían establecer con mayor detalle como es que compuestos como el 2-CP afectan la nitrificación. 


\section{Objetivos}




\section{0.- Objetivos}

\section{1.-General}

Estudiar el efecto del 2-clorofenol sobre los procesos de amonio y nitrito oxidación. Así como la posible oxidación del 2-clorofenol por el consorcio nitrificante utilizando variables de respuesta como la eficiencia de consumo, el rendimiento de producción y las velocidades específicas del proceso.

\section{2.- Particulares}

Estudiar y evaluar en cultivos en lote:

- El efecto del 2-CP sobre los procesos amonio y nitrito oxidantes.

- El efecto del 2-CP en la actividad enzimática y el transporte de amonio utilizando diferentes concentraciones de amonio y extractos libres de células.

- La capacidad del consorcio nitrificante para consumir 2-clorofenol.

- La posible participación de las enzimas amonio y nitrito oxidantes en el consumo de 2-CP, empleando inhibidores selectivos de la amonio monooxigenasa y nitrito óxido reductasa. 


\section{Materiales y Métodos.}




\section{0.- Materiales y métodos}

Para la realización del presente trabajo, se mantuvo un reactor nitrificante alimentado en continuo, a fin de obtener un inóculo nitrificante en estado estacionario. Posteriormente, se llevaron a cabo ensayos en cultivo en lote, que a continuación se describen.

\section{1.- Consorcio nitrificante en cultivo continúo en el reactor de tanque agitado (fuente de inóculo)}

Se utilizó un reactor de tanque agitado (Bioflo 2000 Fermentor) de la marca New Brunswick Scientific Co. Edison New Jersey USA, con una capacidad de 10 litros, en el cual se mantuvo un consorcio nitrificante en estado estacionario que posteriormente fue utilizado como inóculo. En la figura 1 se muestra la configuración del reactor.

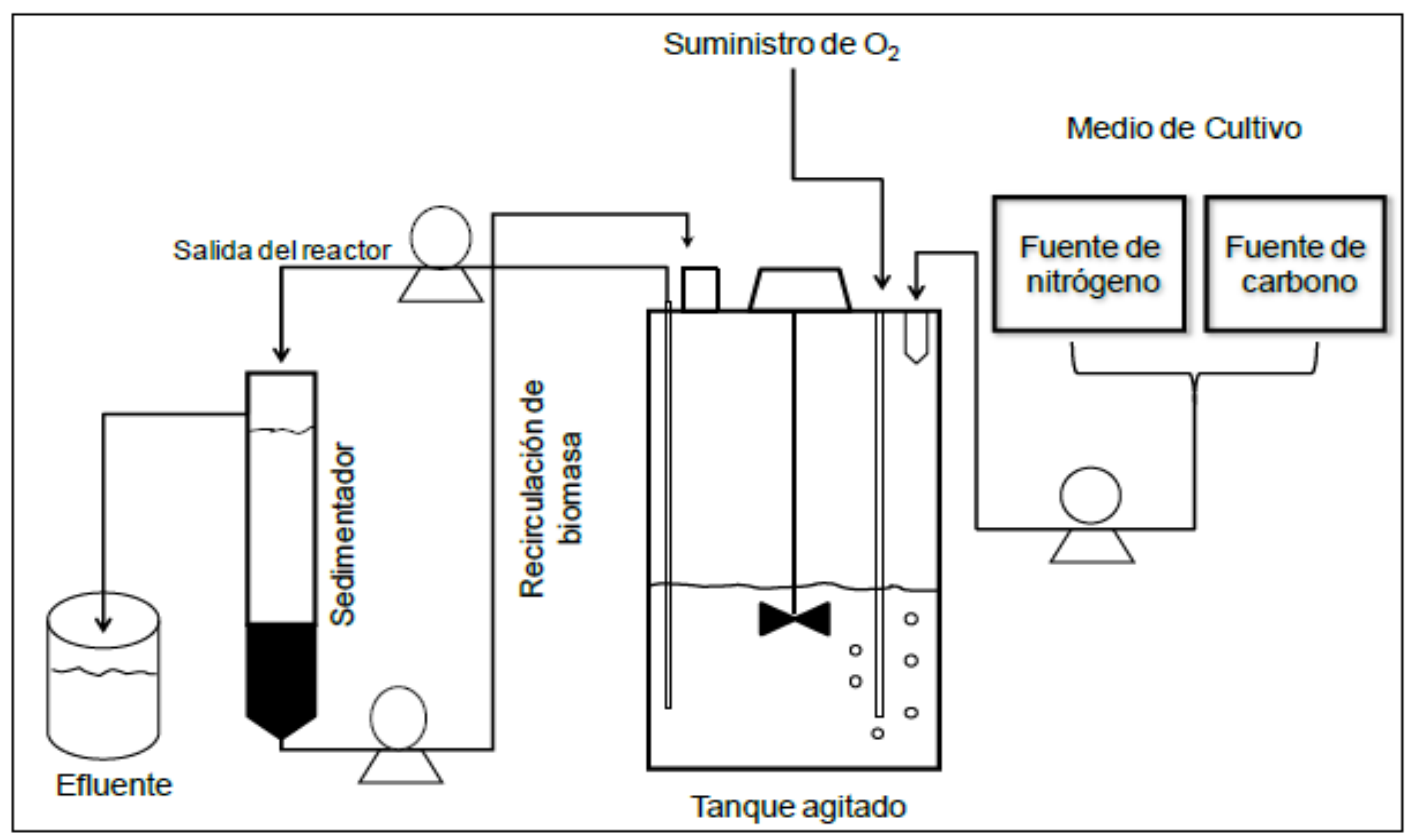

Figura 1. Configuración del reactor de tanque agitado para el consorcio nitrificante Silva (2011).

El reactor en continuo se operó bajo las siguientes condiciones: volumen de trabajo de 6 litros, temperatura de 25드. agitación de 200 rpm, relación carbono/nitrógeno $(\mathrm{C} / \mathrm{N})$ de 2.5, tiempo de residencia hidráulico $(\mathrm{TRH})$ de $1.4 \mathrm{~d}$, $\mathrm{pH}$ de 6.5-7 \pm 0.2 , con una velocidad de carga de nitrógeno de amonio de 248 
$\pm 10 \mathrm{mg} / \mathrm{l} \mathrm{d}$. Se determinaron las eficiencias de consumo de sustrato, rendimientos de generación de producto y las velocidades de consumo de amonio y producción de nitrato a lo largo de todo el tiempo de operación. Se consideró que el lodo alcanzó el estado estacionario cuando las velocidades de consumo y producción tuvieron una variación menor que el 10\% durante 80 días de operación.

\section{2.- Medio de cultivo}

Para evitar la posible precipitación de los componentes y evitar el crecimiento de microorganismos dentro de los tanques de alimentación, el medio de cultivo que se utilizó para alimentar el reactor se dividió en dos soluciones: A (fuente de nitrógeno) y $\mathrm{B}$ (fuente de carbono) (Tabla 1). El flujo de alimentación para los medios fue 1.4 y $1.5 \mathrm{l} / \mathrm{d}$, respectivamente. La composición de ambos fue la siguiente:

Tabla 1. Composición del medio de cultivo para el reactor de tanque agitado.

\begin{tabular}{lclc}
\hline $\boldsymbol{A}$ & $(\boldsymbol{g} / \mathbf{l})$ & $\boldsymbol{B}$ & $(\boldsymbol{g} / \mathbf{l})$ \\
\hline$\left(\mathrm{NH}_{4}\right)_{2} \mathrm{SO}_{4}$ & $(5.9)$ & $\mathrm{NaHCO}_{3}$ & $(9.3)$ \\
$\mathrm{NH}_{4} \mathrm{Cl}$ & $(4.8)$ & $\mathrm{CaCl}$ & $(0.5)$ \\
$\mathrm{KH}_{2} \mathrm{PO}_{4}$ & $(7.0)$ & $\mathrm{FeSO}_{4}$ & $(0.15)$ \\
$\mathrm{MgSO}_{4}$ & $(3.0)$ & & \\
$\mathrm{NaCl}$ & $(5.0)$ & & \\
\hline
\end{tabular}

\section{3.- Cultivos nitrificantes control o de referencia en lote}

La evaluación del comportamiento fisiológico y cinético del consorcio nitrificante en los ensayos en lote se realizó en botellas serológicas de $160 \mathrm{ml}$ de capacidad con un volumen de trabajo de $100 \mathrm{ml}$ y $60 \mathrm{ml}$ de espacio de cabeza. Se agregaron $25 \mathrm{ml}$ del medio A y $25 \mathrm{ml}$ del medio B (Tabla 2), $0.5 \mathrm{ml}$ de $\mathrm{FeSO}_{4}, 30-40 \mathrm{ml}$ de lodo nitrificante dependiendo de la concentración de proteína en el reactor y 10-20 ml de agua destilada dependiendo del volumen de licor mezclado proveniente del reactor, para completar $100 \mathrm{ml}$ en total y tener una concentración de $100 \mathrm{mg} \mathrm{N}-\mathrm{NH}_{4} / \mathrm{l}$ y $250 \mathrm{mg} \mathrm{C}-\mathrm{NaHCO}_{3} / \mathrm{l}$. La relación carbono nitrógeno $(\mathrm{C} / \mathrm{N})$ resultante fue de 2.5. A cada botella se le burbujeó oxígeno durante dos minutos, se inocularon con aproximadamente $200 \pm 9.8$ 
mg de proteína bacteriana/l, proveniente del reactor nitrificante de tanque agitado en estado estacionario (previamente lavado con solución fisiológica). La botella se selló y nuevamente se introdujo oxígeno durante dos minutos. El $\mathrm{pH}$ inicial del medio fue de $7.2 \pm 0.3$.

Las botellas se utilizaron para establecer las cinéticas del proceso nitrificante control, para lo cual, se tomó una muestra a diferentes tiempos durante $48 \mathrm{~h}$. Cada botella correspondió a una medición independiente y fue desechada posterior a su análisis. Los ensayos se realizaron por duplicado a una temperatura de $30^{\circ} \mathrm{C}$ y agitación de 200 rpm.

Tabla 2.Composición del medio de cultivo utilizado en el cultivo en lote.

\begin{tabular}{lcll}
\hline $\boldsymbol{A}$ & $(\boldsymbol{g} / \mathbf{l})$ & $\boldsymbol{B}$ & $(\boldsymbol{g} / \mathbf{l})$ \\
\hline$\left(\mathrm{NH}_{4}\right)_{2} \mathrm{SO}_{4}$ & $(0.95)$ & $\mathrm{NaHCO}_{3}$ & $(7.0)$ \\
$\mathrm{NH}_{4} \mathrm{Cl}$ & $(0.77)$ & $\mathrm{CaCl}$ & $(0.04)$ \\
$\mathrm{KH}_{2} \mathrm{PO}_{4}$ & $(1.12)$ & $\mathrm{FeSO}_{4}$ & $(0.15)$ \\
$\mathrm{MgSO}_{4}$ & $(0.8)$ & & \\
$\mathrm{NaCl}$ & $(0.8)$ & &
\end{tabular}

En todos los cultivos en lote se calcularon sin excepción la eficiencia de consumo de sustratos y rendimientos de generación de productos, así como las velocidades específicas de consumo de sustrato y generación de producto (tabla 3).

\section{4.- Ensayos abióticos de adsorción pérdida por volatilización y oxidación química}

Se realizaron ensayos abióticos para conocer si había pérdida del 2-CP (10 mg C-2CP/I) por oxidación química, volatilización y adsorción, en botellas serológicas con el medio de cultivo descrito en la Tabla 2

Para conocer la pérdida de 2-CP por adsorción en la biomasa nitrificante (200 mg de proteína /l), se esterilizaron en autoclave a 15 psi durante $1 \mathrm{~h}$. La biomasa inactivada en cada botella se dejó enfriar a temperatura ambiente y posteriormente, a cada una se le agregó $10 \mathrm{mg}$ C-2-CP/l. Las botellas se mantuvieron en agitación a $200 \mathrm{rpm}$ durante $48 \mathrm{~h}$, tiempo en el cual se determinó la concentración final de 2-CP.

Para evaluar la pérdida por oxidación química y volatilización, se utilizó una concentración de $10 \mathrm{mg} \mathrm{C-2-CP/l}$ bajo las condiciones mencionadas en los 
ensayos control, pero en ausencia de biomasa. Las botellas se mantuvieron en agitación a 200 rpm durante 48 h tiempo en el cual se determinó la concentración final de 2-CP.

\section{5.- Cultivos nitrificantes en presencia de 2-CP}

Se observó el efecto del 2-CP en el comportamiento fisiológico y cinético del consorcio nitrificante evaluando por separado la amonio oxidación (amonio como sustrato) y la nitrito oxidación (nitrito como sustrato) para lo cual se emplearon las mismas condiciones experimentales ya descritas para los ensayos control en lote (sección 5.3). En este caso el consorcio nitrificante a una concentración aproximada de $200 \mathrm{mg}$ de proteína/l se puso en contacto con $5 \mathrm{mg} \mathrm{C}-2-\mathrm{CP} / \mathrm{l}$, se mantuvo una relación $(\mathrm{C} / \mathrm{N})$ de 2.5. El tiempo de incubación fue de $40 \mathrm{~d}$, tomando muestras a diferentes tiempos (cada 7 días durante los primeros 20 y cada 3 en los siguientes $20 \mathrm{~d}$ ). De igual forma los ensayos se realizaron por duplicado y cada botella fue una unidad experimental independiente que fue desechada tras su análisis.

\section{6.- Ensayos de recuperación de la actividad amonio y nitrito oxidante}

Para evaluar los efectos registrados tras el contacto del consorcio nitrificante con el 2-CP (10 mg C-2-CP/l), se evalúo la capacidad del lodo para recuperar la actividad amonio y nitrito oxidante. Los lodos con previo contacto con 2-CP se lavaron tres veces con $250 \mathrm{ml}$ de solución salina, se centrifugó y se alimentó nuevamente con el medio de cultivo utilizado en los ensayos de referencia. En todos los casos las muestras se tomaron a diferentes tiempos para establecer la cinética del proceso.

\section{7.- Ensayos de inhibición de la amonio y nitrito oxidación}

Basado en las metodologías reportadas por Silva y col., (2009) y Bremner y col. (1989), se provocó la inhibición de las rutas amonio y nitrito oxidantes utilizando aliltiurea $(40 \mathrm{mg} / \mathrm{l})$ como inhibidor específico de la enzima amonio monooxigenasa y clorato de sodio $(80 \mathrm{mg} / \mathrm{l})$ como inhibidor de la enzima nitrito óxido reductasa. La efectividad de ambos inhibidores se verificó con ensayos de referencia utilizando $100 \mathrm{mg} \mathrm{N} / \mathrm{l}$ de amonio o nitrito como sustratos iniciales.

Posteriormente, a fin de evaluar si el 2-CP podría ser consumido aun cuando las enzimas amonio y nitrito oxidantes estuviesen inhibidas, se realizaron 
ensayos con los lodos en presencia de aliltiurea o clorato de sodio y adicionados con $5 \mathrm{mg} \mathrm{C-2-CP/l}$. Estos ensayos cinéticos se realizaron en condiciones semejantes a los ensayos nitrificantes control (sección 5.3) y por duplicado en botellas serológicas de $160 \mathrm{ml}$. La cinética se realizó durante $40 \mathrm{~d}$ y se tomaron muestras a diferente tiempo (cada 7 días durante los primeros 20 d y cada 3 en los siguientes $20 \mathrm{~d}$ ).

\section{8.- Efecto del 2-CP en el transporte de amonio y nitrito}

Como se mencionó con anterioridad los compuestos como el 2-CP pueden afectar la membrana celular y esto puede traer como consecuencia que los fenómenos que ocurren en dicha membrana puedan verse afectados, lo cual podría ser el caso de los mecanismos de transporte por los cuales el amonio y el nitrito son introducidos a la célula. Basado en lo anterior se propusieron los siguientes ensayos que permitirán un mejor entendimiento del daño causado a nivel transporte en los procesos amonio y nitrito oxidantes.

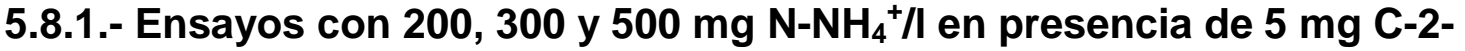 $\mathrm{CP} / \mathrm{I}$}

Se realizaron ensayos nitrificantes control y en presencia de $5 \mathrm{mg} \mathrm{C}-2-\mathrm{CP} / \mathrm{l}$, a diferentes concentraciones iniciales de amonio: 100, 200, 300 y $500 \mathrm{mg} \mathrm{N}$ $\mathrm{NH}_{4}{ }^{+} / \mathrm{l}$. En estos ensayos se utilizaron botellas de $500 \mathrm{ml}$ de capacidad con un volumen de trabajo de $100 \mathrm{ml}$ y un espacio de cabeza de $400 \mathrm{ml}$. Esto a fin de contener el oxígeno necesario para oxidar el $\mathrm{N}^{-N_{4}}{ }_{4}^{+}$y el C-2-CP presentes en las botellas. La relación $\mathrm{C} / \mathrm{N}$ para cada ensayo fue de 1.25 para $200 \mathrm{mg} \mathrm{N}$ $\mathrm{NH}_{4}{ }^{+} / \mathrm{l}$, de 0.83 para $300 \mathrm{mg} \mathrm{N}-\mathrm{NH}_{4}{ }^{+} / l$ y de 0.5 para $500 \mathrm{mg} \mathrm{N}-\mathrm{NH}_{4}{ }^{+} / \mathrm{l}$. A excepción de lo ya descrito, las condiciones de agitación, temperatura, $\mathrm{pH}$ y aireación fueron semejantes a los ensayos controles anteriores (Sección 5.3). Los experimentos tuvieron una duración de $48 \mathrm{~h}$.

\subsection{2.- Ensayos con extractos libres de células}

Se obtuvo un extracto libre de células a partir del consorcio nitrificante del reactor de tanque agitado.

\subsection{3.- Obtención de extractos libres de células}

Se tomó una muestra de $160 \mathrm{ml}$ del lodo nitrificante proveniente del reactor de tanque agitado. Se lavó 3 veces con solución fisiológica, después del lavado se centrifugó el lodo por 10 minutos a 4500 rpm en una centrifuga Sol-Bat (J-600). 
El sedimento se suspendió en una solución amortiguadora de $0.1 \mathrm{M} \mathrm{KH}_{2} \mathrm{PO}_{4} \mathrm{a}$ pH 7 que contenía $5 \mathrm{mg}$ de albúmina bovina/ml y se llevó a un volumen de 30 $\mathrm{ml}$. La ruptura celular se realizó mediante sonicación durante 20 minutos a 60 $\mathrm{KHz}$ a una temperatura de entre 3 y $5^{\circ} \mathrm{C}$. Inmediatamente después de la ruptura, se agregó $0.2 \mathrm{ml}$ de una mezcla de inhibidores de proteasas (4-(2aminoetil) bencensulfonil floruro, Peptastin A, Trans epoxisuccinil-L-leucilamino (4-guanidina) butano (E-64). Se agitó en vortex (Barnstead International mixer 37600). Se tomaron 2 muestras de $2.5 \mathrm{ml}$ para verificar la ruptura celular mediante una observación en microscopio de contrate de fases. Tras la ruptura celular la solución se distribuyó en tubos eppendorf de $2.5 \mathrm{ml}$ y se centrífugó durante 10 minutos a 12000 rpm en una micro-centrifuga Eppendorf (5417C). El sobrenadante resultante se consideró como el extracto libre de células el cual se vertió en un nuevo tubo Eppendorf. Dicho sobrenadante antes de ser utilizado en los ensayos en lote se filtró con membrana de nylon de $13 \mathrm{~mm}$ de diámetro con un tamaño de poro de $0.45 \mu \mathrm{m}$ (Nylaflo, Pall corporation) y posteriormente se evalúo su actividad nitrificante.

Los ensayos con este extracto se realizaron en botellas serológicas de $160 \mathrm{ml}$ y las condiciones experimentales así como la relación $\mathrm{C} / \mathrm{N}$ fueron semejantes a las descritas en la sección 5.3. El tiempo de cultivo tuvo una duración de $24 \mathrm{~h}$. Bajo estas condiciones se realizaron ensayos en presencia y ausencia de $5 \mathrm{mg}$ C-2-CP/I utilizando como sustrato $100 \mathrm{~N}-\mathrm{NH}_{4}{ }^{+} / \mathrm{I}$.

\section{9.- Pruebas estadísticas}

Se realizaron curvas de calibración al menos por triplicado y se calculó promedio, desviación estándar y coeficiente de variación para la pendiente, ordenada al origen y coeficiente de regresión.

Se utilizó el paquete estadístico Number Cruncher Statistical System (NCSS) (Hintze, 2001) para realizar los análisis de ANOVA de un factor y las pruebas de comparación de medias correspondientes (Tukey y Duncan).

Las variables de respuesta que fueron utilizadas para evaluar el proceso respiratorio fueron las siguientes: 
Tabla 3. Variables de respuesta utilizadas para la evaluación de los procesos de amonio y nitrito oxidación así como para el consumo de 2-CP.

\begin{tabular}{|c|c|c|}
\hline $\begin{array}{c}\text { Variable de } \\
\text { respuesta }\end{array}$ & Definición & Unidades \\
\hline $\begin{array}{l}\text { Rendimiento de } \\
\text { producción de N- } \\
\qquad \mathrm{NO}_{2}^{-} \\
\text {Rendimiento de }\end{array}$ & $\mathrm{Y}_{\mathrm{NO}_{2}}{ }^{-}=\frac{\left[\mathrm{mg} \mathrm{N}-\mathrm{NO}_{2}^{-} \text {producido }\right]}{\left[\mathrm{mg} \mathrm{N}-\mathrm{NH}_{4}^{+} \text {consumido }\right]}$ & - \\
\hline $\begin{array}{l}\text { producción de } \mathrm{N}- \\
\mathrm{NO}_{3}^{-} \text {a partir de } \mathrm{NO}_{2}^{-}\end{array}$ & $\mathrm{Y}_{\mathrm{NO}_{3}}{ }^{-}=\frac{\left[\mathrm{mg} \mathrm{N}-\mathrm{NO}_{3}^{-} \text {producido }\right]}{\left[\mathrm{mg} \mathrm{N}-\mathrm{NO}_{2}^{-} \text {consumido }\right]}$ & - \\
\hline $\begin{array}{l}\text { Rendimiento de } \\
\text { producción de } \mathrm{N}^{-\mathrm{NO}_{3}}{ }^{-} \\
\text {a partir de } \mathrm{N}-\mathrm{NH}_{4}^{+}\end{array}$ & $\mathrm{Y}_{\mathrm{NO}_{3}}{ }^{-}=\frac{\left[\mathrm{mg} \mathrm{N}-\mathrm{NO}_{3}^{-} \text {producido }\right]}{\left[\mathrm{mg} \mathrm{N}-\mathrm{NH}_{4}^{+} \text {consumido }\right]}$ & - \\
\hline $\begin{array}{c}\text { Eficiencia de } \\
\text { consumo N-NH }{ }_{4}^{+}\end{array}$ & $\begin{array}{l}\mathrm{E}_{\mathrm{NH}_{4}}{ }^{+} \\
=\frac{\left[\mathrm{mg} \mathrm{N}-\mathrm{NH}_{4}^{+} \text {inicial }\right]-\left[\mathrm{mg} \mathrm{N}-\mathrm{NH}_{4}^{+} \text {final }\right]}{\text { (100) }}\end{array}$ & $\%$ \\
\hline consumo N-NO ${ }_{2}^{-}$ & $=\frac{\left[\mathrm{mg} \mathrm{N}-\mathrm{NO}_{2}^{-} \text {inicial }\right]-\left[\mathrm{mg} \mathrm{N}-\mathrm{NO}_{2}^{-} \text {final }\right]}{\left[\mathrm{mg} \mathrm{N}-\mathrm{NO}_{2}^{-} \text {inicial }\right]}(100)$ & $\%$ \\
\hline $\begin{array}{l}\text { Eficiencia de } \\
\text { consumo de C-2CP }\end{array}$ & $\begin{array}{l}\mathrm{E}_{2 \mathrm{CP}} \\
=\frac{[\mathrm{mg} \mathrm{C}-2 \mathrm{CP} \text { inicial }]-[\mathrm{mg} \mathrm{C}-2 \mathrm{CP} \text { final }]}{[\mathrm{mg} \mathrm{C}-2 \mathrm{CP} \text { inicial }]}(100)\end{array}$ & $\%$ \\
\hline
\end{tabular}

Las velocidades específicas de consumo de amonio, 2-CP y producción de nitrito, nitrato (q) así como las fases de retardo ( $\lambda$ ), se calcularon mediante la función de Gompertz (Zwietering y col., 1990) de acuerdo a la ecuación 1.

\section{$Y=A \exp (-\exp (-B((t)-C)))$}

Donde $\boldsymbol{Y}$ es la concentración de amonio consumida $\mathrm{o}$ de nitrito y nitrato producido durante el proceso nitrificante $(\mathrm{mg} / \mathrm{l}), \boldsymbol{A}$ es la concentración máxima de amonio y 2-CP consumida o de nitrito y nitrato producida $(\mathrm{mg} / \mathrm{l})$ cuando $\mathrm{t}$ tiende a infinito; $\boldsymbol{C}$ es el tiempo de inflexión, mientras que $\boldsymbol{B}$ es la velocidad volumétrica de consumo o producción de amonio y $2-\mathrm{CP}$, nitrito o nitrato $(\boldsymbol{m g} / \mathbf{l d})$ y $\boldsymbol{t}$ el tiempo (d). Se utilizó el programa NCSS para analizar y ajustar los datos en la función de Gompertz obteniéndose los valores de los Jesús Emmanuel Pérez Alfaro | 
coeficientes de $\boldsymbol{A}, \boldsymbol{B} \boldsymbol{y} \boldsymbol{C}$, los coeficientes de regresión $\left(\mathrm{r}^{2}\right)$ y la significancia del modelo. Con los coeficientes obtenidos se calculó la velocidad máxima (vmax) de consumo o producción (ecuación 2) posteriormente se calculó la velocidad específica (q) respectiva de cada caso (ecuación 3 ). La fase de retardo ( $\lambda$ ) fue calculada como lo muestra la ecuación 4.

$v \max =\frac{A \cdot B}{\exp }$

$q=\frac{\text { vmax }}{\text { concentración de proteína }}$

$\lambda=\frac{B C-1}{B}$

\section{0.- Técnicas analíticas}

Las técnicas analíticas que se emplearon en el desarrollo experimental de este trabajo, así como la $\mathrm{R}^{2}$ y el coeficiente de variación para cada uno de los ejemplos mostrados más adelante, se muestran en la siguiente tabla.

Tabla 4. Técnicas analíticas empleadas en la etapa experimental.

\begin{tabular}{l|l|cc}
\hline \multicolumn{1}{c|}{ Determinación } & \multicolumn{1}{c|}{ Método } & $\boldsymbol{R}^{2}$ & $\begin{array}{c}\text { C.V } \\
\boldsymbol{R}^{2} \%\end{array}$ \\
\hline \hline Nitrógeno amoniacal (N- & $\begin{array}{l}\text { Electrodo de lon } \\
\text { selectivo }\end{array}$ & $0.978 \pm 0.02$ & 4.5 \\
$\left.\mathrm{NH}_{4}{ }^{+}\right)$ & HPLC & & \\
2-Clorofenol & HPLC & $0.997 \pm 0.05$ & 2.2 \\
Nitrito y nitrato $\left(\mathrm{NO}_{2}{ }^{-} \mathrm{NO}_{3}{ }^{-}\right)$ & Lowry & $0.999 \pm 0.05$ & 1.5 \\
Proteína & & $0.986 \pm 0.02$ & 6.5 \\
\hline
\end{tabular}

A continuación se desglosan cada una de las técnicas analíticas empleadas con un ejemplo de su respectiva curva de calibración.

\section{1.- Cuantificación de amonio}

Para cuantificar amonio, se utilizó un electrodo selectivo de amoniaco (Phoenix electrode Co). La lectura del potencial ( $\mathrm{mV}$ ) generado por el electrodo se registró con un potenciómetro (Cole-parmer, DigiSense). El valor del potencial es proporcional al logaritmo de la concentración cuyo valor puede ser calculado 
directamente de la ecuación de la recta. Se tomó un volumen de muestra de 50 $\mathrm{ml}$ se centrifugó a 4500 rpm durante 5 minutos y se filtró con membrana de nylon de $13 \mathrm{~mm}$ de diámetro con un tamaño de poro de $0.45 \mu \mathrm{m}$ (Nylaflo, Pall corporation). Esta solución se alcalinizó con $0.5 \mathrm{ml}$ de solución de $\mathrm{NaOH}(10 \mathrm{~N})$ para desprotonar el ión amonio y formar amoniaco. Bajo agitación constante (100 rpm) y temperatura ambiente, se tomó la lectura del potencial (mV) cuando éste fue estable (aproximadamente $3 \mathrm{~min}$. después de agregar el $\mathrm{NaOH}$ ). En la figura 2, se muestra un ejemplo de curva estándar para la determinación de amonio (0 a $\left.100 \mathrm{mg} \mathrm{N}-\mathrm{NH}_{4}{ }^{+} / \mathrm{l}\right)$.

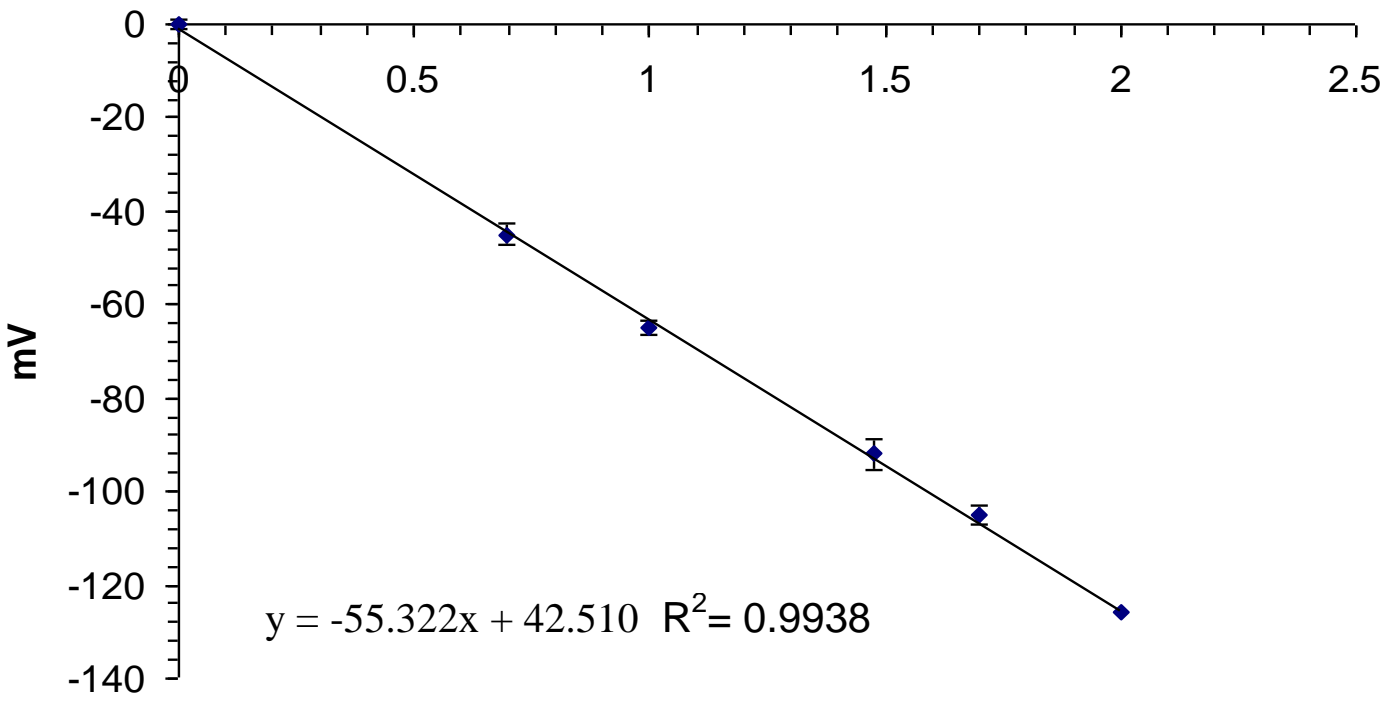

Log de la concentracion de amonio (mg/l)

Figura 2. Ejemplo de curva estándar de $\mathrm{N}$-amonio utilizando un electrodo de ion selectivo.

\section{2.- Nitrito y nitrato}

Para la cuantificación de nitrito y nitrato, se utilizó un cromatógrafo de líquidos (HPLC, Perkin Elmer serie 200) con una columna de intercambio iónico (Waters IC-pak HC) y un detector UV/VIS. La fase móvil consistió en una mezcla de butanol, acetonitrilo y un concentrado de gluconato (20:120:20 v : v) diluidos con agua desionizada a un volumen de $1 \mathrm{l}$. La solución borato-gluconato fue preparada con $16 \mathrm{~g}$ de gluconato de sodio, $18 \mathrm{~g}$ de ácido bórico, $25 \mathrm{~g}$ de tetraborato decahidratado de sodio, $250 \mathrm{ml}$ de glicerol y llevados a 1 I con agua desionizada. La fase móvil, así como las muestras a analizar, se filtraron con membranas de 25 y $13 \mathrm{~mm}$ de diámetro y $0.45 \mu \mathrm{m}$ de tamaño de poro 
respectivamente (Nylaflo, Pall corporation). Se midió a una longitud de onda de $214 \mathrm{~nm}$ y se utilizó un flujo de $2 \mathrm{ml} / \mathrm{min}$. A partir de una solución $\mathrm{N}$-nitrato y nitrito de $1000 \mathrm{mg} / \mathrm{l}$, se construyó una curva estándar para obtener concentraciones de 0, 20, 40, 80 y $100 \mathrm{mg} \mathrm{N}$-nitrito y N-nitrato/l. En las figuras 3 y 4 , se muestra un ejemplo de cada curva estándar para la determinación de nitrito y nitrato.

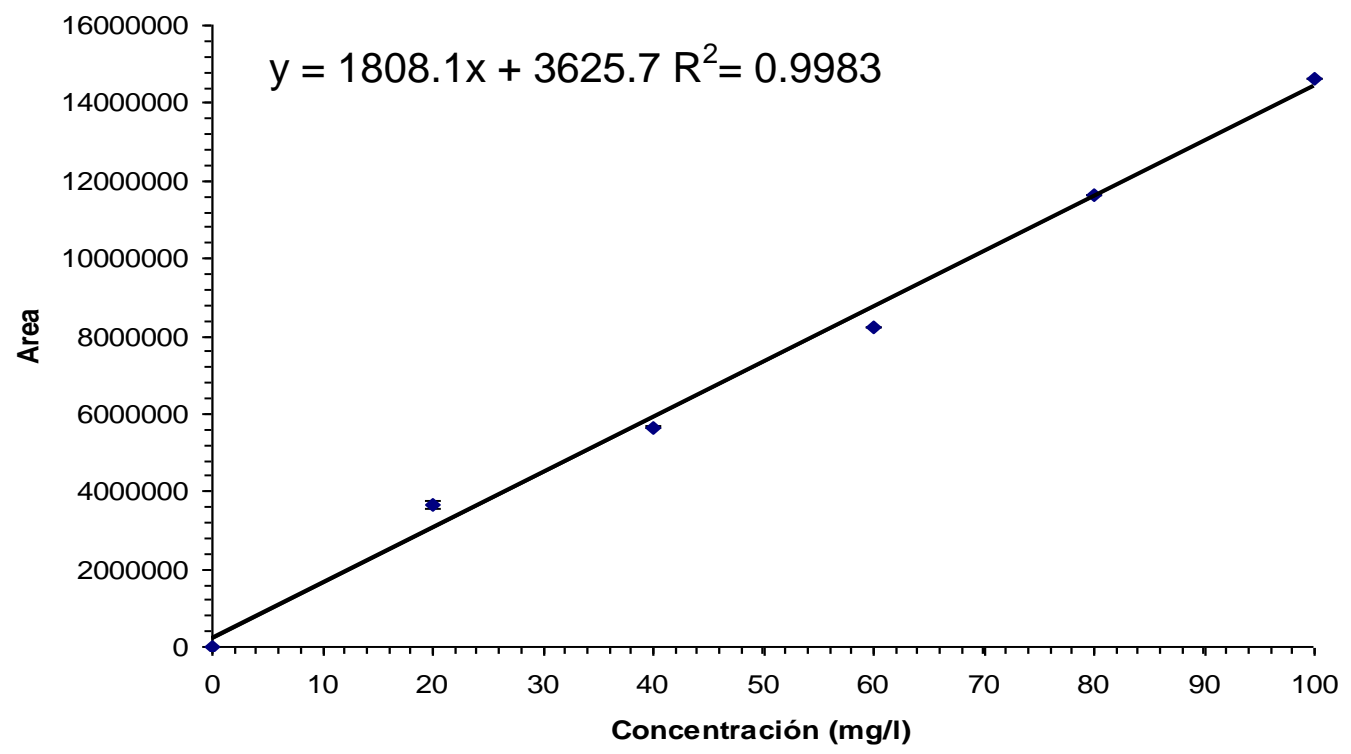

Figura 3. Ejemplo de curva estándar de nitrito por HPLC.

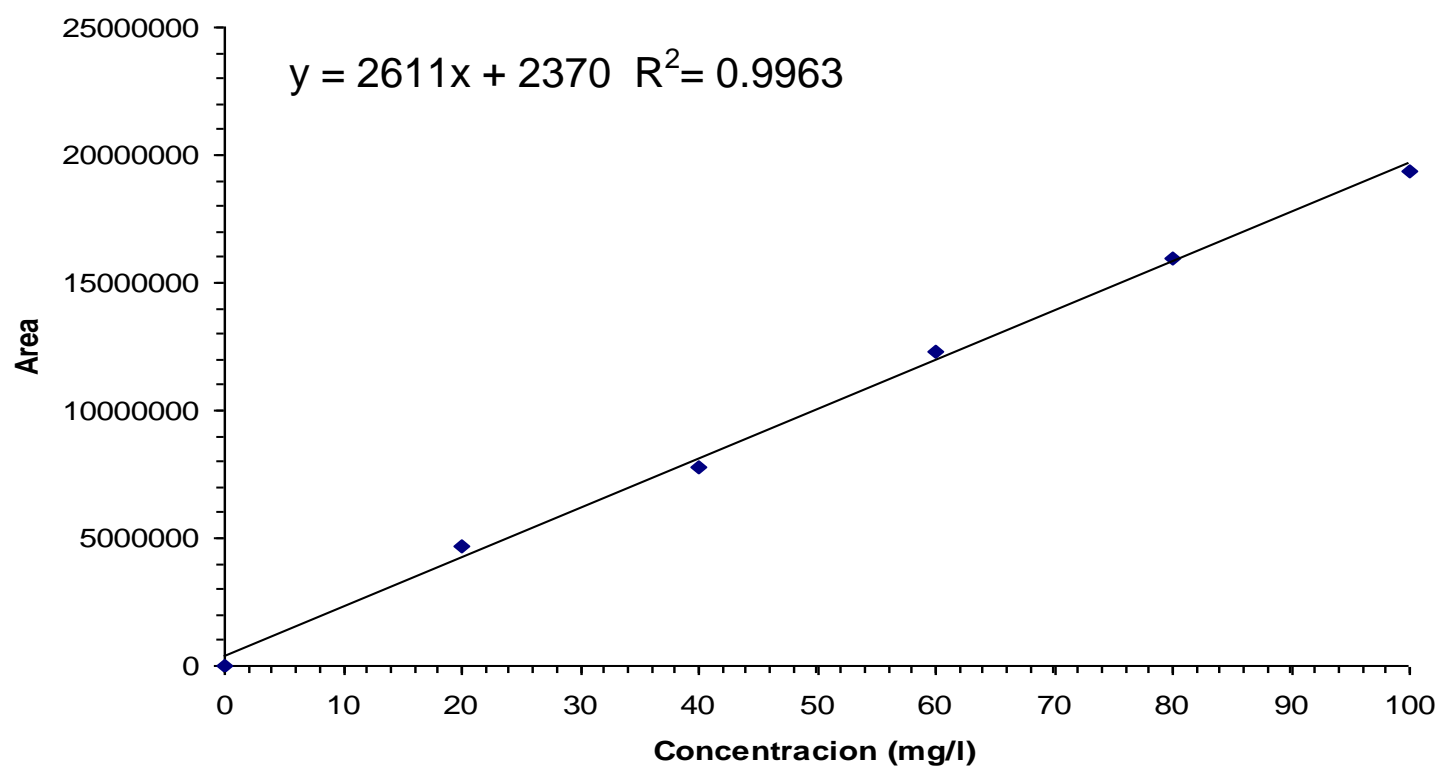

Figura 4. Ejemplo de Curva estándar de nitrato por HPLC. 


\section{3.- Cuantificación de 2-clorofenol}

El 2-clorofenol (Fluka Chemíe Gmbh Sigma-Aldrich UK) se determinó por HPLC (Perkin Elmer serie 200) utilizando una columna C-18 fase reversa (Varian Crompack) y un detector UV/VIS a una longitud de onda de $274 \mathrm{~nm}$. Se utilizó una fase móvil compuesta por acetonitrilo y agua (60: $40 \mathrm{v}: \mathrm{v}$ ), a un flujo de $1.5 \mathrm{~mL} / \mathrm{min}$. La fase móvil fue filtrada $(0.45 \mu \mathrm{m})$ y desgasificada. A partir de una solución de $1000 \mathrm{mg} / \mathrm{l}$ se obtuvieron las siguientes concentraciones estándar: 1, 3, 5, 7.5 y $10 \mathrm{mg} \mathrm{C-2-clorofenol/l.} \mathrm{Todas} \mathrm{las} \mathrm{diluciones} \mathrm{se} \mathrm{hicieron}$ con agua desionizada y las soluciones fueron filtradas por una membrana de nylon de $0.45 \mu \mathrm{m}$ de $13 \mathrm{~mm}$ de diametro (Nylaflo, Pall corporation). En la figura 5 , se muestra un ejemplo de curva estándar para la determinación de 2clorofenol.

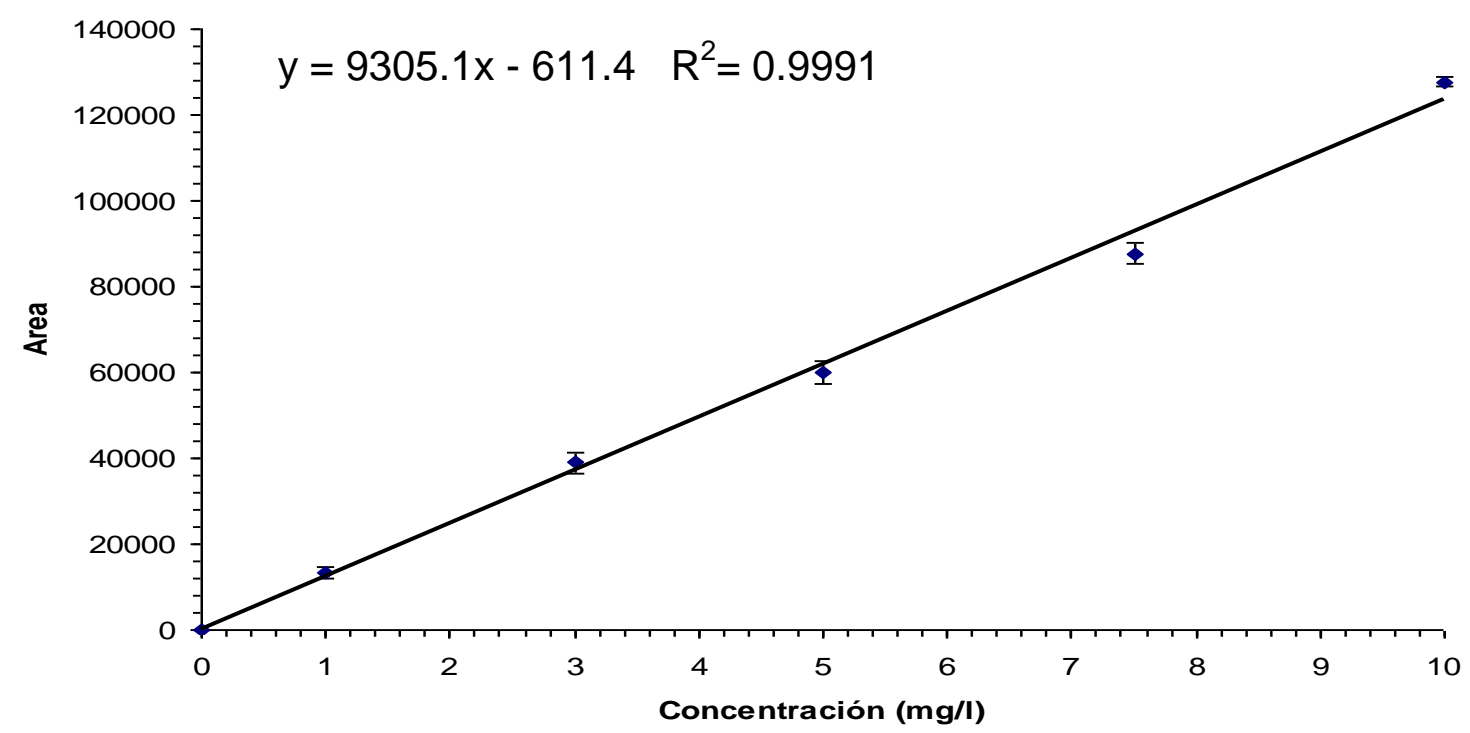

Figura 5. Ejemplo de curva estándar de C-2-clorofenol por HPLC.

\section{4.- Cuantificación de Proteína}

La concentración de proteína fue determinada por el método colorimétrico de Lowry (Lowry y col., 1951). Como referencia se utilizó una curva de calibración de 0 0.12, $0.18,0.24$ y $0.3 \mathrm{~g}$ de albúmina/l (Sigma-Aldrich). Se midió la absorbancia con un espectrofotómetro (ShimadzuTM), a una longitud de onda de $750 \mathrm{~nm}$. En la figura 6 se muestra un ejemplo de las curvas realizadas. 


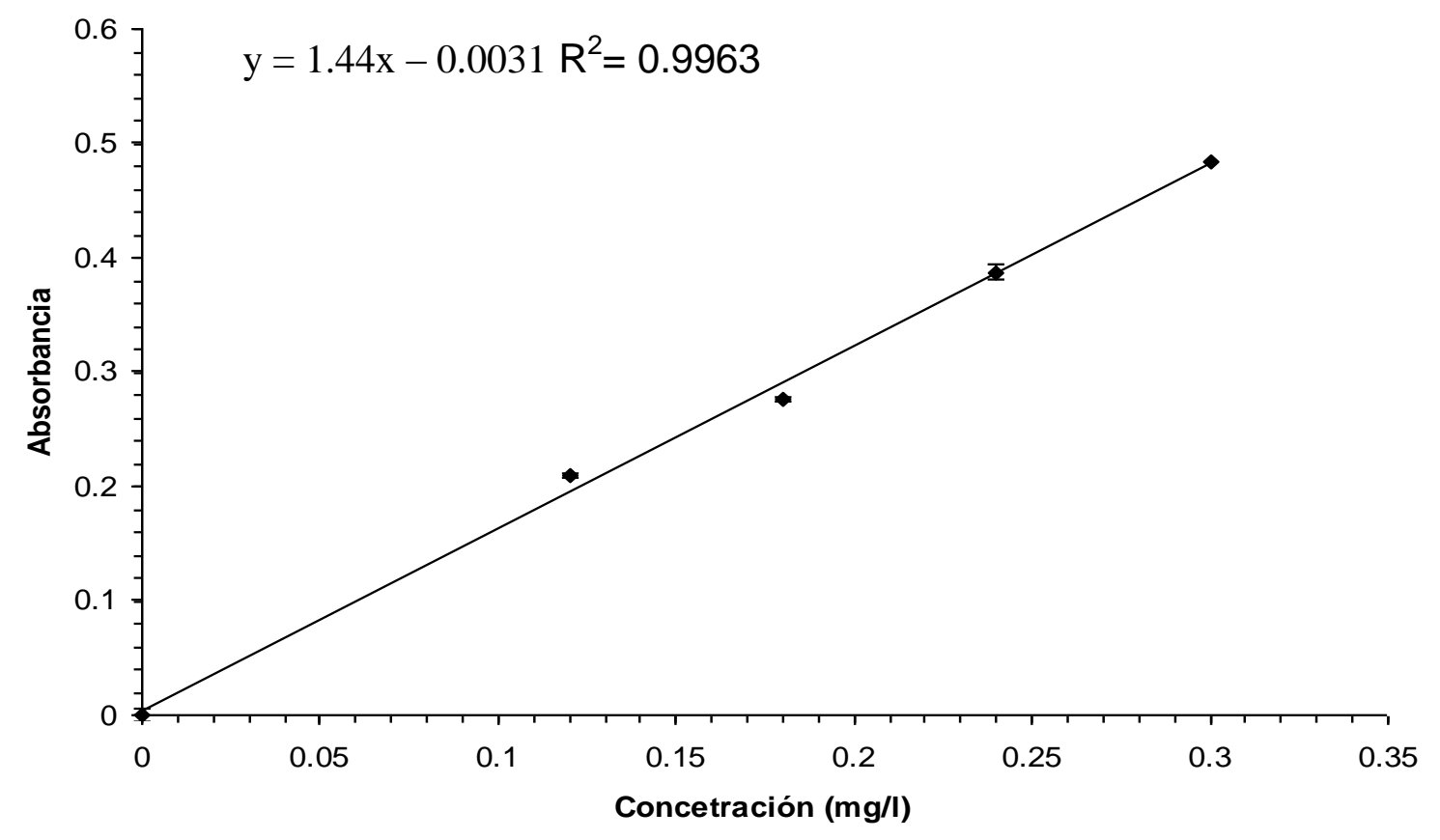

Figura 6. Ejemplo de curva estándar de proteína por el método de Lowry. 


\section{Resultados y Discusión}




\subsection{Resultados y discusión}

\section{1.-Evaluación cinética y fisiológica de los procesos amonio y nitrito oxidante en presencia de 2-clorofenol.}




\title{
Kinetic and Physiological Evaluation of Ammonium and Nitrite Oxidation Processes in Presence of 2-Chlorophenol
}

\author{
J. E. Pérez-Alfaro • G. Buitrón • J. Gomez • \\ A.-C. Texier - F. M. Cuervo-López
}

Received: 29 October 2012 / Accepted: 26 December 2012

(C) Springer Science+Business Media New York 2013

\begin{abstract}
The effect of 2-chlorophenol (2-CP) on ammonium and nitrite-oxidizing processes was kinetically evaluated in batch cultures with nitrifying sludge at steady state. Assays with ammonium or nitrite as energy source and $2.5,5.0$, or $10.0 \mathrm{mg} 2-\mathrm{CP}-\mathrm{C} / 1$ were conducted. Control assays without 2-CP were also performed. Ammonium-oxidizing activity was completely inhibited at the different 2-CP concentrations, whereas nitrite-oxidizing activity was present as nitrite was completely consumed and converted to nitrate irrespectively of 2-CP concentration. In the presence of 2.5 and $5.0 \mathrm{mg} \mathrm{2-CP-C/1}$, no significant effect on specific rates of nitrite consumption and nitrate production was observed, but a significant decrease on these parameters was observed at $10.0 \mathrm{mg} 2-\mathrm{CP}-\mathrm{C} / 1$. The nitrifying sludge previously exposed to $2-\mathrm{CP}$ was unable to completely recover its ammonium and nitrite oxidation capacity. Nevertheless, complete 2-CP consumption was achieved in all assays. The effect of 2-CP on ammonium oxidation was observed at kinetic and metabolic pathway level, whereas the effect on nitrite oxidation was observed only at kinetic level. The results obtained in this work evidenced that in order to achieve a successful nitrification process the presence in wastewater of even $2.5 \mathrm{mg} 2-\mathrm{CP}-\mathrm{C} / 1$ should be avoided.
\end{abstract}

Keywords Ammonium oxidation $\cdot 2$-Chlorophenol $\cdot$ Inhibition $\cdot$ Nitrite oxidation $\cdot$ Membrane Nitrification

\section{Introduction}

Chlorophenols are included in the rank of organic pollutants with a high priority for elimination [1]. These compounds are widely distributed in air, soil, water, and in many

J. E. Pérez-Alfaro · J. Gomez · A.-C. Texier · F. M. Cuervo-López $(\square)$

Department of Biotechnology, Universidad Autónoma Metropolitana-Iztapalapa, Iztapalapa,

Mexico City CP 09340, Mexico

e-mail: fmc1@xanum.uam.mx

G. Buitrón

Department of Environmental Bioprocess of Engineering Institute,

Universidad Nacional Autónoma de México, Mexico City, Mexico

Published online: 08 January 2013 
Appl Biochem Biotechnol

industrial wastewaters [2]. 2-Chlorophenol (2-CP) is widely used for wood preservation, manufacturing herbicides, insecticides, fungicides, and flame retardants, resulting in its accumulation in superficial and underground water [3]. Several biological processes at different conditions have been used to remove chlorophenols from wastewaters, such as aerobic $[4,5]$, anaerobic [6], or combination of them [3, 7]. It has been reported that aerobic 2-CP elimination results in intermediaries accumulation which led inactivation of catechol 2,3-dioxygenase enzyme [8], whereas at anaerobic conditions, Beristain-Montiel et al. [9] observed mineralization and methanization of 2-chlorophenol but a previous sludge acclimation to 2-CP was necessary.

Ammonium is a compound frequently present in industrial wastewaters which its accumulation results in eutrophication of water bodies and toxic effects on aquatic fauna and human health. Nitrification, an aerobic respiratory process which carries out the biological oxidation of ammonium to nitrate via nitrite, has been used for the elimination of ammonium from effluents. It is performed by two successive paths. By the action of ammoniumoxidizing bacteria, ammonium $\left(\mathrm{NH}_{4}{ }^{+}\right)$is oxidized into hydroxylamine by ammonium monooxygenase (AMO) enzyme and then hydroxylamine oxide reductase enzyme oxidizes it to nitrite $\left(\mathrm{NO}_{2}{ }^{-}\right)$. Nitrite is converted to nitrate $\left(\mathrm{NO}_{3}{ }^{-}\right)$by the action of nitrite oxide reductase enzyme present in nitrite-oxidizing bacteria. It has been described that the presence of organic matter exerts a negative effect on nitrification [10-12]. These effects can vary according to concentration and type of organic matter [13-16]. Nevertheless, it has been also reported that nitrifying conditions allows the elimination of ammonium and organic matter [17-19].

There are some evidences about the effect of 2-CP on the nitrification processes. Satoh et al. [20] mentioned that ammonium consumption was not detected in municipal wastewater biofilm in the presence of $10.0 \mathrm{mg} 2-\mathrm{CP}-\mathrm{C} / 1$. Inui et al. [21] have reported that $0.5 \mathrm{mg} 2-\mathrm{CP}$ $\mathrm{C} / 1$ provoked a decrease of $10.0 \%$ in the ammonium consumption of a Nitrosomonas culture; however, the nitrifying activity was not verified as nitrite production was not quantified. Martínez-Hernández et al. [22] suggested that 2-CP exerted a negative influence in both oxidative processes. In general, the available information is focused on the effect of 2-CP on ammonium oxidation [23, 24] and less information is reported about the effect on nitrite oxidation. Data about 2-CP oxidation and its fate at nitrifying conditions are scarce. More information about the effect of 2-CP on both ammonium and nitrite oxidation kinetic processes could be useful for obtaining a better understanding and control of the nitrifying processes in the presence of this compound. Thus, the aim of this study was to evaluate the effect of 2-CP on the ammonium and nitrite oxidation, using response variables (Table 1) as consumption efficiency of ammonium and nitrite $\left({E_{\mathrm{NH}}}^{+}, E_{\mathrm{NO} 2}{ }^{-}\right)$, nitrite and nitrate production yields $\left(Y_{\mathrm{NO}_{2}}{ }^{-}, Y_{\mathrm{NO}_{3}}{ }^{-}\right)$, and specific rates of ammonium and nitrite consumption $\left(q_{\mathrm{NH} 4}{ }^{+}\right.$, $\left.q_{\mathrm{NO} 2}{ }^{-}\right)$and nitrite and nitrate production $\left(q_{\mathrm{NO}_{2}}{ }^{-}\right.$and $\left.q_{\mathrm{NO} 3}{ }^{-}\right)$. The oxidation of 2-CP under nitrifying conditions was also investigated.

\section{Materials and Methods}

Inoculum Source

The sludge used for inoculating batch assays was obtained from a continuous stirred tank reactor (CSTR) operated at steady-state nitrification. CSTR was continuously aerated and operated at $30^{\circ} \mathrm{C}, 200 \mathrm{rpm}, \mathrm{pH}$ of $7.6 \pm 0.6$, and a hydraulic retention time of $2.9 \pm 0.2$ days. The reactor was fed with two lithoautotrophic media (A, containing nitrogen source, and B,

Springer 


\section{Author's personal copy}

Appl Biochem Biotechnol

Table 1 Response variables used for evaluating the nitrifying respiratory process

\begin{tabular}{|c|c|c|}
\hline Response variable & Definition & Units \\
\hline $\begin{array}{l}\mathrm{NO}_{2}^{-}-\mathrm{N} \text { production } \\
\text { yield }\end{array}$ & $Y_{\mathrm{NO}_{2}-}=\left[\frac{m g \mathrm{NO}_{2}^{-}-\mathrm{N} \text { produced }}{m g \mathrm{NH}_{4}^{+}-\mathrm{N} \text { consumed }}\right]$ & - \\
\hline $\begin{array}{l}\mathrm{NO}_{3}^{-}-\mathrm{N} \text { production } \\
\text { yield from nitrite }\end{array}$ & $Y_{\mathrm{NO}_{3}^{-}}=\left[\frac{\mathrm{mg} \mathrm{NO}_{3}^{-}-\mathrm{N} \text { produced }}{\mathrm{mgNO} \mathrm{O}_{2}^{-}-\mathrm{Ncons} \text { uned }}\right]$ & - \\
\hline $\begin{array}{l}\mathrm{NO}_{3}^{-}-\mathrm{N} \text { production } \\
\text { yield from ammonium }\end{array}$ & $Y_{\mathrm{NO}_{3}^{-}}=\left[\frac{m g N O_{3}^{-}-\mathrm{N} \text { produced }}{m g N H_{4}^{+}-\mathrm{N} \text { consumed }}\right]$ & - \\
\hline $\begin{array}{l}\mathrm{NH}_{4}^{+}-\mathrm{N} \text { consumption } \\
\text { efficiency }\end{array}$ & $E_{\mathrm{NH}_{4}^{+}}=\frac{\left[m g N H_{4}^{+}-\mathrm{Nin}\right]-\left[m g N H_{4}^{+}-\mathrm{Nout}\right]}{\left[m g N H_{4}^{+}-\mathrm{Nin}\right]}(100)$ & $\%$ \\
\hline $\begin{array}{l}\mathrm{NO}_{2}^{-}-\mathrm{N} \text { consumption } \\
\text { efficiency }\end{array}$ & $E_{\mathrm{NO}_{2}}+=\frac{\left[\mathrm{mgNO}_{2}^{-}-\mathrm{Nin}\right]-\left[\mathrm{mg} \mathrm{NO}_{2}^{-}-\mathrm{Nout}\right]}{\left[\mathrm{mg} \mathrm{NO}-\mathrm{N}_{2}^{-}-\mathrm{Nin}\right]}(100)$ & $\%$ \\
\hline $\begin{array}{l}\text { 2-CP-C consumption } \\
\text { efficiency }\end{array}$ & $E_{2 C P^{+}}=\frac{[m g 2 C P-C i n]-[m g 2 C P-C \text { out }]}{[m g 2 C P-C \text { in }]]}(100)$ & $\%$ \\
\hline \multicolumn{3}{|l|}{ Specific rates of } \\
\hline $\mathrm{NH}_{4}^{+}-\mathrm{N}$ & $q_{\mathrm{NH}_{4}{ }^{+}=}=\frac{\left[\mathrm{mgNH}_{4}^{+}-\mathrm{N} \text { consumed } / \text { lday }\right]}{[\text { mgprotein } / l]}$ & $\begin{array}{c}\mathrm{mg} \mathrm{NH}_{4}{ }^{+}-\mathrm{N} / \mathrm{mg} \\
\text { protein day }\end{array}$ \\
\hline $\mathrm{NO}_{2}{ }^{-}-\mathrm{N}$ & $q_{\mathrm{NO}_{2}{ }^{-}}=\frac{\left[\mathrm{mgNO}_{2}^{-}-\mathrm{N} \text { consumed } / \text { lday }\right]}{[\mathrm{mg} \text { protein } / \mathrm{l}]}$ & $\begin{array}{l}\mathrm{mg} \mathrm{NO}_{2}{ }^{-}-\mathrm{N} / \mathrm{mg} \\
\text { protein day }\end{array}$ \\
\hline $\mathrm{NO}_{3}{ }^{-}-\mathrm{N}$ & $q_{\mathrm{NO}_{3}{ }^{-}=} \frac{\left[\mathrm{mgNO}_{3}^{-}-\mathrm{Nproduced} / \mathrm{lday}\right]}{[\mathrm{mg} \text { protein } / \mathrm{l}]}$ & $\begin{array}{l}\mathrm{mg} \mathrm{NO}_{3}{ }^{-}-\mathrm{N} / \mathrm{mg} \\
\text { protein day }\end{array}$ \\
\hline 2-CP-C & $q_{2 C P}=\frac{[m g / 2 C P-C \text { consumed } / \text { lday }]}{[m g \text { protein } / l]}$ & $\begin{array}{l}\mathrm{mg} 2 \mathrm{CP}-\mathrm{C} / \mathrm{mg} \\
\text { protein day }\end{array}$ \\
\hline
\end{tabular}

containing carbon source) as follows (in gram per liter): medium A: $\left(\mathrm{NH}_{4}\right)_{2} \mathrm{SO}_{4}(1.73)$, $\mathrm{NH}_{4} \mathrm{Cl}(1.40), \mathrm{KH}_{2} \mathrm{PO}_{4}(2.73), \mathrm{MgSO}_{4}(0.60), \mathrm{NaCl}(1.00)$ and medium $\mathrm{B}: \mathrm{NaHCO}_{3}(9.30)$ and $\mathrm{CaCl}_{2}(0.04)$. Thirty milliliters of $\mathrm{a} \mathrm{FeSO}_{4} \cdot 7 \mathrm{H}_{2} \mathrm{O}$ solution $(5.00 \%, v / v)$ was added daily into the reactor as enzymatic cofactor and in order to prevent its precipitation in the feed thank. At the volumetric loading rate of $250.8 \pm 9.3 \mathrm{mg} \mathrm{NH}{ }_{4}{ }^{+}-\mathrm{N} / 1$ day, the rate of nitrate production was $245.7 \pm 1.8 \mathrm{mg} \mathrm{NO}_{3}{ }^{-} \mathrm{N} / 1$ day. The $E_{\mathrm{NH} 4}{ }^{+}$was $97.1 \% \pm 3.5$ whereas the $Y_{\mathrm{NO} 3}{ }^{-}$was $0.96 \pm 0.05$. This behavior remained for more than 6 months with a variation coefficient of $8.3 \%$. The sludge obtained at these operational conditions was used as inoculum for conducting batch assays. In all assays, the sludge was washed with a solution of $\mathrm{NaCl}(9.00 \mathrm{~g} / \mathrm{l})$ and centrifuged $(4,000 \times \mathrm{g} / 10 \mathrm{~min})$ before being used.

\section{Batch Experiments}

Batch experiments were performed in serological bottles of $160 \mathrm{ml}$ with $100 \mathrm{ml}$ of working volume and $60 \mathrm{ml}$ of headspace. The assays were performed by duplicate. Each bottle represented an independent measurement and it was discarded after analysis. The lithoautotrophic medium was composed of the following nutrients (in milligrams per liter): $\left(\mathrm{NH}_{4}\right)_{2} \mathrm{SO}_{4}(60.0), \mathrm{NH}_{4} \mathrm{Cl}(47.0), \mathrm{KH}_{2} \mathrm{PO}_{4}(7.0), \mathrm{MgSO}_{4}(0.005), \mathrm{NaCl}(5.0), \mathrm{NaHCO}_{3}$ (437.0), and $\mathrm{CaCl}_{2}$ (2.5). Oxygen was bubbled into the liquid phase for $2 \mathrm{~min}$. The bottles were inoculated with the required quantity of microbial protein of nitrifying sludge to obtain $202.0 \mathrm{mg} / 1 \pm 9.6$ as initial concentration. The bottles were sealed and oxygen was flushed 
Appl Biochem Biotechnol

again for $2 \mathrm{~min}$. At these conditions, the lithoautotrophic medium was completely saturated with oxygen, corresponding to an initial dissolved oxygen concentration of $6.5 \pm 1.5 \mathrm{mg} / \mathrm{l}$. The bottles were incubated at $30{ }^{\circ} \mathrm{C}, \mathrm{pH}$ of $7.5 \pm 0.3$, and $200 \mathrm{rpm}$ of agitation in an orbital shaker.

Several assays were conducted under the previously described conditions, where volatilization and chemical reaction of $2-\mathrm{CP}$ were evaluated with abiotic assays containing lithoautotrophic medium and 2-CP $(2.5,5.0$, or $10.0 \mathrm{mg} 2-\mathrm{CP}-\mathrm{C} / \mathrm{l})$. Control assays of ammonium $\left(100.0 \mathrm{mg}\right.$ of $\left.\mathrm{NH}_{4}{ }^{+}-\mathrm{N} / \mathrm{l}\right)$ and nitrite $\left(100.0 \mathrm{mg}\right.$ of $\left.\mathrm{NO}_{2}{ }^{-}-\mathrm{N} / \mathrm{l}\right)$ oxidation were established with nitrifying sludge and lithoautotrophic medium. Results obtained in these cultures were used as reference values for evaluating the respiratory processes in the presence of 2-CP. The effect of 2-CP $(2.5,5.0$, or $10.0 \mathrm{mg} 2-\mathrm{CP}-\mathrm{C} / \mathrm{l})$ on ammonium and nitrite oxidation processes was evaluated with nitrifying sludge in the presence of $\mathrm{NH}_{4}{ }^{+}-\mathrm{N}$ or $\mathrm{NO}_{2}{ }^{-}-\mathrm{N}$. Finally, in order to evaluate the 2-CP effects registered on ammonium and nitrite oxidation processes, the recovery of ammonium and nitrite-oxidizing activity of the sludge previously exposed to $10.0 \mathrm{mg} \mathrm{2-CP-C/}$ 1 for 80 days was determined. In these assays, the nitrifying sludge was washed three times with $250 \mathrm{ml}$ of saline solution, centrifuged, and fed again with lithoautotrophic medium as previously described in control assays. In all cases, samples were withdrawn at different times. Control assays were incubated for $48 \mathrm{~h}$, abiotic assays for 40 days, whereas the rest of the assays were cultured for at least 40 days. Specific rates were determined on the slope observed from linear regressions. In all cases, the coefficient of determination $\left(R^{2}\right)$ was higher than 0.96 .

\section{Analytical Methods}

Ammonium was analyzed by a selective electrode (Phoenix electrode company, USA) as reported by Silva et al. [16]. Nitrite and nitrate were measured by HPLC (Perkin Elmer series 200) using an ion exchange column (IC-Pak Anion HC, $4.6 \times 150 \mathrm{~mm}$, Waters) and a UV detector at $214 \mathrm{~nm}$. The mobile phase at a flow of $2.0 \mathrm{ml} / \mathrm{min}$ was composed of (in milliliter per liter): borate-gluconate solution (20.0), $n$-butanol (20.0), and acetonitrile (120.0). The composition of borate-gluconate solution was (in gram per liter): sodium gluconate (16.0), boric acid (18.0), and sodium tetraborate decahydrated (25.0). 2-CP and 3-chlorocatechol as a potential intermediary product, were analyzed by HPLC (Perkin Elmer, series 200) using a C-18 reverse phase column (Phenomenex, USA) and a UV detector at $274 \mathrm{~nm}$. The mobile phase was acetonitrile/water $(60 / 40, v / v)$ at a flow of $1.5 \mathrm{ml} / \mathrm{min}$ as reported by MartínezHernández et al. [22]. Lowry's method was employed to measure microbial protein concentration [25]. Dissolved oxygen and $\mathrm{pH}$ were measured by selective electrodes (Hanna HI 98186 OD and Digi-Sense digital pH, respectively).

\section{Statistical Analysis}

Standard curves were made in triplicates for each analytical method. In all cases, the variation coefficient for slope, coefficient of determination $\left(R^{2}\right)$, and intercept were less than $10.0 \%$. Reported values represent the mean values obtained in experimental assays and the mean \pm the standard deviation from two independent samples. Response variables obtained at each experimental condition were subjected to one-way ANOVA analysis in order to elucidate differences. Multiple comparison test (Tukey-Kramer, $\alpha$ $=0.05$ ) were also made. The computer package used was Number Cruncher Statistical System [26].

Springer 


\section{Author's personal copy}

Appl Biochem Biotechnol

\section{Results and Discussion}

Abiotic and Control Assays

The abiotic assays showed that after 40 days, around $94 \%$ of the initially added 2-CP remained dissolved in the liquid phase of the serological bottles. Likewise, no chemical reaction or 2-CP volatilization was observed indicating negligible loss of this compound.

In the control assays where ammonium was used as energy source, this compound was totally consumed within $8 \mathrm{~h}$ and converted into nitrate with a transient formation of nitrite. In the assays with nitrite as energy source, it was completely oxidized to nitrate within $7 \mathrm{~h}$. In both reference cultures, the substrate consumption efficiency and yield values were close to 100.0 and 1.0, respectively, and nitrate was the main product (Table 2). Specific rates for ammonium or nitrite consumption and nitrate production were also calculated and used as reference for comparing them with the values obtained when 2-CP was added (Table 2). The dissolved oxygen concentration at the end of the batch assays $(48 \mathrm{~h})$ was $5.1 \pm 0.9 \mathrm{mg} / \mathrm{l}$. This high oxygen concentration and the fact that no residual ammonium or nitrite was detected in the bottles indicate that there was no $\mathrm{O}_{2}$ limitation. Therefore, under the experimental conditions used, nitrification was not limited.

Kinetics of Ammonium and Nitrite Oxidation in Presence of 2-CP

The effect of 2-CP on ammonium and nitrite oxidation processes is summarized in Table 2.

\section{Ammonium Oxidation Process}

The presence of $2.5 \mathrm{mg} 2-\mathrm{CP}-\mathrm{C} / 1$ provoked a total inhibition on ammonium oxidation process as ammonium was not consumed. Value for $q_{\mathrm{NH}_{4}}{ }^{+}$was 0.0 . A similar behavior

Table 2 Consumption efficiencies of nitrogen, yields of nitrite and nitrate, and specific rates (consumption or production) of a nitrifying consortium in presence or absence of 2-CP

\begin{tabular}{|c|c|c|c|c|c|c|c|c|}
\hline $\begin{array}{l}\text { Energy } \\
\text { source }\end{array}$ & $\begin{array}{l}2-\mathrm{CP} \\
(\mathrm{mg} \mathrm{C} / 1)\end{array}$ & $\begin{array}{l}\text { Time culture } \\
\text { (day) }\end{array}$ & $E$ & $Y_{\mathrm{NO}^{-a}}{ }^{-\mathrm{a}}$ & $Y_{\mathrm{NO} 2}{ }^{-\mathrm{b}}$ & $q_{\mathrm{NH} 4}{ }^{+}$ & $q_{\mathrm{NO} 2}^{-}$ & $q_{\mathrm{NO}_{3}}{ }^{-}$ \\
\hline \multirow[t]{5}{*}{$\mathrm{NH}_{4}^{+}$} & 0.0 & 2 & 99.7 & 0.99 & NA & $1.82 \pm 0.04$ & NA & $1.37 \pm 0.12$ \\
\hline & 2.5 & 40 & 0.0 & 0.00 & 0.00 & 0.00 & 0.00 & 0.00 \\
\hline & 5.0 & 40 & 0.0 & 0.00 & 0.00 & 0.00 & 0.00 & 0.00 \\
\hline & 10.0 & 80 & 0.0 & 0.00 & 0.00 & 0.00 & 0.00 & 0.00 \\
\hline & 0.0 (RA) & 5 & 48.0 & 0.00 & 1.00 & $0.05 \pm 0.001$ & $0.03 \pm 0.002$ & 0.00 \\
\hline \multirow[t]{5}{*}{$\mathrm{NO}_{2}^{-}$} & 0.0 & 2 & 100.0 & 1.00 & NA & NA & $1.56 \pm 0.19$ & $1.34 \pm 0.07$ \\
\hline & 2.5 & 40 & 100.0 & 1.00 & NA & NA & $1.27 \pm 0.12$ & $1.22 \pm 0.01$ \\
\hline & 5.0 & 40 & 100.0 & 1.00 & NA & NA & $1.60 \pm 0.10$ & $1.58 \pm 0.10$ \\
\hline & 10.0 & 80 & 100.0 & 1.00 & NA & NA & $0.67 \pm 0.10$ & $0.62 \pm 0.20$ \\
\hline & 0.0 (RA) & 5 & 100.0 & 1.00 & NA & NA & $0.11 \pm 0.02$ & $0.10 \pm 0.01$ \\
\hline
\end{tabular}

$E$ is in percent; $q$ is in milligram of nitrogen $(\mathrm{N})$ per milligram of protein day. $E$ and $Y$ values were calculated at the end of culture time

$0.0(R A)$ recovery assay with sludge previously exposed to $10.0 \mathrm{mg} 2-\mathrm{CP}-\mathrm{C} / \mathrm{l}, \mathrm{NA}$ not applicable

${ }^{\mathrm{a}} \mathrm{NO}_{3}{ }^{-}-\mathrm{N}$ production yield from $\mathrm{NO}_{2}{ }^{-}-\mathrm{N}$ or $\mathrm{NO}_{3}{ }^{-}-\mathrm{N}$ production yield from $\mathrm{NH}_{4}{ }^{+}-\mathrm{N}$, respectively

${ }^{\mathrm{b}} \mathrm{NO}_{2}{ }^{-}-\mathrm{N}$ production yield from $\mathrm{NH}_{4}{ }^{+}-\mathrm{N}$ in recovery assays 
Appl Biochem Biotechnol

was obtained at the other 2-CP concentrations. Thus, ammonium consumption and oxidation process were completely inhibited irrespectively to the initial 2-CP concentration assayed. Nevertheless, in all cases 2-CP was completely consumed and converted to an intermediary. It is important to note that no ammonium consumption was noticed even after consumption of 2-CP was registered. These results are similar to that reported by Martínez-Hernández et al. [22], where after 30 days of experimentation, $E_{\mathrm{NH} 4}{ }^{+}$and $q_{\mathrm{NH} 4}{ }^{+}$diminished by 90 and $95 \%$ in presence of $5.0 \mathrm{mg} 2-\mathrm{CP}-\mathrm{C} / \mathrm{l}$, respectively. It has been evidenced in axenic cultures of Nitrosomonas europaea [18] and nitrifying consortia [14] that ammonium oxidation stage is highly affected in presence of aromatic compounds. Amor et al. [27] suggested an inhibitory effect of phenol on nitrification in an activated sludge; likewise, these authors observed that nitrification occurred only after the aromatic compound was completely consumed. Keener and Arp [18] have proposed that the decrease in ammonium consumption was related with competitive inhibition process considering that AMO enzyme is able to oxidize aromatic compounds. The fact that in the present work no ammonium consumption was observed even after 2-CP depletion was completed suggests that AMO activity might be affected by the presence of 2-CP or carbon intermediaries derived from its oxidation [8]. In this sense, Klecka and Gibson [28] have proposed that in Pseudomonas putida F1, the presence of 3-chlorocatechol could result in the inactivation of dioxygenases enzymes due to the chelation of the $\mathrm{Fe}^{2+}$ cofactor. Thus, AMO inactivation could be observed considering that $\mathrm{Cu}^{2+}$ plays a catalytic role in the reactions catalyzed by this enzyme [29]. Some of these possibilities could be associated with an effect on AMO activity.

\section{Nitrite Oxidation Process}

The effect of $2.5,5.0$, or $10.0 \mathrm{mg} 2-\mathrm{CP}-\mathrm{C} / 1$ on nitrite oxidation process is illustrated in Fig. 1a, b. In contrast to the assays with ammonium, all these experiments resulted in a complete consumption of nitrite and its total conversion to nitrate regardless the initial 2-CP concentration. However, when the 2-CP concentration was $10.0 \mathrm{mg} 2-\mathrm{CP}-\mathrm{C} / 1$, only $75 \%$ of the initial nitrite was consumed within $24 \mathrm{~h}$; thus, a longer time was required for achieving complete nitrite depletion ( $48 \mathrm{~h}$ of culture). Nevertheless, in all cases, the nitrite-oxidizing capacity of the nitrifying consortium remained intact as $Y_{\mathrm{NO} 3}{ }^{-}$was close to 1.0 (Table 2). Statistical analysis indicated that in the assays with nitrite and 2.5 or $5.0 \mathrm{mg} 2-\mathrm{CP}-\mathrm{C} / \mathrm{l}$, no significant difference on $q_{\mathrm{NO} 2}{ }^{-}$and $q_{\mathrm{NO} 3}{ }^{-}$values was obtained when compared with those calculated in the nitrite reference assays. However, a significant effect on $q_{\mathrm{NO} 2}{ }^{-}$and $q_{\mathrm{NO} 3}{ }^{-}$ was determined in the assay with $10.0 \mathrm{mg} 2-\mathrm{CP}-\mathrm{C} / 1(\alpha=0.001)$, as $q_{\mathrm{NO} 2}{ }^{-}$and $q_{\mathrm{NO} 3}{ }^{-}$values decreased in 57 and $55 \%$, respectively. A decrease in specific rate of nitrate production close to $74 \%$ has been reported in a nitrifying consortium amended with ammonium and benzene $(10.0 \mathrm{mg} / \mathrm{l})$ [14]. Silva et al. [16] have reported that the specific rate of nitrate production diminished by $60 \%$ in assays with ammonium and $p$-cresol $(25.0 \mathrm{mg} \mathrm{C}$-p-cresol/l). Nonetheless, the results obtained by these authors have to be considered carefully as the initial substrate was ammonium. Thus, the decrease in the rate of nitrite oxidation process could also be related with a slow ammonium oxidation process, taking into account that nitrite has to be produced in the former process. In this sense, if the concentration of nitrite is low, its oxidation rate will also be low [30]. Kelly et al. [31] have proposed that some aromatic compounds such as dinitrophenol might cause an uncoupling of the electron transfer; nevertheless, the action site is not clear as several electron transporters like ubiquinone, citocrome $\mathrm{C}$, and $\mathrm{FADH}$ are involved in the electron transfer chain of nitrite oxidation [32]. The results obtained in the present assays showed that the effect of 2-CP on nitrite oxidation is at kinetic level as the metabolic pathway remained unaffected. 


\section{Author's personal copy}

Appl Biochem Biotechnol
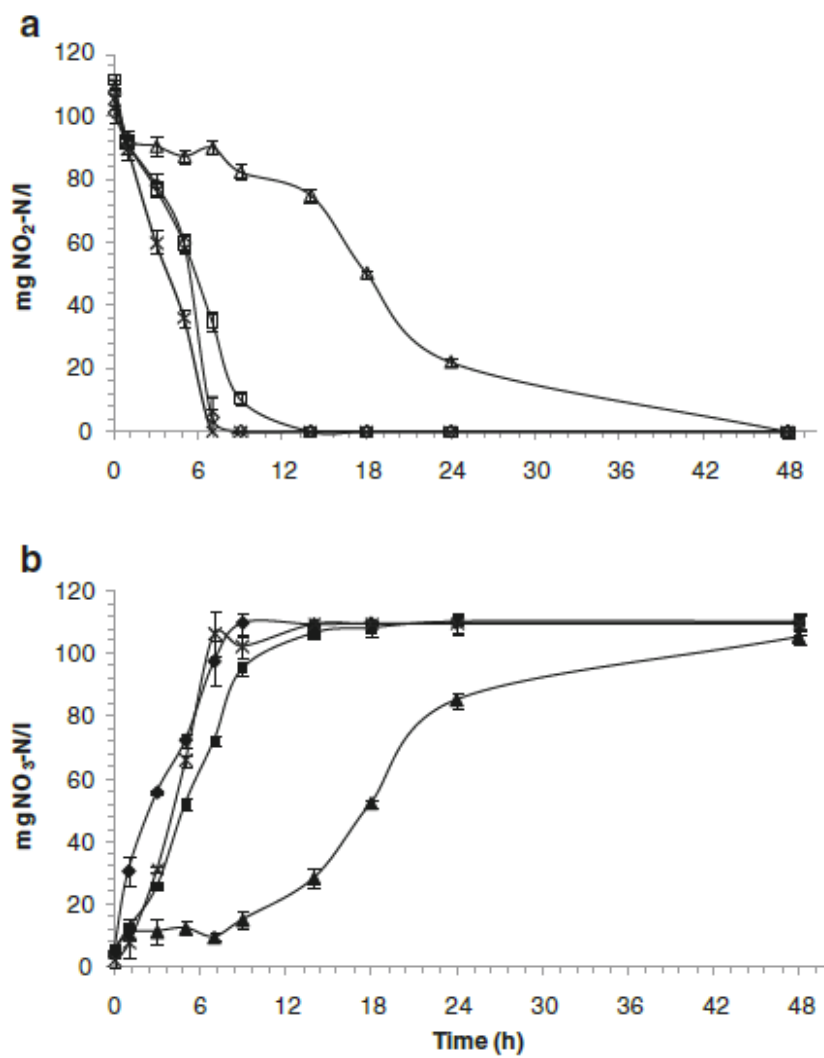

Fig. 1 Shown is the profile of nitrite oxidation: a consumption of nitrite, reference (diamond) in presence of 2.5 (multiplication sign), 5.0 (box), $10.0 \mathrm{mg} 2-\mathrm{CP}-\mathrm{C} / 1$ (triangle) and b production of nitrate, reference (filled diamond) and in presence of 2.5 (multiplication sign), 5.0 (filled box) and $10.0 \mathrm{mg} \mathrm{2-CP-C/1} \mathrm{(filled} \mathrm{triangle)}$

Some other potential effects of 2-CP on ammonium and nitrite oxidation activities could be considered. Keweloh et al. [33] suggested that lipophilic organic solutes may affect the bond between the lipids and membrane proteins altering both the membrane function and the proteins linked to the membrane. Sikkema et al. [34] indicated that the toxicity or inhibitory effects of aromatic compounds generally correlate with their hydrophobicity, which is described by their partition coefficients in a mixture of $n$-octanol and water $\left(\log K_{\text {ow }}\right)$. Compounds with a $\log K_{\text {ow }}$ between 1.00 and 4.00 may be cytotoxic due to their solubility and accumulation in biological membranes [35]. The $\log K_{\text {ow }}$ of 2-chlorophenol is considered between 2.12 and 2.17 [2]; thus, besides to the possible effect of 2-CP on enzymes of ammonium and nitrite oxidation, the effects of 2-CP on membranes should also be considered. Heipieper et al. [36] have proposed that aromatic compounds such as phenol might induce efflux of some ions such as potassium, resulting in alteration of substrate transport. Regarding this, the lack of ammonium consumption, and the decrease in $q_{\mathrm{NO}^{-}}{ }^{-}$and $q_{\mathrm{NO} 3}{ }^{-}$values at $10.0 \mathrm{mg} 2-\mathrm{CP}-\mathrm{C} / 1$ in the nitrite oxidation process, might also be related with the effect of $2-\mathrm{CP}$ on microbial membranes and ammonium and nitrite mechanism transport. More experimentation is required in order to clarify this point.

Recovery of Ammonium and Nitrite Oxidation Processes

The recovery assays amended with ammonium indicated that in contrast with the reference assays, where ammonium was totally consumed within $7 \mathrm{~h}$ and converted to nitrate, a few 
Appl Biochem Biotechnol

ammonium consumption and nitrite production were detected within the experimentation time (Fig. 2a). In fact, it was required a period of approximately $120 \mathrm{~h}$ for initiating the ammonium consumption. Moreover, only $48 \%$ of the substrate had been consumed after $250 \mathrm{~h}$ of culture. Nevertheless, all the ammonium consumed within this time was completely oxidized to nitrite as indicated by the $\mathrm{NO}_{2}{ }^{-}$value (Table 2). These results indicated that in spite that ammonium oxidation process was completely inhibited in the presence of 2-CP, after the contact with this compound, it was possible to partially recover the ammonium consumption and oxidation activity. However, the previous exposition to 2-CP affected the $q_{\mathrm{NH} 4}{ }^{+}$as this value decreased more than $90 \%$ when compared with the reference assays (Table 2). Rasche et al. [37] observed that the presence of compounds such as trichloroethylene can inhibit the ammonium consumption in cultures of $N$. europaea. They also suggest that the recovery of ammonium oxidation in this culture was related to the use of de novo routes for synthesizing new enzymes. Regarding this, in the present work, the lag phase $(120 \mathrm{~h})$ required after the exposure to 2-CP for ammonium consumption might be related to the necessity of synthesizing new AMO enzymes.

In the assays with the sludge previously exposed to $10.0 \mathrm{mg} 2-\mathrm{CP}-\mathrm{C} / 1$ ( 80 days) and amended with nitrite, a lag phase of $36 \mathrm{~h}$ for nitrite consumption was also observed (Fig. 2b). Nitrite was completely consumed within $144 \mathrm{~h}$ and totally converted to nitrate. These results indicate that after the contact with $10.0 \mathrm{mg} \mathrm{2-CP-C/1}$, the nitrifying sludge was able to
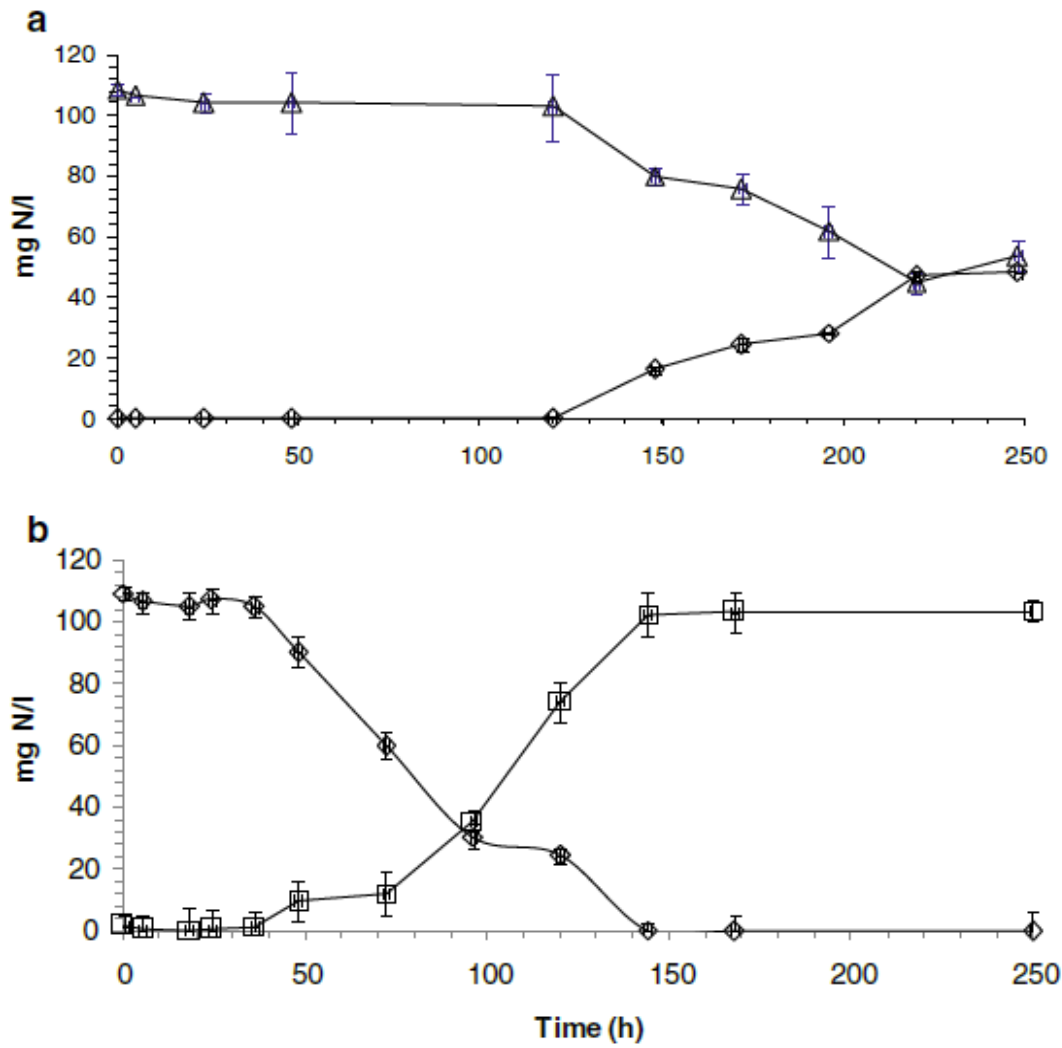

Fig. 2 Recovery assays, a profile of ammonium oxidation activity, ammonium consumed (triangle) and nitrite produced (diamond); b profile of nitrite oxidation activity, nitrite consumed (diamond) and nitrate produced (square)

Springer 
Appl Biochem Biotechnol

recover its nitrite consumption and oxidation activity, but the specific consumption and production rates of nitrite-oxidizing process were significantly decreased by $93 \%$, when compared to the reference assays (Table 2). Considering that in presence of $10.0 \mathrm{mg} 2-\mathrm{CP}-\mathrm{C} /$ 1 the specific rates of the nitrite-oxidizing process were diminished by $57 \%$, the decrease in these parameters after the exposure to 2-CP could be related with the contact time of the sludge with the chlorinated compound.

In summary, ammonium oxidation process was more sensitive to the previous contact to 2-CP than the nitrite oxidation process.

\section{2-Chlorophenol Consumption in Nitrifying Conditions}

Figure 3 shows the profiles of 2-CP consumption. The assays with $2.5,5.0$, and $10.0 \mathrm{mg} 2-$ $\mathrm{CP}-\mathrm{C} / 1$, indicated a respective lag phase of 10,15 , and 30 days for 2-CP consumption while total consumption of the aromatic compound was registered within 25,35 , and 80 days in each case. No statistical difference was determined among the 2-CP-specific consumption rates obtained at the different $2-\mathrm{CP}$ concentrations. Therefore, the nitrifying sludge was able to consume the 2-CP at similar rate irrespective of the initial 2-CP concentration $(0.0168 \pm$ $0.008,0.0240 \pm 0.005$, and $0.0280 \pm 0.007 \mathrm{mg} 2-\mathrm{CP}-\mathrm{C} / \mathrm{mg}$ protein day). These results are in contrast with those reported by Satoh et al. [20] who indicated that a municipal wastewater biofilm was not able to consume $5.6 \mathrm{mg}$ 2-CP-C/1. Our results are similar to those reported by Martínez-Hernández et al. [22], where a nitrifying consortium fed with ammonium and $5.0 \mathrm{mg} 2-\mathrm{CP}-\mathrm{C} / 1$ was able to consume the chlorinated compound.

In all cases, 2-CP was converted into an unidentified intermediary detected by HPLC. It has been reported that in aerobic conditions, Rhodococcus opacus and P. putida were able to oxidize 2-CP by various pathways (ortho I, II and meta), resulting in different products. According to ortho I cleavage, 3-chlorocatechol, 2-chloro-cis, cis-muconate, 5chloromuconolactone trans-dienolactone, maleylacetate, and 3-oxoadipate could be present as intermediaries [38]. On the other hand, meta cleavage has resulted in products such as 3chlorocatechol or 5-chloroformyl-2-hydroxy-penta-2,4 dienoic acid, where 5-chloroformyl2-hydroxy-penta-2,4 dienoic acid has been related to the inactivation of catechol 2,3dioxygenase enzyme [8]. Thus, the culture medium was analyzed by HPLC for the presence

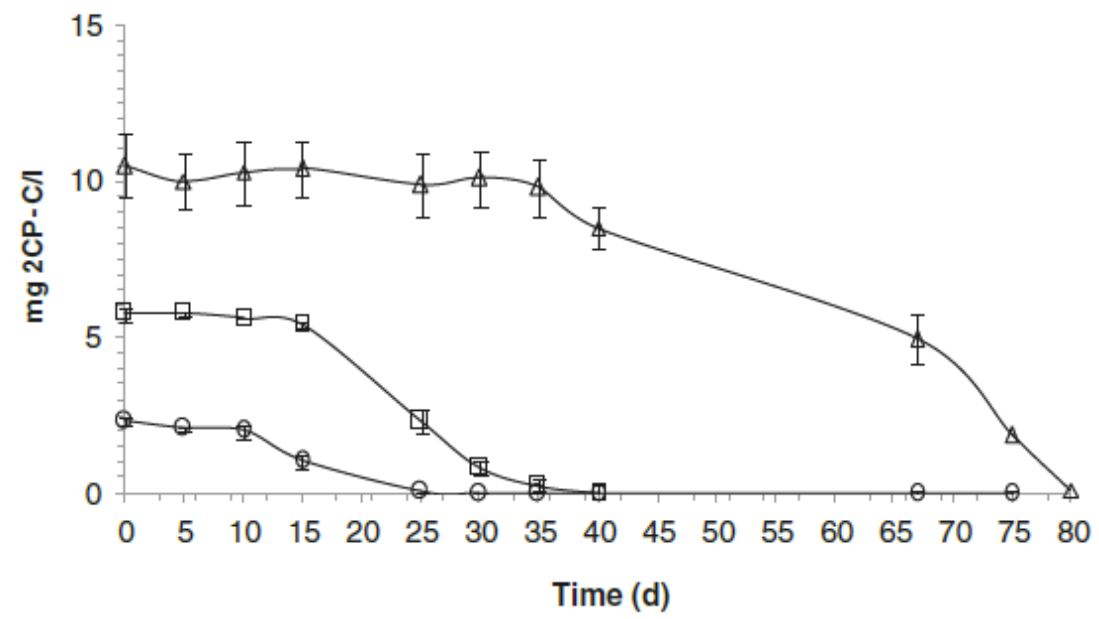

Fig. 3 Consumption profiles of 2-chlorophenol under nitrifying conditions: 2.5 (circle), 5.0 (square), and $10.0 \mathrm{mg} 2-\mathrm{CP}-\mathrm{C} / 1$ (triangle) 
Appl Biochem Biotechnol

of 3-chlorocatechol considering the possible toxicity or inhibitory influence of this compound on aerobic processes $[8,28]$. However, no similarity between the retention time of 3chlorocatechol $(2.5 \mathrm{~min})$ and the retention time of the intermediate detected $(1.6 \mathrm{~min})$ in the assays could be established. Therefore the presence of 5-chloroformyl-2-hydroxy-penta-2,4 dienoic as another possible toxic intermediary at nitrifying conditions should be explored.

\section{Conclusions}

The presence of $2.5,5.0$, or $10.0 \mathrm{mg} 2-\mathrm{CP}-\mathrm{C} / 1$ in nitrifying cultures with ammonium as substrate induced complete inhibition of ammonium consumption and oxidizing activity. Contrarily, no negative effect was registered in the nitrite oxidation process in presence of 2.5 and $5.0 \mathrm{mg} 2-\mathrm{CP}-\mathrm{C} / \mathrm{l}$, as no significant statistical difference was observed between the values of $E_{\mathrm{NO} 2}{ }^{-}, Y_{\mathrm{NO}_{3}}{ }^{-}, q_{\mathrm{NO} 2}{ }^{-}$, and $q_{\mathrm{NO} 3}{ }^{-}$calculated in the reference assays and those obtained in presence of 2-CP. Nevertheless, at $10.0 \mathrm{mg}$ 2-CP-C/1, a significant decrease of 57 and $55 \%$ was respectively detected on $q_{\mathrm{NO} 2}{ }^{-}$and $q_{\mathrm{NO} 3}{ }^{-}$. Results obtained in the present work evidenced that ammonium oxidation process is strongly affected by the presence of even $2.5 \mathrm{mg}$ 2-CP-C/l, whereas no significant effects were detected in the nitrite oxidation process up to $5.0 \mathrm{mg} 2-\mathrm{CP}-\mathrm{C} / \mathrm{l}$. 2-CP was completely consumed in all the assays.

Recovery assays indicated that as a result of the exposure to $10.0 \mathrm{mg} 2-\mathrm{CP}-\mathrm{C} /$, it was possible to partially recover both the ammonium consumption and oxidation activity of the nitrifying sludge. However, the $q_{\mathrm{NH} 4}{ }^{+}$and $q_{\mathrm{NO} 2}{ }^{-}$values decreased in $90 \%$. In contrast, the nitrifying sludge was able to recover its nitrite consumption and oxidation activity but the specific consumption and production rates of nitrite-oxidizing process were significantly affected, as they diminished in $93 \%$. In summary, the effect of 2-CP on ammonium oxidation process was observed at kinetic and metabolic pathway level, whereas, the effect on nitriteoxidizing process was observed only at kinetic level. Finally, in order to achieve a successful nitrification process, the presence in wastewater of even $2.5 \mathrm{mg} 2-\mathrm{CP}-\mathrm{C} / 1$ should be avoided.

Acknowledgments This work was supported by the Council of Science and Technology of Mexico (grant no. CONACYT-CB-2011-01-165174).

\section{References}

1. Agency for toxic substances and disease registry (ATSDR) (2005). www.atsdr.cdc.gov/cercla/05list.html Accessed July, 2012.

2. Czaplicka, M. (2004). Science of the Total Environment, 322, 21-39.

3. Atuanya, E. I., Purohit, H. J., \& Chakrabarti, T. (2000). Journal of Microbiology and Biotechnology, 16, 95-98.

4. Basu, S. K., \& Oleszkiewicz, J. A. (1995). Environmental Technology, 16, 1135-11343.

5. Fava, F., \& Armenante, P. M. (1995). Kafkewitz. Letters in Applied Microbiology, 21, 307-312.

6. Bae, H. S., Yamagishi, T., \& Suwa, Y. (2002). Microbiology, 148, 221-227.

7. Macarie, H. \& Guiot (1995). Ed. Galindo pp 317-322.

8. Farrell, A., \& Quilty, B. (1999). Biodegradation, 10, 353-362.

9. Beristain-Montiel, L., Gómez-Hernández, J., Monroy-Hermosillo, O., Cuervo-López, F., \& de RamírezVives, F. M. (2010). Water Science and Technology, 62(8), 1791-1798.

10. Gomez, J., Lema, J. M., \& Mendez, J. R. (1995). Ciencia, 46, 507-523.

11. McCarty, G. W. (1999). Biology and Fertility of Soils, 29, 1-9.

12. Sayavedra-Soto, L. A., Gvakharia, B., Bottomley, P. J., Arp, D. J., \& Dolan, E. M. (2010). Applied Microbiology and Biotechnology, 86, 435-444.

13. Gomez, J., Mendez, J. R., \& Lema, J. M. (2000). Applied Biochemistry and Biotechnology, 88, 1-12.

14. Zepeda, A., Texier, A. C., \& Gomez, J. (2003). Biotecnologia Progress, 19, 789-793.

15. Zepeda, A., Texier, A. C., Razo-Flores, E., \& Gomez, J. (2006). Water Research, 40, 1643-1649. 


\section{Author's personal copy}

Appl Biochem Biotechnol

16. Silva, C. D., Gómez, J., Houbron, E., Cuervo-López, F. M., \& Texier, A. C. (2009). Chemosphere, 75, 1387-1391.

17. Hyman, M. R., Samsone-Smith, A. W., Shears, J. H., \& Wood, P. M. (1985). Archives of Microbiology, $143,302-306$.

18. Keener, W., \& Arp, D. J. (1994). Applied Microbiology, 60, 1914-1920.

19. Texier, A. C., \& Gomez, J. (2007). Water Research, 41, 315-322.

20. Satoh, H., Sasaki, Y., Nakamura, Y., Okabe, S., \& Suzuki, T. (2005). Wiley Interscience, 91, 133-137.

21. Inui, T., Tanaka, Y., Okayasu, Y., \& Tanaka, H. (2002). Water Science and Technology, 45, 271-278.

22. Martínez-Hernández, S., Texier, A. C., Cuervo-López, F. M., \& Gómez, J. (2011). Journal of Hazardous Materials, 185, 1592-1595.

23. Kim, Y. M., Park, D., Lee, D. S., \& Park, J. M. (2008). Journal of Hazardous Materials, 152, 915-921.

24. Silva, C. D., Gómez, J., \& Beristain-Cardoso, R. (2011). Bioresource Technology, 102, 6464-6468.

25. Lowry, O. H., Brough, N. J., Farr, A. L., \& Randall, R. J. (1951). Journal of Biological Chemistry, 193, 265-275.

26. Hintze, J. (2001). Number cruncher statistical system (NCSS).

27. Amor, L., Eioria, M., Kennes, C., \& Veiga, M. C. (2005). Water Research, 39, 2915-2920.

28. Klecka, G. M., \& Gibson, D. T. (1981). Applied and Environmental Microbiology, 41, 1159-1165.

29. Ensings, A., Hyman, M. R., \& Arp, D. J. (1993). Journal of Bacteriology, 175(7), 1971-1980.

30. Aleem, M. I. H., \& Alexander, M. (1958). Journal of Bacteriology, 76(5), 510-514.

31. Kelly, R. T., Henriques, I. D. S., \& Love, N. G. (2004). Biotechnology and Bioengineering, 6(85), 683-694.

32. Stouthamer, A. H. (1976). Advances in Microbiology Physiology, 14, 315-375.

33. Keweloh, H., Weyrauch, G., \& Rehm, H.-J. (1990). Applied Microbiology and Biotechnology, 33, 66-71.

34. de Sikkema, J., Bont, J. A. M., \& Poolman, B. (1995). Microbial Reviews, 59(2), 201-222.

35. de Bont, J. A. M. (1998). Trends in Biotechnology, 16(12), 493-499.

36. Heipieper, H.-J., Weber, F. J., Sikkema, J., Keweloh, H., \& de Bont, J. A. M. (1994). Mechanisms of resistance of whole cells to toxic organic solvents. Trends in Biotechnology, 12, 409-415.

37. Rasche, M. E., Hyman, M. R., \& Arp, D. J. (1991). Applied and Environmental Microbiology, 10, 2986-2994.

38. Moiseeva, V. O., Solyanikova, P. I., Kaschabek, R. S., Grönig, J., Thiel, M., Golovleva, A. L., \& Schlömann, M. (2002). Journal of Bacteriology, 184, 5282-5292. 
7.2.- Mejora de la actividad nitrificante en un consorcio microbiano expuesto a 2-clorofenol y diferentes concentraciones de amonio: Ensayos con células completas y extractos libres de células. 


\title{
Mejora de la actividad nitrificante en un consorcio microbiano expuesto a 2-clorofenol y diferentes concentraciones de amonio: Ensayos con células completas y extractos libres de células.
}

\author{
J.E. Pérez-Alfaro ${ }^{a}$, G. Buitrón ${ }^{b}$, A.-C. Texier ${ }^{a}$ and F.M. Cuervo-López ${ }^{\star a}$. \\ ${ }^{a}$ Departamento de Biotecnología, Universidad Autónoma Metropolitana-Iztapalapa. D.F \\ Iztapalapa CP 09340, México. ' Unidad Académica Instituto de Ingeniería. Universidad Nacional \\ Autónoma de México, Querétaro 76230 Querétaro México . *E-mail: fmcl@xanum.uam.mx \\ Telefono:-(52) 55 58046408. Fax-(52) 5558046407.
}

\section{Resumen}

En cultivos en lote, se realizaron ensayos cinéticos con un consorcio nitrificante expuesto a 2-clorofenol (5mg C-2-CP/l) y diferentes concentraciones de amonio (100,

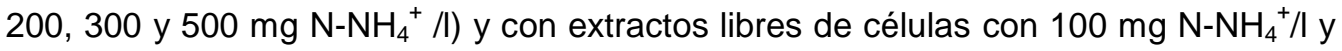
expuesto a $5 \mathrm{mg} \mathrm{C}-2-\mathrm{CP} / \mathrm{l}$. Los resultados con el consorcio nitrificante mostraron que con $100{\mathrm{mg} \mathrm{N}-\mathrm{NH}_{4}}^{+} / \mathrm{l}$, el 2-CP inhibió totalmente la actividad nitrificante ya que no se observó consumo de amonio. El incremento de la concentración de nitrógeno de amonio de 200 y hasta $500 \mathrm{mg} / \mathrm{l}$ permitió observar actividad amonio y nitrito oxidante en presencia de $5 \mathrm{mg} \mathrm{C}$-2-CP/l. Los resultados obtenidos con extractos libres de células, indicaron que éstos mantuvieron el $80 \%$ de la actividad nitrificante respecto a las células completas y fueron capaces de consumir y oxidar amonio inmediatamente aún en presencia de $5 \mathrm{mg} \mathrm{C-2-CP/l.} \mathrm{Asimismo,} \mathrm{el} \mathrm{extracto} \mathrm{libre} \mathrm{de} \mathrm{células} \mathrm{tuvo} \mathrm{la}$ capacidad de oxidar 2-clorofenol. En general, la respuesta fisiológica y cinética obtenida en todos los ensayos realizados, sugiere que la presencia de 2-CP afecta de manera negativa el transporte de amonio, debido probablemente a un daño en la membrana celular y se obtuvieron indicios claros de que el 2-CP también afecta a nivel enzimático la actividad amonio y nitrito oxidante.

Palabras clave: Transporte, inhibición, membrana, amonio oxidación.

\section{Introducción}

En la naturaleza los compuestos nitrogenados son cruciales para soportar la vida, al proporcionar energía y formar parte de la estructura de todos los seres vivos. Para las bacterias, el amonio $\left(\mathrm{NH}_{4}^{+}\right)$es una fuente preferencial de nitrógeno y energía que mantiene el crecimiento de estas (Merrick y Edwards 1995). La nitrificación es un buen ejemplo de ello, ya que es un proceso 
respiratorio aerobio donde las bacterias, en las etapas de amonio y nitrito oxidación respectivamente, usan al amonio y nitrito como fuente de energía (Wood 1986; Juliette y col., 1995). Estas etapas pueden ser sensibles a varios factores, la presencia de materia orgánica de tipo aromática es uno de ellos.

Los compuestos aromáticos como benceno, cresoles y clorofenoles o incluso más complejos como los esteroides, pueden afectar la amonio y nitrito oxidación, disminuyendo la eficiencia de consumo de amonio o nitrito y la velocidad de consumo de los mismos, así como el rendimiento de nitrato y su velocidad de producción (Rasche y col., 1990; Zepeda y col., 2006; Silva y col., 2011; Pérez-Alfaro y col., 2013). En el caso de la amonio oxidación, en cultivos puros de Nitrosomonas europaea, se propone que este efecto podría estar relacionado con una inhibición competitiva sobre la actividad de la enzima amonio monooxigenasa (AMO), ya que se ha observado que esta enzima puede oxidar diversos compuestos aromáticos (Juliette y col., 1993; Keener y Arp 1994; McCarty 1999). En ensayos con consorcios microbianos nitrificantes, se observó también inhibición de la nitrificación y se sugiere que dicha inhibición ocurre sobre la AMO (Rasche y col., 1990).

Además de la posible inhibición enzimática, los compuestos aromáticos pueden provocar alteraciones a nivel de la membrana celular, pues son capaces de modificar la estructura de esta al disolverla o hacerla más fluida (Sikkema y col., 1995). Por ejemplo, la exposición de microorganismos a tolueno puede provocar que su membrana sea más permeable, alterando sus funciones metabólicas. También se sugiere que los compuestos aromáticos pueden promover la rigidez de la membrana. Radniecki y col. (2008), reportan que la exposición por 60 minutos de Nitrosomonas europaea a $40 \mu \mathrm{M}$ de benceno puede provocar un aumento en la expresión de genes encargados de la regulación en la producción de proteínas de membrana y síntesis de ácidos grasos, lo cual confiere rigidez a la membrana. Otros autores como Guckert y col. (1986), Segura y col. (2004), Bernal y col. (2007), proponen que tras el contacto con estos compuestos se observa isomerización de los ácidos grasos de la membrana de la configuración cis a trans, lo cual es la causa de la rigidez en la misma.

Para el caso específico del 2-clorofenol, recientemente se publicó que este compuesto además de inhibir la amonio oxidación, también inhibe la nitrito 
oxidación (Pérez-Alfaro y col., 2013). Se sugiere que dicha inhibición puede estar relacionada con dos causas, una alteración en el transporte de sustratos por un posible daño en la membrana, ya que no se observó consumo de amonio, o bien, a la inhibición de las enzimas de las rutas amonio y nitrito oxidantes, pues en contacto con el 2-CP, las velocidades específicas de ambos procesos resultan afectadas.

Para poder esclarecer las hipótesis anteriores es necesario generar evidencias más concretas que permitan determinar si ocurre o no la inhibición enzimática o la alteración del transporte de sustratos en un consorcio nitrificante expuesto a 2-CP. Por lo que se desarrollaron 2 estrategias. 1) Utilizar concentraciones de amonio más altas a las reportadas en estudios de la nitrificación en presencia de 2-CP, ya que se ha planteado que la forma en que el amonio se transporta puede depender de la concentración del mismo en el medio (Merrick y Edwards 1995). 2) La utilización de extractos libres de células, lo que evitaría el posible daño en la membrana celular y cualquier alteración podría relacionarse con un efecto sobre las enzimas de la nitrificación. Desde hace varias décadas se ha reportado la obtención de dichos extractos libres de células a partir de microorganismos nitrificantes como Nitrosomonas europaea o consorcios nitrificantes para determinar por ejemplo, los cofactores que la enzima AMO requiere (Suzuki y col., 1980; Ensing y col., 1993), así como realizar estudios de inhibición enzimática (Aleem and Alexander 1958; Schmidt y col., 1998).

\section{Metodología}

\section{Fuente de inóculo}

Se utilizó un reactor de tanque agitado de mezcla completa (CSTR) alimentado en continuo y en estado estacionario nitrificante, para producir lodo como inóculo para los ensayos en lote. El reactor fue operado a $25^{\circ} \mathrm{C}$, agitación de 200 rpm, pH entre 7-8, con un tiempo de residencia hidráulico de 1.4 días y alimentado con $280 \pm 16 \mathrm{mg} \mathrm{N}-\mathrm{NH}_{4}{ }^{+} / \mathrm{ld}$. Como medio de cultivo se utilizó el reportado por Pérez-Alfaro y col. (2013). Bajo estas condiciones, se obtuvo una eficiencia de consumo de amonio del 99\%, una velocidad volumétrica de producción de nitrato de $278 \pm 16 \mathrm{mg} \mathrm{N}-\mathrm{NO}_{3}{ }^{-} / \mathrm{ld}$ y un rendimiento de producción de nitrato de 1. Este comportamiento se mantuvo a lo largo de más 
de 5 meses de operación con un coeficiente de variación en las variables de respuesta de $6.7 \%$, lo que indicó el estado estacionario del cultivo nitrificante.

\section{Ensayos en lote}

Utilizando el consorcio nitrificante sin contacto previo con 2-CP proveniente del CSTR, se realizaron dos tipos de ensayos cinéticos en lote: i) con células completas y diferentes concentraciones de amonio y, ii) con extractos libres de células. En ambos casos se utilizó el medio de cultivo reportado por MartínezHernández y col. (2011).

Nitrificación con diferentes concentraciones de amonio.

Se evaluó la actividad nitrificante del consorcio a diferentes concentraciones de amonio $\left(100,200,300\right.$ y $\left.500 \mathrm{mg} \mathrm{N}-\mathrm{NH}_{4}{ }^{+} / \mathrm{I}\right)$, las cuales fueron utilizadas como ensayos de referencia. Como unidades experimentales se utilizaron botellas serológicas de $500 \mathrm{ml}$ de volumen nominal, con $100 \mathrm{ml}$ de volumen de trabajo y $400 \mathrm{ml}$ de espacio de cabeza. Las botellas se inocularon con una concentración promedio de proteína de $213 \pm 10 \mathrm{mg} / \mathrm{l}$, se burbujeó oxígeno durante 2 minutos, el pH se ajustó entre 6.5-7.2 y se sellaron con tapón de látex. Nuevamente se burbujeó oxígeno durante 2 minutos y se incubaron a una temperatura de $30^{\circ} \mathrm{C}$ y agitación de $200 \mathrm{rpm}$ durante $48 \mathrm{~h}$. Con estas mismas concentraciones de amonio y condiciones de operación, se determinó la actividad nitrificante en presencia de $5 \mathrm{mg} \mathrm{C}-2-\mathrm{CP} / \mathrm{l}$.

Nitrificación con extractos libres de células.

Se evaluó la actividad nitrificante de un extracto libre de células obtenido a partir del consorcio nitrificante en estado estacionario. Los ensayos se realizaron en botellas serológicas de $160 \mathrm{ml}$ de capacidad con un volumen de trabajo de $100 \mathrm{ml}$ y $60 \mathrm{ml}$ de espacio de cabeza. Se utilizó $100 \mathrm{mg} \mathrm{N}-\mathrm{NH}_{4}{ }^{+} / \mathrm{l}$ y $250 \mathrm{mg} \mathrm{CNaHCO}_{3} / \mathrm{y}$ y una concentración promedio de proteína del extracto de $110 \pm 9 \mathrm{mg} / \mathrm{l}$. Las botellas se airearon durante 2 minutos con oxígeno puro, se ajustó el pH entre 6.5-7.2, se sellaron con tapón de látex y nuevamente se airearon durante 2 minutos con oxígeno puro. Posteriormente se incubaron durante $24 \mathrm{~h}$, a una temperatura de $30^{\circ} \mathrm{C}$ y agitación de $200 \mathrm{rpm}$. Bajo estas 
mismas condiciones de operación se evaluó la actividad amonio y nitrito oxidante del extracto libre de células y en presencia de $5 \mathrm{mg} \mathrm{C}-2-\mathrm{CP} / \mathrm{l}$.

Todos los ensayos se hicieron por duplicado, cada botella fue desechada tras la toma de la correspondiente muestra. Las variables de respuesta utilizadas para evaluar el desempeño de la nitrificación fueron la eficiencia de consumo de amonio $\left(\mathrm{E}_{\mathrm{N}-\mathrm{NH} 4+}\right)$ y nitrito $\left(\mathrm{E}_{\mathrm{N}-\mathrm{NO} 2-}\right)$, el rendimiento de producción de nitrito $\left(\mathrm{Y}_{\mathrm{N}-\mathrm{NO2}-}\right)$ y nitrato $\left(\mathrm{Y}_{\mathrm{N}-\mathrm{NO}}-{ }_{-}\right)$.

Las velocidades específicas de consumo de amonio y producción de nitrito y nitrato (q) así como las fases de retardo $(\lambda)$, se calcularon mediante la función de Gompertz (Zwietering y col., 1990) y el paquete estadístico Number Cruncher Statistical System (NCSS) (Hintze, 2001), de acuerdo a la ecuación 1.

\section{$Y=A \exp (-\exp (-B((t)-C)))$}

Donde $\boldsymbol{Y}$ es la concentración de amonio consumida o de nitrito y nitrato producido durante el proceso nitrificante $(\mathrm{mg} \mathrm{N} / \mathrm{l}), \boldsymbol{A}$ es la concentración máxima de amonio consumida o de nitrito y nitrato producida ( $\mathrm{mg} \mathrm{N}$ ) cuando $\mathrm{t}$ tiende a infinito; $\boldsymbol{C}$ es el tiempo de inflexión, mientras que $\boldsymbol{B}$ es la velocidad de consumo o producción de amonio, nitrito o nitrato $(\mathbf{m g N} / \mathbf{l d})$ y $\boldsymbol{t}$ el tiempo (d) (NCSS, 2001). Se utilizó el programa NCSS para analizar y ajustar los datos en la función de Gompertz obteniéndose los valores de los coeficientes de $\boldsymbol{A}, \boldsymbol{B} \boldsymbol{y}$ $\boldsymbol{C}$, los coeficientes de regresión $\left(r^{2}\right)$ y la significancia del modelo (anexo 1 ). Con los coeficientes obtenidos se calculó la velocidad máxima (vmax) de consumo de amonio o producción de nitrito y nitrato (ecuación 2) posteriormente se calculó la velocidad específica (q) respectiva de cada caso (ecuación 3). Así mismo se calculó la fase de retardo (ecuación 4).

$\operatorname{vmax}=\frac{A \cdot B}{e x p}$

$q=\frac{v m a x}{\text { concentración de proteína }}$

$\lambda=\frac{B C-1}{B}$ 
Obtención de extractos libres de células

Del consorcio nitrificante proveniente del CSTR en continuo y en estado estacionario respiratorio, se tomó una alícuota de $160 \mathrm{ml}$, que fue lavada tres veces con solución fisiológica para remover los restos del medio de cultivo. La biomasa contenida en este volumen se suspendió en una solución buffer de fosfatos ( $\mathrm{pH} 7.0$ ) 0.1M de $\mathrm{K}_{2} \mathrm{HPO}_{4} \mathrm{y} \mathrm{KH}_{2} \mathrm{PO}_{4}$ y se centrifugó a 4500 rpm durante 15 minutos. Se descartó el sobrenadante y el sedimento obtenido, se sometió a ruptura por sonicación (ultrasonic processor) a $60 \mathrm{Khz}$ durante 20 minutos a una temperatura entre 3 y $5^{\circ} \mathrm{C}$.

Posteriormente, el sedimento se distribuyó en 4 tubos Eppendorf de $2.5 \mathrm{ml}$ y se agregó una mezcla de inhibidores de proteasas: $(0.2 \mathrm{ml}$ de una mezcla de 4(2aminoetil) bencensulfonil fluoruro, peptastin $A$, trans-epoxisuccinil-Lleucilamino (4-guanidina) butano) y $10 \mathrm{mg} / \mathrm{ml}$ de sero-albumina. Nuevamente se centrifugó en una microcentrifuga Eppendorf 5417C a 12000 rpm durante 10 minutos. El sobrenadante obtenido fue considerado como el extracto libre de células, se filtró con membrana de nylon de $0.45 \mu \mathrm{m}$ y se utilizó para realizar los respectivos ensayos cinéticos previamente descritos.

\section{Métodos analíticos}

La concentración de amonio se cuantificó utilizando un electrodo selectivo de amoniaco (Phoenix electrode Co), acoplado a un potenciómetro (Cole-parmer, DigiSense) como lo reporta Bejarano Ortiz y col., (2013). Para determinar la concentración de nitrito y nitrato se utilizó un cromatógrafo de líquidos (HPLC, Perkin Elmer serie 200) con una columna de intercambio iónico (Waters IC-pak HC) y un detector UV-visible de acuerdo a lo reportado por Silva y col., (2009). La proteína microbiana se determinó por el método de Lowry y col. (1951). Para cada caso se construyeron curvas de calibración que se realizaron por triplicado y la $r^{2}$ fue mayor a 0.98 en el ajuste de los datos.

\section{Resultados}

Actividad nitrificante con diferentes concentraciones de amonio en ausencia y presencia de 2-CP.

En la tabla 1 se muestran los valores obtenidos de las variables de respuesta, calculados al final del tiempo de cultivo (48 horas) para evaluar el consumo de 
las diferentes concentraciones de amonio sin 2-CP. En el ensayo con $100 \mathrm{mg}$ $\mathrm{N}-\mathrm{NH}_{4}{ }^{+} / \mathrm{l}$ la eficiencia de consumo de amonio $\left(\mathrm{E}_{\mathrm{N}-\mathrm{NH} 4}{ }^{+}\right)$fue de $100 \%$, mientras que en los ensayos con 200, 300 y $500 \mathrm{mg} \mathrm{N}-\mathrm{NH}_{4}{ }^{+} / \mathrm{l}$, las $\mathrm{E}_{\mathrm{N}-\mathrm{NH}_{4}}{ }^{+}$fueron superiores al $60 \%$. A $100 \mathrm{mg} \mathrm{N}-\mathrm{NH}_{4}{ }^{+} / \mathrm{l}$, se requirieron aproximadamente $7 \mathrm{~h}$ para consumir el total del amonio presente y no se detectó una fase de retardo para su consumo. Al aumentar la concentración de amonio a 200, 300 y 500 $\mathrm{mg} \mathrm{N}-\mathrm{NH}_{4}{ }^{+} / /$el consumo de amonio inició inmediatamente, sin embargo tras 48 h de cultivo no se observó el consumo total de amonio. Se descartó la falta de oxígeno en el sistema experimental, como posible causa del consumo parcial de amonio, pues se contaba con el espacio de cabeza suficiente para contener el oxígeno necesario para oxidar totalmente las concentraciones de amonio utilizadas. Al final del cultivo se determinó una saturación de oxígeno del medio líquido de $75 \%$. En todos los ensayos, el nitrito producido se consumió y se oxidó a nitrato totalmente. Las velocidades específicas de consumo de amonio $\left(\mathrm{qNH}^{+}\right)$, no mostraron incrementos significativos con el aumento en la concentración de amonio, lo que podría indicar una cinética de orden cero, además permite descartar una posible inhibición por sustrato debido a la concentración de amonio utilizada. Por lo que cabe esperar que con un tiempo de cultivo más prolongado se alcance una eficiencia de consumo de amonio de $100 \%$.

Tabla 1. Variables de respuesta para el consumo de amonio en presencia y ausencia de $5 \mathrm{mg}$ C-2-CP/l.

\begin{tabular}{|c|c|c|}
\hline Ensayo & $\begin{array}{c}E_{\mathrm{N}-\mathrm{NH} 4^{+}} \\
(\%)\end{array}$ & $\begin{array}{l}q_{\mathrm{N}-\mathrm{NH} 4_{+}} \\
\left(\mathrm{mg} \mathrm{N}-\mathrm{NH}_{4}+/ \mathrm{mg} \text { prot. }\right.\end{array}$ \\
\hline \multicolumn{3}{|l|}{ Controles } \\
\hline $\begin{array}{l}100 \mathrm{mg} \mathrm{N}^{-\mathrm{NH}_{4}^{+}}+\mathrm{l} \\
200 \mathrm{mg} \mathrm{N}-\mathrm{NH}_{4}^{+} / \\
300 \mathrm{mg} \mathrm{N}-\mathrm{NH}_{4}^{+} / \\
500 \mathrm{mg} \mathrm{N}_{4} \mathrm{NH}_{4}^{+} /\end{array}$ & $\begin{array}{c}100.0 \pm 2.1 \\
86.5 \pm 1.1 \\
60.6 \pm 1.5 \\
64.7 \pm 0.2\end{array}$ & $\begin{array}{l}0.113 \pm 0.030 \\
0.082 \pm 0.003 \\
0.133 \pm 0.004 \\
0.144 \pm 0.010\end{array}$ \\
\hline
\end{tabular}

Con $5 \mathrm{mg} C-2-C P / 1$

$100 \mathrm{mg} \mathrm{N}-\mathrm{NH}_{4}^{+} / \mathrm{l}$ $200 \mathrm{mg} \mathrm{N}^{-\mathrm{NH}_{4}+/ \mathrm{l}}$ 0.0 $300 \mathrm{mg} \mathrm{N}-\mathrm{NH}_{4}^{+} / \mathrm{l}$ $20.4 \pm 2.2$ 0.0 $500{\mathrm{mg} \mathrm{N}-\mathrm{NH}_{4}{ }^{+} /}^{4} \quad 42.2 \pm 1.9 \quad 0.045 \pm 0.0030$

$\mathrm{E}_{\mathrm{N}-\mathrm{NH} 4^{+}}{ }^{+}$Eficiencia de consumo de amonio, $\mathrm{q}_{\mathrm{N}-\mathrm{NH} 4+}=$ Velocidad especifica de consumo de amonio.

Los ensayos en presencia de 2-CP (tabla 1) mostraron que con $200 \mathrm{mg} \mathrm{N}$ $\mathrm{NH}_{4}{ }^{+} / \mathrm{l}$ la eficiencia de consumo de amonio fue $76 \%$ menor que en el ensayo 
control, mientras que con $300 \mathrm{mg} \mathrm{N}-\mathrm{NH}_{4}{ }^{+} / /$la eficiencia de consumo disminuyó $55 \%$, finalmente con $500 \mathrm{mg}$ de amonio la eficiencia de consumo de amonio decreció solo $35 \%$ todo en referencia con su respectivo ensayo control. Lo que indica que el incremento en la concentración de amonio puede repercutir favorablemente en la mejora de la eficiencia de consumo del mismo cuando esta presente el 2-CP.

En la figura 1 se presentan los perfiles de incremento de consumo de amonio en los ensayos en presencia de $5 \mathrm{mg} \mathrm{C-2-CP/l}$ así como el ajuste con el modelo de Gompertz que presentó una $r^{2}$ promedio de 0.90 (anexo 1). Cuando la concentración de amonio ensayada fue de $100 \mathrm{mg} \mathrm{N}-\mathrm{NH}_{4}{ }^{+} / \mathrm{l}$, no se detectó consumo de amonio durante el tiempo de cultivo. Pérez-Alfaro y col. (2013), utilizando lodos nitrificantes sin contacto previo con 2-CP y con $100 \mathrm{mg} \mathrm{N}$ $\mathrm{NH}_{4}^{+} /$, también reportaron un consumo nulo de amonio en presencia de $5 \mathrm{mg}$ de C-2-CP/l y a lo largo 40 días de cultivo. Al ensayar con una concentración de $200 \mathrm{mg} \mathrm{N}-\mathrm{NH}_{4}{ }^{+} / \mathrm{l}$, el comportamiento del consorcio cambió ya que pudo observarse consumo de amonio (alrededor de $34 \mathrm{mg} / \mathrm{l}$ ), pero se requirió de una fase de retardo de aproximadamente $1.09 \mathrm{~h}$. Con $300 \mathrm{mg} \mathrm{N}-\mathrm{NH}_{4}{ }^{+} / \mathrm{l}$, la fase de retardo disminuyó a $0.6 \mathrm{~h}$ y se consumieron cerca de $80 \mathrm{mg} \mathrm{N}-\mathrm{NH}_{4}^{+} / \mathrm{l}$. El consumo de amonio aumentó, cuando se probó con una concentración de 500 $\mathrm{mg} \mathrm{N}-\mathrm{NH}_{4}{ }^{+} / /$, en este caso no se detectó fase de retardo en el consumo y la concentración de amonio consumido aumentó a $212 \mathrm{mg} \mathrm{N}-\mathrm{NH}_{4}^{+} / \mathrm{l}$ aproximadamente, al final del tiempo de cultivo.

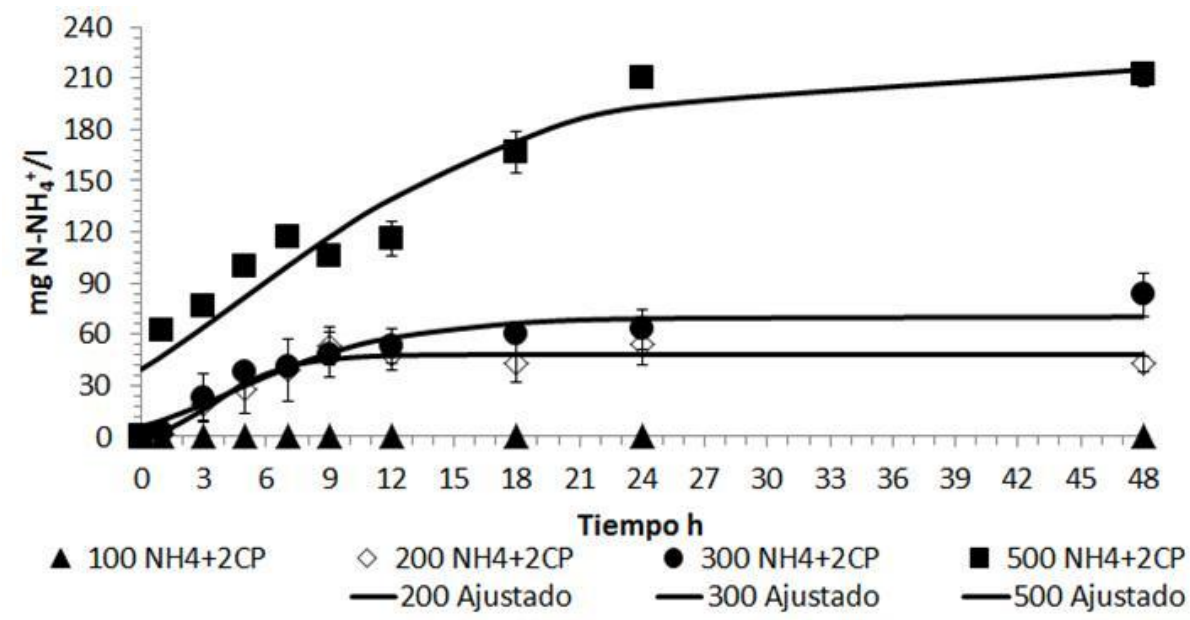

Figura 1. Perfiles en el incremento de consumo de $100,200,300$ y $500 \mathrm{mg} \mathrm{N}^{-\mathrm{NH}_{4}} / / \mathrm{l}$ en presencia de $5 \mathrm{mg} \mathrm{C-2-CP/l}$. Las líneas representan el ajuste del modelo de Gompertz a los perfiles obtenidos. 
Debe resaltarse que se observó consumo de amonio prácticamente de forma inmediata, mientras el 2-CP estaba presente en el medio, lo cual no ha sido reportado para un lodo nitrificante sin contacto previo a compuestos aromáticos, como el usado en estos ensayos. Es también de gran importancia que se haya observado consumo de amonio en presencia de 2-CP sólo cuando la concentración de amonio se incrementó, ya que esto puede ser un indicativo de que el 2-CP puede tener un efecto sobre la membrana celular, lo que puede repercutir en el transporte de amonio. Se ha reportado que en bacterias Gram negativas como E. coli, el transporte de amonio puede ocurrir por dos tipos de mecanismos: i) por difusión pasiva, el cual se realiza a favor de un gradiente de concentración (Mathews 2003), por lo que, generalmente es observado a altas concentraciones de amonio (Burkovski 2003); o ii) mediante transportadores especiales de amonio realizado mediante proteínas transportadoras, o por difusión facilitada, que ocurre por mediadores conocidos como canales iónicos o permeasas y no requiere energía (Soupene y col., 2002; Mathews 2003). Considerando que las bacterias nitrificantes como Nitrosomonas europaea son Gram negativas, es posible que la presencia de 2-CP alterara el mecanismo por el cual el amonio es transportado. Compuestos aromáticos como benceno, cresoles o incluso más complejos como los esteroides, poseen la capacidad de alterar la estructura de la membrana, haciéndola más fluida o más rígida (Sikkema y col., 1993; Radnieki y col. 1997). Entonces, al incrementar la concentración de amonio, el transporte de éste probablemente se realizó de una forma diferente. La evaluación cinética del consumo de amonio, mostró que las velocidades específicas de consumo en todos los ensayos en presencia de 2-CP, presentaron una disminución significativa del 65, 81 y 68\% con respecto a las $\mathrm{q}_{\mathrm{N}-\mathrm{NH} 4}{ }^{+}$obtenidas en los ensayos sin 2-CP (tabla 1). Esta disminución podría ser atribuida al daño en el sistema de transporte de amonio hacia la célula y/o a una inhibición enzimática.

Además de ser consumido el amonio, éste fue oxidado principalmente a nitrito y nitrato. En la figura 2 se muestran los perfiles de producción de nitrato en presencia de 2-CP y los ajustes con el modelo de Gompertz (con $r^{2}$ superior a 0.71 , anexo 1). Mientras que en el ensayo control sin 2-CP se observó la producción de $100 \mathrm{mg} \mathrm{N}-\mathrm{NO}_{3}{ }^{-} / /$después de $48 \mathrm{~h}$ de cultivo, con la misma 
concentración de amonio (100 $\left.\mathrm{mg} \mathrm{N}^{-\mathrm{NH}_{4}+} / \mathrm{l}\right)$, pero en presencia de $5 \mathrm{mg} \mathrm{C}-2-$ $\mathrm{CP} / \mathrm{l}$, no se observó producción de nitrato. El incremento de la concentración de amonio a $200 \mathrm{mg} \mathrm{N}-\mathrm{NH}_{4}{ }^{+} / \mathrm{l}$, permitió la detección de nitrato $(20 \mathrm{mg} / \mathrm{l})$ pero se requirió de una fase de retardo de aproximadamente $3 \mathrm{~h}$ para iniciar su producción. En los ensayos con $300 \mathrm{mg} \mathrm{N}-\mathrm{NH}_{4}{ }^{+} / /$, la concentración de nitrato aumentó a $42 \mathrm{mg} / \mathrm{l}$ y la fase de retardo disminuyó a $1.1 \mathrm{~h}$. Cuando la concentración de amonio aumentó a $500 \mathrm{mg} \mathrm{N}-\mathrm{NH}_{4}^{+} /$, la concentración de nitrato se incrementó cerca de los $130 \mathrm{mg} / \mathrm{l}$. A lo largo del tiempo de cultivo que fue de $48 \mathrm{~h}$ también se detectó nitrito. La presencia de estos compuestos como productos principales de la oxidación de amonio es una clara evidencia de que la presencia de 2-CP no inhibe inmediatamente la ruta metabólica nitrificante como se ha reportado en la literatura, ya que el consorcio nitrificante puede mantener activas las rutas amonio y nitrito oxidantes en presencia de este compuesto.

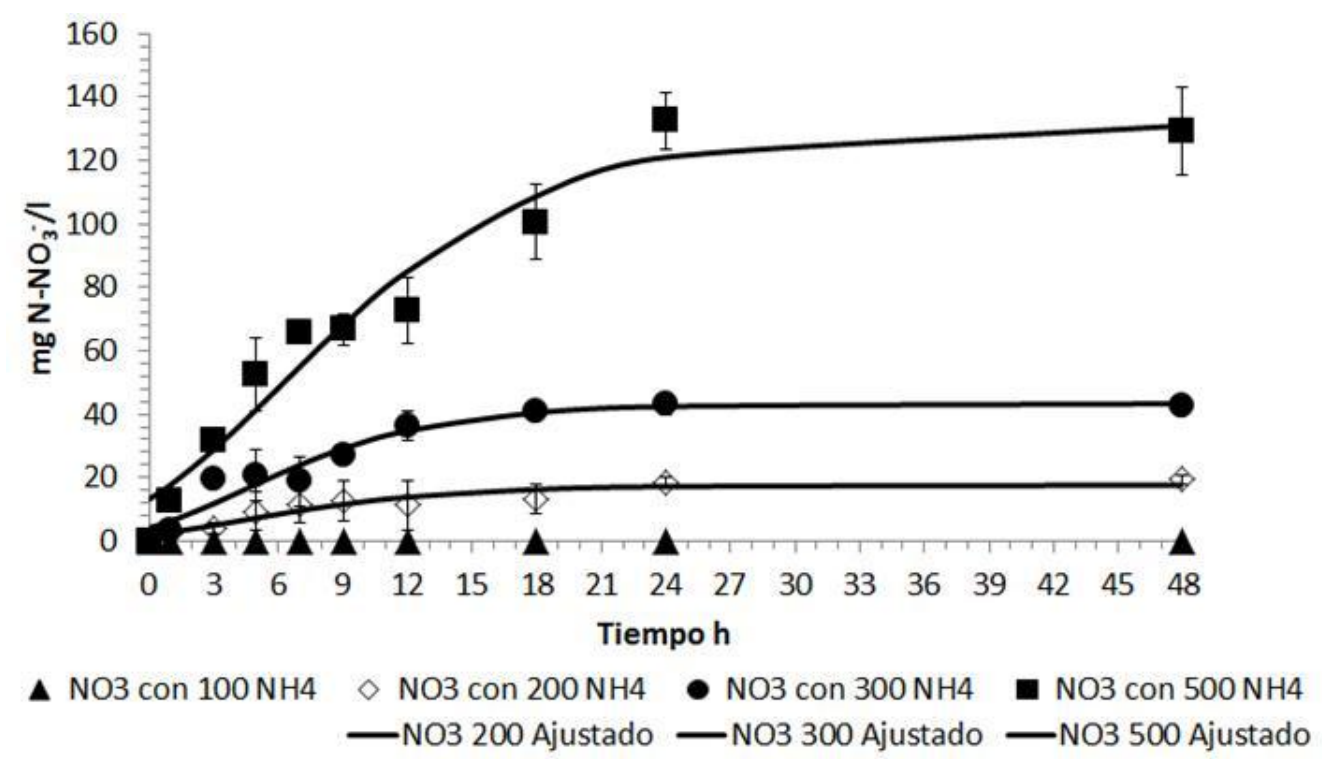

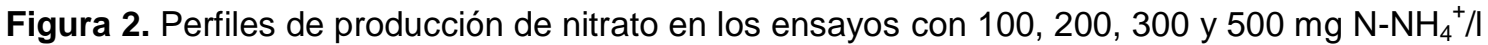
en presencia de $5 \mathrm{mg} \mathrm{C}-2-\mathrm{CP} / \mathrm{l}$. Las líneas representan el ajuste del modelo de Gompertz a los perfiles obtenidos.

En la tabla 2 se muestran los valores de los rendimientos de producción de nitrito y nitrato $\left(\mathrm{Y}_{\mathrm{N}-\mathrm{NO2}}{ }^{-}\right.$y $\left.\mathrm{Y}_{\mathrm{N}-\mathrm{NO} 3}{ }^{-}\right)$y velocidades específicas de producción de ambos compuestos ( $\left.\mathrm{q}_{\mathrm{N}-\mathrm{NO} 2} \mathrm{q}_{\mathrm{N}-\mathrm{NO} 3}{ }^{-}\right)$, obtenidos en los ensayos control ( $\sin 2-\mathrm{CP}$ ) $y$ en presencia de 2-CP. En los ensayos control se muestra que el amonio consumido es transformado mayoritariamente a nitrato y se detectó una 
fracción menor de nitrito. Con lo que puede decirse que la actividad amonio y nitrito oxidante se realizó de manera adecuada bajo las condiciones ensayadas. Además se observó un metabolismo netamente desasimilativo, pues no se detectó aumento significativo en la concentración de biomasa.

En los ensayos con $100 \mathrm{mg} \mathrm{N}-\mathrm{NH}_{4}{ }^{+} / /$y 2-CP, no hubo consumo de amonio, por lo tanto no se detectó producción de nitrito y nitrato. En el ensayo con $200 \mathrm{mg}$ $\mathrm{N}-\mathrm{NH}_{4}{ }^{+} /$l, se registró producción de nitrato pero no de nitrito y el rendimiento de nitrato fue $53 \%$ menor que en su respectivo ensayo control. Con $300 \mathrm{mg} \mathrm{N}$ $\mathrm{NH}_{4}{ }^{+} / /$el rendimiento de producción de nitrito fue de 0.09 y el de nitrato de 0.97 en este caso el rendimiento de nitrato fue $39 \%$ menor respecto a su control, pero en comparación con el ensayo con $200 \mathrm{mg} \mathrm{N}-\mathrm{NH}_{4}{ }^{+} / \mathrm{l}$ el rendimiento de producción de nitrato aumento $28 \%$. Finalmente con $500 \mathrm{mg} \mathrm{N}-\mathrm{NH}_{4}{ }^{+} / \mathrm{l}$ el rendimiento de nitrato disminuyó $35 \%$ en comparación con el control. Las velocidades específicas de producción de nitrito y nitrato muestran una disminución promedio de 73 y 84\%, en comparación con los ensayos control (tabla 2), lo que podría indicar además de un posible efecto en el transporte de sustratos, un efecto inhibitorio sobre la actividad de las enzimas que participan en el proceso nitrificante. Resultados semejantes se han reportado para distintos compuestos como BTX (Zepeda y col., 2003), p-cresol (Silva y col., 2009) y el mismo 2-CP (Pérez-Alfaro y col., 2013). Sin embargo este es el primer trabajo donde se reporta producción de nitrito y nitrato aún en presencia de 2-CP.

Tabla 2. Variables de respuesta para la producción de nitrito y nitrato con 100, 200, 300 y 500 $\mathrm{mg} \mathrm{N}-\mathrm{NH}_{4}{ }^{+} / /$en presencia y ausencia de $5 \mathrm{mg} \mathrm{C}-2 \mathrm{CP} / \mathrm{l}$.

\begin{tabular}{|c|c|c|c|c|}
\hline Ensayo & $Y_{\mathrm{N}-\mathrm{NO} 2}^{-}$ & $Y_{\mathrm{N}-\mathrm{NO} 3}{ }^{-}$ & $\begin{array}{l}q_{\mathrm{N}-\mathrm{NO} 2}^{-} \\
\left(\mathrm{mg} \mathrm{N}^{-} \mathrm{NO}_{2}^{-} / \mathrm{mg}_{\text {prot. }} \text { ) }\right.\end{array}$ & $\begin{array}{l}q_{\mathrm{N}-\mathrm{NO} 3}^{-} \\
\left(\mathrm{mg} \mathrm{N}-\mathrm{NO}_{3}^{-} / \mathrm{mg} \text { prot. } \mathrm{h}\right)\end{array}$ \\
\hline \multicolumn{5}{|l|}{ Controles } \\
\hline $100 \mathrm{mg} \mathrm{N}-\mathrm{NH}_{4}^{+} / \mathrm{I}$ & ND & $1.00 \pm 0.10$ & ND & $0.051 \pm 0.001$ \\
\hline $200 \mathrm{mg} \mathrm{N}-\mathrm{NH}_{4}{ }^{+} / \mathrm{I}$ & $0.06 \pm 0.01$ & $0.98 \pm 0.03$ & $0.010 \pm 0.001$ & $0.069 \pm 0.005$ \\
\hline 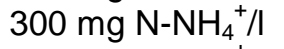 & $0.09 \pm 0.03$ & $0.97 \pm 0.01$ & $0.037 \pm 0.002$ & $0.095 \pm 0.004$ \\
\hline 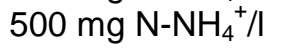 & $0.07 \pm 0.06$ & $0.98 \pm 0.04$ & $0.022 \pm 0.004$ & $0.124 \pm 0.006$ \\
\hline \multicolumn{5}{|l|}{ Con $5 \mathrm{mg} C-2-C P / l$} \\
\hline $100{\mathrm{mg} \mathrm{N}-\mathrm{NH}_{4}{ }^{+} / \mathrm{I}}^{-}$ & 0.0 & 0.0 & 0.0 & 0.0 \\
\hline 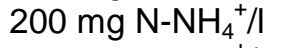 & ND & $0.46 \pm 0.04$ & ND & $0.005 \pm 0.001$ \\
\hline 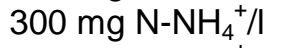 & $0.27 \pm 0.05$ & $0.59 \pm 0.01$ & $0.005 \pm 0.0002$ & $0.014 \pm 0.003$ \\
\hline $500 \mathrm{mg} \mathrm{N}-\mathrm{NH}_{4}^{+} / \mathrm{I}$ & $0.33 \pm 0.01$ & $0.64 \pm 0.01$ & $0.009 \pm 0.0001$ & $0.030 \pm 0.003$ \\
\hline
\end{tabular}


Consumo de amonio en presencia de 2-clorofenol utilizando extractos libres de células.

Aunque se observó consumo de amonio y actividad nitrificante en presencia de 2-CP, la cinética del proceso continuó afectada. A fin de obtener más información al respecto, se emplearon extractos libres de células para evaluar la nitrificación en presencia de 2-CP. La figura 3a muestra la cinética control con los extractos libres de células ( $\sin 2-\mathrm{CP}$ ) así como el ajuste de los datos al modelo de Gompertz con ajustes $\left(r^{2}\right)$ de 0.89 (anexo 1). El extracto libre de células presentó actividad a lo largo de $24 \mathrm{~h}$, periodo durante el cual se detectó consumo de amonio desde el inicio. Además hubo una acumulación transitoria de nitrito que desapareció al final del cultivo, siendo el nitrato el producto principal del ensayo.
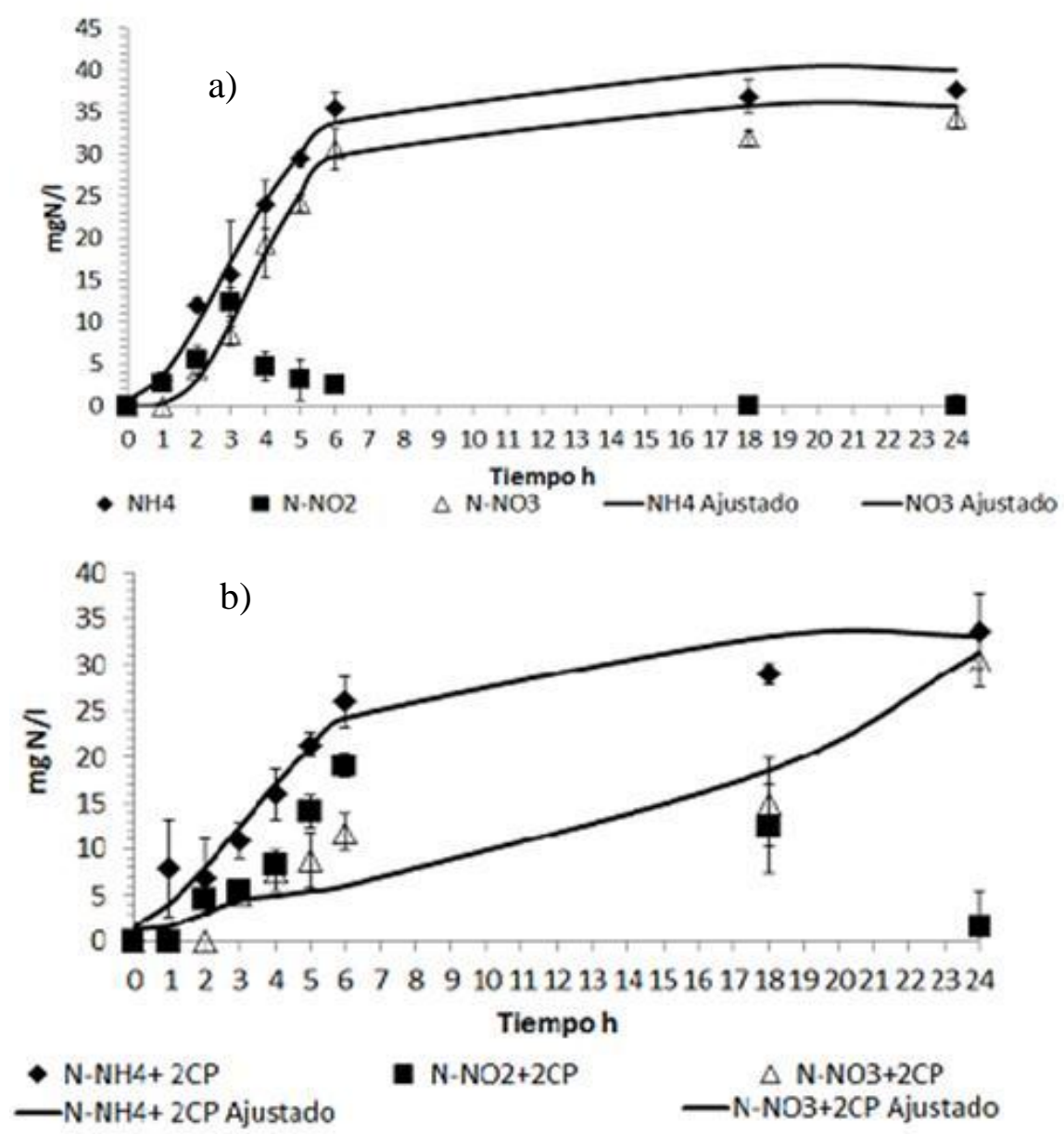

Figura 3. Muestra los perfiles de incremento de consumo y producción de los compuestos nitrogenados, obtenidos en los ensayos con extractos libres de células. Donde a) son los ensayos $\sin 2$-CP y b) con 2-CP. El ajuste del modelo de Gompertz a los perfiles obtenidos se representa por las lineas. 
En la figura 3b se muestran los perfiles de incremento de consumo de amonio y producción de nitrito y nitrato obtenidos con los extractos libres de células en presencia de 2 -CP tras $24 \mathrm{~h}$ de cultivo. Se observó nuevamente que el consumo de amonio es inmediato. El nitrito se acumuló pero al final del cultivo su concentración fue muy baja por lo que podría considerarse que al igual que en el control también fue un producto transitorio. Sin embargo que se haya mantenido durante más tiempo en el medio podría ser indicativo de un efecto adverso por parte del 2-CP sobre la nitrito oxidación ya que esta etapa oxidativa puede ser sensible a la materia orgánica (Pérez-Alfaro 2010). Este comportamiento muestra que al eliminar la membrana celular, es posible observar consumo de amonio con una concentración de $100 \mathrm{mg} \mathrm{N}-\mathrm{NH}_{4}{ }^{+} / /$y en presencia de 2-CP, lo cual no ocurre con células completas.

La tabla 3 muestra las variables de respuesta calculadas para los ensayos con extracto libres de células. Al hacer un comparativo entre los ensayos con células completas y $\sin 2$-CP se pudo observar que la eficiencia de consumo de amonio en los ensayos $\sin 2$-CP fue $66 \%$ menor que en los ensayos con células completas pero se obtuvo un rendimiento de nitrato de 0.93 es decir el amonio consumido fue principalmente oxidado a nitrato. La velocidad específica de consumo de amonio fue $20 \%$ menor que en los ensayos con células completas pero se observó un incremento de $29 \%$ en la velocidad específica de producción de nitrato. Dicho incremento pudo deberse a que mientras en las células completas la velocidad de consumo de nitrito depende de la velocidad de producción de este en la etapa de amonio oxidación, para después salir de la célula y llegar al microorganismo nitrito oxidante. Cuando se tienen extractos libres de células esto no es necesario ya que el sustrato de la nitrito oxidación puede estar rápidamente disponible para su oxidación.

Se ha reportado que con extractos obtenidos a partir de cultivos puros de Nitrosomonas europea, las velocidades específicas resultaron $90 \%$ menores a las obtenidas con células completas, y la actividad nitrificante solo se mantuvo durante aproximadamente 4h (Suzuki y col., 1981; Ensing y col., 1993). En el presente trabajo, el extracto obtenido conservo cerca del $80 \%$ de su actividad, presentó una velocidad específica de producción de nitrato superior a las 
células completas y además mantuvo actividad durante un tiempo más prolongado que otros extractos reportados en la literatura.

Haciendo una comparación entre los extractos sin 2-CP y con 2-CP las variables de respuesta (tabla 3) permitieron determinar que no hay una diferencia significativa en la eficiencia de consumo de amonio. Tanto en los ensayos sin 2-CP como en presencia de 2-CP. La producción de nitrito es transitoria, pero con 2-CP se el nitrito se mantiene por más tiempo en el medio de cultivo. Mientras que al parecer la presencia de 2-CP solo afectó levemente la producción de nitrato ya que solo disminuyó $4 \%$.

Tabla 3. Variables de respuestas calculadas para los ensayos con los extractos libres de células en presencia y ausencia de 2-CP.

\begin{tabular}{|c|c|c|c|c|c|}
\hline Ensayo & $\begin{array}{c}E_{\mathrm{N}-\mathrm{NH} 4^{+}} \\
(\%)\end{array}$ & $Y_{\mathrm{N}-\mathrm{NO} 2^{-}}$ & $Y_{\mathrm{N}-\mathrm{NO} 3^{-}}$ & $\begin{array}{l}q_{\mathrm{N}-\mathrm{NH} 4}^{+} \\
m g \mathrm{~N}-\mathrm{NH}_{4}^{+} / \mathrm{mg} \\
\text { prot.h }\end{array}$ & $\begin{array}{l}q_{\mathrm{N}-\mathrm{NO} 3}^{-} \\
m g \mathrm{~N}-\mathrm{NO}_{3}^{-} / \mathrm{mg} \\
\text { prot.h }\end{array}$ \\
\hline$\frac{\frac{\text { Células }}{\text { completas }}}{\underline{\text { sin } 2-C P}}$ & $100 \pm 2.1$ & ND & $1.00 \pm 0.09$ & $0.095 \pm 0.030$ & $0.049 \pm 0.001$ \\
\hline $\begin{array}{l}\text { Extractos } \\
\underline{\sin 2-C P}\end{array}$ & $34.1 \pm 1.1$ & ND & $0.93 \pm 0.03$ & $0.076 \pm 0.003$ & $0.063 \pm 0.001$ \\
\hline$\frac{\text { Extractos }}{\text { con } 2-C P}$ & $33.6 \pm 1.4$ & $0.03 \pm 0.01$ & $0.89 \pm 0.01$ & $0.045 \pm 0.003$ & $0.039 \pm 0.0005$ \\
\hline
\end{tabular}

Las velocidades específicas del proceso también se afectaron ya que la $\mathrm{qN}_{\mathrm{N}-\mathrm{NH}^{+}}{ }^{+}$ y la $\mathrm{q}_{\mathrm{N}-\mathrm{NO} 3^{-}}$disminuyeron aproximadamente un 40 y $38 \%$, respectivamente. Lo que una vez más podría indicar que la presencia de 2-CP si podría tener efecto sobre la actividad enzimática tanto de la ruta amonio oxidante como nitrito oxidante.

\section{Conclusiones}

Se encontró que cuando la concentración de amonio se incrementó de 100 a 200, 300 y $500 \mathrm{mg} \mathrm{N}-\mathrm{NH}_{4}{ }^{+} /$es posible llevar a cabo la nitrificación, en presencia de 2-CP incluso con un consorcio nitrificante sin previa exposición a algún compuesto aromático semejante. Se obtuvo un extracto libre de células que conservó actividad nitrificante durante 24 horas. Con este extracto fue posible observar el consumo y oxidación de amonio de manera inmediata, aun 
en presencia de $5 \mathrm{mg} \mathrm{C}-2 \mathrm{CP} / \mathrm{l}$. Este es el primer reporte donde se muestra que la actividad nitrificante puede mantenerse activa en presencia de 2-CP.

Como resultado de estos ensayos se puede sugerir que el 2-CP afecta la membrana celular de los microorganismos del consorcio nitrificante repercutiendo en el transporte de amonio y las enzimas nitrificantes al disminuir sus velocidades específicas tanto de consumo como de producción, siendo la actividad amonio oxidante la más afectada.

\section{Referencias}

1. Aleem M. I. H. y Alexander M. (1958). Cell free nitrification by Nitrobacter agile. Bacteriol.Proc. pp 510-514.

2. Bejarano Ortiz. D. I., Thalasso F., Cuervo-Lopez F.M. and Texier A-C. (2013). Inhibitory effect of sulfide on the nitrifying respiratory process $J$ Chem. Technol. Biotechnol. ; 88: pp.1344-1349.

3. Beristain-Cardoso, R., Texier, A-C., Sierra-Álvarez, R., Razo-Flores, E., Field, J., Gómez, J. (2009). Effect of initial sulfide concentration on sulfide and phenol oxidation under denitrifying conditions. Chemosphere. 74, 200-205.

4. Bernal, P.; Segura, A.; Ramos, J. L. (2007). Compensatory role of thecistrans-isomerase and cardiolipin synthase in the membranefluidity of Pseudomonas putida DOT-T1E. Environ. Microbiol., 9 (7), 1658-1664.

5. Burkovski A. (2003). I do it my way: regulation of ammonium uptake and ammonium assimilation in Corynebacterium glutamicum. Arch. Microbiol. 179, pp.83-88.

6. Ensing S. A., Hyman M. R., y Arp, D. J. (1993). In Vitro Activation of Ammonia Monooxygenase from Nitrosomonas europaea by Copper J. of Bacteriol. Vol. 175, No. 7 p. 1971-1980.

7. Guckert, J. B. Hood, M. A. y White D. C. (1986). Phospholipid EsterLinked Fatty Acid Profile Changes during Nutrient Deprivation of Vibrio cholerae: Increases in the trans/cis Ratio and Proportions of Cyclopropyl Fatty Acids. Applied and Environmental Microbiology. Vol. 52, No. 4. pp. 794-801. 
8. Hintze, J., NCSS and PASS (2001) Number Cruncher Statistical Systems. Kaysville. www.ncss.com

9. Juliette L.Y., Hyman M.R. y Arp D. J. (1995). Roles of Bovine Serum Albumin and Copper in the Assay and Stability of Ammonia Monooxygenase Activity In Vitro. Journal of Bacteriology, Vol. 177, No. 17. p. 4908-4913.

10. Keener W and Arp D.J. (1994). Transformation of aromatics compounds by Nitrosomonas europaea. Appl. Microbiol. 60: 1914-1920.

11.Lowry O.H., Rosen Brough N.J. and Randall R.J. (1951). Protein measurement with the folin phenol reagent J. Biol. Chem. 198, 265-275.

12. Martínez-Hernández S, Texier AC, Cuervo-López F.M. and Gómez J. (2011). 2-Chlorophenol consumption and its effect on the nitrifying sludge. J. Hazard. Mater. 185: 1592-1595.

13. Mathews C. K.; Van Holde, K.E; Ahern, K.G. (2003). Bioquímica (3rd ed.). ISBN 84-7829-053-2.

14. McCarty G.W. (1999). Modes of action of nitrification inhibitors. Biol. Fertil. Soils. 29,1-9.

15. Merrick M. J. y Edwars R. A. (1995). Nitrogen Control in Bacteria. Microbiological reviews. pp. 604-622.

16. Pérez-Alfaro J. E. Buitrón G. Gomez J. Texier A.-C. Cuervo-López F. M. (2013). Kinetic and Physiological Evaluation of Ammonium and Nitrite Oxidation Processes in Presence of 2-Chlorophenol. Appl. Biochem. Biotechnol. 169(3). pp. 990-1000

17.Pérez-González D, Gómez J., Beristain-Cardoso R. (2012). Biological removal of $\mathrm{p}$-cresol, phenol, $\mathrm{p}$-hydroxybenzoate and ammonium using a nitrifying continuous-flow reactor Bioresource Technology 120 194-198.

18. Radniecki, T. Dolan M. y Semprini L. (2008). Physiological and Transcriptional Responses of Nitrosomonas europaea to Toluene and Benzene Inhibition. Environ. Sci. Technol. 42. pp. 4093-4098.

19. Rasche M. E., Hyuman M. R. y Arp D. J. (1990). Biodegradation of Halogenated Hydrocarbon Fumigants by Nitrifying Bacteria. Applied and environmental microbiology. Vol. 56, No. 8. pp. 2568-2571. 
20. Schmidt I. y Bock E. (1998). Anaerobic ammonia oxidation by cell-free extracts of Nitrosomonas eutropha. Antonie van Leeuwenhoek 73. pp 271-278.

21.Segura, A.; Duque, E.; Rojas, A.; Godoy, P.; Delgado, A.; Hurtado,A.; Cronan, J. E.; Ramos, J. L. (2004). Fatty acid biosynthesis is involved in solvent tolerance in Pseudomonas putida DOT-T1E. Environ. Microbiol. $6(4), 416-423$.

22. Sikkema J, de Bont JAM. and Poolman B. (1995). Mechanisms of membrane toxicity of hydrocarbons. Microbial Reviews 59(2): 201-222.

23. Silva CD, Gómez J, Beristain-Cardoso R. (2011). Simultaneous removal of 2-chlorophenol, phenol, p-cresol and p-hydroxybenzaldehyde under nitrifying conditions: Kinetic study. Bioresour. Technol. 102: 6464-6468.

24. Silva CD, Gómez J, Houbron E, Cuervo-López FM and Texier AC. (2009). p-Cresol biotransformation by a nitrifying consortium. Chemosphere 75: 1387-1391.

25. Soupene, E, Lee H, Kustu S. (2002). Ammonium/methylammonium transport (Amt) proteins facilitate diffusion of $\mathrm{NH}_{3}$ bidirectionally. Proc Natl. Acad. Sci. USA 99:3926-3931.

26. Suzuki, I., Kwok, S.C., Dular, U. y Tsang, D.C.Y. (1981). Cell-free ammonia-oxidizing system of Nitrosomonas europaea: general conditions and properties. Can. J. Biochem. 59, pp 477-483.,

27. Texier AC, and Gomez J. (2007). Simultaneous nitrification and p-cresol oxidation in a nitrifying sequencing batch reactor. Water. Res. 41: 315322.

28. Weber, F. J.; de Bont, J. A. M. (1996). Adaptation mechanisms of microorganisms to the toxic effects of organic solvents on membranes. Biochim. Biophys. Acta, 1286, 225-245.

29. Wood, P. M. (1986). Nitrification as a bacterial energy source. In J. I.Prosser (ed.), Nitrification. Society for General Microbiology, Washington,D.C. p. 39-62

30.Zepeda A, Texier AC, Razo-Flores E, Gomez J. (2006). Kinetic and metabolic study of benzene, toluene and $\mathrm{m}$-xylene in nitrifying batch cultures. Water. Res. 40: 1643-1649. 
31.Zwietering M. H. Jongenburger I., Rombouts F. M., and Van 't riet. K. (1990). Modeling of the Bacterial Growth Curve. Applied and Environmental Microbiology, 56 (6) pp. 1875-1881. 
7.3.- Aumento en la velocidad de consumo de 2clorofenol en un consorcio nitrificante: participación de la amonio monooxigenasa. 


\title{
Aumento en la velocidad de consumo de 2- clorofenol en un consorcio nitrificante: participación de la amonio monooxigenasa.
}

\author{
J.E. Pérez-Alfaro ${ }^{a}$, G. Buitrón ${ }^{b}$, A.-C. Texier ${ }^{a}$ and F.M. Cuervo-López ${ }^{* a}$. \\ ${ }^{a}$ Departamento de Biotecnología, Universidad Autónoma Metropolitana-Iztapalapa. D.F \\ Iztapalapa CP 09340, México. 'Unidad Académica Juriquilla Instituto de Ingeniería. Universidad \\ Nacional Autónoma de México, Querétaro 76230 Querétaro México D.F. México. *E-mail: \\ fmcl@xanum.uam.mx Teléfono:-(52) 55 58046408. Fax-(52) 5558046407.
}

\section{Resumen}

En un consorcio nitrificante con capacidad de consumir 2-clorofenol (2-CP), se evaluó fisiológica y cinéticamente en cultivos en lote, la participación de las enzimas amonio monooxigenasa (AMO) y nitrito óxido reductasa (NOR) en el consumo de este compuesto mediante inhibidores específicos de dichas enzimas (aliltiourea y clorato de sodio). Asimismo, se evaluó el efecto de diferentes concentraciones de amonio (100, 200, 300 y $500 \mathrm{mg} \mathrm{N}-\mathrm{NH}_{4}^{+} /$l) en el consumo de 2-CP. Se encontró que al inhibir la enzima AMO la velocidad específica de consumo de 2-CP disminuyó 50\% lo que muestra la posible participación de la AMO en el consumo del 2-CP. Al inhibir la NOR no se observó cambio significativo en la velocidad específica de consumo de 2-CP indicando que esta enzima nitrificante no estaría involucrada en el consumo del compuesto fenólico. En comparación con los ensayos con $100{\mathrm{mg} \mathrm{N}-\mathrm{NH}_{4}}^{+} /$, donde se requiere de una fase de retardo de 18.5 días y de 35 días para consumir totalmente el 2-CP, cuando se ensayó con una

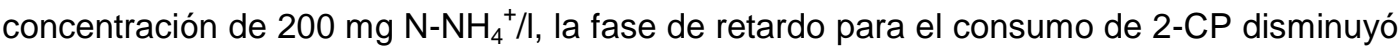

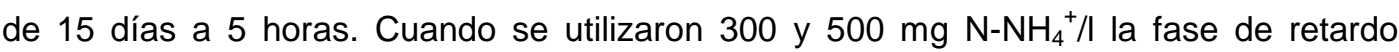

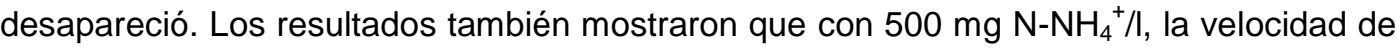
consumo de 2-CP se incrementó 1.4 veces en comparación con el ensayo con 200 mg N$\mathrm{NH}_{4}{ }^{+} /$l. Dichos resultados mostraron que al aumentar la concentración de amonio, se favoreció el consumo de $2-\mathrm{CP}$, sugiriendo que dicho consumo podría darse por cometabolismo. Estos resultados pueden ofrecer la posibilidad de tratar efluentes contaminados con altas concentraciones de amonio y compuestos aromáticos recalcitrantes como el 2-clorofenol.

Palabras clave: 2-clorofenol, nitrificación, amonio monoxigenasa, cometabolismo, aliltiourea, clorato de sodio.

\section{Introducción}

El consumo y la biodegradabilidad de compuestos fenólicos en efluentes, suelos o aguas subterráneas, se ha reportado en diversos trabajos y con diferentes esquemas de biotratamientos, como pueden ser sistemas aerobios, 
anaerobios o una combinación de ambos (Field y Sierra-Álvarez, 2007). A pesar de la estabilidad termodinámica que otorga el anillo bencénico de estas moléculas, existe una amplia diversidad de bacterias que pueden mineralizarlos (Gibson y Harwood, 2001; Vaillancourt y col., 2004). Bajo condiciones aerobias o nitrificantes puede consumirse una variedad relativamente amplia de compuestos aromáticos, desde benceno (Zepeda y col., 2003), fenol (Amor y col., 2005), cresoles (Silva y col., 2011), p-hidroxibelzaldehido y $p$ hidroxibenzoato (Beristain Cardoso y col., 2011; Pérez-González y col., 2012), entre otros. En el caso de los clorofenoles, Baker y Mayfield (1980), reportan la degradación de 2-, 3-,y 4-clorofenol; 2,4-, 2,6- y 3,4-diclorofenol; 2,4,6-, y 2,4,5triclorofenol; e incluso el pentaclorofenol por varias rutas metabólicas. En estas rutas, las enzimas mono o di oxigenasas son muy importantes, pues son las primeras que reaccionan con el anillo aromático produciendo generalmente clorocatecoles como intermediarios de la oxidación de 2-clorofenol (2-CP) 0 3,4-diclorofenol (Farrell y Quilty 2002). En el caso de los fenoles policlorados como el penta-clorofenol, generalmente son convertidos a clorohidroquinonas (Solyanikova y Golovleva, 2004).

No obstante que existe evidencia del consumo de clorofenoles en condiciones aerobias, compuestos como el 3,4,5-triclorofenol o el 2,3,4,5-tetraclorofenol no son degradados en dichas condiciones (Field y Sierra-Álvarez, 2007). En condiciones nitrificantes se ha observado el consumo de compuestos como el 2-CP al utilizar cultivos que han sido expuestos a compuestos aromáticos durante varios meses (Silva y col., 2011). En tanto que, con microorganismos nitrificantes sin aclimatación previa, el tiempo de consumo del 2-CP puede ser de varias semanas. Estudios realizados por Martínez-Hernández y col. (2011) y Pérez-Alfaro y col. (2013), utilizando un consorcio nitrificante sin contacto previo a compuestos aromáticos y adicionado con $5 \mathrm{mg} \mathrm{C}-2-\mathrm{CP} / \mathrm{l}$ y $100 \mathrm{mg}$ de $\mathrm{N}-\mathrm{NH}_{4} / \mathrm{l}$, mostraron que, después de una fase de retardo de 15 días, el consorcio tiene la capacidad de consumir 2-CP y se requieren 40 días para lograr el consumo completo del compuesto.

Una de las estrategias implementadas para lograr o mejorar el consumo de compuestos recalcitrantes como los aromáticos es el cometabolismo, que se entiende como la transformación biológica de un sustrato, que no se utiliza para 
crecimiento de la bacteria, a través de enzimas que pueden ser inducidas o activadas por un sustrato de crecimiento (sustrato primario o co-sustrato), el cual provee la energía para el crecimiento y mantenimiento de la célula (Kokameni 2010) y funcionamiento de las enzimas catalíticas (Wang y Loh., 1999). Además existen varios estudios donde para favorecer el consumo de 2$\mathrm{CP}$, se utilizan compuestos análogos como el fenol (Cobos-Vasconcelos y col., 2006; Loh y Wu, 2006; Beristain Montiel y col., 2010). Bestetti y col. (1992), reporta que en cultivos con Pseudomonas putida el metilestireno actúa como co-sustrato en la oxidación de 2- y 4-clorofenol. Se propone que este tipo de compuestos, son inductores de enzimas mono o di oxigenasas que oxidan los clorofenoles (Field y Sierra-Álvarez, 2007). También se ha reportado que el uso de azúcares como la glucosa, puede soportar el cometabolismo del 4-CP, ya que permite generar el NADH requerido para la función de las oxigenasas (Wang y Loh, 1999), así como para la disminución de la fase de retardo para el consumo de 4-CP (Tobajas y col., 2012). Asimismo, Haider y col. (1974), han reportado el uso de azúcares como co-sustrato en la oxidación de 2-CP, mientras que Fakhruddin y Quilty (2005), encontraron que en microorganismos como Pseudomonas putida, la velocidad de consumo de 2-CP puede incrementarse en presencia de $1 \%$ de fructosa.

En condiciones nitrificantes con Nitrosomonas europaea, donde el amonio es el sustrato primario, se ha reportado el cometabolismo de compuestos como el tricloroetileno, dicloroetano y cloroformo (Arciero y col., 1989; Ely y col., 1995,1997; Álvarez- Cohen y Speitel 2001; Alpaslan Kocamemi y Çeçen 2005). Nevalainen y col. (1993), utilizando amonio como sustrato primario, observaron la oxidación de 2,4,6-triclorofenol hasta su mineralización, en un lapso de 20 a 30 días. Considerando entonces que el amonio pudiese actuar como sustrato primario para soportar la oxidación de compuestos aromáticos, y que además se ha reportado la capacidad de la enzima amonio monooxigenasa (AMO) presente en microorganismos nitrificantes, para oxidar materia orgánica de tipo alifática y aromática, el presente trabajo estuvo enfocado en dos puntos: Observar si las enzimas nitrificantes, la amonio monooxigenasa y la nitrito óxidorreductasa, tienen participación en el consumo de 2-clorofenol; y evaluar 
bajo condiciones nitrificantes, el comportamiento cinético del consumo de 2clorofenol al utilizar diferentes concentraciones de amonio.

\section{Materiales y métodos}

\section{Fuente de inóculo}

El lodo utilizado como inóculo en los ensayos en lote fue obtenido de un reactor de tanque agitado de 6 litros de volumen de trabajo, alimentado en continuo con una velocidad de carga de amonio de $280 \mathrm{mg} \mathrm{N}-\mathrm{NH}_{4}{ }^{+} / \mathrm{l}$, a temperatura ambiente y $\mathrm{pH}$ entre 6.6 y 7.5 con un tiempo de residencia hidráulico de 1.4 días. El reactor contó con un sedimentador y recirculador de biomasa y se mantuvo con una concentración de oxígeno disuelto de aproximadamente 5 $\mathrm{mg} / \mathrm{l}$. El medio de cultivo utilizado fue dividido en fuente de nitrógeno $(A)$ y carbono (B), y su composición fue la siguiente $(\mathrm{g} / \mathrm{l})$ : $(\mathrm{A})$ : $\left(\mathrm{NH}_{4}\right)_{2} \mathrm{SO}_{4}(1.18)$, $\mathrm{NH}_{4} \mathrm{Cl}$ (0.96), $\mathrm{KH}_{2} \mathrm{PO}_{4}$ (1.40), $\mathrm{MgSO}_{4}$ (0.60), $\mathrm{NaCl}$ (1.0). (B): (9.33) y $\mathrm{CaCl}_{2}$ (0.05). Bajo estas condiciones y a lo largo de 80 días de operación, el lodo nitrificante permaneció en estado estacionario nitrificante con una eficiencia de consumo de amonio de 99\%, así como un rendimiento de producción de $\mathrm{N}$ $\mathrm{NO}_{3}{ }^{-}$de 1 , por lo que el lodo proveniente de este reactor fue utilizado como inóculo en los cultivos en lote, después de ser lavado con solución salina 3 veces.

\section{Cultivos nitrificantes control}

Como control de la nitrificación, se realizaron ensayos en lote en botellas serológicas de $160 \mathrm{ml}$ de capacidad con $100 \mathrm{ml}$ de volumen de trabajo y $60 \mathrm{ml}$ de espacio de cabeza. La composición del medio de cultivo fue la siguiente en $\mathrm{mg} / \mathrm{l}: \mathrm{KH}_{2} \mathrm{PO}_{4}(7), \mathrm{MgSO}_{4}$ (0.005), $\mathrm{NaCl}$ (5), $\mathrm{NaHCO}_{3}$ (437) y $\mathrm{CaCl}_{2}$ (2.5) N$\mathrm{NH}_{4}{ }^{+}$(100). Se burbujeó oxígeno en las botellas durante dos minutos, se inocularon con aproximadamente $200 \pm 3.1 \mathrm{mg}$ de proteína bacteriana/l, proveniente del reactor nitrificante de tanque agitado en estado estacionario. Las botellas se sellaron y nuevamente se introdujo oxígeno durante dos minutos. El pH del medio fue de $7.0 \pm 0.4$, la temperatura de $30{ }^{\circ} \mathrm{C}$ y la agitación de 200 rpm. El tiempo de cultivo fue de 48 horas. Se tomaron 
muestras independientes a diferentes tiempos para obtener el perfil de consumo y producción de compuestos nitrogenados.

Consumo de C-2-CP en presencia de inhibidores de la amonio y nitrito oxidación

En botellas serológicas de $160 \mathrm{ml}$ de capacidad y $100 \mathrm{ml}$ de volumen de trabajo y bajo condiciones semejantes a las descritas en los cultivos nitrificantes control, se corroboró la capacidad inhibitoria de aliltiourea $(40 \mathrm{mg} / \mathrm{l})$ como inhibidor específico de la enzima amonio monooxigenasa y clorato de sodio (80 $\mathrm{mg} / \mathrm{l}$ ) como inhibidor de la enzima nitrito óxido reductasa, de acuerdo a lo reportado por Silva y col. (2009) y Hynes y Knowles (1983). El ensayo tuvo una duración de 40 días y las condiciones fueron semejantes a las utilizadas en los ensayos control. Tras verificar la inhibición de las respectivas actividades amonio y nitrito oxidantes, se evaluó la capacidad del lodo para consumir 2-CP, para lo cual, a cada ensayo se le adicionaron $5 \mathrm{mg} \mathrm{C}-2-\mathrm{CP} / \mathrm{l}$, se sometieron a las mismas condiciones que las descritas en los ensayos nitrificantes control, con $100 \mathrm{mg} \mathrm{N}-\mathrm{NH}_{4}{ }^{+} / \mathrm{l}$ o $100 \mathrm{mg} \mathrm{N}-\mathrm{NO}_{2}{ }^{-} / /$como fuentes de nitrógeno y se adicionó aliltiourea o clorato de sodio como inhibidores. Los ensayos se realizaron por duplicado y se tomaron muestras independientes a diferentes tiempos durante 40 días de cultivo.

\section{Consumo de 2-clorofenol en presencia de altas concentraciones de amonio}

Con un tratamiento experimental semejante al realizado en los ensayos control, se evalúo el consumo de $5 \mathrm{mg}$ C-2-CP/l por el consorcio nitrificante sin contacto previo a 2-clorofenol, utilizando diferentes concentraciones de nitrógeno de amonio (100, 200, 300 y $\left.500 \mathrm{mg} \mathrm{N}-\mathrm{NH}_{4}{ }^{+} / \mathrm{l}\right)$. Para este caso, se utilizaron, botellas serológicas de $500 \mathrm{ml}$ de volumen nominal, con $100 \mathrm{ml}$ de volumen de trabajo y $400 \mathrm{ml}$ de espacio de cabeza, a fin de asegurar que el contenido de oxígeno en las unidades experimentales fuera el necesario para oxidar el amonio y 2-CP presente en el medio. Cada botella se inoculó con una concentración promedio de proteína de aproximadamente de $223 \pm 7 \mathrm{mg} / \mathrm{l}$. El $\mathrm{pH}$ del medio fue de $7.0 \pm 0.4$, la temperatura de $30^{\circ} \mathrm{C}$ y la agitación de 200 rpm. El ensayo tuvo una duración de 48 horas y se tomaron muestras independientes cada 3 horas durante el tiempo de cultivo. 


\section{Métodos analíticos}

El 2-clorofenol se determinó por HPLC (Perkin Elmer serie 200) utilizando una columna C-18 fase reversa (Varian Crompack) y un detector UV-visible a una longitud de onda de $274 \mathrm{~nm}$. Se utilizó una fase móvil compuesta por acetonitrilo y agua (60:40, v:v), a un flujo de $1.5 \mathrm{ml} / \mathrm{min}$. La fase móvil fue filtrada $(0.45 \mu \mathrm{m})$ y desgasificada. La concentración de amonio se cuantificó utilizando un electrodo selectivo de amoniaco (Phoenix electrode Co), acoplado a un potenciómetro (Cole-parmer, DigiSense) como lo reporta Pérez-Alfaro y col., (2013). Para la detección de nitrito y nitrato se utilizó un cromatógrafo de líquidos (HPLC, Perkin Elmer serie 200) con una columna de intercambio iónico (Waters IC-pak HC) y un detector UV-visible de acuerdo a lo reportado por Silva y col., (2009). Todas las diluciones se hicieron con agua desionizada y las soluciones fueron filtradas por una membrana de $0.45 \mu \mathrm{m}$.

Para las lecturas de oxígeno disuelto se utilizó un medidor de oxígeno disuelto (Hanna, HI 98186) con un electrodo polarográfico (HI76407/4F). El pH fue medido mediante un medidor portátil (Digi-Sense, Cole Palmer) acoplado a un electrodo combinado de calomel y vidrio.

\section{Evaluación de la respuesta del cultivo y análisis estadístico}

La respuesta fisiológica y cinética del cultivo nitrificante se evaluó mediante variables de respuesta como eficiencia de consumo de $\mathrm{N}-\mathrm{NH}_{4}{ }^{+}\left(\mathrm{E}_{\mathrm{N}-\mathrm{NH} 4}{ }^{+}\right)$y de 2$\mathrm{CP}\left(\mathrm{E}_{2-\mathrm{CP}}\right)$, rendimiento de producción de $\mathrm{N}-\mathrm{NO}_{2}{ }^{-}\left(\mathrm{Y}_{\mathrm{N}-\mathrm{NO} 2}{ }^{-}\right)$y de $\mathrm{N}-\mathrm{NO}_{3}{ }^{-}\left(\mathrm{Y}_{\mathrm{N}-\mathrm{NO}}{ }^{-}\right)$, y velocidades específicas de consumo de $\mathrm{N}_{-} \mathrm{NH}_{4}{ }^{+}\left(\mathrm{q}_{\mathrm{N}-\mathrm{NH} 4}{ }^{+}\right)$y de $2-\mathrm{CP}\left(\mathrm{q}_{2-\mathrm{CP}}\right)$, así como velocidades específicas de producción de $\mathrm{N}^{-\mathrm{NO}_{2}}{ }^{-}\left(\mathrm{q}_{\mathrm{N}-\mathrm{NO}}{ }^{-}\right)$y de $\mathrm{N}$ $\mathrm{NO}_{3}^{-}\left(\mathrm{Y}_{\mathrm{N}-\mathrm{NO}}{ }^{-}\right)$.

Las velocidades específicas de consumo de 2 -CP (q) y las fases de retardo $(\lambda)$, se calcularon mediante la función de Gompertz (Zwietering y col., 1990) y el paquete estadístico Number Cruncher Statistical System (NCSS) (Hintze, 2001), de acuerdo a la ecuación 1. En este modelo, el consumo de 2-CP puede ser expresado como una función del tiempo, para lo cual, se calcularon los incrementos en el consumo del 2-CP (mg/l) a lo largo del tiempo de experimentación.

$$
Y=A \exp (-\exp (-B((t)-C)))
$$


Donde $\boldsymbol{Y}$ es la concentración de 2-CP consumida (mg $\mathrm{C} / \mathrm{l}$ ), $\boldsymbol{A}$ es la concentración máxima de 2-CP consumida ( $\mathrm{mg} \mathrm{C}$ ) cuando t tiende a infinito; $\boldsymbol{C}$ es el tiempo de inflexión, mientras que $\boldsymbol{B}$ es la velocidad volumétrica de consumo de 2-CP ( $m g / l d)$ y $\boldsymbol{t}$ el tiempo (d) (NCSS, 2001). Se utilizó el programa NCSS para analizar y ajustar los datos en la función de Gompertz obteniéndose los valores de los coeficientes de $\boldsymbol{A}, \boldsymbol{B} \boldsymbol{y} \boldsymbol{C}$, los coeficientes de regresión $\left(r^{2}\right)$ y la significancia del modelo (anexo 1). Con los coeficientes obtenidos se calculó la velocidad máxima (vmax) de consumo (ecuación 2) posteriormente se calculó la velocidad específica de consumo $\left(\mathrm{q}_{2-\mathrm{CP}}\right)$ de cada caso (ecuación 3 ). La fase de retardo ( $\lambda$ ) fue calculada como lo muestra la ecuación 4.

vmax $=\frac{A \cdot B}{\text { exp }}$

$q=\frac{\text { vmax }}{\text { concentración de proteína }}$

$\lambda=\frac{B C-1}{B}$

Las velocidades de consumo de 2-CP obtenidas en presencia y ausencia de los inhibidores, se compararon entre sí utilizando las pruebas estadísticas de homogeneidad de coeficientes en modelos de regresión (Martínez y Castillo, 1987). Mediante el paquete estadístico NCSS. De acuerdo a la ecuación 5, donde $B$ y $B$ ' son los valores del coeficiente $B$ calculado en el modelo de Gompertz y corresponden al ensayo control y los ensayos con inhibidores específicos respectivamente. $S^{2}$ es valor del error del coeficiente $B$ en el ensayo control y $S^{2}$ son los valores del error del coeficiente B' en los ensayos con inhibidores específicos de la amonio y nitrito oxidación. Los valores de los parámetros se presentan en el anexo 2 .

$t=\frac{B-B \prime}{\sqrt{S^{2+} S^{2 \prime}}}$

\section{Resultados}

Participación de las enzimas nitrificantes amonio monooxigenasa (AMO) y nitrito óxido reductasa (NOR) en el consumo de 2-clorofenol.

Ensayos nitrificantes control con y sin inhibidores: En los ensayos control sin

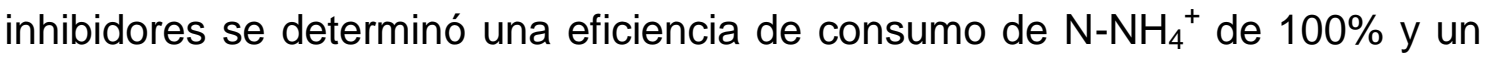


rendimiento de producción de nitrato de 1, mientras que la velocidad específica de consumo de $\mathrm{N}-\mathrm{NH}_{4}{ }^{+}$fue de $0.12 \mathrm{mg} \mathrm{N}-\mathrm{NH}_{4}{ }^{+} / \mathrm{mg}$ proteína $\mathrm{h}$ y la velocidad específica de producción de $\mathrm{N}-\mathrm{NO}_{3}{ }^{-}$fue de $0.11 \mathrm{mg} \mathrm{N}-\mathrm{NO}_{3}{ }^{-} / \mathrm{mg}$ proteína $\mathrm{h}$. Estos resultados indican que los procesos de amonio y nitrito oxidación se llevaron a cabo adecuadamente. Los ensayos nitrificantes realizados con aliltiourea y clorato de sodio indicaron que a lo largo de 40 días de cultivo, no se observó consumo de amonio ni de nitrito, respectivamente, con lo cual se corroboró la eficacia de los compuestos inhibitorios seleccionados.

En la figura 1, se muestra el perfil de incremento en el consumo de 2-CP a lo largo del tiempo de cultivo en los ensayos sin inhibidores, con amonio y aliltiourea como inhibidor de la AMO y con nitrito y clorato de sodio como inhibidor de la NOR, todos ellos en presencia de $5 \mathrm{mg} \mathrm{C-2-CP/l,} \mathrm{así} \mathrm{como} \mathrm{el}$ ajuste de cada uno de estos con el modelo de Gompertz (en todos los casos el ajuste con este modelo fue mayor a 0.95 , anexo 2). Se puede observar que en los tres ensayos, el 2-CP se consumió totalmente. En el ensayo de referencia sin inhibidores, el perfil de consumo presentó una fase de retardo de aproximadamente 18.5 días, tras la cual inició el consumo de 2-CP. En un término de 35 días el cultivo consumió la totalidad de este compuesto. En el ensayo donde la NOR es inhibida por el clorato de sodio, también se presentó una fase de retardo, en este caso de 19.2 días y se requirió de 35 días para consumir totalmente el 2-CP.

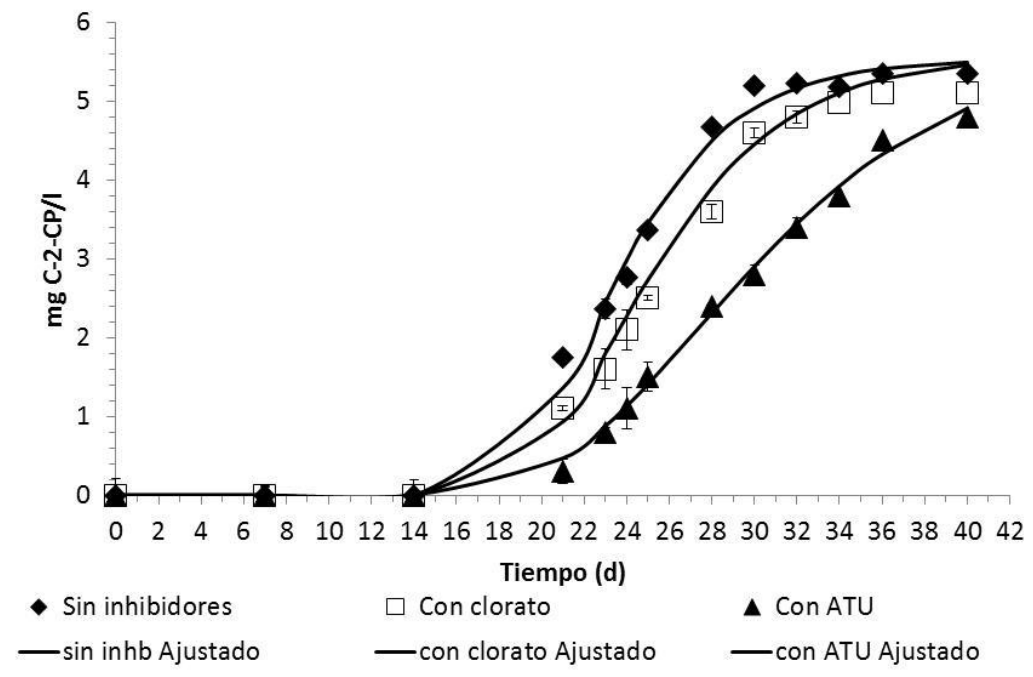

Figura 1.- Perfil de incremento en el consumo de $5 \mathrm{mg} \mathrm{C-2-CP/l} \mathrm{en} \mathrm{ausencia} \mathrm{y} \mathrm{presencia} \mathrm{de}$ inhibidores específicos de la amonio y nitrito oxidación y el ajuste con el modelo de Gompertz. 
El análisis estadístico para probar la homogeneidad de coeficientes (anexo 1) indicó que no existe diferencia significativa entre la velocidad de consumo observada en los ensayos control sin inhibidores y la velocidad específica de consumo de 2-CP donde se adicionó clorato de sodio como inhibidor de la nitrito óxido reductasa. Lo que podría ser evidencia de que la enzima NOR no participa en el consumo de 2-CP.

Cuando la AMO fue inhibida por la aliltiourea, la fase de retardo resultó más prolongada, ya que tuvo una duración de 20.4 días y el consumo total de los 5 mg C-2-CP/l se observó hasta los 40 días de cultivo, se determinó que la q2-CP disminuye más del 50\%. Esta disminución en la velocidad específica de consumo de 2-CP en presencia de aliltiourea permite sugerir que la AMO sí tiene participación en el consumo del 2-CP. El análisis estadístico para probar la homogeneidad de coeficientes (anexo 2) muestra que hay una diferencia significativa entre las velocidades de consumo obtenidas en el ensayo sin inhibidores y la obtenida en el ensayo con aliltiourea $(\alpha=0.02)$, lo cual puede ser indicativo de la participación de la $\mathrm{AMO}$ en el consumo del compuesto clorado. Se ha reportado en cultivos de Nitrosomonas europaea, que la AMO puede oxidar compuestos alifáticos y aromáticos halogenados 0 no halogenados, como metilbromuro, 1,2-dicloropropano, 1,2-dibromo-3cloropropano, tricloro etileno, etano, cloropropano, tolueno, benceno y fenol (Rasche y col., 1990; Keener y Arp 1994; Hyman y col., 1995; Alvarez-Cohen y Spietel 2001). Asimismo, en consorcios nitrificantes, también ha sido observada la oxidación de fenol, benceno, 2-CP y acetato entre otros compuestos (Zepeda y col., 2003; Beristain-Cardoso y col., 2011; Pérez González y col., 2012).

En contraste, Silva y col. (2009), quienes al inhibir con allitiourea la actividad de la AMO en un consorcio microbiano nitrificante capaz de consumir $p$-cresol, encontraron que el compuesto aromático fue consumido en un tiempo y velocidad semejante con y sin la AMO inhibida, descartando así la participación de la $\mathrm{AMO}$ en el consumo del $p$-cresol. 
Tabla 1.- Variables de respuestas en los ensayos con inhibidores específicos de la AMO y NOR.

\begin{tabular}{lcc}
\hline \multicolumn{1}{c}{ Ensayo } & $\begin{array}{l}\text { Eficiencia de } \\
\text { consumo } \\
(\%)\end{array}$ & $\begin{array}{l}\text { Velocidad específica de } \\
\text { consumo } \\
\text { (mg C-2-CP/mg prot. } \boldsymbol{d})\end{array}$ \\
\hline $\mathbf{5 ~ m g ~ 2 C P}$ en presencia & & \\
de: & & \\
Sin inhibidores (control) & $100 \pm 2.1$ & $0.0025 \pm 0.0001$ \\
Clorato de sodio & $100 \pm 1.1$ & $0.0022 \pm 0.0003$ \\
Aliltiourea & $100 \pm 1.5$ & $0.0012 \pm 0.0001$ \\
\hline
\end{tabular}

En la ruta metabólica aerobia propuesta para el 2-CP, la oxidación de éste a 2clorocatecol es catalizada por la enzima catecol-oxigenasa. Posteriormente ocurre el rompimiento del anillo aromático para ser finalmente integrado al ciclo de Krebs (Farrel y Quilty 2000). Se ha propuesto que cualquier microorganismo que posea una mono o dioxigenasa, tiene el potencial de oxidar compuestos aromáticos clorados (Ward y col. 1997). También se ha reportado que la enzima AMO, posee afinidad por compuestos alifáticos clorados como el dicloro etilieno, tricloro etileno e incluso el cloroformo (Ely y col., 1996). Tomando en consideración los resultados obtenidos en el presente trabajo, indicando la participación de la $\mathrm{AMO}$ en el consumo de 2-CP, es posible proponer que la AMO podría estar involucrada en la primera reacción de oxidación del 2-CP a clorocatecol. Sin embargo deben realizarse más estudios para corroborar esta posibilidad.

Efecto de la concentración de $\mathrm{N}_{-} \mathrm{NH}_{4}^{+}$en el consumo de 2-CP

La figura 2 muestra los perfiles de incremento en el consumo de 2-CP obtenidos en presencia de diferentes concentraciones de amonio, así como el ajuste de cada uno de ellos con el modelo de Gompertz (en todos los casos donde hubo consumo, el ajuste con este modelo fue mayor a 0.90 anexo 2).

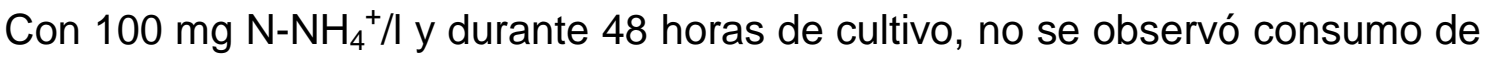
2-CP. Silva y col. (2011), reportaron en ensayos en lote bajo condiciones

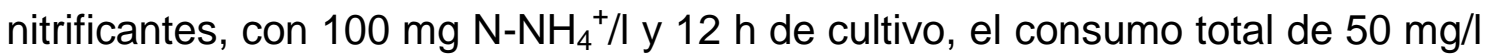
de 2-CP, concentración 10 veces mayor que la usada en el presente trabajo. Sin embargo estos autores utilizaron un consorcio nitrificante aclimatado durante aproximadamente un año a $p$-cresol. Mientras que en el presente trabajo se utilizó un consorcio sin contacto previo con materia orgánica. 
Cuando se incrementó la concentración de amonio a $200 \mathrm{mg} \mathrm{N}-\mathrm{NH}_{4}^{+} / \mathrm{l}$, se detectó consumo de 2-CP. Después de una fase de retardo de $5 \mathrm{~h}$ y durante 48 $\mathrm{h}$ de cultivo se consumieron aproximadamente $2 \mathrm{mg} \mathrm{C}-2-\mathrm{CP} / \mathrm{l}$. En presencia de $300 \mathrm{mg} \mathrm{N}-\mathrm{NH}_{4}{ }^{+} /$, el cambio fue todavía más notable, pues la fase de retardo disminuyó a 1 h y se consumió más del $50 \%$ del 2-CP. Cuando se incrementó la concentración de amonio a $500 \mathrm{mg} \mathrm{N}-\mathrm{NH}_{4}+/ /$, no se detectó fase de retardo y el consumo de 2-CP inicio inmediatamente. Es decir estas condiciones permitieron un comportamiento similar al reportado por Silva y col. (2011) pero sin la necesidad de una fase de adaptación.

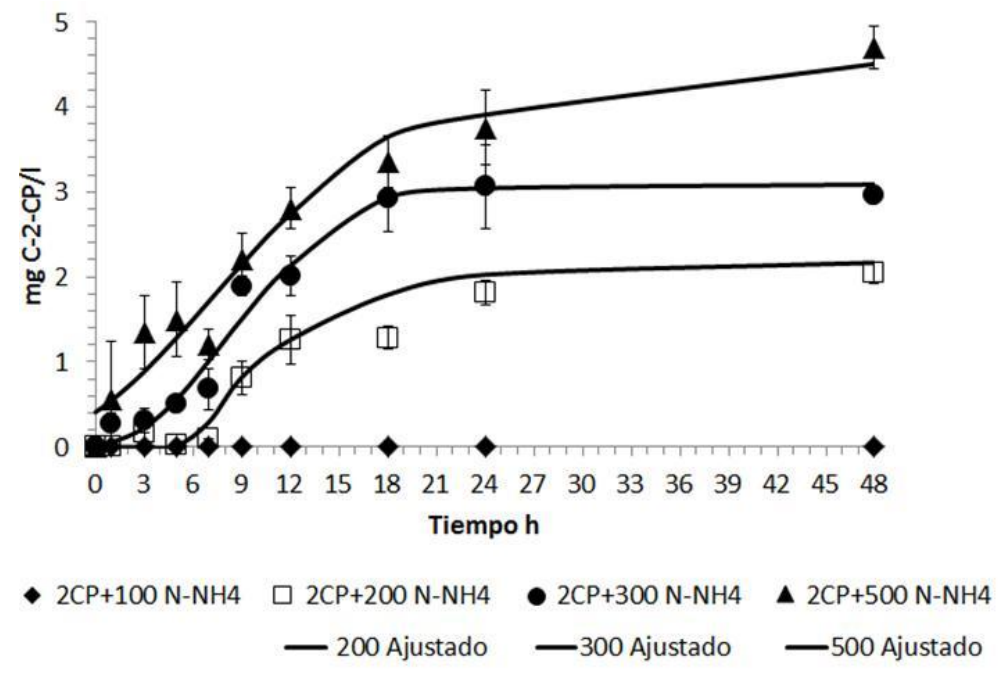

Figura 2.- Perfil de incremento en el consumo de $5 \mathrm{mg} \mathrm{C-2-CP/l}$ en presencia de diferentes concentraciones de amonio bajo condiciones nitrificantes y el ajuste con el modelo de Gompertz.

En la tabla 2 se presentan los parámetros para evaluar el efecto de diferentes concentraciones de amonio en el consumo de 2-CP. La eficiencia de consumo de 2-CP fue de $41 \%$ con $200 \mathrm{mg} \mathrm{N}-\mathrm{NH}_{4}{ }^{+} /$, de $47 \%$ cuando la concentración de amonio se incrementó a $300 \mathrm{mg} \mathrm{N}-\mathrm{NH}_{4}{ }^{+} / \mathrm{l}$. Con $500 \mathrm{mg} \mathrm{N}-\mathrm{NH}_{4}{ }^{+} / / \mathrm{la}$ eficiencia de consumo de 2 -CP aumentó a $88 \%$. Lo cual muestra claramente que el incremento en la concentración de amonio puede contribuir a consumir una concentración significativa del 2-CP en periodos de tiempo mas cortos en relación a los reportados en la literatura, debe señalarse que tras su consumo se detectó por HPLC la formación de un intermediario no identificado.

En lo referente a la evaluación cinética de los ensayos, se encontró que la velocidad específica de consumo de 2 -CP se incrementó 1.4 veces en el

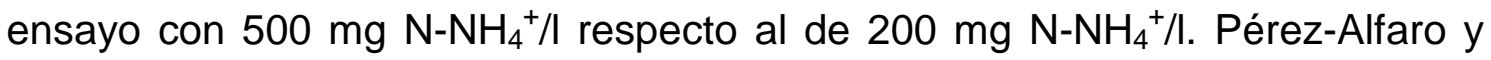


col. (2013) para un cultivo con $100 \mathrm{mg} \mathrm{N}-\mathrm{NH}_{4}{ }^{+} / \mathrm{l}$ reportó una velocidad específica de consumo de 2-CP de $0.023 \mathrm{mg}$ C-2-CP/mg proteína $\mathrm{d}$, requiriendo 40 días de cultivo. Bajo las condiciones ensayadas en este trabajo con $500 \mathrm{mg} \mathrm{N}-\mathrm{NH}_{4}{ }^{+} / /$se pudo alcanzar una velocidad 3 veces mayor $(0.066 \mathrm{mg}$ C-2-CP/mg proteína d) en un periodo de tiempo de solamente $12 \mathrm{~h}$.

Tabla 2.- Variables de respuesta del consumo de 2-CP en un consorcio nitrificante con diferentes concentraciones de $\mathrm{N}-\mathrm{NH}_{4}{ }^{+} / \mathrm{l}$ a las 12 horas de cultivo.

\begin{tabular}{lcc}
\hline \multicolumn{1}{c}{ Ensayo } & $\begin{array}{c}\text { Eficiencia de } \\
\text { consumo } \\
\text { (\%) }\end{array}$ & $\begin{array}{l}\text { Velocidad específica de } \\
\text { consumo } \\
\text { (mg C-2-CP/mg prot. } \boldsymbol{h} \text { ) }\end{array}$ \\
\hline $\begin{array}{l}\text { Concentración de } \\
\text { amonio }\end{array}$ & & \\
$100 \mathrm{mg} \mathrm{N}-\mathrm{NH}_{4}{ }^{+} / \mathrm{l}$ & 0.0 & 0.0 \\
$200 \mathrm{mg} \mathrm{N}-\mathrm{NH}_{4}{ }^{+} / \mathrm{l}$ & $40.9 \pm 2.4$ & $0.00114 \pm 0.00001$ \\
$300 \mathrm{mg} \mathrm{N}-\mathrm{NH}_{4}{ }^{+} / \mathrm{l}$ & $47.1 \pm 2.7$ & $0.00100 \pm 0.00002$ \\
$500 \mathrm{mg} \mathrm{N}-\mathrm{NH}_{4}{ }^{+} / \mathrm{l}$ & $88.6 \pm 3.3$ & $0.00276 \pm 0.00002$ \\
\hline
\end{tabular}

Es posible que el efecto de la concentración de amonio en el consumo de 2-CP esté asociado a diferentes factores. Kocamemi y Çeçen (2007), mencionan que la concentración relativa de amonio es crucial para la degradación cometabólica de compuestos como el tricloroetileno, puesto que la velocidad de degradación del compuesto clorado aumenta con el aumento en la concentración de amonio, ya que este funciona como donador de electrones. Esto podría explicar el aumento en la $q_{2-C P}$ y la ausencia de la fase de retardo encontradas en el presente trabajo cuando se incrementa la concentración a 200, 300 y $500 \mathrm{mg} \mathrm{N}-\mathrm{NH}_{4}{ }^{+} /$. En tal caso, el amonio podría funcionar como sustrato primario y proveer de energía a las enzimas que oxidan el 2-CP, o bien que la concentración de amonio favorezca la inducción de nuevas enzimas por ejemplo la $\mathrm{AMO}$, que de acuerdo con lo obtenido en los ensayos con inhibidores específicos, podrían estar contribuyendo en el consumo de 2-CP. Por otro lado, el aumento en la concentración de amonio podría favorecer el crecimiento de microorganismos heterótrofos que pueden utilizarlo como fuente de nitrógeno. El balance de compuestos nitrogenados muestra que en promedio, $7.5 \%$ del amonio consumido no fue oxidado a nitrito o a nitrato, por lo que pudo ser asimilado y usado como sustrato para el crecimiento y sostenimiento de los microorganismos que consumen el 2-CP. También es probable que ambos escenarios se presenten de forma simultánea. Es decir, 
que a la par del posible crecimiento y participación de los microorganismos heterótrofos en el consumo de 2-CP, se sume la actividad de los microorganismos nitrificantes que posean la AMO. Sin embargo, por el momento no es posible determinar de forma clara cuál de estas alternativas ocurre en las condiciones experimentales utilizadas.

\section{Conclusiones}

Los ensayos con inhibidores selectivos clorato de sodio y aliltiourea muestran que la velocidad de consumo de 2-CP disminuye significativamente cuando la enzima amonio monoxigenasa se encuentra inhibida, lo que permite sugerir que esta enzima participa en la oxidación del 2-clorofenol, indicando que el 2CP podría sumarse a la amplia gama de compuestos con los que dicha enzima puede reaccionar. Además este es el primer reporte donde se evidencia que bajo las condiciones nitrificantes ensayadas, la enzima nitrito óxido reductasa, no tiene participación en el consumo de 2-CP.

Los resultados obtenidos en el presente trabajo muestran claramente que la concentración de amonio en el medio tiene un efecto significativo en el consumo de 2-CP. De hecho, el efecto máximo de la concentración de amonio sobre el consumo de 2-CP se observó con $500 \mathrm{mg} \mathrm{N}-\mathrm{NH}_{4}{ }^{+} / \mathrm{l}$, concentración a la cual no se presenta una fase de retardo y las $\mathrm{q}_{2-\mathrm{CP}}$ incrementan hasta 1.4 veces. Esto puede ser aplicable para el tratamiento de efluentes contaminados con altas concentraciones de amonio y que contengan compuestos tan recalcitrantes como el 2-clorofenol, como por ejemplo, los efluentes provenientes de la industria petroquímica, papelera o de las actividades agronómicas. Asimismo, los resultados indican que los periodos de aclimatación a compuestos recalcitrantes como los aromáticos, podrían ser innecesarios, lo que representaría una disminución en gastos de mantenimiento de los reactores de tratamiento. 


\section{Referencias}

1. Alan Farrell y Brid Quilty (2002). The enhancement of 2-chlorophenol degradation by a mixed microbial community when augmented with Pseudomonas putida CP1. Water Research 36: pp. 2443-2450.

2. Alpaslan Kocamemi, B., \& Çeçen, F. (2007a). Kinetic analysis of the inhibitory effect of trichloroethylene (TCE) on nitrification in cometabolic degradation. Biodegradation, 18, pp. 71-81.

3. Alvarez-Cohen, L., \& Speitel, G. E., Jr. (2001). Kinetics of aerobic cometabolism of chlorinated solvents. Biodegradation, 12, pp. 105-126.

4. Arciero, D., Vannelli, T., Logan, M., \& Hooper, A. B. (1989). Degradation of trichloroethylene by ammonia-oxidizing bacterium Nitrosomonas europaea. Biochemistry and Biophysical Research Communications, 159, pp. 640-643.

5. Baker, M.D., Mayfield, C.I., (1980). Microbial and nonbiological decomposition of chloro phenols and phenol insoil. Water Air Soil Pollut. 13, pp. 411-424.

6. Beristain-Cardoso, R., Texier, A-C., Sierra-Álvarez, R., Razo-Flores, E., Field, J., Gómez, J. (2009). Effect of initial sulfide concentration on sulfide and phenol oxidation under denitrifying conditions. Chemosphere. 74, pp. 200-205.

7. Beristain-Montiel L, Gómez-Hernández J, Monroy-Hermosillo O, CuervoLópez F de M, Ramírez-Vives F. (2010). Methanization and mineralization of 2-chlorophenol by anaerobic digestion. Water Sci Technol.;62(8): pp. 1791-8. doi: 10.2166/wst.2010.461.

8. Bestetti, G., Galli, E., Leoni, B., Pelizzoni, F., Sello, G., (1992). Regioselective hydroxylation of chlorobenzene and chlorophenols by a Pseudomonas putida. Appl. Microbiol. Biotechnol. 37, pp. 260-263. 
9. Cobos-Vasconcelos, D.D.L., Santoyo-Tepole, F., Juarez-Ramirez, C., Ruiz-Ordaz, N., Galindez-Mayer, C.J.J., (2006). Cometabolic degradation of chlorophenols by a strain of Burkholderia in fed-batch culture. Enzyme Microb. Technol. 40, pp. 57-60.

10. Egland, P.G., Gibson, J., Harwood, C.S., (2001). Reductive, coenzyme A-mediated pathway for 3-chlorobenzoate degradation in the phototrophic bacterium Rhodopseudomonas palustris. Appl. Environ.Microbiol. 67, pp. 1396-1399.

11. Ely, R. L., Hyman, M. R., Arp, D. J., Guenther, R. B., \& Williamson, K. J. (1995). A cometabolic kinetics model incorporating enzyme inhibition, inactivation, and recovery: II Trichloroethylene degradation experiments. Biotechnology and Bioengineering, 46, pp. 232-245.

12. Ely, R. L., Williamson, K. J., Hyman, M. R., \& Arp, D. J. (1997). Cometabolism of chlorinated solvents by nitrifying bacteria: kinetics, substrate, interactions, toxicity effects, and bacterial response. Biotechnology and Bioengineering, 54, pp. 520-534.

13. Fakhruddin A. and Quilty B., (2005). The influence of glucose and fructose on degradation of 2-chlorophenol by Pseudomonas putida CP1, World J. Microbiol. Biotechnol. 21 pp. 1541-1548.

14. Field J. A y Sierra-Alvarez R. (2007). Biodegradability of chlorinated aromatic compounds. Science Dossier 12, Euro Chlor, University of Arizona. pp. 1-119.

15. Haider, K., Jagnow, G., Kohnen, R., Lim, S.U., (1974). Degradation of chlorinated benzenes phenols and cyclo hexane derivatives by benzene utilizing and phenol utilizing soil bacteria under aerobic conditions. Archives of Microbiology. 96(3): pp. 183-200.

16. Hintze, J., NCSS and PASS (2001) Number Cruncher Statistical Systems. Kaysville. www.ncss.com 
17. Hyman, M. R., Russell, S. A., Ely, R. L., Williamson, K. J., \& Arp, D. J. (1995). Inhibition, inactivation, and recovery of ammonia-oxidizing activity in cometabolism of trichloroethylene by Nitrosomonas europaea. Applied and Environmental Microbiology, 61(4), pp. 1480-1487.

18. Hynes K. R., Knowles R. (1983). Inhibition of chemoautotrophic nitrification by Sodium Chlorate and sodium chlorite: a reexamination. App. And Environ. Microbiol. pp. 1178-1182.

19. Keener W and Arp D.J. (1994). Transformation of aromatics compounds by Nitrosomonas europaea. Appl. Microbiol. 60: pp.1914-1920.

20. Kocamemi F. Ç, A, Aktaş Ö (2010). Xenobiotics in the Urban Water Cycle: Mass Flows, Environmental Processes, Mitigation and Treatment Strategies, Chapter: 9, Publisher: Springer, Editors: Despo-Fatto Kasinos, Kai Bester, Klaus Bilge Kümmerer, pp.161-178 DOI: 10.1007/978-90-481-3509-7_9 In book.

21.Loh, K.C., Wu, T.T., (2006). Cometabolic transformation of 2chlorophenol and 4-chlorophenol in the presence of phenol by Pseudomonas putida. Can. J. Chem. Eng. 84, pp. 356-367.

22. Martínez G., A,: Castillo. M., A. (1987). Teoría de la Regresión con aplicación agronómica. Ed. Colegio de Posgraduados. México. 490 p.

23. Martínez-Hernández S, Texier AC, Cuervo-López F.M. and Gómez J. (2011). 2-Chlorophenol consumption and its effect on the nitrifying sludge. J. Hazard. Mater. 185: pp. 1592-1595.

24. Nevalainen I, Eszti K, Nurmiaho-Lassila E-L, Puhakka J y SalkinohanSalonen(1993). Dechloration of 2,4,6-tricholorophenol by a nitrifying biofilm. Wat, Res, Voi. 27, No. 5, pp. 757-767.

25. Pérez-Alfaro J. E. Buitrón G. Gomez J. Texier A.-C. Cuervo-López F. M. (2013). Kinetic and Physiological Evaluation of Ammonium and Nitrite Oxidation Processes in Presence of 2-Chlorophenol. Appl. Biochem. Biotechnol. 169(3). pp. 990-1000. 
26. Pérez-González D.N, Gómez J. Beristain-Cardoso (2012). Biological removal of $p$-cresol, phenol, p-hydroxybenzoate and ammonium using a nitrifying continuous-flow reactor. Biores. Technol. (120). pp. 194-198.

27. Sikkema J, de Bont JAM. and Poolman B. (1995). Mechanisms of membrane toxicity of hydrocarbons. Microbial Reviews 59(2): pp.201222.

28. Silva CD, Gómez J, Beristain-Cardoso R. (2011). Simultaneous removal of 2-chlorophenol, phenol, p-cresol and p-hydroxybenzaldehyde under nitrifying conditions: Kinetic study. Bioresour. Technol. 102: pp.64646468.

29. Silva CD, Gómez J, Houbron E, Cuervo-López FM and Texier AC. (2009). p-Cresol biotransformation by a nitrifying consortium. Chemosphere 75: pp.1387-1391.

30.Solyanikova, I.P., Golovleva, L.A., (2004). Bacterial degradation of chlorophenols: Pathways, biochemica, and genetic aspects. J. Environ. Sci. Health Part B-Pestic. Contam. Agric. Wastes 39, pp.333-351.

31. Texier AC, and Gomez J. (2007). Simultaneous nitrification and p-cresol oxidation in a nitrifying sequencing batch reactor. Water. Res. 41: pp. 315-322.

32. Tobajas M, Monsalvo V. M, Mohedano A. F, Rodriguez J. J. (2012). Enhancement of cometabolic biodegradation of 4-chlorophenol induced with phenol and glucose as carbon sources by Comamonas testosterone. Journal of Environmental Management. 95 S116eS121.

33. Vaillancourt, F. H., J. T. Bolin, y L. D. Eltis. (2004). Ring-cleavage dioxygenases. Pseudomonas, vol. 3. Kluwer Academic/Plenum Publishers, New York. pp. 359-395.

34. Wang, S.J., Loh, K.C., (1999). Facilitation of cometabolic degradation of 4-chlorophenol using glucose as an added growth substrate. Biodegradation 10, pp. 261-269. 
35.Zwietering M. H. Jongenburger I., Rombouts F. M., and Van 't riet. K. (1990). Modeling of the Bacterial Growth Curve. Applied and Environmental Microbiology, 56 (6) pp. 1875-1881. 


\section{Conclusiones y Recomendaciones}




\section{0.- Conclusiones generales}

Los resultados obtenidos en este trabajo mostraron que cuando la fuente de nitrógeno es el amonio, el proceso nitrificante en presencia de 2-clorofenol puede ser inhibido totalmente incluso con $2.5 \mathrm{mg} / \mathrm{l}$ de este compuesto. Por el contrario cuando el nitrito es la fuente principal de nitrógeno, si puede observarse consumo de nitrito y producción de nitrato aun en presencia de 10 $\mathrm{mg} / \mathrm{l}$ de 2-CP. Lo que indica que la etapa amonio oxidante es la más afectada por la presencia de dicho compuesto. El consorcio nitrificante puede recuperar su actividad amonio oxidante pero solo de manera parcial, ya que las velocidades específicas tanto de consumo de amonio y nitrito, como de producción de nitrito y nitrato, no alcanzan los valores obtenidos en consorcios sin contacto previo con el 2-CP.

Los datos generados permiten sugerir que el 2-CP afecta el transporte de amonio hacia la célula. En general las eficiencias, los rendimientos y las velocidades específicas del proceso aumentan cuando la concentración de amonio se incrementa. Sin embargo, las velocidades específicas de consumo registradas son inferiores a las reportadas en los cultivos $\sin 2-\mathrm{CP}$. Los ensayos realizados con extractos libres de células mostraron que al parecer, el efecto negativo que el 2-CP provoca en la nitrificación puede ser tanto a nivel de transporte de sustratos como de una inhibición a nivel enzimático, siendo la enzima amonio monooxigenasa la que se ve afectada.

Los ensayos con inhibidores de las enzimas nitrificantes mostraron que sin la actividad de la AMO la velocidad de consumo de 2-CP se ve disminuida más del $50 \%$. Esto indica que la amonio monooxigenasa tiene participación en el consumo de 2-CP.

Se mostró que el 2-CP puede ser consumido por el consorcio microbiano nitrificante en concentraciones desde 2.5 hasta $10 \mathrm{mg} / \mathrm{l}$ de 2-CP. Para esto se requiere de fases de retardo entre 10 y 30 días y entre 30 y 80 días para lograr el consumo de 2.5 y hasta $10 \mathrm{mg} / \mathrm{l}$ de $2-\mathrm{CP}$ respectivamente. En todos los casos se detectó un intermediario que hasta el momento no fue posible identificar. 
El incremento en la concentración de amonio en el medio de cultivo impacta de manera positiva la capacidad del lodo nitrificante para consumir $2-\mathrm{CP}$, ya que con $500 \mathrm{mgN}^{-\mathrm{NH}_{4}}+/ \mathrm{l}$ no se requieren fases de retardo y podría disminuir drásticamente el tiempo de consumo de 2-CP de 30 días a solo unas horas. Esto permitiría la eliminación simultánea de altas concentraciones de amonio presentes en efluentes provenientes de la industria petroquímica, papelera o de las actividades agrícolas y de compuestos recalcitrantes como los clorofenoles, sin la necesidad de periodos largos de aclimatación de los lodos a los compuestos aromáticos o la utilización de cepas específicas degradadoras de compuestos orgánicos 


\section{1.- Recomendaciones}

Tras el análisis y discusión de los resultados obtenidos así como de la metodología y diseño experimental utilizados para la realización de este trabajo se hacen las siguientes recomendaciones:

Sería recomendable continuar con los ensayos en lote utilizando altas concentraciones de amonio, ya que debe recabarse más información para poder entender qué sucede con el transporte de amonio en el proceso nitrificante. Es decir, si se logra entender cómo es que compuestos como el 2$\mathrm{CP}$ afectan la membrana y por ende el transporte de sustratos, podrían implementarse estrategias puntuales que permitan disminuir o incluso evitar dicho efecto. La evaluación podría realizarse en un reactor de lotes secuenciados (SBR) donde podrían obtenerse mejoras en el proceso a nivel metabólico y cinético e incluso se podría sugerir la eliminación de concentraciones de 2-CP superiores a la utilizada en este trabajo.

Es también recomendable hacer un seguimiento de los cambios en la abundancia de la amonio monooxigenasa y otras oxigenasas en general. Es decir observar si su número se incrementa con el aumento de la concentración de amonio en el medio. Es probable que este estudio, permita entender de mejor manera, las diferencias encontradas en la respuesta fisiológica del inóculo con las diferentes concentraciones de amonio y quizás se pueda relacionar la respuesta fisiológica del consorcio con algún grupo microbiano. Esto se puede realizar con ayuda de distintos métodos por ejemplo: El espectrofotométrico donde puede seguirse el curso de una reacción observando cómo cambia la luz absorbida por la solución en la que se está dando la reacción. Para poder utilizar un ensayo de este tipo debe haber entre los sustratos o los productos alguno que absorba luz a una longitud de onda determinada, y que sea la única molécula de la mezcla de reacción que lo hace a la misma; de esta forma, se puede observar el aumento o la disminución de la absorbancia a dicha longitud de onda. Por ensayos radiométricos donde se mide la incorporación de radiactividad en los sustratos o su liberación desde sustratos. Los radioisótopos más usados en estos ensayos son ${ }^{14} \mathrm{C},{ }^{32} \mathrm{P},{ }^{35} \mathrm{~S}$ y ${ }^{125} \mathrm{I}$. Como los isótopos radiactivos permiten 
el marcaje de un sólo átomo de un sustrato, estos ensayos son extremadamente sensibles y específicos. Son frecuentemente utilizados en bioquímica y son a menudo la única manera de medir una reacción específica en extractos crudos (mezclas complejas de las enzimas liberadas al lisar células). O bien darle seguimiento al aumento o disminución de la población de las bacterias nitrificantes por métodos de biología molecular como el DGGE o FISH utilizados para determinar cambios en las poblaciones microbianas.

Recordando que el proceso nitrito oxidante no se vio afectado en cuanto al consumo de sustrato por la presencia de 2-CP. Un punto de partida sería realizar una comparación a nivel de membrana de los microorganismos nitrito oxidantes contra los amonio oxidantes, utilizando técnicas de microscopia electrónica. Otro punto sería establecer claramente si el transporte de nitrito es distinto al de amonio.

Por último sería interesante poder identificar el intermediario que se ha detectado en los ensayos realizados. Esto nos permitiría corroborar si el compuesto formado tras la oxidación del 2-CP pertenece a la ruta propuesta en la literatura, si forma parte de otra ruta de las ya propuestas para el llamado embudo metabólico de los compuestos aromáticos o inclusive si dicho intermediario pertenece a una nueva ruta aun no reportada. Esto se podría hacer detectando nuevamente el intermediario por HPLC y posteriormente analizar esta muestra por medio de un detector de masas acoplado a un cromatógrafo de gases. 


\section{ANEXOS}

Anexo 1: Ajustes con el modelo de Gompertz mediante el programa NCSS se presentan los coeficientes $A, B, C$ necesarios para el cálculo de las velocidades específicas de consumo de amonio y producción de nitrato y nitrito utilizando diferentes concentraciones de amonio $\left(100,200,300\right.$ y $500{\mathrm{mg} \mathrm{N}-\mathrm{NH}_{4}+}^{+} / \mathrm{l})$ en presencia de $5 \mathrm{mg} \mathrm{C}-2-\mathrm{CP} / \mathrm{l}$ y de los ensayos con extractos libres de células, así como el ajuste del modelo $\left(r^{2}\right)$ y el análisis de normalidad.

Anexo 2: Ajuste con el modelo de Gompertz mediante el programa NCSS. Se presentan los coeficientes A,B,C necesarios para el cálculo de las velocidades específicas de consumo de 2-CP en presencia de inhibidores específicos de la AMO y NOR. Así como el consumo de 2-CP en presencia de diferentes

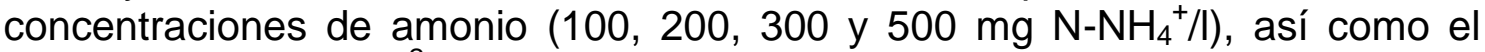
ajuste del modelo $\left(r^{2}\right)$ y el análisis de normalidad. Así como las pruebas estadísticas de homogeneidad de coeficientes en modelos de regresión. 
Anexo 1: Ajustes con el modelo de Gompertz mediante el programa NCSS se presentan los coeficientes $A, B, C$ necesarios para el cálculo de las velocidades específicas de consumo de amonio y producción de nitrato y nitrito utilizando diferentes concentraciones de amonio $\left(100,200,300\right.$ y $\left.500 \mathrm{mg} \mathrm{N}-\mathrm{NH}_{4}{ }^{+} / \mathrm{I}\right)$ en presencia de $5 \mathrm{mg} \mathrm{C}-2-\mathrm{CP} / \mathrm{l}$ y de los ensayos con extractos libres de células, así como el ajuste del modelo $\left(r^{2}\right)$, la significancia del mismo y el análisis de normalidad.

\section{CINÉTICAS CONTROL CON DIFERENTES CONCENTRACIONES DE AMONIO}

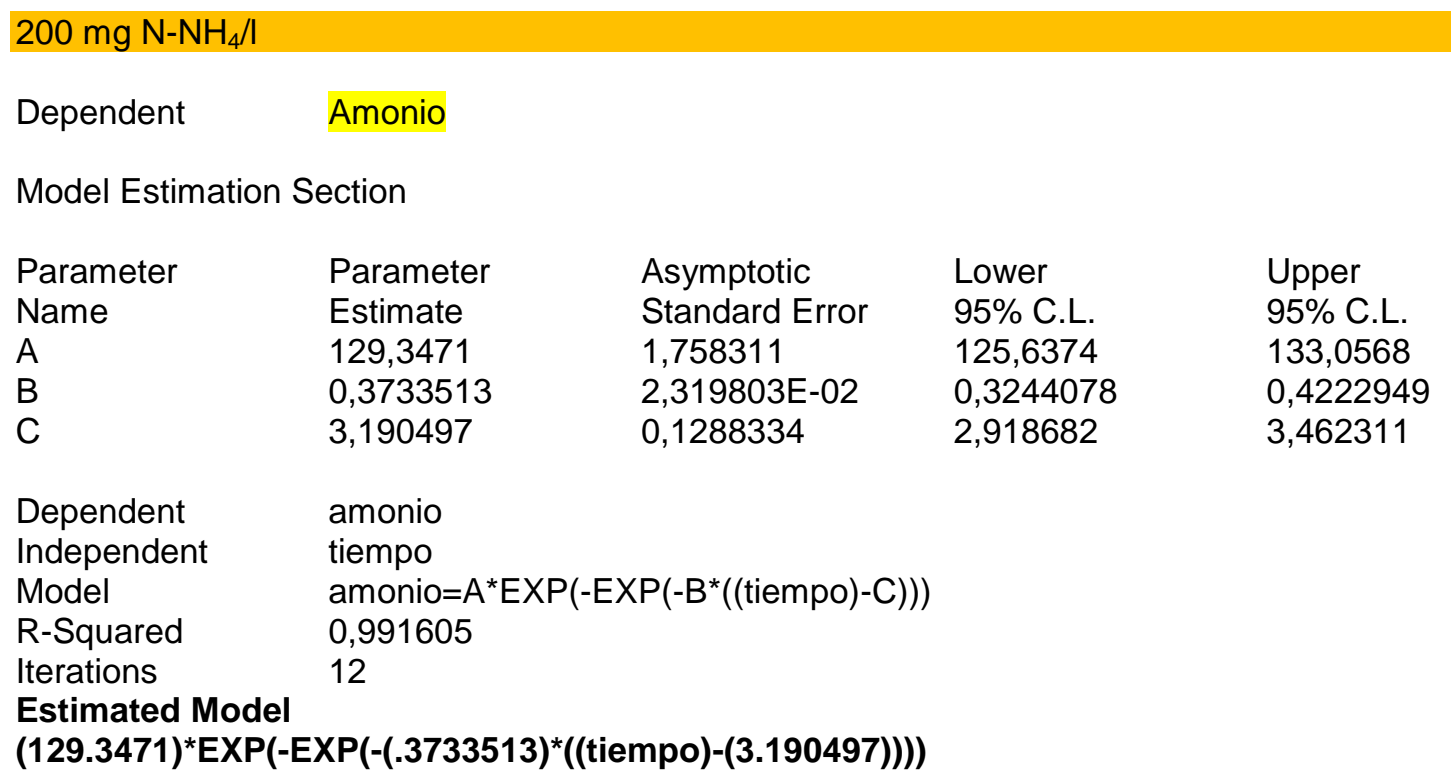

Analysis of Variance Table

$\begin{array}{llll} & & \text { Sum of } & \text { Mean } \\ \text { Source } & \text { DF } & \text { Squares } & \text { Square } \\ \text { Mean } & 1 & 150866,8 & 150866,8 \\ \text { Model } & 3 & 194850,1 & 64950,04 \\ \text { Model (Adjusted) } & 2 & 43983,34 & 21991,67 \\ \text { Error } & 17 & 372,3816 & 21,9048 \\ \text { Total (Adjusted) } & 19 & 44355,73 & \\ \text { Total } & 20 & 195222,5 & \end{array}$

Curve Fit Report

Page/Date/Time 3 27/01/2015 20:08:31

Database

Dependent amonio

Plot of amonio= $A^{*} \operatorname{EXP}\left(-\operatorname{EXP}\left(-B^{*}((\right.\right.$ tiempo $\left.\left.)-C)\right)\right)$

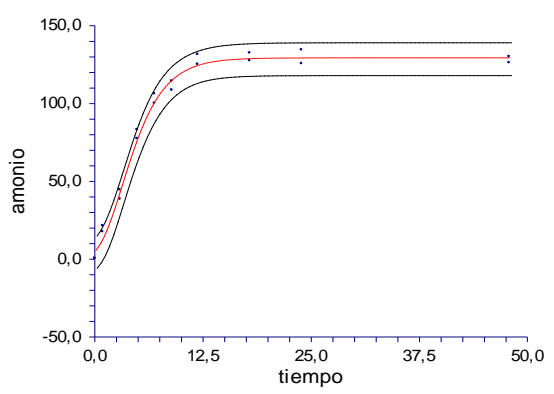




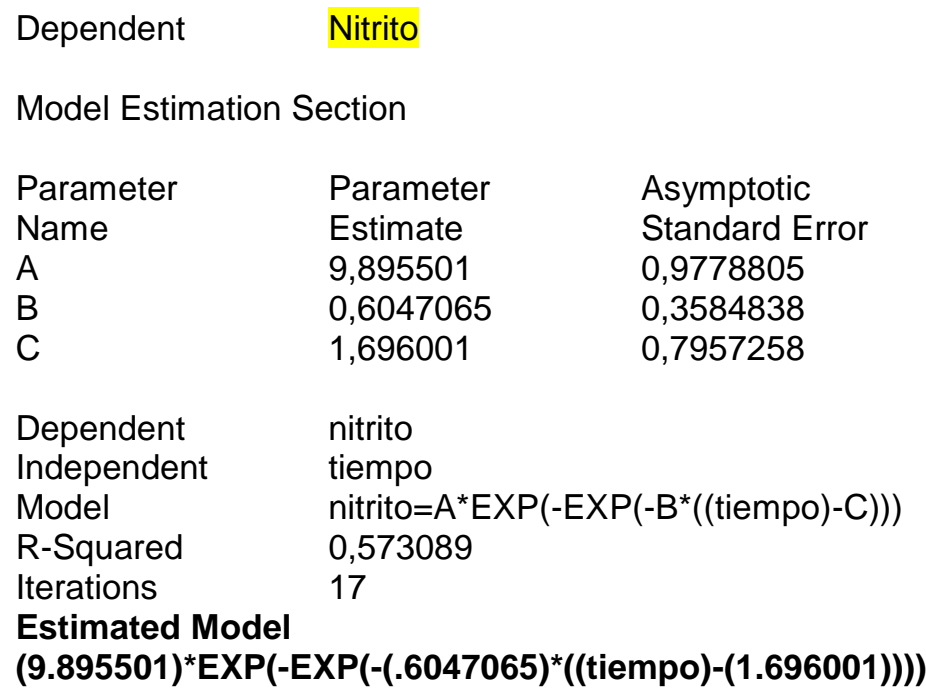

Analysis of Variance Table

\begin{tabular}{llll} 
Source & & Sum of & Mean \\
Mean & 1 & Squares & Square \\
Model & 3 & 1166,323 & 1166,323 \\
Model (Adjusted) & 2 & 1392,925 & 464,3082 \\
Error & 17 & 226,602 & 113,301 \\
Total (Adjusted) & 19 & 168,8024 & 9,929554 \\
Total & 20 & 395,4044 & \\
\hline
\end{tabular}

Page/Date/Time 3 27/01/2015 20:11:10

Dependent nitrito

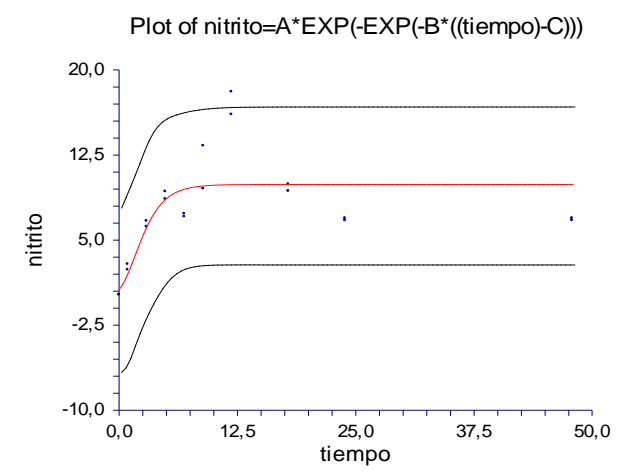

Dependent

Nitrato

Model Estimation Section

$\begin{array}{ll}\text { Parameter } & \text { Parameter } \\ \text { Name } & \text { Estimate } \\ \text { A } & 129,0175 \\ \text { B } & 0,3175878 \\ \text { C } & 5,350408 \\ & \\ \text { Dependent } & \text { nitrato } \\ \text { Independent } & \text { tiempo }\end{array}$

Jesús Emmanuel Pérez Alfaro |
Upper

95\% C.L.

11,95865

1,361041

$-0,1516282$

3,374836

$\begin{array}{ll}\text { Lower } & \text { Upper } \\ 95 \% \text { C.L. } & 95 \% \text { C.L. } \\ 7,832353 & 11,95865 \\ -0,1516282 & 1,361041 \\ 1,716629 E-02 & 3,374836\end{array}$

\section{Curve Fit Report}

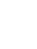




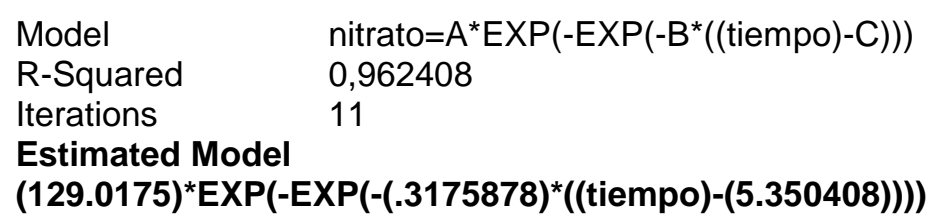

Analysis of Variance Table

$\begin{array}{llll} & & \text { Sum of } & \text { Mean } \\ \text { Source } & \text { DF } & \text { Squares } & \text { Square } \\ \text { Mean } & 1 & 104060,5 & 104060,5 \\ \text { Model } & 3 & 156673,4 & 52224,48 \\ \text { Model (Adjusted) } & 2 & 52612,93 & 26306,47 \\ \text { Error } & 17 & 2055,081 & 120,8871 \\ \text { Total (Adjusted) } & 19 & 54668,01 & \\ \text { Total } & 20 & 158728,5 & \end{array}$

Page/Date/Time $3 \quad$ 27/01/2015 20:11:34
Database

Curve Fit Report

Dependent nitrato

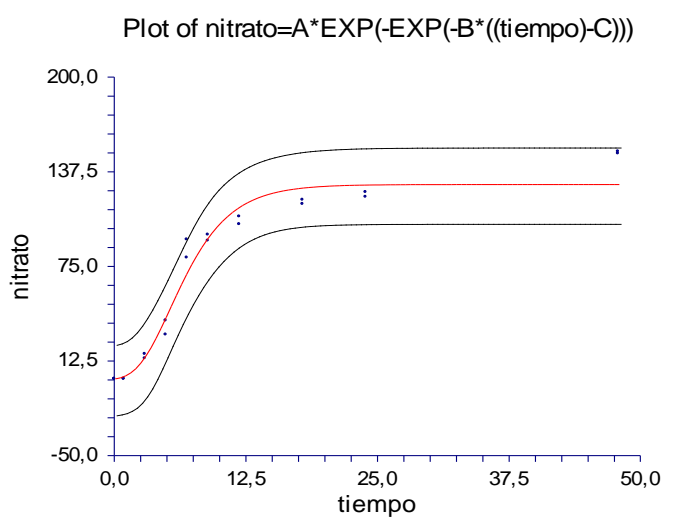

\begin{tabular}{|c|c|c|c|c|}
\hline \multicolumn{5}{|c|}{ 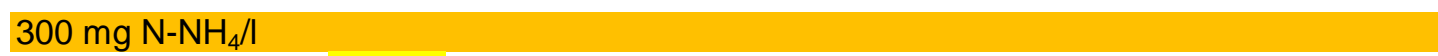 } \\
\hline Dependent & Amonio & & & \\
\hline \multicolumn{5}{|c|}{ Model Estimation Section } \\
\hline Parameter & Parameter & Asymptotic & Lower & Upper \\
\hline Name & Estimate & Standard Error & $95 \%$ C.L. & $95 \%$ C.L. \\
\hline A & 200,9994 & 3,41238 & 193,7999 & 208,1989 \\
\hline B & 0,4190792 & 0,0347468 & 0,3457698 & 0,4923885 \\
\hline C & 2,8513 & 0,1561927 & 2,521762 & 3,180838 \\
\hline Dependent & \multicolumn{4}{|c|}{ amonio } \\
\hline Independent & \multirow{2}{*}{\multicolumn{4}{|c|}{$\begin{array}{l}\text { tiempo } \\
\text { amonio= } A^{*} \operatorname{EXP}\left(-\operatorname{EXP}\left(-B^{*}((\text { tiempo })-C)\right)\right)\end{array}$}} \\
\hline Model & & & & \\
\hline R-Squared & \multicolumn{4}{|c|}{0,985305} \\
\hline Iterations & \\
\hline \multicolumn{5}{|c|}{$\begin{array}{l}\text { Estimated Model } \\
(200.9994)^{\star} \operatorname{EXP}\left(-\operatorname{EXP}\left(-(.4190792)^{\star}((\text { tiempo })-(2.8513))\right)\right)\end{array}$} \\
\hline
\end{tabular}


Analysis of Variance Table

$\begin{array}{llll} & & \text { Sum of } & \text { Mean } \\ \text { Source } & \text { DF } & \text { Squares } & \text { Square } \\ \text { Mean } & 1 & 392070 & 392070 \\ \text { Model } & 3 & 495117,1 & 165039 \\ \text { Model (Adjusted) } & 2 & 103047,1 & 51523,56 \\ \text { Error } & 17 & 1536,831 & 90,40181 \\ \text { Total (Adjusted) } & 19 & 104584 & \\ \text { Total } & 20 & 496654 & \end{array}$

\section{Page/Date/Time $\quad 3 \quad$ 27/01/2015 20:12:42}

Curve Fit Report

Database

Dependent amonio

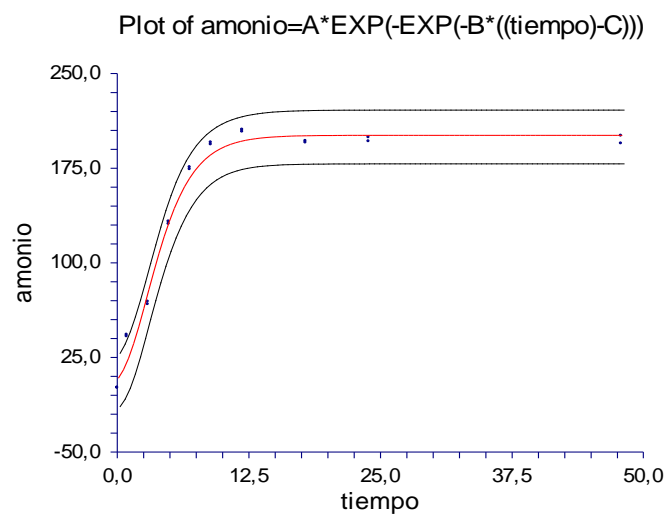

Dependent Nitrito

Model Estimation Section

$\begin{array}{lllll}\text { Parameter } & \text { Parameter } & \text { Asymptotic } & \text { Lower } & \text { Upper } \\ \text { Name } & \text { Estimate } & \text { Standard Error } & 95 \% \text { C.L. } & 95 \% \text { C.L. } \\ \text { A } & 38,97543 & 3,666401 & 31,23999 & 46,71086 \\ \text { B } & 0,5656974 & 0,314363 & -9,755049 \mathrm{E}-02 & 1,228945 \\ \text { C } & 2,38979 & 0,8126556 & 0,6752361 & 4,104343\end{array}$

$\begin{array}{ll}\text { Dependent } & \text { nitrito } \\ \text { Independent } & \text { tiempo } \\ \text { Model } & \text { nitrito= } A^{\star} \operatorname{EXP}\left(-\operatorname{EXP}\left(-\mathrm{B}^{\star}((\text { tiempo })-\mathrm{C})\right)\right) \\ \text { R-Squared } & 0,631895 \\ \text { Iterations } & 27 \\ \text { Estimated Model } & \\ \left.\left.\text { (38.97543)*EXP(-EXP(-(.5656974) })^{\star}((\text { tiempo })-(2.38979))\right)\right)\end{array}$

Analysis of Variance Table

$\begin{array}{llll} & & \text { Sum of } & \text { Mean } \\ \text { Source } & \text { DF } & \text { Squares } & \text { Square } \\ \text { Mean } & 1 & 16623,38 & 16623,38 \\ \text { Model } & 3 & 20347,76 & 6782,588 \\ \text { Model (Adjusted) } & 2 & 3724,386 & 1862,193 \\ \text { Error } & 17 & 2169,611 & 127,6242 \\ \text { Total (Adjusted) } & 19 & 5893,997 & \\ \text { Total } & 20 & 22517,38 & \end{array}$




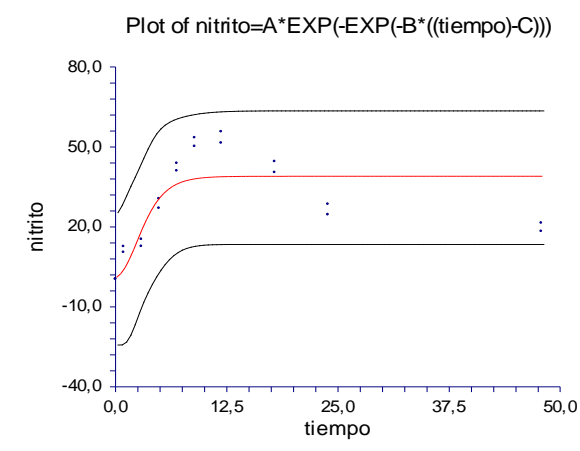

Dependent Nitrato

Model Estimation Section

$\begin{array}{lllll}\text { Parameter } & \text { Parameter } & \text { Asymptotic } & \text { Lower } & \text { Upper } \\ \text { Name } & \text { Estimate } & \text { Standard Error } & 95 \% \text { C.L. } & 95 \% \text { C.L. } \\ \text { A } & 171,4662 & 3,149468 & 164,8215 & 178,1111 \\ \text { B } & 0,3251492 & 2,530412 \text { E-02 } & 0,2717621 & 0,3785362 \\ \text { C } & 3,247807 & 0,1802457 & 2,867522 & 3,628093\end{array}$

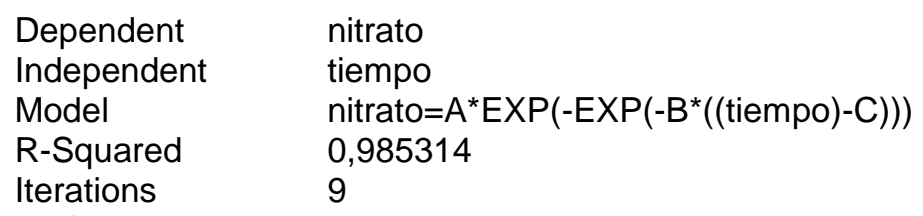

Analysis of Variance Table

$\begin{array}{llll}\text { Source } & \text { DF } & \text { Sum of } & \text { Mean } \\ \text { Mean } & 1 & \text { Squares } & \text { Square } \\ \text { Model } & 3 & 256904,8 & 256904,8 \\ \text { Model (Adjusted) } & 2 & 330288,7 & 110096,2 \\ \text { Error } & 17 & 73383,88 & 36691,94 \\ \text { Total (Adjusted) } & 19 & 1093,793 & 64,34077 \\ \text { Total } & 20 & 74477,66 & \\ \end{array}$

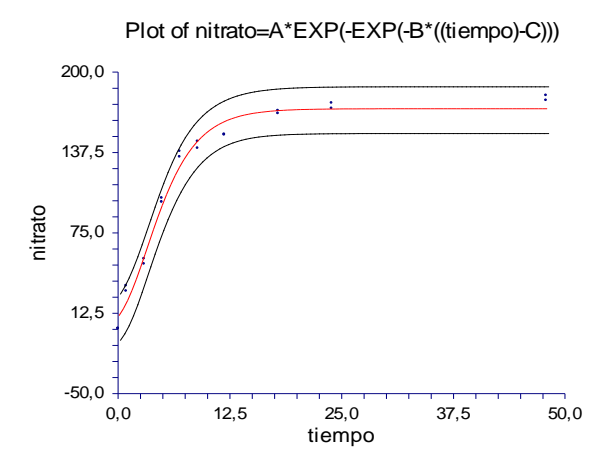




$500 \mathrm{mg} \mathrm{N}-\mathrm{NH}_{4} / \mathrm{l}$
$\begin{aligned} & \text { Curve Fit Report } \\ & \text { Page/Date/Time }\end{aligned}$
$\begin{aligned} & \text { Database } \\ & \text { Dependent }\end{aligned} \quad$ Amonio

Model Estimation Section

\begin{tabular}{|c|c|c|}
\hline Parameter & Parameter & Asymptotic \\
\hline Name & Estimate & Standard Error \\
\hline A & 310,6794 & 5,324655 \\
\hline$B$ & 0,251894 & 0,0164935 \\
\hline C & 5,292343 & 0,1788197 \\
\hline Dependent & \multicolumn{2}{|l|}{ amonio } \\
\hline Independent & \multicolumn{2}{|c|}{ tiempo } \\
\hline Model & \multicolumn{2}{|c|}{ amonio $=\mathrm{A}^{*} \operatorname{EXP}\left(-\operatorname{EXP}\left(-\mathrm{B}^{\star}((\right.\right.$ tiempo $\left.\left.)-\mathrm{C})\right)\right)$} \\
\hline R-Squared & \multicolumn{2}{|c|}{0,991359} \\
\hline Iterations & \multicolumn{2}{|c|}{9} \\
\hline \multicolumn{3}{|c|}{$\begin{array}{l}\text { Estimated Model } \\
(310.6794)^{\star} \operatorname{EXP}\left(-\operatorname{EXP}\left(-(.251894)^{\star}((\text { tiempo })-(5.292343))\right)\right)\end{array}$} \\
\hline
\end{tabular}

Analysis of Variance Table

$\begin{array}{llll}\text { Source } & \text { DF } & \begin{array}{l}\text { Sum of } \\ \text { Squares }\end{array} & \text { Mean } \\ \text { Mean } & 1 & 597702,5 & 597702,5 \\ \text { Model } & 3 & 863112,3 & 287704,1 \\ \text { Model (Adjusted) } & 2 & 265409,8 & 132704,9 \\ \text { Error } & 17 & 2313,366 & 136,0804 \\ \text { Total (Adjusted) } & 19 & 267723,1 & \\ \text { Total } & 20 & 865425,6 & \end{array}$

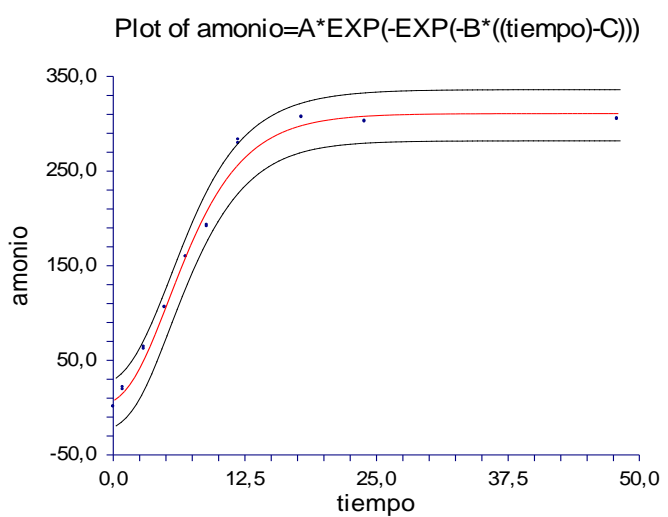

Dependent Nitrito

Model Estimation Section

$\begin{array}{lllll}\text { Parameter } & \text { Parameter } & \text { Asymptotic } & \text { Lower } & \text { Upper } \\ \text { Name } & \text { Estimate } & \text { Standard Error } & 95 \% \text { C.L. } & 95 \% \text { C.L. } \\ \text { A } & 26,74903 & 1,802939 & 22,94516 & 30,55289 \\ \text { B } & 0,4464756 & 0,1580324 & 0,1130563 & 0,7798949 \\ \text { C } & 4,292358 & 0,5969779 & 3,032845 & 5,551871\end{array}$

Dependent nitrito 


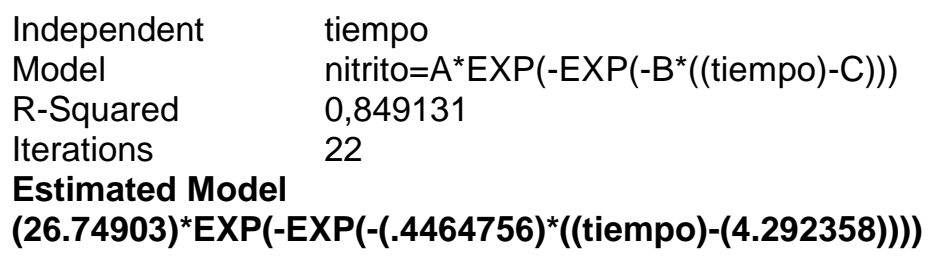

Analysis of Variance Table

$\begin{array}{llll}\text { Source } & \text { DF } & \begin{array}{l}\text { Sum of } \\ \text { Squares }\end{array} & \text { Mean } \\ \text { Mean } & 1 & 5693,962 & 5693,962 \\ \text { Model } & 3 & 7910,833 & 2636,945 \\ \text { Model (Adjusted) } & 2 & 2216,871 & 1108,435 \\ \text { Error } & 17 & 393,8823 & 23,16955 \\ \text { Total (Adjusted) } & 19 & 2610,753 & \\ \text { Total } & 20 & 8304,716 & \end{array}$

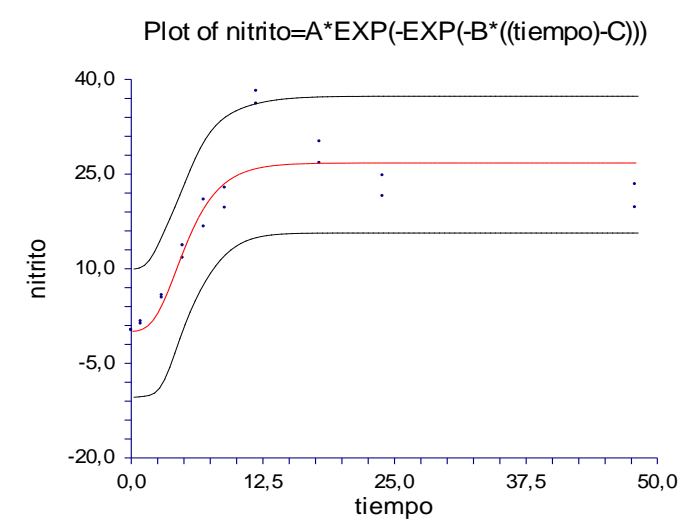

Dependent Nitrato

Model Estimation Section

$\begin{array}{lllll}\text { Parameter } & \text { Parameter } & \text { Asymptotic } & \text { Lower } & \text { Upper } \\ \text { Name } & \text { Estimate } & \text { Standard Error } & 95 \% \text { C.L. } & 95 \% \text { C.L. } \\ \text { A } & 277,4576 & 7,451866 & 261,7355 & 293,1797 \\ \text { B } & 0,2620012 & 2,811321 \text { E-02 } & 0,2026875 & 0,3213149 \\ \text { C } & 6,077868 & 0,2735867 & 5,500651 & 6,655086\end{array}$

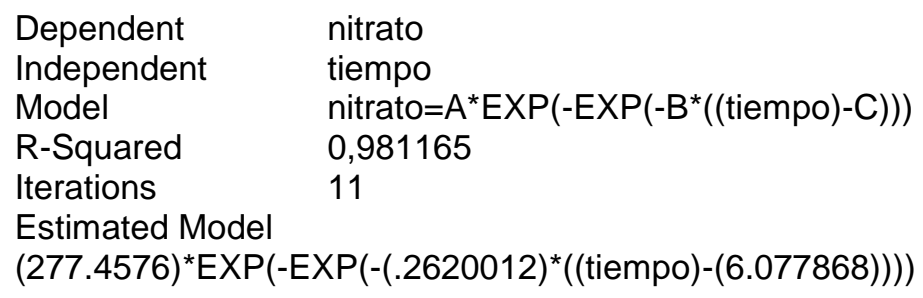

Analysis of Variance Table

$\begin{array}{llll}\text { Source } & \text { DF } & \begin{array}{l}\text { Sum of } \\ \text { Squares }\end{array} & \text { Mean } \\ \text { Mean } & 1 & 422029,7 & 422029,7 \\ \text { Model } & 3 & 652345,9 & 217448,7 \\ \text { Model (Adjusted) } & 2 & 230316,3 & 115158,1 \\ \text { Error } & 17 & 4421,364 & 260,0802 \\ \text { Total (Adjusted) } & 19 & 234737,6 & \\ \text { Total } & 20 & 656767,3 & \end{array}$




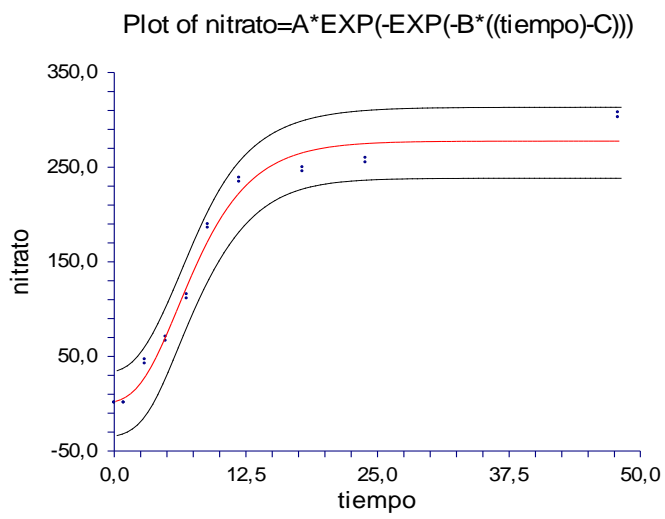

-Velocidades de consumo de diferentes concentraciones de amonio en presencia de 2CP (100-500 mg/l)

Dependent Control

Model Estimation Section

$\begin{array}{lllll}\text { Parameter } & \text { Parameter } & \text { Asymptotic } & \text { Lower } & \text { Upper } \\ \text { Name } & \text { Estimate } & \text { Standard Error } & 95 \% \text { C.L. } & 95 \% \text { C.L. } \\ \text { A } & 106.3183 & 1.560561 & 103.0258 & 109.6108 \\ \text { B } & 0.625804 & 5.813495 \mathrm{E}-02 & 0.50315 & 0.748458 \\ \text { C } & 1.387407 & 0.114825 & 1.145147 & 1.629667\end{array}$

Dependent

Control

Independent Tiempo

Model

Control $=A^{*} \operatorname{EXP}\left(-\operatorname{EXP}\left(-B^{*}((\right.\right.$ Tiempo $\left.\left.)-C)\right)\right)$

R-Squared

0.981958

Iterations

7

Estimated Model

$(106.3183)^{\star} \operatorname{EXP}\left(-\operatorname{EXP}\left(-(.625804)^{\star}((\right.\right.$ Tiempo $\left.\left.)-(1.387407))\right)\right)$

Plot of Control $=A^{*} \operatorname{EXP}\left(-\operatorname{EXP}\left(-B^{*}((\right.\right.$ Tiempo $\left.\left.)-C)\right)\right)$

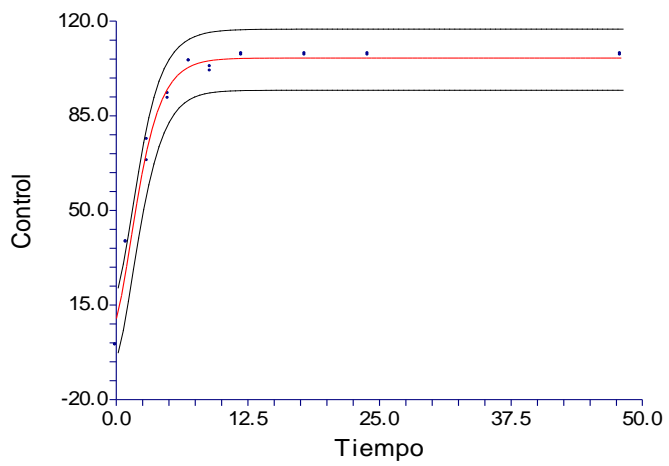


Normality Test Section of Res control

$\begin{array}{lll}\text { Test NameValue } & \text { Test } & \begin{array}{l}\text { Prob } \\ \text { Level }\end{array} \\ \text { Shapiro-Wilk W0 } & .9016232 & 0.044237 \\ \text { Anderson-Darling0. } & 9725237 & 0.014395 \\ \text { Martinez-Iglewicz2. } & 222556 & \\ \text { Kolmogorov-Smirnov } & 0.2021204 & \\ \text { D'Agostino Skewness } & -0.6816 & 0.495521 \\ \text { D'Agostino Kurtosis } & 0.6733 & 0.500749 \\ \text { D'Agostino Omnibus } & 0.9179 & 0.631958\end{array}$

$\begin{array}{ll}\begin{array}{ll}10 \% \text { Critical } \\ \text { Value }\end{array} & \begin{array}{l}5 \% \text { Critical } \\ \text { Value }\end{array} \\ 1.216194 & 1.357297 \\ 0.176 & 0.192 \\ 1.645 & 1.960 \\ 1.645 & 1.960 \\ 4.605 & 5.991\end{array}$

Decision

(5\%)

Reject Normality

Reject Normality

Reject Normality

Reject Normality

Accept Normality

Accept Normality

Accept Normality

Dependent

Amonio 200

Model Estimation Section

$\begin{array}{lllll}\text { Parameter } & \text { Parameter } & \text { Asymptotic } & \text { Lower } & \text { Upper } \\ \text { Name } & \text { Estimate } & \text { Standard Error } & 95 \% \text { C.L. } & 95 \% \text { C.L. } \\ \text { A } & 48.27496 & 3.355593 & 41.19528 & 55.35464 \\ \text { B } & 0.4733787 & 0.1810136 & 9.147336 \text { E-02 } & 0.855284 \\ \text { C } & 3.20659 & 0.6257266 & 1.886422 & 4.526757\end{array}$

Dependent

$\mathrm{NH} 200$

Independent

Tiempo

Model

$\mathrm{NH} 200=\mathrm{A}^{*} \operatorname{EXP}\left(-\operatorname{EXP}\left(-\mathrm{B}^{*}((\right.\right.$ Tiempo $\left.\left.)-\mathrm{C})\right)\right)$

R-Squared

0.817068

Iterations

9

Estimated Model

$(48.27496){ }^{\star} \operatorname{EXP}\left(-\operatorname{EXP}\left(-(.4733787)^{\star}((\right.\right.$ Tiempo)-(3.20659))))

Plot of $\mathrm{NH} 200=\mathrm{A}^{*} \mathrm{EXP}\left(-\mathrm{EXP}\left(-\mathrm{B}^{\star}((\right.\right.$ Tiempo $\left.\left.)-\mathrm{C})\right)\right)$

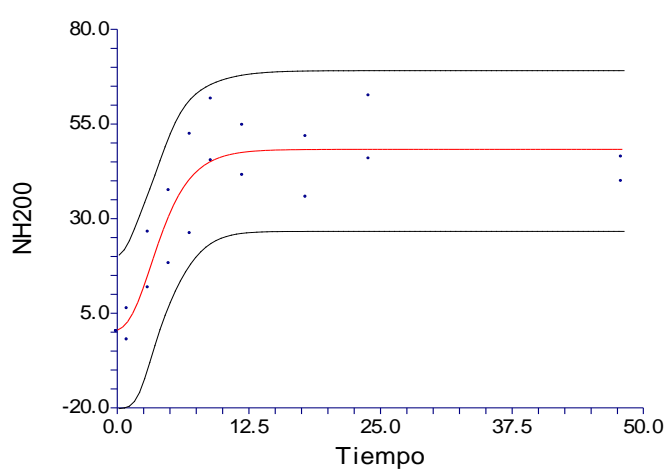

Normality Test Section of Res200

$\begin{array}{lcl}\text { Test NameValue } & \text { Test } & \begin{array}{l}\text { Prob } \\ \text { Level }\end{array} \\ \text { Shapiro-Wilk W } & 0.9738779 & 0.833693 \\ \text { Anderson-Darling } & 0.1632235 & 0.944322 \\ \text { Martinez-Iglewicz } & 0.9609138 & \\ \text { Kolmogorov-Smirnov } & 0.1041932 & \\ \text { D'Agostino Skewness } & 0.1957 & 0.844856 \\ \text { D'Agostino Kurtosis } & -0.6957 & 0.486645 \\ \text { D'Agostino Omnibus } & 0.5222 & 0.770193\end{array}$

$10 \%$ Critical

Value

1.216194

0.176

1.645

1.645

4.605
5\% Critica

Value

1.357297

0.192

1.960

1.960

5.991
Decision

(5\%)

Accept Normality Accept Normality Accept Normality Accept Normality Accept Normality Accept Normality Accept Normality 
Model Estimation Section

$\begin{array}{lllll}\text { Parameter } & \text { Parameter } & \text { Asymptotic } & \text { Lower } & \text { Upper } \\ \text { Name } & \text { Estimate } & \text { Standard Error } & 95 \% \text { C.L. } & 95 \% \text { C.L. } \\ \text { A } & 70.25768 & 4.711656 & 60.31695 & 80.19839 \\ \text { B } & 0.2124759 & 5.038349 \text { E-02 } & 0.106176 & 0.3187758 \\ \text { C } & 4.231035 & 0.7453873 & 2.658405 & 5.803665\end{array}$
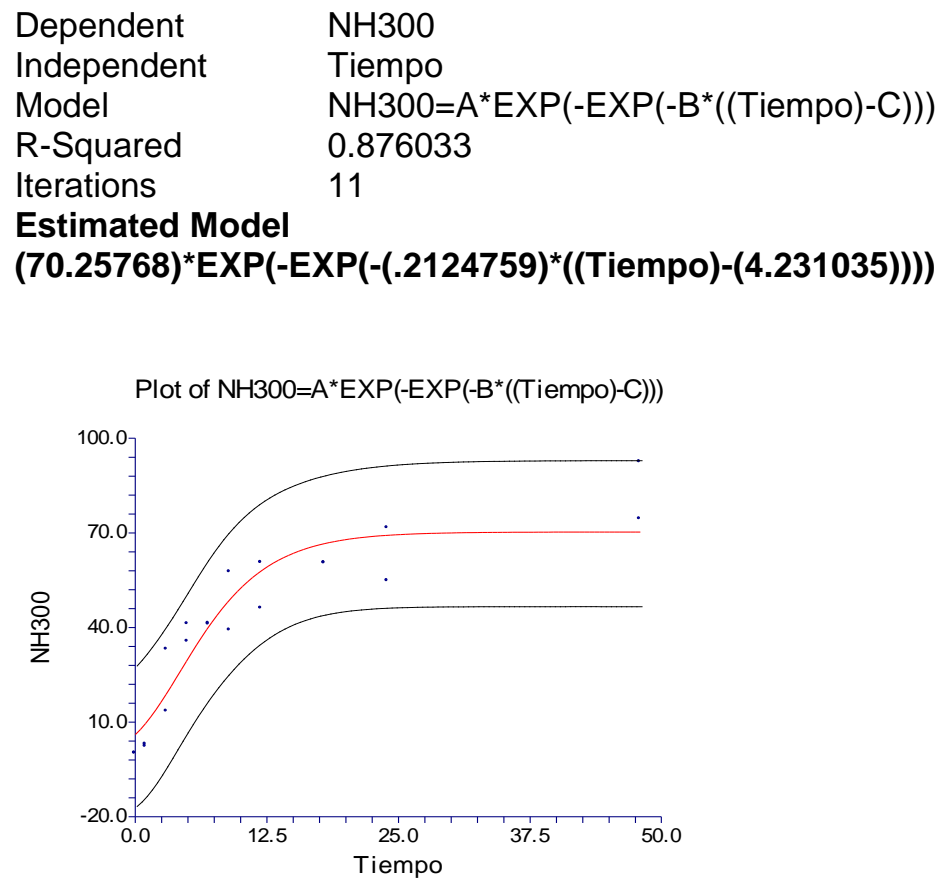

Normality Test Section of Res300

$\begin{array}{llllll}\text { Test NameValue } & \text { Test } & \begin{array}{l}\text { Prob } \\ \text { Level }\end{array} & \begin{array}{l}10 \% \text { Critical } \\ \text { Value }\end{array} & \begin{array}{l}5 \% \text { Critical } \\ \text { Value }\end{array} & \begin{array}{l}\text { Decision } \\ (5 \%)\end{array} \\ \begin{array}{l}\text { Shapiro-Wilk W } \\ \text { Anderson-Darling }\end{array} & 0.9418433 & 0.259748 & & \begin{array}{l}\text { Accept Normality } \\ \text { Accept Normality }\end{array} \\ \text { Martinez-Iglewicz } & 0.5064222 & 0.201251 & 1.216194 & 1.357297 & \text { Accept Normality } \\ \text { Kolmogorov-Smirnov } & 1.091816 & & 0.176 & 0.192 & \text { Reject Normality } \\ \text { D'Agostino Skewness } & 1.4968 & 0.134455 & 1.645 & 1.960 & \text { Accept Normality } \\ \text { D'Agostino Kurtosis } & 0.4901 & 0.624056 & 1.645 & 1.960 & \text { Accept Normality } \\ \text { D'Agostino Omnibus } & 2.4805 & 0.289311 & 4.605 & 5.991 & \text { Accept Normality }\end{array}$

\section{Dependent}

NH500

Model Estimation Section

$\begin{array}{lllll}\text { Parameter } & \text { Parameter } & \text { Asymptotic } & \text { Lower } & \text { Upper } \\ \text { Name } & \text { Estimate } & \text { Standard Error } & 95 \% \text { C.L. } & 95 \% \text { C.L. } \\ \text { A } & 216.9808 & 14.40078 & 186.5978 & 247.3638 \\ \text { B } & 0.1124306 & 2.158122 \mathrm{E}-02 & 6.689823 \mathrm{E}-02 & 0.157963 \\ \text { C } & 4.740814 & 0.94744 & 2.741891 & 6.739738\end{array}$

Dependent Independent Model

R-Squared

$\mathrm{NH} 500$

Tiempo $\mathrm{NH} 500=\mathrm{A}^{*} \operatorname{EXP}\left(-\operatorname{EXP}\left(-\mathrm{B}^{*}((\right.\right.$ Tiempo $\left.\left.)-\mathrm{C})\right)\right)$ 0.905442 
Iterations 7
Estimated Model
$(\mathbf{2 1 6 . 9 8 0 8 ) \star E X P ( - E X P ( - ( . 1 1 2 4 3 0 6 ) * ( ( T i e m p o ) - ( 4 . 7 4 0 8 1 4 ) ) ) ) ~}$

Plot of $\mathrm{NH} 500=\mathrm{A}^{\star} \mathrm{EXP}\left(-\mathrm{EXP}\left(-\mathrm{B}^{\star}((\right.\right.$ Tiempo $\left.\left.)-\mathrm{C})\right)\right)$

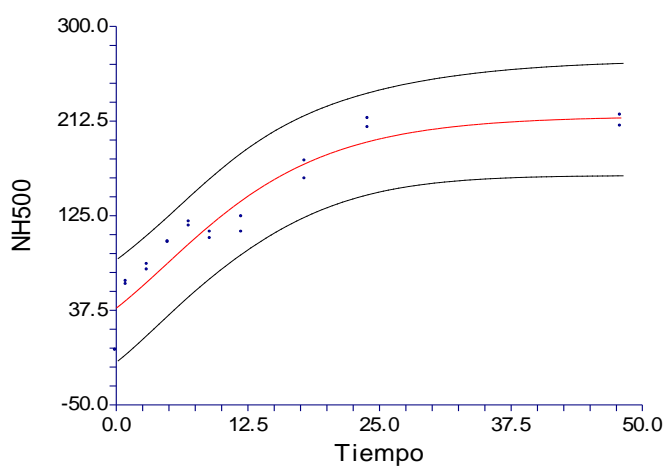

Normality Test Section of Res500

\begin{tabular}{|c|c|c|c|c|c|}
\hline Test & Prob & 10\% Critical & $5 \%$ Critical & Decision & \\
\hline Test & NameValue & Level & Value & Value & $(5 \%)$ \\
\hline Shapiro-Wilk W & 0.8682327 & 0.010940 & & & Reject Normality \\
\hline Anderson-Darling & 0.9535097 & 0.016035 & & & Reject Normality \\
\hline Martinez-Iglewicz & 1.083484 & & 1.216194 & 1.357297 & Accept Normality \\
\hline Kolmogorov-Smirnov & 0.1491376 & & 0.176 & 0.192 & Accept Normality \\
\hline D'Agostino Skewness & -1.6389 & 0.101233 & 1.645 & 1.960 & Accept Normality \\
\hline D'Agostino Kurtosis & -0.3589 & 0.719683 & 1.645 & 1.960 & Accept Normality \\
\hline D'Agostino Omnibus & 2.8148 & 0.244779 & 4.605 & 5.991 & Accept Normality \\
\hline
\end{tabular}

\section{- Velocidades de producción de nitrato en presencia de diferentes concentraciones de}

\section{CP $(100-500 \mathrm{mg} / \mathrm{l})$}

Dependent Nitrato control

Model Estimation Section

$\begin{array}{lllll}\text { Parameter } & \text { Parameter } & \text { Asymptotic } & \text { Lower } & \text { Upper } \\ \text { Name } & \text { Estimate } & \text { Standard Error } & 95 \% \text { C.L. } & 95 \% \text { C.L. } \\ \text { A } & 98.72234 & 3.247518 & 91.87068 & 105.574 \\ \text { B } & 0.2881536 & 3.808263 \text { E-02 } & 0.2078063 & 0.3685009 \\ \text { C } & 3.437111 & 0.3348511 & 2.730637 & 4.143585\end{array}$

Dependent Independent

Nitcontrol

Model

Tiempo

R-Squared

Nitcontrol=A*EXP $\left(-\operatorname{EXP}\left(-B^{*}((\right.\right.$ Tiempo $\left.\left.)-C)\right)\right)$

Iterations

0.957970

Estimated Model

$(98.72234) \star \operatorname{EXP}(-\operatorname{EXP}(-(.2881536) \star((T i e m p o)-(3.437111))))$

Plot Section 


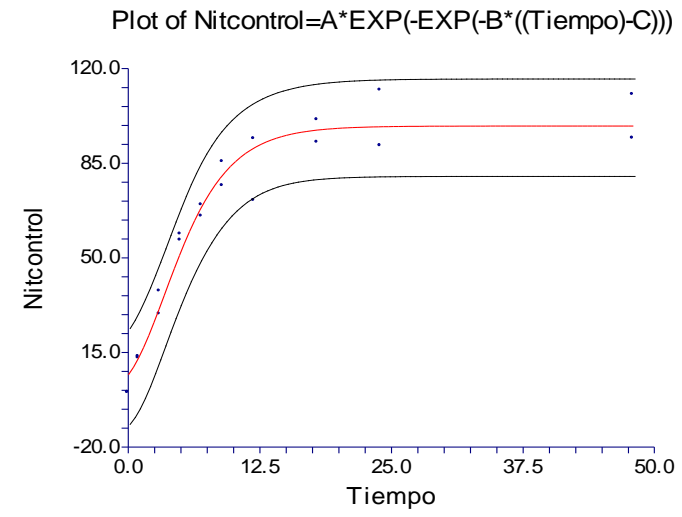

Normality Test Section of ResNcontrol

Test Name

Shapiro-Wilk W

Anderson-Darling

Martinez-Iglewicz

Kolmogorov-Smirnov

D'Agostino Skewness

D'Agostino Kurtosis

D'Agostino Omnibus

Test
Value
0.9561581
0.3306228
1.127954
$8.288394 \mathrm{E}-02$
-0.8997
1.2960
2.4892

Prob

Level

0.470230

0.513528

1.216194

0.368286

0.194962

0.288062

10\% Critical
Value

1.357297
0.176
1.645
1.645
4.605

5\% CriticalDecision

Value (5\%)

Accept Normality

Accept Normality

Accept Normality

0.192 Accept Normality

1.960 Accept Normality

1.960 Accept Normality

5.991 Accept Normality

\section{Dependent}

Nitrato 200

Model Estimation Section

$\begin{array}{lllll}\text { Parameter } & \text { Parameter } & \text { Asymptotic } & \text { Lower } & \text { Upper } \\ \text { Name } & \text { Estimate } & \text { Standard Error } & 95 \% \text { C.L. } & 95 \% \text { C.L. } \\ \text { A } & 17.66028 & 2.025251 & 13.38737 & 21.93318 \\ \text { B } & 0.1826212 & 7.059764 \mathrm{E}-02 & 3.367314 \mathrm{E}-02 & 0.3315692 \\ \text { C } & 4.292459 & 1.340489 & 1.464275 & 7.120643\end{array}$

$\begin{array}{ll}\text { Dependent } & \text { Nit200 } \\ \text { Independent } & \text { Tiempo } \\ \text { Model } & \text { Nit200=A*EXP(-EXP(-B*((Tiempo)-C))) } \\ \text { R-Squared } & 0.718308 \\ \text { Iterations } & 21\end{array}$

\section{Estimated Model}

$(17.66028)^{\star} \operatorname{EXP}\left(-\operatorname{EXP}\left(-(.1826212)^{\star}((\right.\right.$ Tiempo)$\left.\left.)-(4.292459))\right)\right)$

Analysis of Variance Table

$\begin{array}{llll} & & \text { Sum of } & \text { Mean } \\ \text { Source } & \text { DF } & \text { Squares } & \text { Square } \\ \text { Mean } & 1 & 2085.086 & 2085.086 \\ \text { Model } & 3 & 2758.828 & 919.6095 \\ \text { Model (Adjusted) } & 2 & 673.7422 & 336.8711 \\ \text { Error } & 17 & 264.215 & 15.54206 \\ \text { Total (Adjusted) } & 19 & 937.9573 & \\ \text { Total } & 20 & 3023.043 & \end{array}$




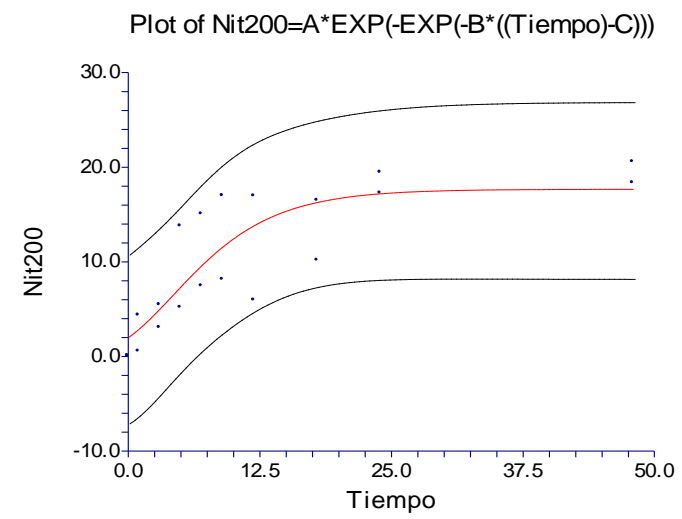

Normality Test Section of ResN200

Test Name

Shapiro-Wilk W

Anderson-Darling

Martinez-Iglewicz

Kolmogorov-Smirnov

D'Agostino Skewness

D'Agostino Kurtosis

D'Agostino Omnibus

Dependent

Nitrato 300

Model Estimation Section

$\begin{array}{lllll}\text { Parameter } & \text { Parameter } & \text { Asymptotic } & \text { Lower } & \text { Upper } \\ \text { Name } & \text { Estimate } & \text { Standard Error } & 95 \% \text { C.L. } & 95 \% \text { C.L. } \\ \text { A } & 43.31374 & 2.497767 & 38.04391 & 48.58356 \\ \text { B } & 0.1971418 & 3.914408 \text { E-02 } & 0.114555 & 0.2797286 \\ \text { C } & 4.32938 & 0.6566222 & 2.944028 & 5.714731\end{array}$

\section{Dependent Nit300 \\ Independent Tiempo \\ Model Nit300 $=A^{*} \operatorname{EXP}\left(-\operatorname{EXP}\left(-B^{*}((\right.\right.$ Tiempo $\left.\left.)-C)\right)\right)$ \\ R-Squared $\quad 0.905946$ \\ Iterations \\ 23}

Estimated Model

$(43.31374)^{\star} \operatorname{EXP}\left(-\operatorname{EXP}\left(-(.1971418)^{*}((\right.\right.$ Tiempo $\left.\left.)-(4.32938))\right)\right)$

Plot Section

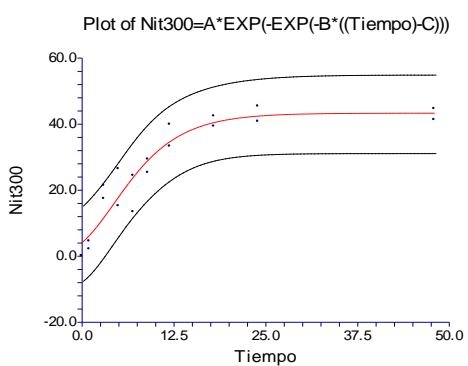


Normality Test Section of ResN300

\begin{tabular}{|c|c|c|c|c|c|}
\hline & Test & Prob & 10\% Critical & $5 \%$ Critical & Decision \\
\hline Test Name & Value & Level & Value & Value & $(5 \%)$ \\
\hline Shapiro-Wilk W & 0.9550732 & 0.450675 & & & Accept Normality \\
\hline Anderson-Darling & 0.4363814 & 0.297492 & & & Accept Normality \\
\hline Martinez-Iglewicz & 1.105155 & & 1.216194 & 1.357297 & Accept Normality \\
\hline Kolmogorov-Smirnov & 0.1408992 & & 0.176 & 0.192 & Accept Normality \\
\hline D'Agostino Skewness & 0.5015 & 0.616019 & 1.645 & 1.960 & Accept Normality \\
\hline D'Agostino Kurtosis & 0.7335 & 0.463263 & 1.645 & 1.960 & Accept Normality \\
\hline D'Agostino Omnibus & 0.7895 & 0.673848 & 4.605 & 5.991 & Accept Normality \\
\hline
\end{tabular}

\section{Dependent Nitrato 500}

Model Estimation Section

$\begin{array}{lllll}\text { Parameter } & \text { Parameter } & \text { Asymptotic } & \text { Lower } & \text { Upper } \\ \text { Name } & \text { Estimate } & \text { Standard Error } & 95 \% \text { C.L. } & 95 \% \text { C.L. } \\ \text { A } & 131.3704 & 7.244662 & 116.0855 & 146.6553 \\ \text { B } & 0.1388707 & 2.219304 \mathrm{E}-02 & 9.204748 \mathrm{E}-02 & 0.1856939 \\ \text { C } & 5.997126 & 0.7257194 & 4.465992 & 7.52826\end{array}$

$\begin{array}{ll}\text { Dependent } & \text { Nit500 } \\ \text { Independent } & \text { Tiempo } \\ \text { Model } & \text { Nit500=A*EXP(-EXP(-B*((Tiempo)-C }))) \\ \text { R-Squared } & 0.937837 \\ \text { Iterations } & 5 \\ \text { Estimated Model } & \end{array}$

$(131.3704)^{\star} \operatorname{EXP}\left(-\operatorname{EXP}\left(-(.1388707)^{\star}((\right.\right.$ Tiempo)$\left.\left.)-(5.997126))\right)\right)$

Plot Section

Plot of Nit500=A*EXP(-EXP(-B* $((T i e m p o)-C)))$

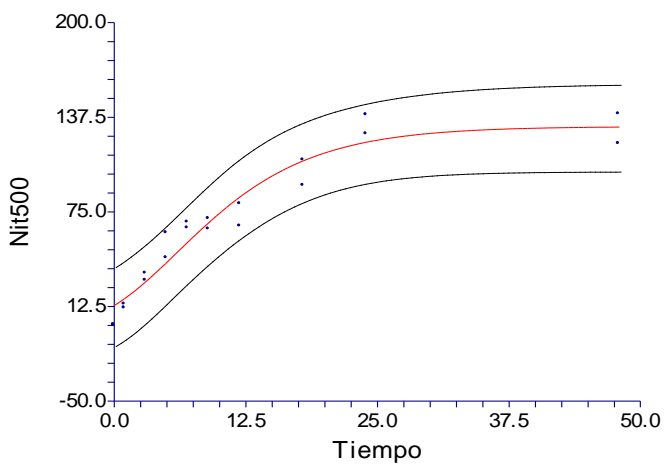

Normality Test Section of ResN500

Critical

Decision

Test Name

Value

0.9778976

0.1496937

Anderson-Darling

0.9605678

Kolmogorov-Smirnov

$8.384258 \mathrm{E}-02$

0.1134

$-0.6783$

D'Agostino Kurtosis

0.4729

$\begin{array}{lll}\text { Prob } & 10 \% \text { Critical } & 5 \% \\ \text { Level } & \text { Value } & \text { Value } \\ 0.904158 & & \\ 0.963461 & & \\ & 1.216194 & 1.357297 \\ 0.909675 & 0.176 & 0.192 \\ 0.497613 & 1.645 & 1.960 \\ 0.789428 & 1.645 & 1.960 \\ & 4.605 & 5.991\end{array}$

(5\%)

Accept Normality Accept Normality Accept Normality Accept Normality Accept Normality Accept Normality Accept Normality 


\section{-Velocidades de consumo de amonio con extractos y 100 de amonio}

Dependent

Amonio con extractos Control

Model Estimation Section

\begin{tabular}{|c|c|c|c|}
\hline Parameter & Parameter & Asymptotic & Lower \\
\hline Name & Estimate & Standard Error & 95\% C.L. \\
\hline A & 40.13579 & 1.505209 & 36.92751 \\
\hline $\mathrm{B}$ & 0.5278185 & 6.874029E-02 & 0.381302 \\
\hline C & 2.659428 & 0.1813514 & 2.272887 \\
\hline Dependent & \multicolumn{3}{|c|}{ AmoExtControl } \\
\hline Independent & \multicolumn{3}{|c|}{ TiempoExt } \\
\hline Model & \multicolumn{3}{|c|}{ AmoExtControl=A*EXP(-EXP $\left(-B^{*}((\right.$ TiempoExt $\left.\left.)-C)\right)\right)$} \\
\hline R-Squared & \multicolumn{3}{|c|}{0.962777} \\
\hline Iterations & \multicolumn{3}{|c|}{4} \\
\hline $\begin{array}{l}\text { Estimated } M \\
(40.13579)^{\star} E\end{array}$ & \multicolumn{3}{|c|}{$X P\left(-(.5278185)^{\star}((\right.$ TiempoExt $\left.\left.)-(2.659428))\right)\right)$} \\
\hline
\end{tabular}

Analysis of Variance Table

$\begin{array}{llll}\text { Source } & \text { DF } & \begin{array}{l}\text { Sum of } \\ \text { Squares }\end{array} & \text { Mean } \\ \text { Mean } & 1 & 8852.038 & 8852.038 \\ \text { Model } & 3 & 12554.38 & 4184.793 \\ \text { Model (Adjusted) } & 2 & 3702.341 & 1851.171 \\ \text { Error } & 15 & 143.1385 & 9.542563 \\ \text { Total (Adjusted) } & 17 & 3845.479 & \\ \text { Total } & 18 & 12697.52 & \end{array}$

Plot Section

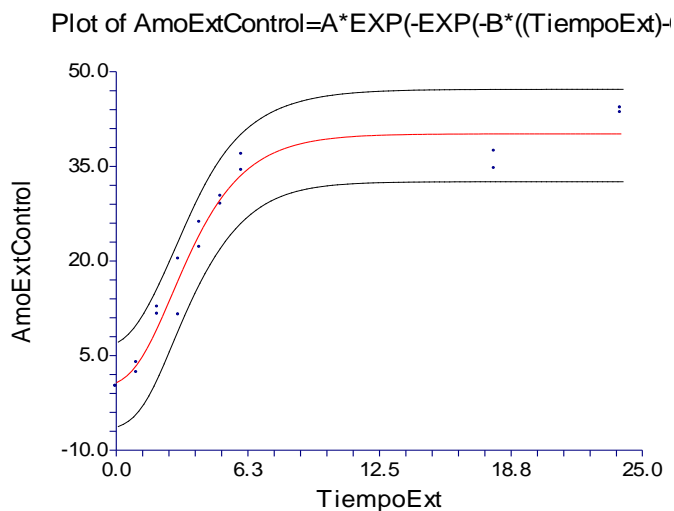

Dependent Nitrito con extractos Control

Model Estimation Section

$\begin{array}{lllll}\text { Parameter } & \text { Parameter } & \text { Asymptotic } & \text { Lower } & \text { Upper } \\ \text { Name } & \text { Estimate } & \text { Standard Error } & 95 \% \text { C.L. } & 95 \% \text { C.L. } \\ \text { A } & 12.70326 & 0.4045791 & 11.84092 & 13.5656 \\ \text { B } & 1.234246 & 0.2361628 & 0.7308767 & 1.737615 \\ \text { C } & 1.560634 & 0.1239961 & 1.296342 & 1.824925\end{array}$




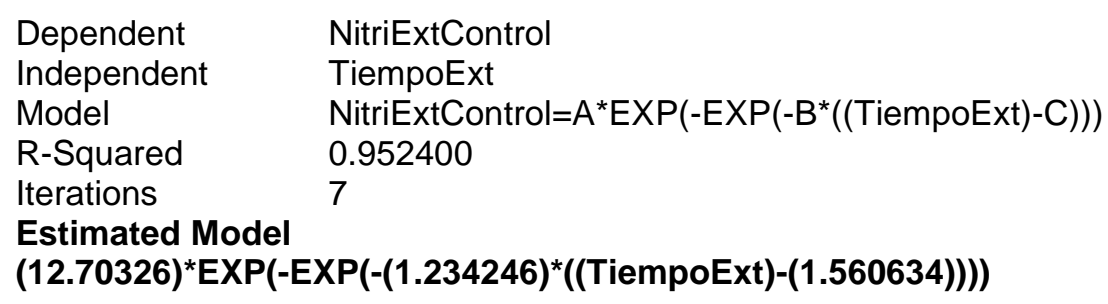

Plot Section

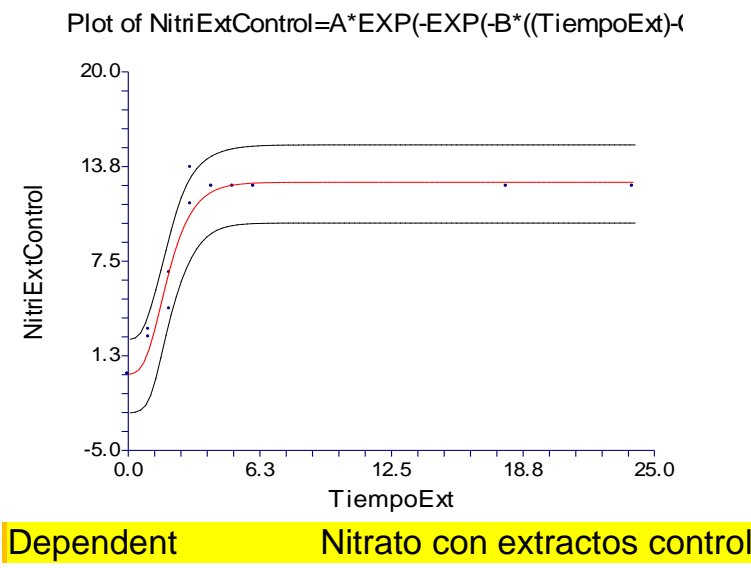

Model Estimation Section

$\begin{array}{lllll}\text { Parameter } & \text { Parameter } & \text { Asymptotic } & \text { Lower } & \text { Upper } \\ \text { Name } & \text { Estimate } & \text { Standard Error } & 95 \% \text { C.L. } & 95 \% \text { C.L. } \\ \text { A } & 35.82949 & 1.227037 & 33.21412 & 38.44485 \\ \text { B } & 0.6464766 & 8.289942 E-02 & 0.4697807 & 0.8231726 \\ \text { C } & 3.379529 & 0.1458955 & 3.06856 & 3.690498\end{array}$

Dependent NitraExtcontrol

Independent TiempoExt

Model NitraExtcontrol=A*EXP(-EXP(-B*((TiempoExt)-C)))

R-Squared $\quad 0.973626$

Iterations

3

Estimated Model

$(35.82949)^{\star} \operatorname{EXP}\left(-\operatorname{EXP}\left(-(.6464766)^{\star}((\right.\right.$ TiempoExt)-(3.379529))))

Analysis of Variance Table

$\begin{array}{llll} & & \text { Sum of } & \text { Mean } \\ \text { Source } & \text { DF } & \text { Squares } & \text { Square } \\ \text { Mean } & 1 & 5596.115 & 5596.115 \\ \text { Model } & 3 & 9077.292 & 3025.764 \\ \text { Model (Adjusted) } & 2 & 3481.177 & 1740.588 \\ \text { Error } & 15 & 94.30124 & 6.286749 \\ \text { Total (Adjusted) } & 17 & 3575.478 & \\ \text { Total } & 18 & 9171.593 & \end{array}$




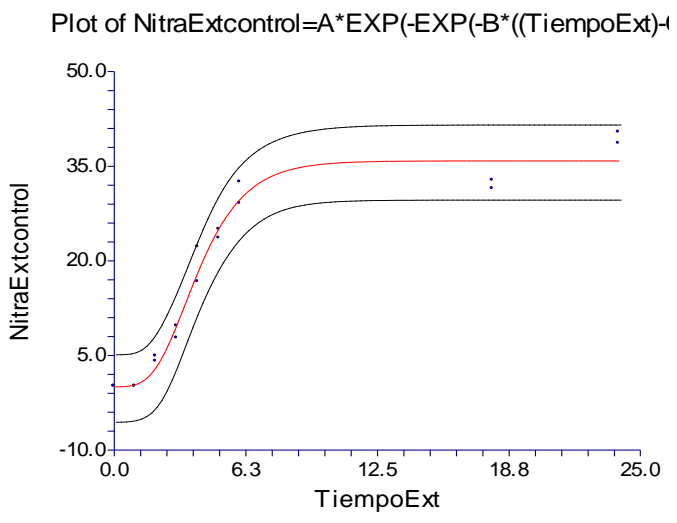

\section{Extractos libres de células en presencia de 2CP}

Dependent

Amonio con extractos con $2 \mathrm{CP}$

Model Estimation Section

$\begin{array}{lllll}\text { Parameter } & \text { Parameter } & \text { Asymptotic } & \text { Lower } & \text { Upper } \\ \text { Name } & \text { Estimate } & \text { Standard Error } & 95 \% \text { C.L. } & 95 \% \text { C.L. } \\ \text { A } & 33.14204 & 1.799323 & 29.30687 & 36.97721 \\ \text { B } & 0.3798471 & 0.0689007 & 0.2329887 & 0.5267054 \\ \text { C } & 2.952929 & 0.313682 & 2.284331 & 3.621526\end{array}$

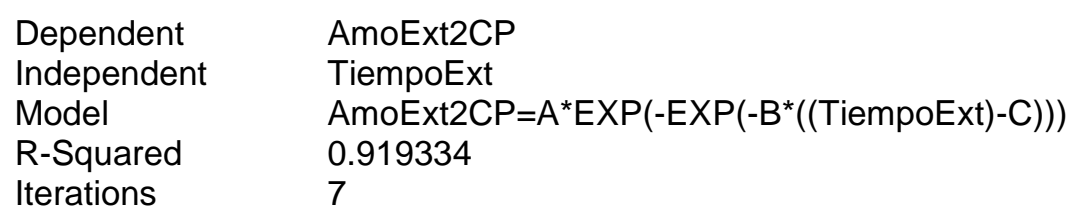

Analysis of Variance Table

$\begin{array}{llll} & & \text { Sum of } & \text { Mean } \\ \text { Source } & \text { DF } & \text { Squares } & \text { Square } \\ \text { Mean } & 1 & 5294.891 & 5294.891 \\ \text { Model } & 3 & 7468.822 & 2489.607 \\ \text { Model (Adjusted) } & 2 & 2173.931 & 1086.965 \\ \text { Error } & 15 & 190.7483 & 12.71655 \\ \text { Total (Adjusted) } & 17 & 2364.679 & \\ \text { Total } & 18 & 7659.57 & \end{array}$

Plot Section 


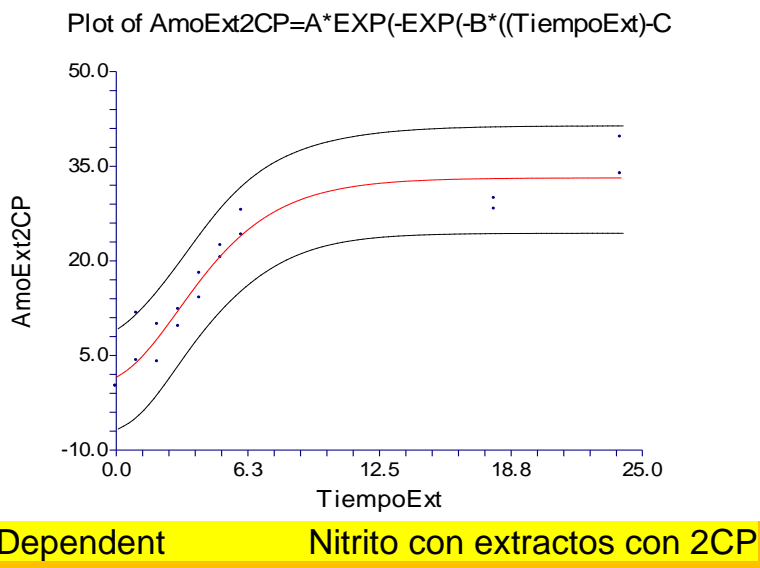

Model Estimation Section

$\begin{array}{lllll}\text { Parameter } & \text { Parameter } & \text { Asymptotic } & \text { Lower } & \text { Upper } \\ \text { Name } & \text { Estimate } & \text { Standard Error } & 95 \% \text { C.L. } & 95 \% \text { C.L. } \\ \text { A } & 17.8941 & 0.9244648 & 15.92365 & 19.86455 \\ \text { B } & 0.6917669 & 0.1369099 & 0.3999504 & 0.9835833 \\ \text { C } & 3.079162 & 0.2143744 & 2.622234 & 3.53609\end{array}$

$\begin{array}{ll}\text { Dependent } & \text { NitExt2CP } \\ \text { Independent } & \text { TiempoExt } \\ \text { Model } & \text { NitExt2CP }=A^{\star} \operatorname{EXP}\left(-\operatorname{EXP}\left(-B^{\star}((\text { TiempoExt })-C)\right)\right) \\ \text { R-Squared } & 0.938666 \\ \text { Iterations } & 9\end{array}$

\section{Estimated Model}

$(17.8941)^{\star} \operatorname{EXP}(-\operatorname{EXP}(-(.6917669) \star((T i e m p o E x t)-(3.079162))))$

Analysis of Variance Table

$\begin{array}{llll} & & \text { Sum of } & \text { Mean } \\ \text { Source } & \text { DF } & \text { Squares } & \text { Square } \\ \text { Mean } & 1 & 1612.931 & 1612.931 \\ \text { Model } & 3 & 2458.768 & 819.5894 \\ \text { Model (Adjusted) } & 2 & 845.8375 & 422.9188 \\ \text { Error } & 15 & 55.2689 & 3.684593 \\ \text { Total (Adjusted) } & 17 & 901.1064 & \\ \text { Total } & 18 & 2514.037 & \end{array}$

Plot Section

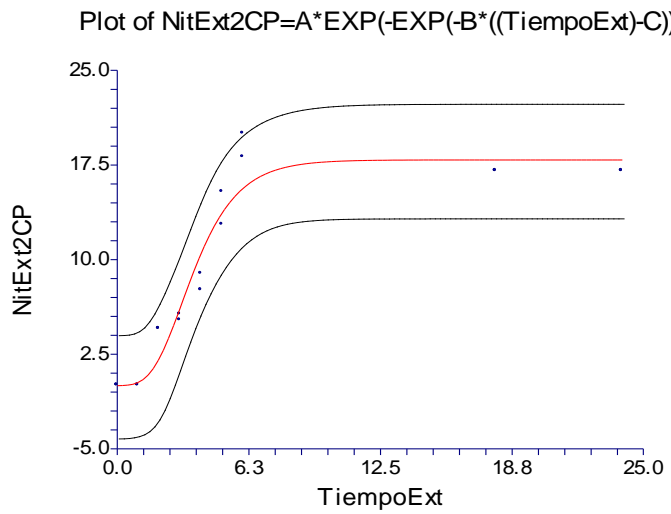


Dependent Nitrato con extractos con 2CP

Dependent NitratoExt2CP

Curve Fit Report

Model Estimation Section

$\begin{array}{lllll}\text { Parameter } & \text { Parameter } & \text { Asymptotic } & \text { Lower } & \text { Upper } \\ \text { Name } & \text { Estimate } & \text { Standard Error } & 95 \% \text { C.L. } & 95 \% \text { C.L. } \\ \text { A } & 4921136 & 6.401576 \mathrm{E}+08 & -1.359543 \mathrm{E}+09 & \\ & 1.369385 \mathrm{E}+09 & & & \\ \text { B } & 7.218261 \mathrm{E}-03 & 8.627187 \mathrm{E}-02 & -0.1766659 & 0.1911024 \\ \text { C } & 367.826 & 5615.357 & -11601.02 & 12336.68\end{array}$

$\begin{array}{ll}\text { Dependent } & \text { NitratoExt2CP } \\ \text { Independent } & \text { TiempoExt } \\ \text { Model } & \text { NitratoExt2CP }=A^{\star} E X P\left(-E X P\left(-B^{*}((\text { TiempoExt })-C)\right)\right) \\ \text { R-Squared } & 0.851982 \\ \text { Iterations } & 238\end{array}$

Estimated Model

$(4921136)^{\star} \operatorname{EXP}\left(-\operatorname{EXP}\left(-(7.218261 E-03)^{\star}((\right.\right.$ TiempoExt)-(367.826))))

Analysis of Variance Table

$\begin{array}{llll} & & \text { Sum of } & \text { Mean } \\ \text { Source } & \text { DF } & \text { Squares } & \text { Square } \\ \text { Mean } & 1 & 1445.786 & 1445.786 \\ \text { Model } & 3 & 2947.624 & 982.5412 \\ \text { Model (Adjusted) } & 2 & 1501.838 & 750.9189 \\ \text { Error } & 15 & 260.9192 & 17.39461 \\ \text { Total (Adjusted) } & 17 & 1762.757 & \\ \text { Total } & 18 & 3208.543 & \end{array}$

Plot Section

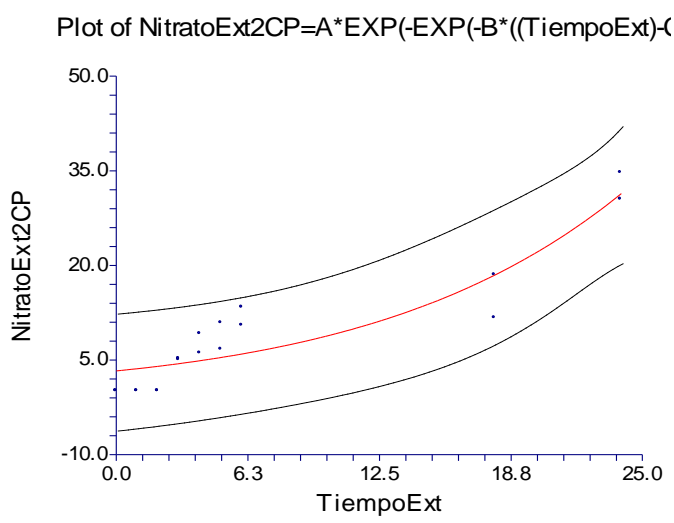




\section{Ajuste con línea recta...}

Linear Regression Plot Section

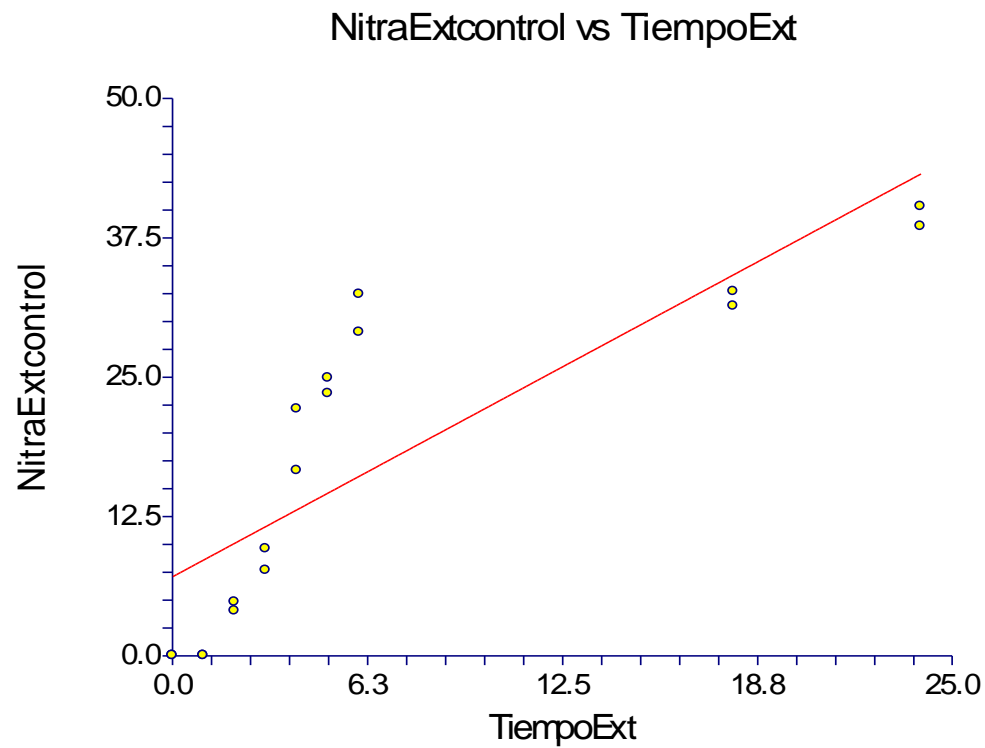

Run Summary Section

Parameter

Value

Dependent Variable

Independent Variable

Frequency Variable

Weight Variable

Intercept

Slope

R-Squared

Correlation

Mean Square Error
NitraExtcontrol

TiempoExt

None

None

7.0926

1.5054

0.6970

0.8349

67.70023
Parameter

Rows Processed

Rows Used in Estimation

Rows with X Missing

Rows with Freq Missing

Rows Prediction Only

Sum of Frequencies

Sum of Weights

Coefficient of Variation

Square Root of MSE
Value

20

18

2

0

0

18

18.0000

0.4666

8.228015

Page/Date/Time

2 21/01/2015 01:47:14 p.m.

Database

Linear Regression Report

2CP.S0

C:IUSERSIFLOR.FLOR.002IDOCUM ... OMPERTZ CONS AMONIO Y

$Y=$ NitraExtcontrol $X=$ TiempoExt

Estimated Model

$(7.0926298702086)+(1.50541709519319) *($ TiempoExt $)$

Page/Date/Time

3 21/01/2015 01:47:14 p.m.

Linear Regression Report

Database

C:IUSERSIFLOR.FLOR.002IDOCUM ... OMPERTZ CONS AMONIO Y

2CP.SO

$\mathrm{Y}=$ NitraExtcontrol $\mathrm{X}=$ TiempoExt 
Analysis of Variance Section

$\begin{array}{lrrrrrr}\text { Source } & \text { DF } & \begin{array}{r}\text { Sum of } \\ \text { Squares }\end{array} & \begin{array}{r}\text { Mean } \\ \text { Square }\end{array} & \text { F-Ratio } & \begin{array}{r}\text { Prob } \\ \text { Level }\end{array} & \begin{array}{r}\text { Power } \\ (5 \%)\end{array} \\ \text { Intercept } & 1 & 5596.115 & 5596.115 & & & \\ \text { Slope } & 1 & 2492.275 & 2492.275 & 36.8134 & 0.0000 & 0.9999 \\ \text { Error } & 16 & 1083.204 & 67.70023 & & & \\ \text { Adj. Total } & 17 & 3575.478 & 210.3222 & & & \\ \text { Total } & 18 & 9171.593 & & & & \\ \mathrm{~S}=\text { Square Root }(67.70023)=8.228015 & & & & \end{array}$

Notes:

The above report shows the F-Ratio for testing whether the slope is zero, the degrees of freedom,

and the mean square error. The mean square error, which estimates the variance of the residuals,

is used extensively in the calculation of hypothesis tests and confidence intervals.

Tests of Assumptions Section

$\begin{array}{lrrr}\begin{array}{r}\text { Test } \\ \text { Value }\end{array} & \begin{array}{r}\text { Prob } \\ \text { Level }\end{array} & \begin{array}{r}\text { Reas } \\ \text { Reve }\end{array} \\ \begin{array}{llrl}\text { Assumption/Test } \\ \text { Residuals follow Normal Distribution? }\end{array} & & \\ \text { Shapiro Wilk } & 0.8657 & 0.015123 & \text { No } \\ \text { Anderson Darling } & 1.0194 & 0.011034 & \text { No } \\ \text { D'Agostino Skewness } & 1.5757 & 0.115106 & \text { No } \\ \text { D'Agostino Kurtosis } & -0.6629 & 0.507393 & \text { Yes } \\ \text { D'Agostino Omnibus } & 2.9221 & 0.231991 & \text { Yes }\end{array}$

\section{Linear Regression Report}

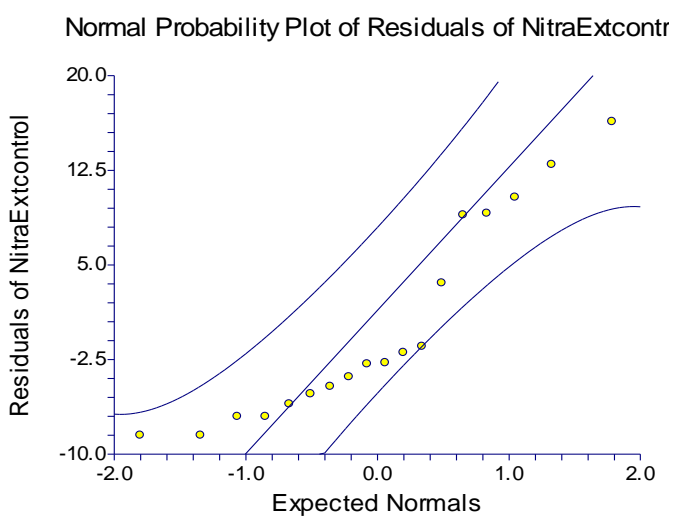

Modelo línea recta nitrato con $2 \mathrm{CP}$

\begin{tabular}{|c|r|r|r|}
\hline \multicolumn{4}{|c|}{ Resumen del modelo } \\
\hline R & R cuadrado & $\begin{array}{c}\text { R cuadrado } \\
\text { corregida }\end{array}$ & $\begin{array}{c}\text { Error típico de } \\
\text { la estimación }\end{array}$ \\
\hline .927 & .859 & .850 & 3.943 \\
\hline
\end{tabular}

La variable independiente esTiempo. 


\begin{tabular}{|l|r|r|r|r|r|}
\hline & \multicolumn{1}{|c|}{$\begin{array}{c}\text { Suma de } \\
\text { cuadrados }\end{array}$} & gl & $\begin{array}{c}\text { Media } \\
\text { cuadrática }\end{array}$ & \multicolumn{1}{|c|}{ F } & Sig. \\
\hline Regresión & 1513.956 & 1 & 1513.956 & 97.360 & .000 \\
Residual & 248.801 & 16 & 15.550 & & \\
Total & 1762.757 & 17 & & & \\
\hline
\end{tabular}

La variable independiente esTiempo.

Coeficientes

\begin{tabular}{|c|c|c|c|c|c|}
\hline & \multicolumn{2}{|c|}{ Coeficientes no estandarizados } & \multirow{2}{*}{$\begin{array}{c}\begin{array}{c}\text { Coeficientes } \\
\text { estandarizados }\end{array} \\
\text { Beta }\end{array}$} & \multirow[b]{2}{*}{$\mathrm{t}$} & \multirow[b]{2}{*}{ Sig. } \\
\hline & $\mathrm{B}$ & Error típico & & & \\
\hline Tiempo & 1.173 & .119 & .927 & 9.867 & .000 \\
\hline (Constante) & .748 & 1.248 & & .599 & .557 \\
\hline
\end{tabular}


Anexo 2: Ajuste con el modelo de Gompertz mediante el programa NCSS. Se presentan los coeficientes $A, B, C$ necesarios para el cálculo de las velocidades específicas de consumo de 2-CP en presencia de inhibidores específicos de la AMO y NOR. Así como el consumo de 2-CP en presencia de diferentes

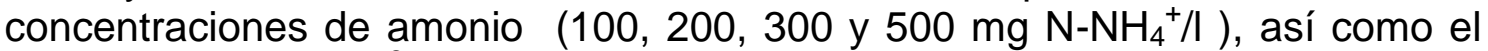
ajuste del modelo $\left(r^{2}\right)$, la significancia del mismo y el análisis de normalidad. Así como las pruebas estadísticas de homogeneidad de coeficientes en modelos de regresión

\section{-Consumo de 2-CP en presencia de inhibidores específicos de la AMO y NOR}

Dependent control

Model Estimation Section

$\begin{array}{lllll}\text { Parameter } & \text { Parameter } & \text { Asymptotic } & \text { Lower } & \text { Upper } \\ \text { Name } & \text { Estimate } & \text { Standard Error } & 95 \% \text { C.L. } & 95 \% \text { C.L. } \\ \text { A } & 5.54061 & 0.1196253 & 5.293146 & 5.788074 \\ \text { B } & 0.2727295 & 2.750856 \text { E-02 } & 0.2158237 & 0.3296353 \\ \text { C } & 22.23862 & 0.1902912 & 21.84497 & 22.63227\end{array}$

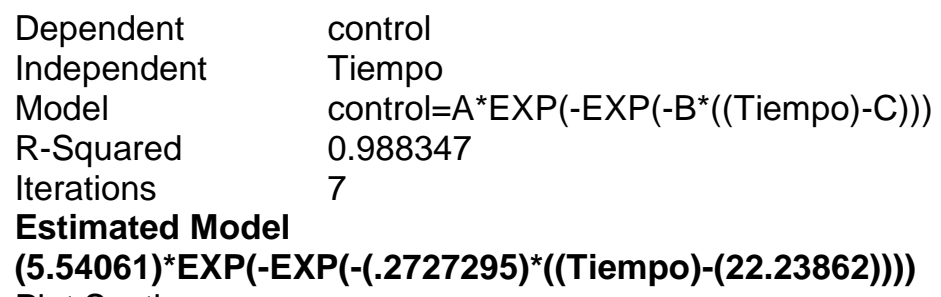

Estimated Model

$(5.54061)^{\star} \operatorname{EXP}\left(-\operatorname{EXP}\left(-(.2727295)^{\star}((\right.\right.$ Tiempo)$\left.\left.)-(22.23862))\right)\right)$

Plot Section

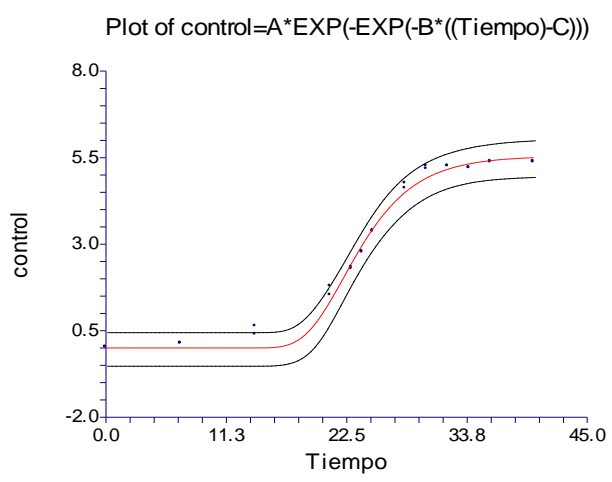

Dependent clorato

Model Estimation Section

$\begin{array}{lllll}\text { Parameter } & \text { Parameter } & \text { Asymptotic } & \text { Lower } & \text { Upper } \\ \text { Name } & \text { Estimate } & \text { Standard Error } & 95 \% \text { C.L. } & 95 \% \text { C.L. } \\ \text { A } & 5.591282 & 0.158643 & 5.263104 & 5.919461 \\ \text { B } & 0.2291915 & 0.0223051 & 0.1830499 & 0.2753331 \\ \text { C } & 23.53361 & 0.2194392 & 23.07967 & 23.98755 \\ & & & & \\ \text { Dependent } & \text { clorato } & & & \\ \text { Independent } & \text { Tiempo } & & \end{array}$




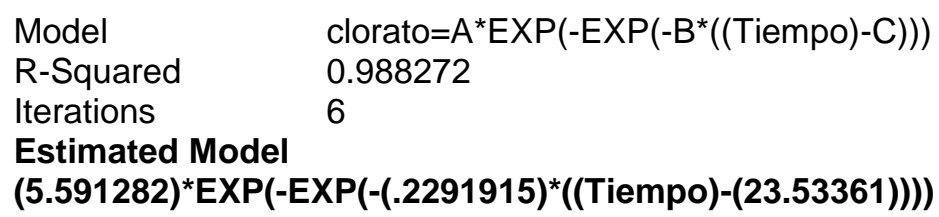

Analysis of Variance Table

$\begin{array}{llll} & & \text { Sum of } & \text { Mean } \\ \text { Source } & \text { DF } & \text { Squares } & \text { Square } \\ \text { Mean } & 1 & 213.6305 & 213.6305 \\ \text { Model } & 3 & 318.2982 & 106.0994 \\ \text { Model (Adjusted) } & 2 & 104.6677 & 52.33385 \\ \text { Error } & 23 & 1.242075 & 5.400327 \mathrm{E}-02 \\ \text { Total (Adjusted) } & 25 & 105.9098 & \\ \text { Total } & 26 & 319.5403 & \end{array}$

Plot Section

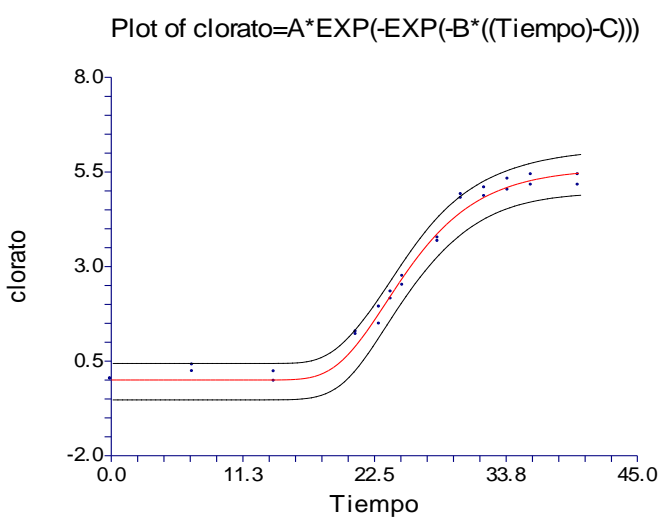

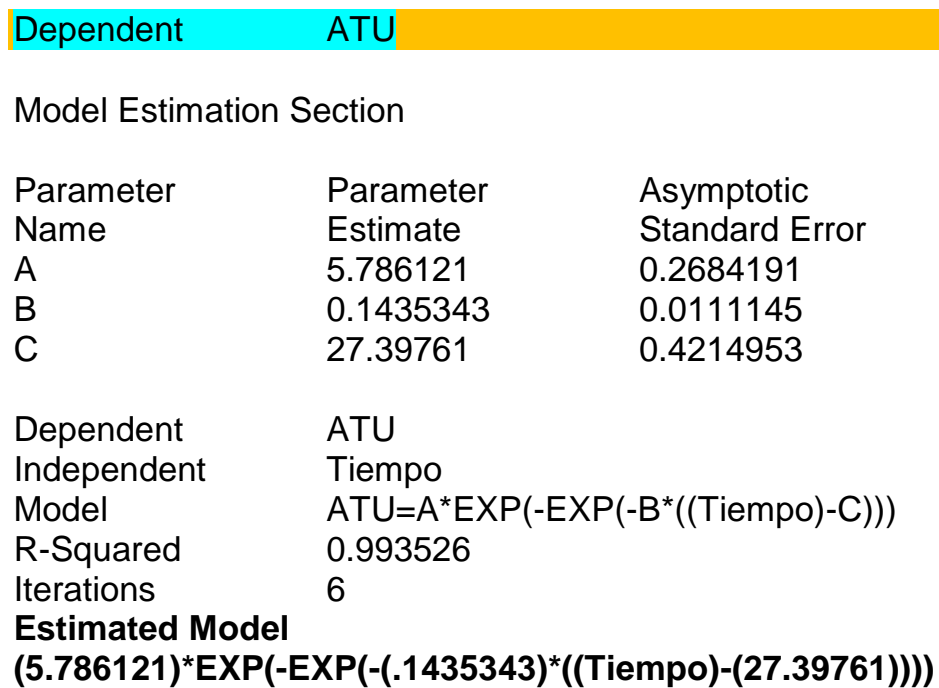

Analysis of Variance Table

$\begin{array}{llll} & & \text { Sum of } & \text { Mean } \\ \text { Source } & \text { DF } & \text { Squares } & \text { Square } \\ \text { Mean } & 1 & 101.4995 & 101.4995 \\ \text { Model } & 3 & 176.5081 & 58.83603 \\ \text { Model (Adjusted) } & 2 & 75.00861 & 37.5043 \\ \text { Error } & 23 & 0.4887785 & 2.125124 \mathrm{E}-02 \\ \text { Total (Adjusted) } & 25 & 75.49738 & \end{array}$


Plot Section

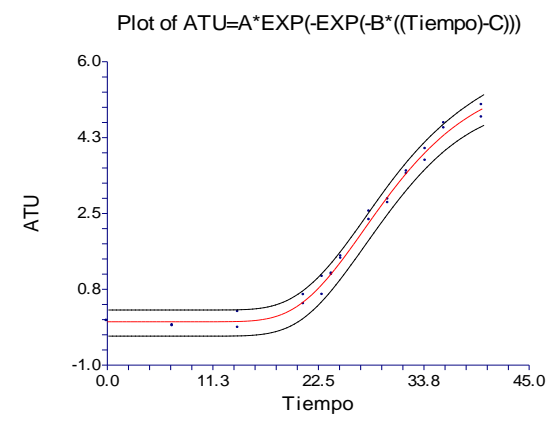

\section{-Prueba estadística de homogeneidad de coeficientes en modelos de regresión.}

Realizada para comparar las pendientes obtenidas en los ensayos con inhibidores de la amonio monooxigenasa y nitrito oxido reductasa. Donde la hipótesis nula $(\mathrm{Ho})$ se refiere a que las pendientes de los perfiles de consumo de 2-CP en presencia de inhibidores son iguales al perfil control (ecuación 1) y la hipótesis alternativa $(\mathrm{Ha})$ es que al menos una de las dos es diferente (ecuación 2).

$$
\begin{aligned}
& H o: \beta o=\beta o^{\prime} \\
& H a: \beta o \neq \beta o^{\prime} \\
& t=\frac{B-B \prime}{\sqrt{S^{2+} S^{2 \prime}}}
\end{aligned}
$$

La ecuación 3 muestra la fórmula para el cálculo de la homogeneidad de coeficientes donde $B$ y $B$ ' son los valores del coeficiente B calculado en el modelo de Gompertz y corresponden al ensayo control y los ensayos con inhibidores específicos respectivamente. $S^{2}$ es valor del error del coeficiente B en el ensayo control y $S^{2}$ son los valores del error del coeficiente $B$ en los ensayos con inhibidores específicos de la amonio y nitrito oxidación, dichos valores se presentan en la siguiente tabla.

\begin{tabular}{lllll}
\hline Ensayo & $R^{2}$ & $B$ & $S$ & $g l$ \\
\hline Control & 0.988 & 0.2727295 & 0.02750 & 23 \\
Clorato & 0.988 & 0.2291915 & 0.02230 & 23 \\
ATU & 0.993 & 0.1435343 & 0.01111 & 23 \\
\hline
\end{tabular}

Sustituyendo los valores de $b, b^{\prime} S^{2}$ y $S^{2}$ de los respectivos ensayos en la ecuación 3 se obtuvieron valores de $b$ que fueron comparados con la t de tablas, que indica que un valor por encima de $\mathrm{t}=2.0687$ rechaza la hipótesis nula.

$\mathrm{Ho}=\mathrm{q}$ control $=\mathrm{q}$ clorato $\quad \mathrm{Ho}=\mathrm{q}$ control $\neq \mathrm{q}$ clorato $t=1.22$ = se acepta Ho es decir las pendientes de los perfiles son semejantes

$\mathrm{Ho}=\mathrm{q}$ control $=\mathrm{q}$ ATU $\quad \mathrm{Ho}=\mathrm{q}$ control $\neq \mathrm{q}$ ATU 
$\mathrm{t}=4.35$ = se rechaza Ho es decir las pendientes de los perfiles son diferentes lo que indica que la amonio monooxigenasa si participa ene I consumo de 2-CP

\section{-Consumo de 2-CP en presencia de 200, 300 y $500 \mathrm{mg} \mathrm{N}-\mathrm{NH}_{4}^{+} / \mathrm{I}$}

Model Estimation Section

$\begin{array}{lllll}\text { Parameter } & \text { Parameter } & \text { Asymptotic } & \text { Lower } & \text { Upper } \\ \text { Name } & \text { Estimate } & \text { Standard Error } & \text { 95\% C.L. } & \text { 95\% C.L. } \\ \text { A } & 2.170651 & 0.2251718 & 1.69558 & 2.645722 \\ \text { B } & 0.1725504 & 5.598795 \mathrm{E}-02 & 5.442615 \mathrm{E}-02 & 0.2906747 \\ \text { C } & 8.46216 & 1.266448 & 5.790189 & 11.13413\end{array}$

$\begin{array}{ll}\text { Dependent } & \text { amonio200 } \\ \text { Independent } & \text { tiempo } \\ \text { Model } & \text { amonio200 }=\mathrm{A}^{\star} \operatorname{EXP}\left(-\operatorname{EXP}\left(-\mathrm{B}^{*}((\text { tiempo })-\mathrm{C})\right)\right) \\ \text { R-Squared } & \mathbf{0 . 8 4 7 7 6 8} \\ \text { Iterations } & 14 \\ \text { Estimated Model } & \\ (\mathbf{2 . 1 7 0 6 5 1})^{\star} \operatorname{EXP}\left(-\operatorname{EXP}\left(-(. \mathbf{1 7 2 5 5 0 4})^{\star}((\text { tiempo })-(\mathbf{8 . 4 6 2 1 6}))\right)\right)\end{array}$

\section{Analysis of Variance Table}

$\begin{array}{ll}\text { Source } & \text { DF } \\ \text { Mean } & 1 \\ \text { Model } & 3 \\ \text { Model (Adjusted) } & 2 \\ \text { Error } & 17 \\ \text { Total (Adjusted) } & 19 \\ \text { Total } & 20 \\ \text { Plot of amonio200=A*EXP(-EXP(-B*((tiempo)-C))) }\end{array}$

$\begin{array}{ll}\text { Sum of } & \text { Mean } \\ \text { Squares } & \text { Square } \\ 16.44754 & 16.44754 \\ 29.76171 & 9.920571 \\ 13.31418 & 6.657088 \\ 2.390793 & 0.1406349\end{array}$

Plot of amonio200=A*EXP(-EXP(-B*((tiempo)-C)))

15.70497

32.15251

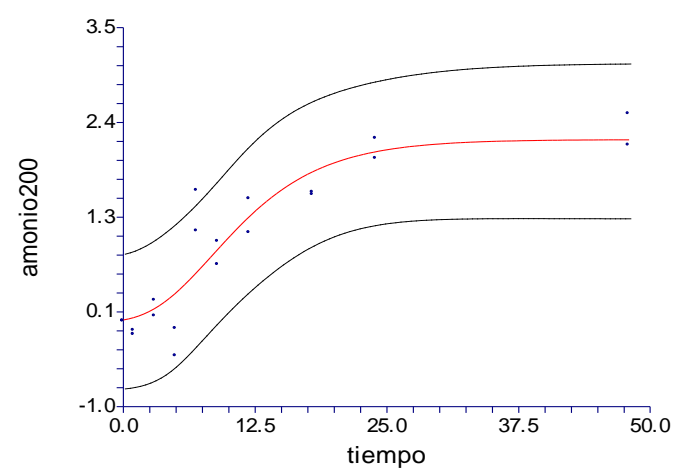

\section{Model Estimation Section}

\begin{tabular}{|c|c|}
\hline $\begin{array}{l}\text { Parameter } \\
\text { Name }\end{array}$ & $\begin{array}{l}\text { Parameter } \\
\text { Estimate }\end{array}$ \\
\hline A & 3.087768 \\
\hline$B$ & 0.2104642 \\
\hline C & 3.914722 \\
\hline Dependent & amonio300 \\
\hline
\end{tabular}

$\begin{array}{ll}\text { Asymptotic } & \text { Lower } \\ \text { Standard Error } & 95 \% \text { C.L. } \\ 0.2062298 & 2.652662 \\ 5.006642 \mathrm{E}-02 & 0.1048333 \\ 0.7457774 & 2341269\end{array}$

Upper

95\% C.L.

3.522875

0.3160951

$0.7457774 \quad 2.341269$

5.488175 


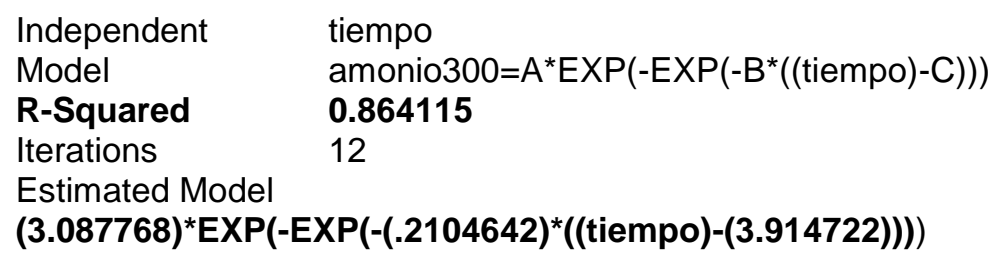

Analysis of Variance Table

$\begin{array}{llll}\text { Source } & \text { DF } & \begin{array}{l}\text { Sum of } \\ \text { Squares }\end{array} & \begin{array}{l}\text { Mean } \\ \text { Square }\end{array} \\ \text { Mean } & 1 & 70.12138 & 70.12138 \\ \text { Model } & 3 & 90.58382 & 30.1946 \\ \text { Model (Adjusted) } & 2 & 20.46244 & 10.23122 \\ \text { Error } & 17 & 3.217774 & 0.1892808\end{array}$

Total (Adjusted) 19

23.68021

Total 20

93.80159

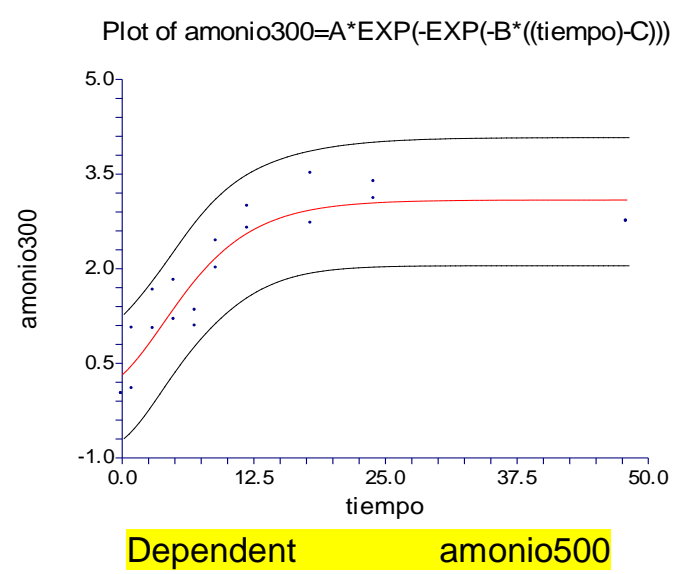

\section{Model Estimation Section}

\begin{tabular}{|c|c|c|c|c|}
\hline $\begin{array}{l}\text { Parameter } \\
\text { Name }\end{array}$ & $\begin{array}{l}\text { Parameter } \\
\text { Estimate }\end{array}$ & $\begin{array}{l}\text { Asymptotic } \\
\text { Standard Error }\end{array}$ & $\begin{array}{l}\text { Lower } \\
\text { 95\% C.L. }\end{array}$ & $\begin{array}{l}\text { Upper } \\
95 \% \text { C.L. }\end{array}$ \\
\hline A & 4.751557 & 0.3746611 & 3.961091 & 5.542023 \\
\hline B & 0.1243422 & $2.446306 \mathrm{E}-02$ & 7.272961E-02 & 0.1759547 \\
\hline C & 10.87591 & 1.175229 & 8.396395 & 13.35543 \\
\hline Dependent & \multicolumn{4}{|l|}{ amonio500 } \\
\hline Independent & \multirow{2}{*}{\multicolumn{4}{|c|}{ tiempo }} \\
\hline Model & \multirow{2}{*}{\multicolumn{4}{|c|}{$\begin{array}{l}\text { amonio500 }=A^{*} E X P\left(-E X P\left(-B^{*}((\text { tiempo })-C)\right)\right) \\
0.918303\end{array}$}} \\
\hline R-Squared & & & & \\
\hline Iterations & \multicolumn{4}{|c|}{7} \\
\hline $\begin{array}{l}\text { Estimated Moo } \\
(4.751557)^{\star} \mathrm{EX}\end{array}$ & \multicolumn{4}{|c|}{$\mathrm{XP}\left(-(.1243422)^{\star}((\right.$ tiempo $\left.\left.)-(10.87591))\right)\right)$} \\
\hline
\end{tabular}

\section{Analysis of Variance Table}

$\begin{array}{llll}\text { Source } & \text { DF } & \begin{array}{l}\text { Sum of } \\ \text { Squares }\end{array} & \begin{array}{l}\text { Mean } \\ \text { Square }\end{array} \\ \text { Mean } & 1 & 59.1852 & 59.1852 \\ \text { Model } & 3 & 108.9195 & 36.30648 \\ \text { Model (Adjusted) } & 2 & 49.73425 & 24.86713 \\ \text { Error } & 17 & 4.424601 & 0.2602706 \\ \text { Total (Adjusted) } & 19 & 54.15886 & \\ \text { Total } & 20 & 113.3441 & \end{array}$




\section{Curve Fit Report}

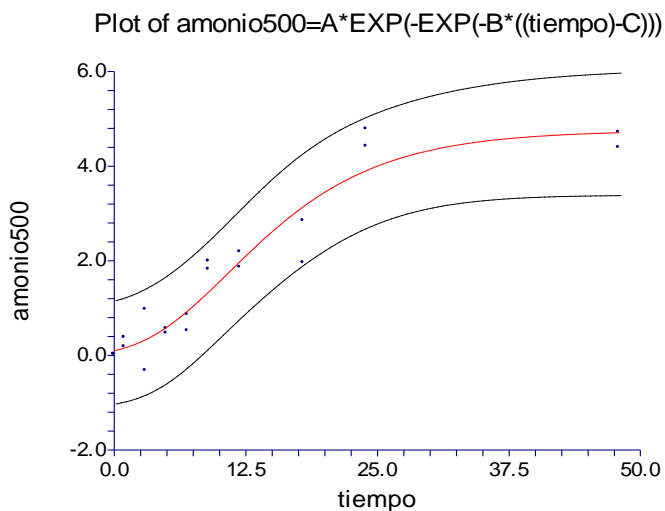

Pruebas de normalidad

Normality Test Section of res200

\begin{tabular}{|c|c|c|c|c|c|}
\hline Test & \multicolumn{2}{|c|}{ Prob } & $10 \%$ Critical & $5 \%$ Critical & I Decision \\
\hline Test Name & Value & Level & Value & Value & $(5 \%)$ \\
\hline Shapiro-Wilk W & 0.932947 & 0.175929 & & & Accept Normality \\
\hline Anderson-Darling & 0.5643043 & 0.144222 & & & Accept Normality \\
\hline Martinez-Iglewicz & 1.557118 & & 1.216194 & 1.357297 & 7Reject Normality \\
\hline olmogorov-Smirnov & 0.143064 & & 0.176 & 92 & Accept Normality \\
\hline stino Skewness & 1.6579 & 0.097328 & 1.645 & & Accept Normality \\
\hline 'Agostino Kurtosis & 2.0487 & 0.040493 & 1.645 & 1.960 & Reject Normality \\
\hline D'Agostino Omnibus & 6.9459 & 0.031025 & 4.605 & 5.991 & Reject Normality \\
\hline
\end{tabular}

\section{Normality Test Section of res300}

\begin{tabular}{|c|c|c|c|c|c|}
\hline $\begin{array}{l}\text { Test } \\
\text { Test Namo }\end{array}$ & Prob & 10\% Critic & & $5 \%$ Critical & Decision \\
\hline & & Level & Value & Value(5\%) & \\
\hline Shapiro-Wilk W & 0.8872501 & 0.023946 & & & Reject Normality \\
\hline nderson-Darling & 0.7235427 & 0.059174 & & & Accept Normality \\
\hline Martinez-Iglewicz & 0.9833889 & & 1.216194 & 1.357297 & Accept Normality \\
\hline Kolmogorov-Smirnov & 0.1245148 & & 0.176 & 0.192 & Accept Normality \\
\hline Agostino Skewness & -0.5735 & 0.566279 & 1.645 & 1.960 & Accept Normality \\
\hline Agostino Kurtosis & -2.4477 & 0.014376 & 1.645 & 1.960 & Reject Normality \\
\hline Agostino Omnibus & 6.3204 & 0.042418 & 4.605 & 5.991 & Reject Normality \\
\hline
\end{tabular}

\begin{tabular}{|c|c|c|c|c|c|}
\hline \\
\hline \multicolumn{6}{|c|}{$\begin{array}{lll}\text { Test } & \text { Prob } & 10 \% \text { Critical5\% Critical }\end{array}$} \\
\hline Test Name & Value & Level & Value & Value(5\%) & \\
\hline Shapiro-Wilk W & 0.9601427 & 0.546705 & & & Accept Normality \\
\hline Anderson-Darling & 0.3822785 & 0.398623 & & & Accept Normality \\
\hline Martinez-Iglewicz & 1.070132 & & 1.216194 & 1.357297 & Accept Normality \\
\hline Kolmogorov-Smirnov & 0.1373613 & & 0.176 & 0.192 & Accept Normality \\
\hline D'Agostino Skewness & -0.8077 & 0.419263 & 1.645 & 1.960 & Accept Normality \\
\hline D'Agostino Kurtosis & 1.0149 & 0.310170 & 1.645 & 1.960 & Accept Normality \\
\hline D'Agostino Omnibus & 1.6823 & 0.431207 & 4.605 & 5.991 & Accept Normality \\
\hline
\end{tabular}

